Production Efficiency of Mussel Bottom Culture

Jacob J. Capelle 



\section{Production efficiency of mussel bottom culture}

Jacob J. Capelle 


\section{Thesis committee}

\section{Promotors}

Prof. Dr A.C. Smaal

Professor of Sustainable Shellfish Culture

Wageningen University \& Research

Prof. Dr P.M.J. Herman

Professor of Estuarine Ecology

Radboud University Nijmegen

\section{Copromotor}

Dr J.W.M. Wijsman

Marine Ecologist, Regional centre Yerseke

Wageningen University \& Research

\section{Other members}

Prof. Dr A.J. Murk, Wageningen University \& Research

Prof. Dr J.G. Ferreira, New University of Lisbon, Portugal

Prof. Dr J. van der Meer, VU University, Amsterdam

Prof. Dr J.K. Petersen, Technical University of Denmark, Denmark

This research was conducted under the auspices of the Graduate School of Wageningen Institute of Animal Sciences 


\title{
Production efficiency of mussel bottom culture
}

\author{
Jacob J. Capelle
}

\section{Thesis}

submitted in fulfillment of the requirement for the degree of doctor

at Wageningen University

by the authority of the Rector Magnificus

Prof. Dr A.P.J. Mol

in the presence of the

Thesis Committee appointed by the Academic Board

to be defended in public

on Friday 10 March 2017

at 4 p.m. in the Aula 
Jacob J. Capelle

Production efficiency of mussel bottom culture, 240 pages.

PhD Thesis, Wageningen University, Wageningen, the Netherlands (2017) With references, with summaries in Dutch and English

ISBN: 978-94-6343-086-9

DOI: $10.18174 / 404677$ 


\section{Table of contents}

$\begin{array}{lll}\text { Chapter } 1 \text { General Introduction } & 7\end{array}$

Chapter 2 Review of mussel culture in the Netherlands 31

Chapter 3 Spatial organisation and biomass development after 61 relaying of mussel seed

Chapter 4 Effect of seeding density on biomass production in 89 mussel bottom culture

Chapter 5 The role of shore crabs and mussel density in mussel 113 losses at a commercial intertidal mussel plot after seeding

Chapter 6 Population dynamics of subtidal mussels (Mytilus edulis L.) and the impact of cultivation

Chapter 7 General Discussion

References

Summary

Samenvatting

Acknowledgements 



\section{Chapter I}

\section{General Introduction}

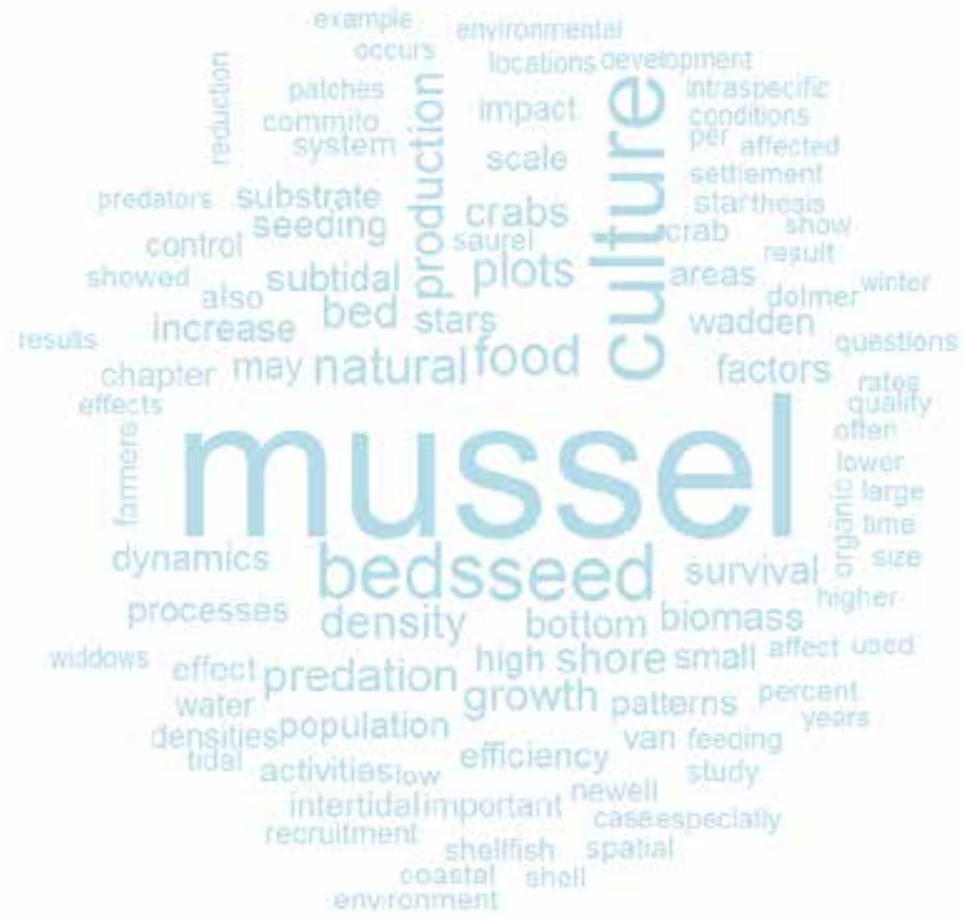




\section{Chapter 1}

Coastal areas are productive ecosystems (Beck et al. 2001, Wilson 2002), which is an important factor that made coastal environments attractive areas for human settlement (Bailey 2004). Shellfish are abundant food resources in coastal ecosystems, are easy to collect, and have been an important protein source worldwide since prehistoric times (Erlandson 1988). Ethnoecological studies have shown that shellfish were target species for early human foragers and local depletion promoted human dispersal (Mannino \& Thomas 2002). Evidence of shellfish consumption over time has been found in coastal areas around the world, and shellfish harvest from natural stocks has been carried out in most coastal areas (Waselkov 1987, MacKenzie Jr et al. 1997). There is still a harvest from natural stocks, but nowadays more than $90 \%$ of the main shellfish species are produced in aquaculture. Worldwide the most important species in terms of production volume (2010) were clams, cockles and arkshells (4.9 million tonnes), oysters (4.5 million tonnes) and mussels ( 1.8 million tonnes) (FAO 2012).

In Europe the volume of shellfish production is dominated by mussels (79\%) and Europe has historically a rich diversity in mussel culture techniques and production methods, dating back to $>2000$ years (Smaal 2002). Seed collection and subsequent outgrow on wooden poles (bouchot culture) has been practiced in France since the $13^{\text {th }}$ century (Dijkema 1997, Goulletquer \& Heral 1997, FAO 2004). Relaying from natural beds to designated culture plots was introduced in the $19^{\text {th }}$ century in several places, including the Netherlands (Dijkema 1997). The advantage of private plots is that mussel growers have legal ownership of the stock and are able to control mussel production by promoting growth and survival, by reducing predators, using optimal growing densities and making use of optimal locations. Nowadays large scale mussel culture makes use of ropes and longlines in the water column. This technique requires some shelter against hydrodynamic forces and sufficient water depth. It is applied in many parts of the world and is the dominant culture technique worldwide because 


\section{Chapter 1}

of fast growth and high yields, although it is relatively labor intensive. The techniques for mussel farming reflect the environmental conditions: bouchot culture in areas with a large tidal range, bottom culture in shallow dynamic coastal areas and suspended culture in deeper water that offers some protection against storm (Smaal 1991).

The blue mussel (Mytilus edulis L.) has an important function in coastal ecosystem, as it is a gregarious organism organised in mussel beds that increases structural complexity of the coastal environment. This is especially the case because mussels are autogenic ecosystem engineers that substantially modify the physical environment, creating heterogeneity in homogeneous environments such as extensive mudflats (Jones et al. 1997). Therefore, mussels have a large effect on the biodiversity on the bed and surrounding the bed; for example, by providing refuge and habitat for a range of other species (Bouma et al. 2009, Buschbaum et al. 2009). Mussels are also an important food source for predators such as birds, crabs, and sea stars (Ens \& Alting 1996, Dolmer 1998). Apart from food, mussels have also been used for bait, animal food, and fertilizer (Spångberg et al. 2013).

This thesis is focused on culture of mussels on subtidal culture plots. It is an extensive type of aquaculture with no addition of food or medicine. This type of culture depends on natural resources for feed, seed and space. It makes use of nature and also depends on nature. The central theme of the thesis is how culture makes use of the natural processes, how these processes can be characterized, what impacts the culture has on the natural mussel dynamics and how mussel culture techniques can be improved. 


\section{Chapter 1}

\subsection{Conceptual model of the human-natural system of mussel culture}

Mussel culture consists of translocation of seed from natural beds to designated culture areas, where mussel farmers try to increase the growth and/ or survival of their stocks. However, since mussel culture is practiced in natural environments, cultured mussels are subjected to comparable environmental factors that influence growth and survival at natural mussel beds, however, some control is possible. The human-natural system of mussel culture is schematized in Figure 1.1 where mussels are subjected to growth and survival, linked to effort, cost, and income.

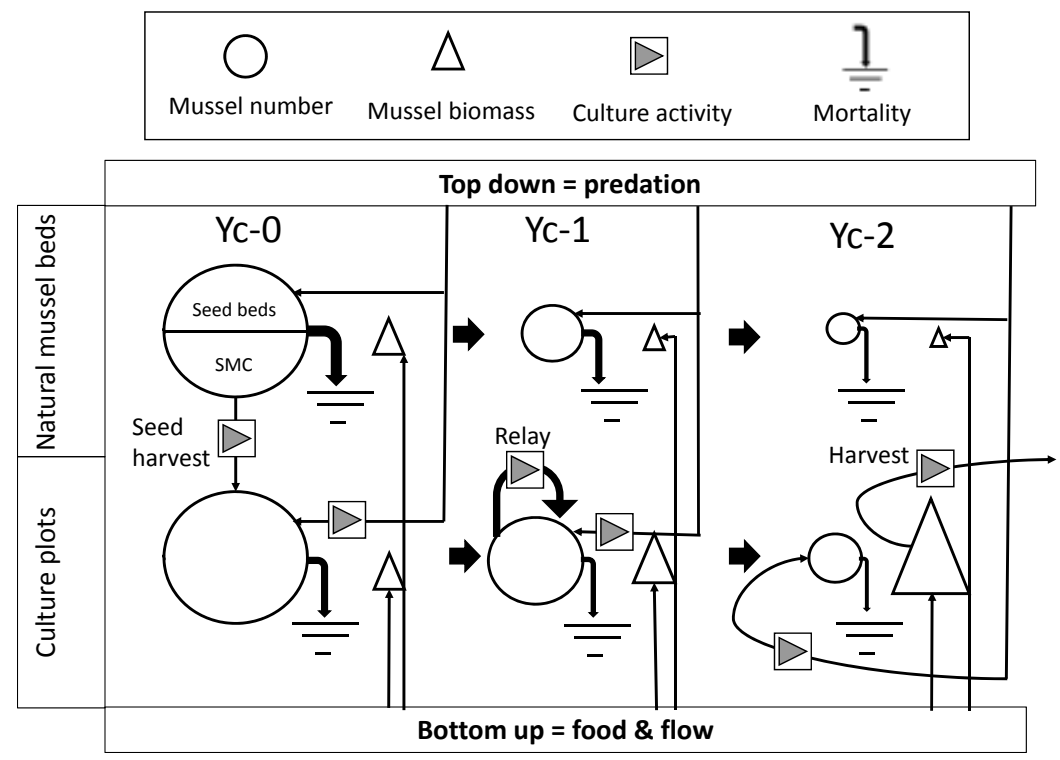

Figure 1.1. Schematic overview of the main processes on subtidal mussel beds and the role of mussel culture in system scale mussel production ( $\mathrm{Yc}=$ year class, $\mathrm{SMC}=$ seed mussel collector). Numbers indicate the various natural factors and human factors that affect the mussel population dynamics; see text for a description of these processes. 


\section{Chapter 1}

Mussel culture activities aim at increasing the production efficiency. Production efficiency is a measure on how successful mussel farmers are at increasing the growth and survival of mussels on culture plots. The parameter of production efficiency used throughout this thesis is relative biomass production (RBP). It is expressed as units of biomass harvested from one unit of biomass seeded, and is synonymous to the average physical product (APP) (Ferreira et al. 2007b) and harvest-to-seed ratio (Newell 2007). The RBP for mussel bottom culture is commonly below 5 (Ferreira et al. 2007b, Wijsman et al. 2014).

Factors in the human-natural system of mussel culture indicated in Figure 1.1. Factors are tied to the processes and they also apply when the same process reoccurs. The factors we identified are natural seed bed formation [1], after which the establishment mussel biomass will increase through growth that is dependent on food and water transport provided by the environment [2]; mussel numbers decline because of storm-induced dislodgement [2]. Mussel numbers are also reduced by predation [3]. Intraspecific processes on the mussel bed affect biomass production through competition [4]. On culture plots, farmer's manipulate processes, through seeding [5], trough site selection [6], and predator control [7]. These factors in the human-natural system of mussel culture are reviewed briefly in the next section.

\subsection{Factors determining population dynamics of natural mussel beds}

\section{Recruitment}

Mussel larvae have a planktonic stage of three to four weeks, which can be extended slightly in search for suitable substrate, and often settle first on filamentous substrates, hydrozoans, tubeworms and macroalgae (primary settlement, when the substrate has low stability) (Sprung 1984). From there, 


\section{Chapter 1}

the mussels will assemble on larger substrates (secondary settlement on substrate with a higher stability) or when the stable substrate is scarce aggregate (interconnect by their byssus threads) into mussel seedbeds, that can stretch out over extensive areas (km scale) (Seed 1976, Seed \& Suchanek 1992, Commito \& Dankers 2001).

Suitable substrates with high stability might consist of solid material such as rocks, or artificial structures (such as floating spat mussel collectors), but can also be sedimentary, such as macrophytes, shell material, or pebbles (Seed 1976, Witman \& Suchanek 1984, Dankers \& Zuidema 1995, Widdows et al. 2002, Kangeri et al. 2014). Several studies have suggested that beds with older mussels are a preferred settlement substrate, adding to the rejuvenation of existing mussel beds (Herlyn \& Millat 200o, Dare et al. 2004, Dolmer \& Stenalt 2010, Commito et al. 2014). However, this older mussel bed preference might be system-specific. For example, although small 'background' recruitment is observed on existing mussel beds on a regular basis, massive recruitment in the western Wadden Sea, which results in new seed beds, does not seem to have a preference to establish on existing mussel beds (Van Stralen et al. 2013). When extensive settlement of spat occurs on older mussel beds, it may smother or outcompete the older mussels (Theisen 1968).

The processes that lead to the successful establishment of mussel seedbeds are complex, and consequently, formation of new seedbed areas are difficult to predict and vary greatly between years. One factor that directly limits the establishment success on soft bottom substrates is predation, such as that by shrimp, shore crabs, and fish (Dare 1976, Beukema 1991, 1992, Strasser 2003, Beukema \& Dekker 2007, Van der Heide et al. 2014). Severe winters are often followed by successful recruitment of mussels, which is ascribed as a mismatch between spat fall and predator abundance, when low temperatures prevent predators from timely migration to the coast (Beukema 1991, 1992, Beukema et 


\section{Chapter 1}

al. 1998b, Dare et al. 2004). However, this is not always the case. For example, although the winter of 2015-2016 was the second mildest winter in the Netherlands for the last 100 years, a massive mussel recruitment in the summer of 2016 resulted in the highest mussel seed stock in the Wadden Sea, since this is systematically recorded (1992). In this western Wadden Sea, an analysis of long-term recruitment from 1955-2002 showed that abundant recruitment occurs on average once every two years in the subtidal and once every four years in the intertidal areas (Van Stralen 2002).

\subsection{Bottom-up: Food and water transport}

\section{Growth}

Growth is the net result of food assimilation and respiration. Food consists of living micro-algae and detritus and uptake is affected by various factors, which are introduced briefly below.

In order to be used, food needs to be transported to mussels in the bed; this occurs through horizontal advection (mostly by tidal currents) and vertical mixing of the water column (Smaal et al. 1986, Fréchette et al. 1989, Folkard \& Gascoigne 2009, Saurel et al. 2013). Mussels can thereby maintain filtration at current velocities up to $0.8 \mathrm{~m} \mathrm{~s}-1$ (Widdows et al. 2002). Furthermore, vertical mixing is enhanced by the roughness of the sea floor and thereby enhanced by the structural complexity of the mussel bed, thus exerting a positive feedback loop of mussels on their food transport (Fréchette et al. 1989, Wiles et al. 2006, Saurel et al. 2013, Folmer et al. 2014).

Particles larger than $4 \mu \mathrm{m}$ are filtered by the gills of mussels with 100 percent efficiency (Møhlenberg \& Riisgård 1978). The quantity and quality of food varies spatially and temporarily; for example, by wind and wave action and water depth that affects resuspension of food particles from the sea floor, which has a low 


\section{Chapter 1}

organic content (Smaal \& Haas 1997). Food quality is often expressed as organic versus inorganic content; therefore, silt and sand particles that are common above the bottom reduce food quality. However, organic matter also differs in quality; for example, quality improves when the $\mathrm{C} / \mathrm{N}$ ratio of the organic matter is lower, as organic nitrogen is an essential and more limiting resource than organic carbon and organic material from marine origin has lower $\mathrm{C} / \mathrm{N}$ ratios than organic material of terrestrial origin (Herman et al. 1999). Mussels are able to adapt feeding behaviour to counteract some of the fluctuations in food quality (Hawkins et al. 1996, Bayne 2004). Changes in feeding behaviour include adjustment of filtration rates, changes in proportion rejected as pseudo-faeces, and changes in selection efficiency (Bayne et al. 1993).

Energy budget is affected by temperature, which jointly affects assimilation and respiration of food in shellfish. Van der Veer et al. (2006) reported a Q1o value of 2.47 for M. edulis, meaning that at an increase of $10 \mathrm{~K}$ physiological processes accelerate with a factor of 2.47 .

\section{Hydrodynamic-induced losses}

Waves and currents can limit suitable settling areas for mussel seed and may cause substantial losses of parts of or entire mussel beds over the course of a winter (Nehls \& Thiel 1993, Reusch \& Chapman 1995, Brinkman et al. 2002). Indeed, losses of the intertidal mussel bed area after settlement as a result of winter storms can be very high (for example, approximately 50 percent in the Dutch Wadden Sea; (Steenbergen et al. 2006)). Distribution of intertidal mussel beds in highly dynamic soft-bottom systems such as the Wadden Sea is limited to more sheltered locations (Nehls \& Thiel 1993, Steenbergen et al. 2006). When there is no hard substrate available for attachment, mussels are especially vulnerable to dislodgement by waves of current. Mussels are also more prone to dislodgement or even suffocation because a thick layer of mud from 


\section{Chapter 1}

accumulated faeces, pseudo-faeces, and sedimented silt builds up underneath the mussels over time, destabilizing the sediment (Theisen 1968). Observations of flow-induced losses on subtidal beds are very limited. In general, long-term observations suggest that dislodgement on natural subtidal beds seems to be a less important loss factor than on intertidal beds (M. van Stralen, pers. com.).

\subsection{Top-down: Predation}

Blue mussels are an important food source in the diet of a variety of predatory species. The Wadden Sea intertidal mussels are preyed on by shore crabs and shore birds (oystercatchers, herring gulls), while subtidal mussels are preyed on by shore crabs, sea stars and molluscivorous (diving) ducks.

\section{Sea stars}

Sea stars (Asterias rubens L.) are mainly active on subtidal mussel beds. Consumption rates of sea stars are approximately $0.003^{-0.01}$ gram organic material per day per gram fresh bodyweight (Nauen 1978, Dolmer 1998, Sommer et al. 1999). However, sea star predation is affected by temperature. Feeding rates reach zero at temperatures below $2^{\circ} \mathrm{C}$ and increase sharply with increasing temperatures. Maximum feeding rates are reached at temperatures between 10 and $13{ }^{\circ} \mathrm{C}$ (Agüera et al. 2012). Sea stars are capable of wiping out entire mussel beds in a short amount of time, especially because they aggregate in large swarms and form a moving feeding front on a mussel (seed) bed (Dare 1982, Lauzon-Guay et al. 2008). Agüera (2015) suggested that, in the development of mussel beds, sea stars establish themselves and grow sat a faster rate than the mussels. It is therefore unlikely that mussels reach a size refuge against sea star predation under natural conditions.

Mussel seed survival in the subtidal Wadden Sea is strongly structured by sea star predation; the majority of mussel beds are limited to locations where sea 


\section{Chapter 1}

star feeding is inhibited by environmental conditions (Agüera 2015).

\section{Shore crabs}

The shore crab (Carcinus maenas L.) is an omnivore (Crothers, 1968) that feeds intensively on blue mussels (Dare et al. 1983). The life history of the shore crab is known in quite some detail as field studies have been performed to identity abundances, spatial dispersion patterns, and (sub) population traits and compositions (Crothers 1968, Smallegange et al. 2009). According to Dare and Edwards (1981), the activity of shore crabs is influenced by both the tidal cycle and a day/night rhythm. The highest activity is to be expected at high tide during the night and the lowest during low tide in daylight. The shore crabs migrate with the flood from the low water mark to the high water mark and vice versa. Elner and Hughes (1978) showed that mussels can outgrow crab predation because predation sharply declined from a mussel size of $2.5 \mathrm{~cm}$ onwards; see also Murray et al. (2007b). Mussels defend themselves against crab predation through an increase in shell thickness and a stronger attachment through increased byssus production (Côté 1995, Freeman 2007). Furthermore, aggregation in dense clumps may result in per capita safety, because intraspecific competition can reduce feeding behaviour efficiency when shore crabs encounter each other during foraging activities (Sneddon et al. 1997, Smallegange \& Van Der Meer 2007).

There are a few quantitative estimations of predation losses by shore crabs on culture plots. Murray et al. (2007b) estimated a to percent loss due to shore crab predation over the entire culture cycle from seeding to harvest in the Menai strait in Wales. In a study on the economic impact of the invasion of green crabs in North America, Grosholz et al. (2011) estimated a 52 percent loss of shellfish including blue mussels. Crabs can have a large impact on culture yields, but results are not always consistent, which is not surprising, because shore crabs 
are omnivores that switch easily between diets and show seasonal patterns in abundance (Crothers 1968).

\section{Molluscivorous birds}

Small intertidal mussel seed is eaten by wading birds and by herring gulls (Larus argentatus). Predation by these predators is mainly limited to small mussels because they swallow the mussels whole, including the shells (Kats 2007). Incidentally, gulls prey on larger mussels by dropping them from the air repeatedly onto hard or sometimes even soft substrate until the shell breaks (Cadée 2001). Larger shellfish are preyed upon by oystercatchers (Haematopus ostralegus), whichareabletoopen mussels with their bills, and by molluscivorous ducks, especially the common eider (Somateria mollissima) and, to a lesser extent, the common scoter (Mellanitta nigra, who is more specialized on Spisula) and who swallow the mussels whole (Hilgerloh et al. 1997, Kats 2007). Eider ducks prefer subtidal mussels as a food source, as subtidal mussels have a thinner shell and higher meat content than intertidal mussels (Steenbergen et al. 2005, Cervencl et al. 2015). Eider ducks have a substantial impact on the subtidal mussel biomass in the western Wadden Sea, with an estimated consumption of $2.26 \mathrm{~kg}$ M. edulis per day and an overwintering population of approximately 59,00o birds (Nilsson 2005, Ekroos et al. 2012). By recording the amount of time the eider duck population forage on culture plots (Cervencl et al. 2015) estimated (for 2006-2011) an annual cultured mussel consumption between 4.5 and $8.2 \mathrm{Mkg}$ of mussels per year.

\subsection{Intraspecific processes}

In soft substrate environments, mussels live on sediment that consists of relatively small, loose particles. However, mussels do not attach to particles smaller than $850 \mu \mathrm{m}$ (Young 1983), which means that they will have to attach to 


\section{Chapter 1}

each other. Mussel aggregations protect against dislodgement (Van De Koppel et al. 2008) and against predation (Bertness \& Grosholz 1985), but also increase intraspecific competition (Okamura 1986, Newell 1990). (Commito et al. 2016) described the process of aggregation as "a form of bet-hedging that balances benefits and costs."

\section{Density-dependent loss}

In mussel beds, a strong density-dependent mortality occurs within the first winter of o-year class mussels (McGrorty et al. 1990, Munch-Petersen \& Kristensen 2001). Even when there is a wide variation in spat densities in autumn, survivors up to one year of age vary in numbers within relative narrow limits (Newell \& Shumway 1993, Stillman et al. 2000). Okamura (1986) showed that mussels grow faster when the number of mussels per patch is relatively small. Differences in the condition index of mussels between the edges of a patch and the middle of a patch can be used to indicate a density-dependent growth (Newell 1990, Saurel et al. 2013).

After settlement, mussel density on the mussel beds is often very high (McGrorty et al. 1990, McGrorty \& Goss-Custard 1993). Dense mussel aggregations can deplete the food and, under unidirectional tidal driven current as well as in micro-tidal systems, creates a food-depleted boundary layer above the bed (Fréchette \& Bourget 1985, Fréchette et al. 1989, Dolmer 200o, Petersen et al. 2013). The rough structure and patterning of a mussel bed promotes turbulent mixing and the water jets from the siphons promote biomixing at lower turbulence conditions (Lassen et al. 2006, Van De Koppel et al. 2008, Saurel et al. 2013). However, the high filtration potential (a dense mussel bed can filter between 0.4-2.7 $\mathrm{m}^{3} \mathrm{~m}^{-2} \mathrm{~h}^{-1}$ (Prins et al. 1994)) and high mussel densities will result in re-filtration, which reduces growth moving over the mussel occupied area (Newell 1990, Petersen et al. 2013). This effect can ultimately result in 
growth limitation and in density- and size-dependent self-thinning (Petraitis 1995b, Fréchette \& Bacher 1998).

In mussel seedbeds, biomass growth can offset losses in number because of the high growth rate of small mussels. Model calculations of Petraitis (1995a), based on data of Theisen (1968) and Seed (1976), show that small mussels can maintain 100 percent cover in one year with 60 percent mortality when mussels double in length.

\subsection{Aggregation}

Soft substrate mussel beds are often organised in complex spatial patterns. These patterns emerge at different temporal and spatial scales. Mussels on mussel beds (100m - 100om scale) are often heterogeneously distributed, with dense mussel assemblages alternated with bare sediment (Snover \& Commito 1998, Commito \& Dankers 2001, Commito et al. 2006). On young mussel (seed)beds at locations (such as the Wadden Sea) where strong tidal currents occur, these patterns can manifest as regular bands of mussels (5-10 m scale) perpendicular to the tidal direction (Van de Koppel et al. 2005). The banded patterns can be explained by a negative feedback resulting from local depletion of the mussels' food source; mussel seeds will aggregate at location where food is replenished by vertical mixing, or do not survive at locations where food is depleted (Van De Koppel et al. 2008, Saurel et al. 2013). At smaller scale (<1 $\mathrm{m})$, mussels organise in interconnected net-like structures at high densities or in small mussel patches at low densities, that elevate from the sediment, (hummocks) due to the mud build-up underneath the mussel assemblages, which subsequently increases food supply (Liu et al. 2012). Aggregation within the $<1 \mathrm{~m}$ scale can be explained by density-dependent processes, where mussels actively organise in small clusters and move away from higher density spots (Liu et al. 2014). When mussel beds get older, patterns may break up due to 


\section{Chapter 1}

physical forcing, resulting in patterns that show fractal geometry (they have both small- and large-scale patterns that show similar geometry while being irregular in themselves) over multiple orders of magnitude (Snover \& Commito 1998, Commito \& Rusignuolo 2000, Crawford et al. 2006). These patterns may persist over time as a result of recruitment facilitation, in systems, such as Maine, USA, where recruits show preference for existing mussel assemblages over bare sediment (Commito et al. 2014).

These patterns affect the population dynamics of the mussels. Patterning promotes food delivery by increasing near bed turbulenceand in an environment with strong tidal currents, growth and survival is higher in patterned mussel beds compared to homogeneous beds (Van De Koppel et al. 2008, Saurel et al. 2013). Models show that patterned mussel beds that are organised on small and large scales can survive at lower algal concentrations and are able to persist in lower mussel densities because of more efficient food uptake (Liu et al. 2014). Mussel bed stability is affected by scour, resulting in erosion of the substrate around mussel patches, which may increase dislodgement of mussels (Widdows et al. 2002). Here as well, mussel cover and spatial organisation on the bed plays an important role in mussel bed stability. Low density clumps were reported to have eight times higher anchorage to the substrate compared to high-density clumps, which made them less likely to dislodge (Widdows et al. 2002). These results underline the hypothesis that a more homogeneous mussel bed (high number of patches with low within patch density) is less prone to dislodgement of mussel seed caused by scouring around patches and erosion of substrate.

\subsection{Impact of mussel bottom culture activities}

Figure 1.1 showed that cultured mussels are subject to the same environmental factors that influence growth and survival as natural mussel beds, but are affected by human activities. Several activities were identified: seed harvesting 


\section{Chapter 1}

and seeding [5], bottom-up control through site selection [6], and top-down control through predator control [7]. The roles that these activities play in mussel population dynamics are summarized below.

\subsection{Seed harvest and seeding}

Seed harvesting, either by fishery on natural seed beds or from seed mussel collectors (SMCs), is followed by the seeding/relay of mussels on culture plots. The typical seeding patterns are sometimes visible from the sky (Figure 1.2) and from satellites. Mussel density is regulated by the mussel farmers, based on experience.

Figure 1.2. Aerial photograph of intertidal mussel culture plots at the Zandkreek (Oosterschelde) with mussels arranged in typical seeding patterns (Photo by D. van der Ende). 


\section{Chapter 1}

Seed is traditionally fished from natural seed beds, using dredges (Figure 1.3). In several countries this activity has raised questions about the environmental impact on the development of natural mussel beds and on the effects of dredging activities on bottom fauna (Beukema et al. 1998a, Dolmer et al. 1999, Dankers et al. 2001, Dolmer et al. 2001, Maguire et al. 2007, Christensen 2012, Dolmer et al. 2012, Frandsen et al. 2015).

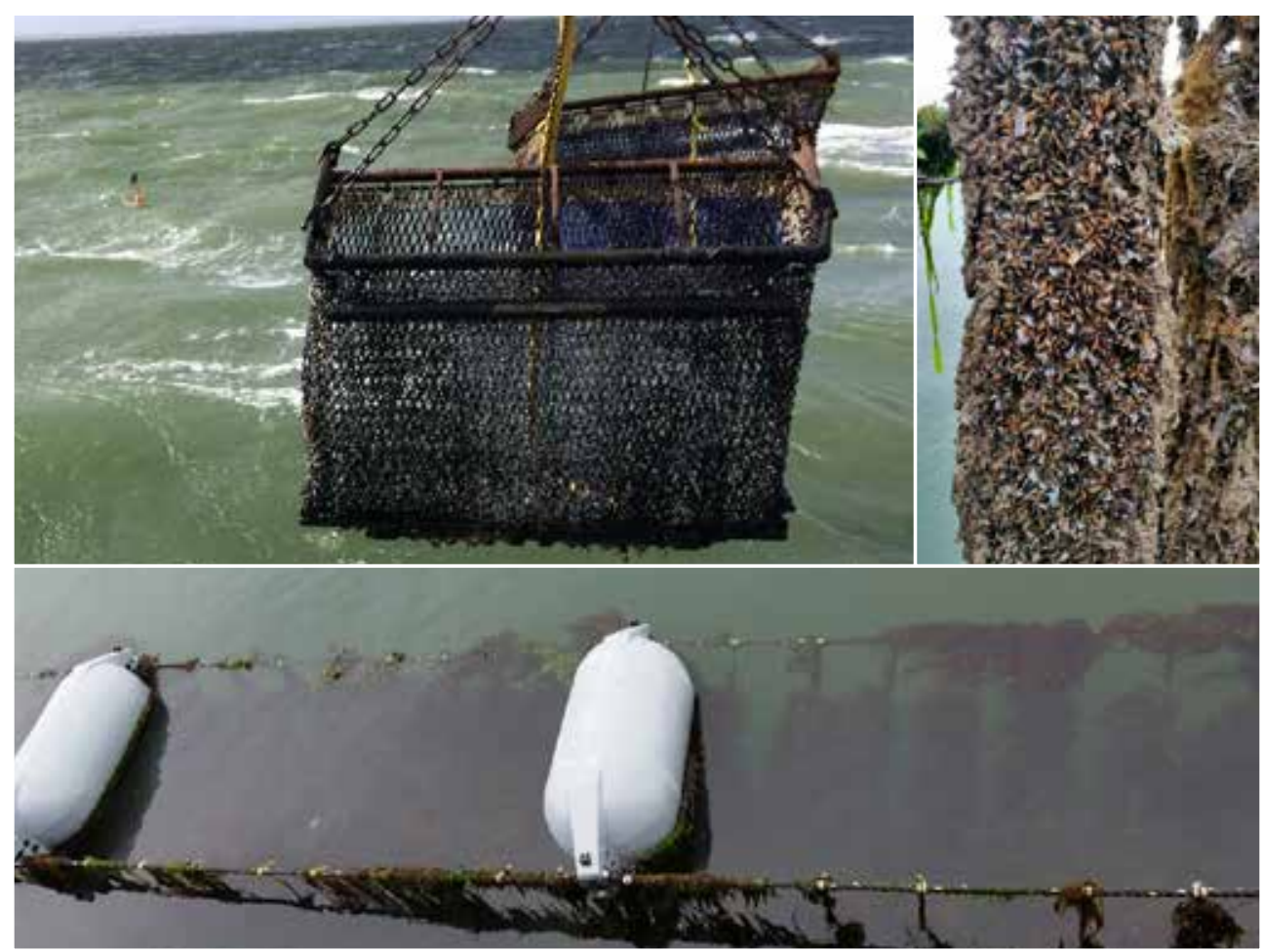

Figure 1.3. Mussel boxcore dredge standard $1.9 \mathrm{~m}$ wide (top left), seed mussel collector system with floating buoys (bottom) and lifted lines from the same system (top right).

Such questions have been debated and contributed to the development of alternative methods for seed acquirement. Floating SMCs (Figure 1.3) have 
been introduced in the Netherlands and Germany and are extensively used to obtain mussel seed. It acts as a resource of seed that compensates for reduction bottom fishery and it safeguards seed availability in year of failing bottom recruitment.

\section{Seed handling}

Seed fishing or collecting, transportation, and seeding are activities that may cause stress to the mussels resulting in a reduced condition and/or survival. This is especially the case during transportation when keeping the mussels out of the water. Calderwood et al. (2014) showed adverse effects in transport for longer than $24 \mathrm{~h}$. Nonetheless, shore crabs or sea stars did not have a higher predation rate on stressed mussels compared to unstressed mussels of the same size (Calderwood et al. 2015, Calderwood et al. 2016a). However, increasing substrate complexity by adding shell material to mussel seed did increase survival rates through increased predation resistance, because mussels were able to attach more firmly (Christensen et al. 2015). Attachment strength of mussels acts as a feedback mechanism that will make the mussel more resistant to predation and increase survival probability. Another feedback mechanism is the increase in shell thickness that occurs in the presence of predators or under harsh environmental conditions and protects the mussels against predation or dislodgement (Leonard et al. 1999, Freeman 2007, Caro et al. 2008, Garner \& Litvaitis 2013). In mussel culture practice this trait was used to 'toughen up' the mussels, and was successfully applied by Beadman et al. (2003) through seeding mussel seed temporarily on high shore levels of the intertidal. This resulted in an increase in shell thickness, a reduction in growth, and a significance reduction in crab predation. 


\section{Chapter 1}

\section{Density control}

Experiments on culture plots in Maine showed that a stepwise reduction of mussel seed density from 1800 mussels $\mathrm{m}^{-2}$ to 50 mussels $\mathrm{m}^{-2}$ increased mussel weight substantially over the entire range - from about $2 \mathrm{~g}$ steamed meat weight to $8 \mathrm{~g}$ steamed meat weight, respectively (Newell 2007). At the same time, the relative biomass production increased at lower densities from 1:1 to 2:1 (Newell 2007). Measurements on mussel patches on culture plots showed that severe competition occurs in the middle of the patches within $0.5 \mathrm{~m}$ from the edge of the patch (Newell 1990). Similar measurements on culture plots in Wales were used to test seeding density on condition (Saurel et al. 2013). In that study, a positive effect of patchiness on food supply was found, caused by an increase in vertical turbulence (Saurel et al. 2013). However, Newell (2007) strongly recommends a more homogeneous spreading of the seed, contrary to current culture practices (see also Figure 1.2). Seed fished from natural beds relayed in different densities and followed at different scales showed that density effects may be dependent on the spatial scale and the season (Gascoigne et al. 2005). Over the summer, density-dependent mortality was observed on small-scale $\left(0.06 \mathrm{~m}^{2}\right)$ and on larger scale $\left(400 \mathrm{~m}^{2}\right)$. Over the winter, survival increased with small-scale density, probably because of a better facilitation against wave dislodgement. On mussel bed scale, a reduction in mussel condition (density not mentioned) was found going from the edges of the bed towards the centre on a mussel bed in the Irish Sea, a system with strong tidal currents (Knights 2012). These cases indicate that seeding density is an important issue in bottom culture in systems with a strong horizontal current. In micro-tidal systems such as the Limforden, where food delivery is dependent on vertical mixing, such a relation was not found (at an average density of $3.5 \mathrm{~kg} \mathrm{~m}^{-2}$ ) (Dolmer et al. 2012). 


\subsection{Bottom-up control through site selection}

Site selection may affect production considerably. In nature, mussel seed beds establish and may survive in areas where local conditions are suitable. However, in mussel bottom culture, culture plots are defined locations, where adaptations to the environment cannot surpass the physical boundary of the plot and the constantly changing environment dictates the growth and survival of mussels, hence the success of the culture activities.

Selecting the best site, with high replenishment and food fluxes, may substantially increase culture productivity (Herman et al. 1999, Ferreira et al. $2007 \mathrm{~b}$ ). Growth rates may increase up to a flow velocity of $0.8 \mathrm{~m} \mathrm{~s}^{-1}$ (Widdows et al. 2002); at a certain threshold, mussels may be dislodged and mussel farmers need to optimize production within this range.

Transplanting mussels between areas may require physiological adaptations, physiological differences between (sub)populations are affected by the environment (Bayne 2004). After a transplantation experiment between two systems in southern England, it took two months for the mussels to adapt to the new environment (Widdows et al. 1984). In mussels, an adaptation in the gill-to-palp ratio was observed after transplantation, which is an adaptation to changes in food quality (Essink \& Bos 1985, Payne et al. 1995).

\subsection{Predator control}

The number of sea stars on culture plots is reduced by freshwater treatment and there is a selective fishery on sea star with sea star mops (NL, UK, Ger, and Irl) and purse-seines (DK, Petersen et al. 2016). Freshwater treatment is applied before seeding when mussels and sea stars are both in the vessels' hold; the process consists of the joint exposure of mussels and sea stars to freshwater for a certain amount of time. Mussels will keep their shells shut, while sea stars are 


\section{Chapter 1}

unable to protect themselves against osmotic stress and will not survive. Sea star mops are made of fuzzy rope entwined around small chains that are towed over the mussel plots (Figure 1.4).
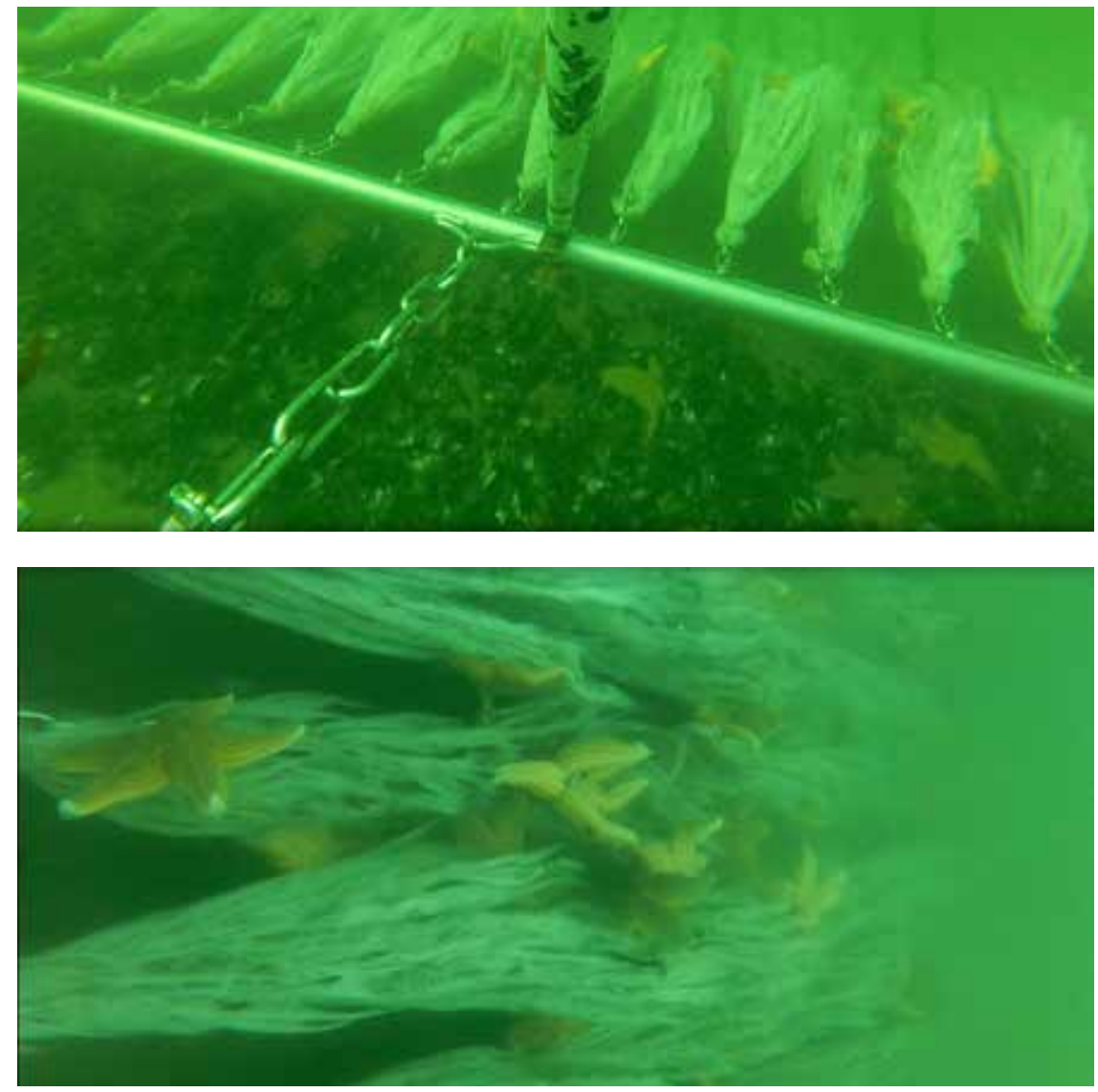

Figure 1.4. Sea star mop in action, fluffy rope around chains are connected to a central iron bar (upper photo, vertical bar was just for camera attachment); sea stars get stuck into the fluffy rope (lower photo: view from central iron bar to the rear side of the gear.

Sea stars will get stuck in the fuzzy rope and are subsequently removed from the mussel plots. The efficiency of sea star removal by mops was estimated in a case 


\section{Chapter 1}

study in Belfast Lough in Northern Ireland. The results show a large variation in the catch efficiency (4-78 percent), while the mean sea star reduction applying this method was 27\% (Calderwood et al. 2016b).

When Davies et al. (1980) tested the effect of exclusion of shore crabs in newly formed intertidal mussel beds on a scale of $800 \mathrm{~m}^{2}$; they found that exclusion of shore crabs resulted in a $400-500$ percent increase in yield over a period of two years. Experiments have been conducted on selective crab fisheries in a comparative study on culture plots in the Wadden Sea, but no differences in survival between culture plots were crabs were removed vs. culture plots where no crab fishery took place could be found (Kamermans 2010). Therefore, exclosure of shore crabs seems to have more effect than a selective fishery.

\subsection{Aims and research questions}

The knowledge on the population dynamics of mussel beds, briefly reviewed in the previous paragraphs, is largely based on research in the lab or at intertidal beds. This thesis provides a case study focused on the dynamics of subtidal mussel populations in the western Wadden Sea, and the impact of mussel culture activities on these dynamics.

The aims of this thesis are (1) to better understand the population dynamics of subtidal mussel populations and (2) to analyse which factors determine production efficiency in mussel bottom culture and how this can be improved.

System scale processes are complex and most of the knowledge on the human component in the human-natural system of mussel culture is based on experience. In order to achieve meaningful results, the approach of our study was based on combining field measurements and monitoring of mussel populations, with information on culture activities. 


\section{Chapter 1}

\section{Outline of the thesis}

In the main text in the introduction in Chapter 1, we introduced the framework of this thesis and reviewed factors that affect the population dynamics of mussels in the human-natural system of mussel culture. The relation between technological developments and production efficiency is addressed in Chapter 2. Here we review the developments in culture techniques in relation to the need to optimize production efficiency for mussel bottom culture in the Netherlands.

In the following chapters we investigate the effect of mussel bottom culture on the population dynamics of mussels. Structured according to Figure 1.1, by effects of seeding, effects of predator control and the integrated effect of culture on the development of mussel numbers and mussel biomass, compared with developments on natural mussel beds. The following research questions are addressed:

Does spatial organisation of the mussels imposed at seeding affect biomass production?

Spatial organisation is an important feature of mussel beds that affects the growth and survival of mussels on natural beds and on culture plots. Mussel seed is relayed on culture plots with a spatial heterogeneity in mussel density that differs from that of a natural mussel bed. The implications of this spatial density on growth and survival are discussed in Chapter 3 in an experiment that tested the effect on mussel redistribution and its effect on biomass development in a case study on a culture plot in the Oosterschelde. That chapter provides further understanding on how the effects of seeding and relaying relate to intraspecific processes, especially to aggregation.

What is the impact of mussel density on biomass production? 


\section{Chapter 1}

Natural subtidal mussel seed beds often establish at high mussel densities and in some years may not establish at all. Apart from seed fished at natural mussel beds, farmers obtain seed from SMCs. These seed types differ in size and farmers apply seeding techniques depending on the size of the seed, which may result in different seed densities on the culture plots, and subsequent variation in survival rates. In Chapter 4, we investigate the relation between seeding density and factors that determine mussel biomass development on a substantial subset of subtidal mussel plots in the Wadden Sea. Like in Chapter 3, this chapter focuses on the effects of seeding and relaying related to intraspecific processes, but especially looks at the effect of mussel density herein.

What is the effect of shore crab predation on mussel biomass production?

The impact of sea stars and molluscivorous ducks on mussel dynamics in the Wadden Sea has recently been investigated by Agüera (2015) and Cervencl et al. (2015). However, shore crabs are also important predators on mussels, both intertidal and subtidal. The magnitude of crab predation might be underestimated, at least by the mussel farmers. This idea is challenged in Chapter 5, where different loss factors are separated from each other, in a case study on an intertidal culture plot in the Oosterschelde. This study, which makes use of exclosures for crabs, addresses the impact of predation and provides an estimate on how the prevention of shore crab predation on the culture plot would affect production.

To what extent does mussel culture impact system-scale biomass mussel production?

Figure 1.1 hypothesizes by the size of the shapes for mussel biomass and mussel density, which culture activities results in a higher density and biomass on culture plots compared to natural mussel beds. This expected impact of mussel 


\section{Chapter 1}

culture on the subtidal mussel population is addressed in Chapter 6. In this chapter, we compare population dynamics of mussels on natural mussel beds with the population dynamics of mussels on culture plots in the Wadden Sea.

The aim of these research questions is to better understand the population dynamics of subtidal mussels and the effect of mussel culture thereon. In Chapter 7 the research questions are related to literature and discussed in a broader context to investigate the main factors that are affecting production efficiency. In a second part of the discussion in Chapter 7 we discuss - given the factors identified, the best practice method for mussel farmers to increase production efficiency, here the following research questions are addressed:

How do current culture practices relate to production efficiency? and How can the RBP in mussel bottom culture be improved? 


\section{Chapter 2 \\ Review of mussel culture in the Netherlands}

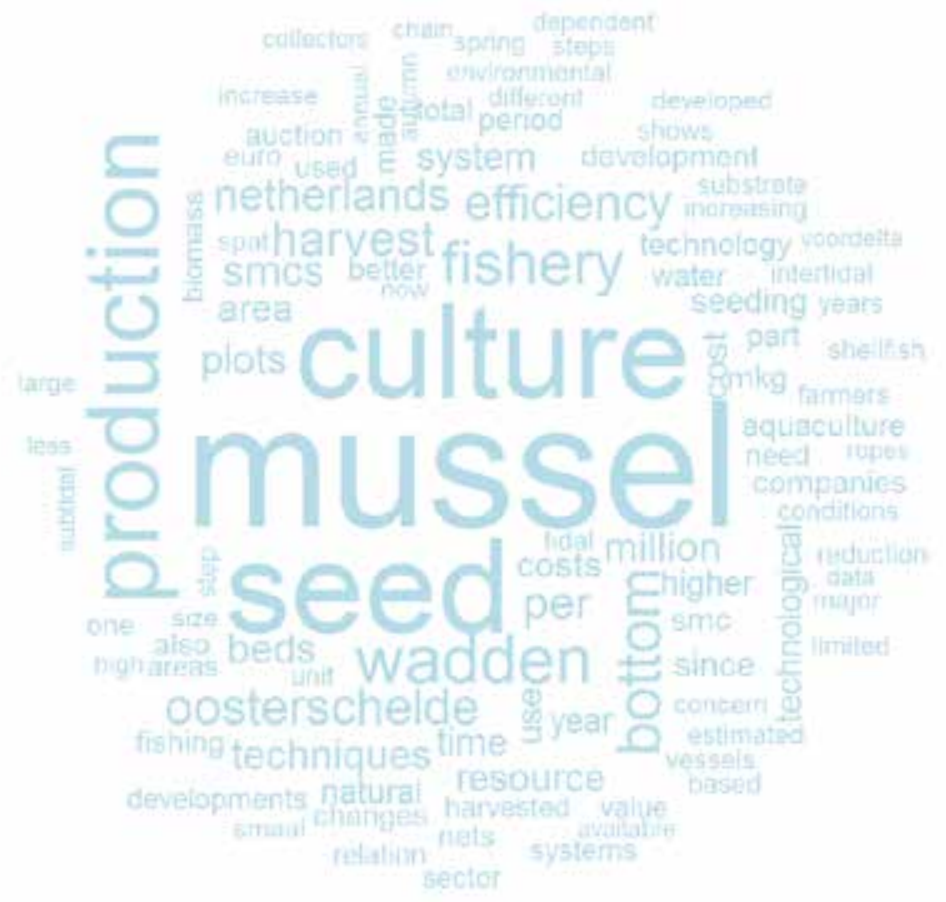

Jacob J. Capelle, Marnix R. van Stralen, Jeroen W.M. Wijsman, Peter M.J. Herman \& Aad C. Smaal 


\section{Abstract}

This chapter provides an overview of the mussel bottom culture in the Netherlands and addresses the developments in culture techniques in relation to the need to optimize production efficiency. The blue mussel (Mytilus edulis L.) is the most important aquaculture product of the Netherlands. Approximately 50 companies with 60 vessels produce roughly 6o Mkg of mussels annually (1990-2014) on bottom culture plots in the Wadden Sea and Oosterschelde. Between the 1960 and 1980 os mussel bottom culture in the Netherlands started to make the major technological transition from laborintensive to mechanized. This step included more efficient fishery and innovations that made it possible to process high mussel biomasses in a short amount of time. Between the 1970 and 2000 s mussel production reached annual production levels of 100 up to 150 Mkg of fresh product. Production was mainly limited by factors such as: space, temporal depletion and limitation of resources and an increasing competition between fishermen. The policy following environmental concern has led to a substantial reduction in resource availability through fishery since the 1990s. A further reduction is initiated since 2009 in the form of an agreement based on the stepwise reduction of bottom seed fishery determined by the rate at which alternative seed supply techniques could be made available. From 2000 to the present annual production dropped to levels of 40-6o Mkg of mussels. Environmental concerns have resulted in a second major technological transition in system innovation; specifically, the increasing use of spat mussel collector (SMC) technology for resource provisioning. The higher efforts and costs of using SMCs compared to seed fishery have increased the prizes of the resource. Efficiency improvement through better seed use is now of major concern for a sustainable culture. Furthermore, when one part of the technology changes, it is needed to review the entire technological cycle, for example, productivity of seed from SMCs needs to increase by implementing better seeding techniques to become cost efficient. This emphasizes the need for innovations that obtain higher control on each step in the production chain from seeding to harvest and will rely on better understanding the relation between culture techniques and population dynamics of mussels throughout the culture chain. 


\subsection{Introduction}

Shellfish aquaculture production represented $16 \%$ of the global aquaculture production (in 2014) and increased from $300 \mathrm{Mkg}$ in 1950 to $16000 \mathrm{Mkg}$ in 2014, an increase of 7\% per year (FAO 2015). In the European Union, shellfish aquaculture represented $53 \%(1995-2010)$ of the total aquaculture biomass production; $73 \%$ of shellfish production consisted of mussel culture and $36 \%$ of cultured mussels were Mytilus edulis (Figure 2.1). However, aquaculture has stagnated in the EU since 1995, as has the shellfish culture that follows the same pattern as overall aquaculture production (Figure 2.1). This is a concern for EU policy makers (Breuer 2016). Apart from economic parameters that explain part of this trend, issues on environment, health and sustainability have contributed to a stagnation or decrease of production in some areas. Specifically, production in the main culture areas has reached the carrying capacity of the system; developments of other functions in traditional culture areas (conservation, recreation) has put limits on aquaculture developments; spat availability might be limiting in extensive culture; and shellfish diseases (such as Herpes viruses in oysters) and introduced species (such as the Japanese Oyster drill), are reducing shellfish survival (Renault et al. 1994, Goulletquer et al. 2002, Smaal 2002). 
EU annual aquaculture production (1995-2014)

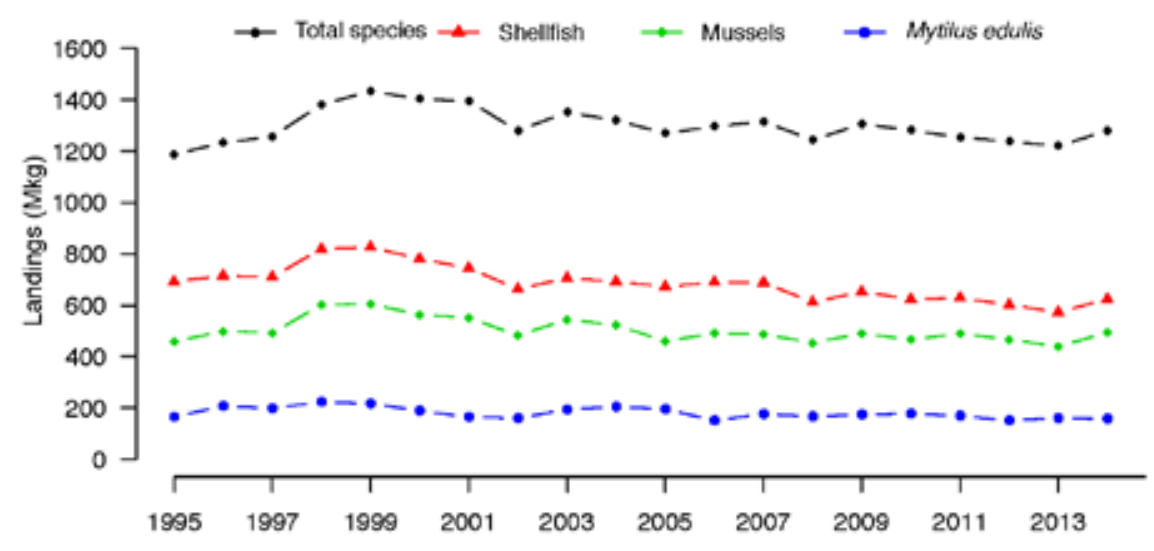

Figure 2.1 Annual aquaculture production of the European Union in Mkg, 1995-2014

Blue mussels (Mytilus edulis) are cultured off-bottom, especially on longlines and bouchot, and on-bottom on culture plots. Off-bottom mussel production has shown a steady increase since the 1970s, while mussel bottom culture production, shows no obvious trend (Figure 2.2a). According to expert judgments in Lane et al. (2014) technological improvements are expected to develop in the suspended cultivation systems, but for mussel in bottom culture the use of technology is expected to decrease in the coming period. 


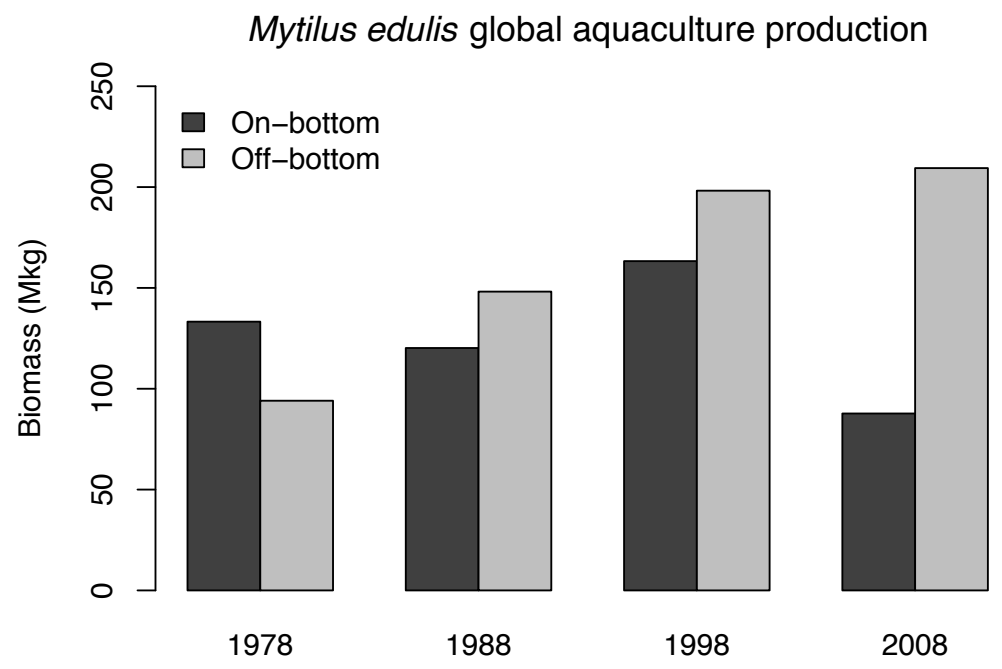

Mytilus edulisbottom grown production per country

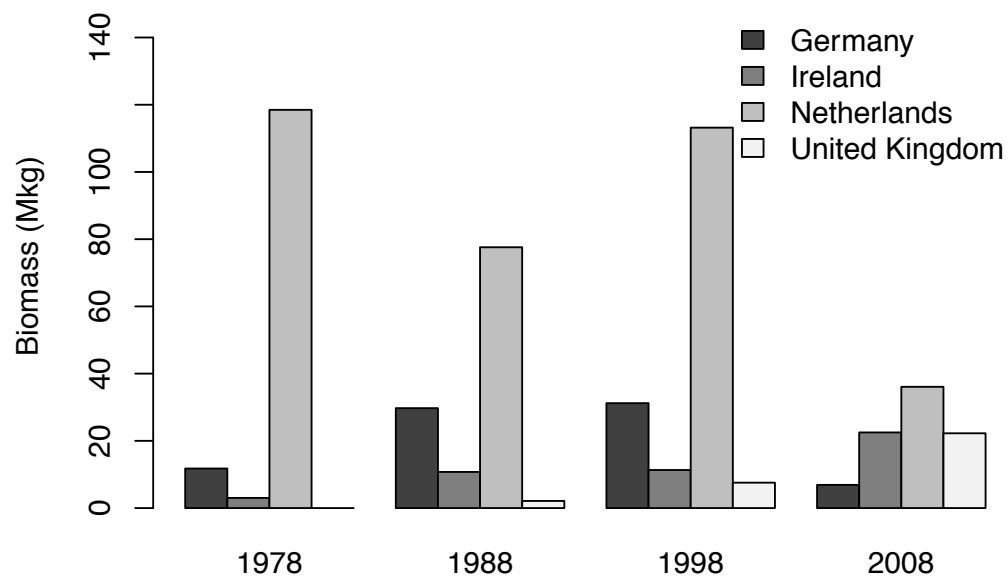

Figure 2.2a. Global on-bottom and off-bottom production of Mytilus edulis and $\mathbf{b}$. bottom grown production of Mytilus edulis specified per country in Europe, based on FAO data (FAO 2015) 
Figure 2.2b shows the trend in production, specified for mussel bottom culture per country. Large-scale bottom culture of Mytilus edulis is traditionally almost the only production method in the Netherlands and Germany, and takes a substantial share in mussel production in Great Britain and Ireland. Some bottom culture has been undertaken in the USA, France, and Denmark. Mussel culture in the Netherlands has faced many challenges in the last decade. There have been pressures on production because of sustainability concerns (and subsequent limitations) and because of technological issues. However, the former (environmental issues) has become a driver for the latter (technology). This chapter will document that link and sketch a future perspective for the relation between technological developments and production efficiency.

The blue mussel is the most important aquaculture product of the Netherlands. There are roughly 50 companies, with 60 vessels, producing approximately 60 million $\mathrm{kg}$ of mussels each year (1990-2014) on bottom culture plots in the Wadden Sea (48\%) and Oosterschelde (52\%). Other important aquaculture products are pacific oysters (Crassostrea gigas, 3 million $\mathrm{kg}$ fresh weight annual harvest, 3 million euro landing value), flat oysters (Ostrea edulis, annual o.1 million $\mathrm{kg}$, o.1 million euro), eel ( 5 million $\mathrm{kg} 38$ million euro farm gate value), tilapia (o.6 million kg, 2 million euro farm gate value), turbot (o.1 million $\mathrm{kg}$, 0.7 million farm gate value) and catfish (4 million $\mathrm{kg}, 5$ million euro farm gate value) (FAO 2015).

Mussel production reached annual production levels of up to 100-150 million $\mathrm{kg}$ fresh product between the 1980 os and the 20oos. These levels has decreased since due to a combination of factors, including competing claims with other stakeholders, increasing environmental awareness leading to areas closed for seed harvest, and years with recruitment failure. Other contributing factors included friction between a growth-based economic model and decreasing productivity of the system, coupled with a lack of understanding and 
acceptance of recruitment variability has had an effect. Hence, the industry faced many external and internal challenges to develop production in a sustainable way. In order to explore different options, a process was initiated by the mussel producers' organisation, in cooperation with the mussel traders, to identify critical success factors, under the slogan "uit de schulp" (out of the shell). It became clear that the mussel industry needed to invest in a "license to produce". The triple-P concept implied that the "planet" and "people" require just as much attention as "profit". With active support of various scientists, led by Martin Scholten (TNO, now WUR), a program was developed to come up with new ideas on sustainable culture, make better use of the resources, improve culture techniques and culture efficiencies, and better explain what mussel culture is about (ODUS 2001). However, the implementation of the EU bird and habitat directives through the Dutch nature conservation law (all of which are summarized as Natura 2000 rules) forced the mussel farmers to apply for permits for each period of mussel seed fishery. As this is normally done in autumn and in spring, extensive procedures had to be followed. This process turned out to be vulnerable for objections from other stakeholders, particularly nature conservation NGOs, as any stakeholder has the right to ask for a state court evaluation of the permit supplied by the government. Eventually, after the state court rejected a mussel seed fishery permit in 2008, an agreement was reached between the mussel producers' organisation, the government, and the nature conservation NGOs. NGOs had to accept mussel culture in a nature conservation area. Mussel farmers had to accept that nature was not their exclusive "property" and that there were rules and restrictions to observe that had reasons outside their own practice and goals. The agreement was based on the stepwise reduction of bottom seed fishery determined by: (a) the rate at which alternative seed supply techniques could be made available, (b) closure of mussel bed areas to promote natural mussel bed development, (c) improving culture plot quality, and (d) refraining from state court procedures. 
It was agreed that the mussel sector would make a gradual transition from an input resource dependent on bottom dredging to a culture independent from bottom seed, by obtaining seed from other sources (LNV 2009b). Steps in this transition were estimated at $20 \%$ of average spring fishery biomass. This amount equates to 5.5 million $\mathrm{kg}$ per time step and represents an area of mussel seedbeds that will gradually close for fishing with five steps of $20 \%$ each. With some boundary conditions it was agreed that, within each step, mussel farmers are given time to develop other sources to obtain their mussel seed as compensation for bottom-dredged seed. These steps are not time steps per se, but are completed when 5.5 million tons of mussel seed can be obtained from alternative sources. As a result of this covenant, mussel seed from seed mussel collectors (ropes and nets) steadily increased since 2009 in both the Wadden Sea and Oosterschelde, and near shore on the North Sea. The introduction of seed mussel collectors required an investment of the mussel sector, but has resulted in a more reliable seed supply, providing mussel seed also in years without natural seed beds.

Use of SMCs required a change in technology and when one part of the technology changes (here SMCs), it is necessary to review the entire technological cycle - for instance, because economic optimization changes towards optimizing efficiency of resource use. The fact that this has not been done, is a primary reason why the study presented in this thesis was set up. Seed from SMCs differs from bottom seed in regard to size, shell thickness, and the absence of attachment substrate such as shells (Kamermans et al. 2009, Christensen et al. 2015). SMC seed is very loosely aggregated, whereas bottom seed is often clumped around substrate; this and the small size of the seed promotes spatial heterogeneity at seeding. Reduced shell thickness and size may increase predation risk, but the smaller size also increases potential productivity. 
This thesis addresses the central theme of production efficiency. More efficient use of the resource being mussel seed is critical for a sustainable mussel culture. Traditional mussel culture produces an average $1-2.5 \mathrm{~kg}$ of end product out of $1 \mathrm{~kg}$ mussel seed and is seldom above $5 \mathrm{~kg}$ from $1 \mathrm{~kg}$ of seed (Dare \& Edwards 1976, Ferreira et al. 2007b). These figures need to enhanced in order to reduce pressure on a resource that is become scarcer, due to various reasons, and to reduce the costs of the production cycle when the resource costs increase.

Production efficiency is determined by the effects of biological factors and culture environment on the population dynamics of mussels on culture plots and the effects that culture exerts on these factors (Chapter 1). Culture activities are constrained by the available culture techniques and regulative framework. This chapter provides an overview of the mussel bottom culture sector in the Netherlands and addresses the developments in culture techniques in relation to the need to optimize production efficiency.

\subsection{Historic development}

Mussel bottom culture in the Netherlands developed in the course of the $19^{\text {th }}$ century, together with culture of the famous flat oyster (Ostrea edulis L.). Before this time there was a fishery on natural stocks for local and regional markets. The first culture plots were registered in the Westerschelde estuary in 1827, in the Oosterschelde and Grevelingen in 1865 and in the northern Zuiderzee (now part of Wadden Sea) in 1930 (Dijkema 1997). Almost all mussel culture companies were based in Zeeland, a province in the southwest of the Netherlands. Since spat fall was more abundant in the north of the Netherlands, farmers from Zeeland started seed dredging in Zuiderzee and Wadden Sea from the early $20^{\text {th }}$ century and transported seed to Zeeland (Havinga 1960). The occurrence of an exotic parasite (Mytilicola intestinalis) in 1949 in Zeeland resulted in the introduction of mussel culture in the Wadden Sea (Havinga 
1960). This turned out to be quite successful and production and seed fishery expanded in the Wadden Sea, making this the main production area. This was partly due to large scale loss of production areas in the Zeeland province, owing to coastal engineering works (Nienhuis \& Smaal 1994). Today, mussel culture is still dominated by companies from Zeeland, and carried out on culture plots in the Wadden Sea and Oosterschelde (Figure 2.3).

\subsection{Main culture areas}

\section{Wadden Sea}

The Wadden Sea is a shallow estuarine area in the north of the Netherlands, that extends to Germany and Denmark (Figure 2.3), the Dutch part covers about $2500 \mathrm{~km}^{2}$ (of a total area of $8000 \mathrm{~km}^{2}$ ), with half of the area consisting of tidal flats and a tidal range between $1.4 \mathrm{~m}$ and $3.4 \mathrm{~m}$ (Wolff 2000). The Wadden Sea borders the North Sea, divided by a range of small barrier islands and connected through tidal inlet channels. The bulk of the water flux is provided by ebb and flood tides through the narrow and deep inlet channels, from there the water is distributed into the Wadden Sea through an extensive system of branching gullies (Elias et al. 2012). Since 1932 the Wadden Sea has been separated from the former Zuiderzee, now the freshwater lake IJssel, by a $32 \mathrm{~km}$ dam called the 'Afsluitdijk'. This dike has two sluices for freshwater discharge. Salinity shows a strong gradient from the tidal inlets (about $30 \mathrm{ppm}$ ) towards lake IJssel, (about 15 ppm) (Duran-Matute et al. 2014). Chlorophyll-a concentrations in the Wadden Sea show a yearly peak in spring, with highest values of $>12 \mathrm{mg} \mathrm{m}^{3}$ in June and July and an infrequent bloom in autumn, with values of 10-11 $\mathrm{mg} \mathrm{m}^{3}$ (Philippart et al. 2010). 


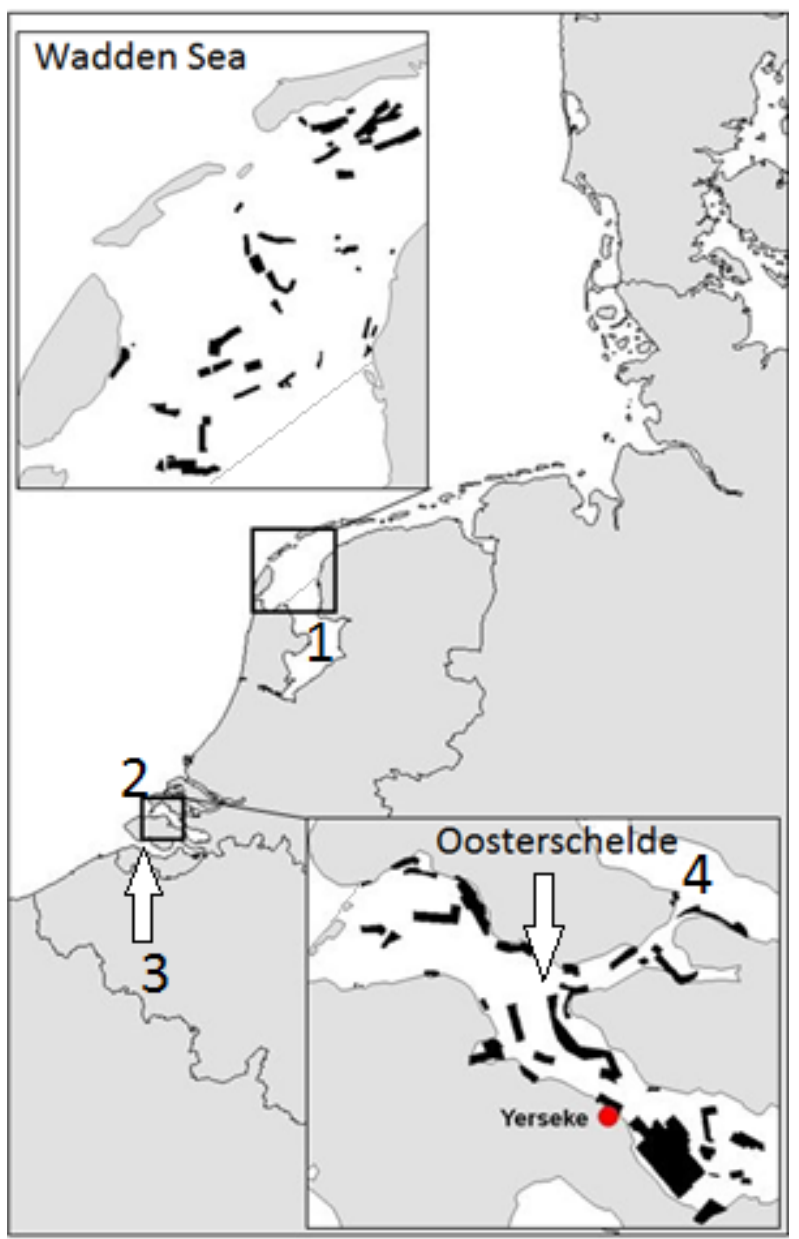

Figure 2.3 Mussel culture plots (in black) in the Netherlands at the Wadden Sea and Oosterschelde, 1 = Zuiderzee (now: Lake IJssel), 2 = Voordelta, 3=Westerschelde, 4=Grevelingen 
The western Wadden Sea harbors the largest mussel bottom culture area in the world, with 7700 ha and 510 plots available for culture. The western Wadden Sea is a dynamic area where constant changes occur in the morphology of channels, tidal flats and sediment composition (Wang et al. 2012). Locations of mussel culture plots were defined shortly after mussel culture was established in this area in 1949 and have hardly changed since then (Dankers \& Zuidema 1995. Smaal 2002). Such static plot management does not match with a dynamic geomorphology, as it can be expected that the conditions (water depth, current velocity, sediment composition) on the plots will change due to morphodynamics. The suitability of the plots for mussel culture may also change. Currently, only about 50\% of the designed culture areas are actively used for production (Smaal et al. 2010).

\section{Oosterschelde}

The Oosterschelde estuary is a tidal system in the Rhine-Meuse-Scheldt delta in the SW of the Netherlands (Figure 2.3). It has a tidal range of 2.5- $4 \mathrm{~m}$. The total area is $351 \mathrm{~km}^{2}$, of which $117 \mathrm{~km}^{2}$ is intertidal area. In 1987 a major coastal engineering project was completed including a storm surge barrier in the mouth and compartment dams in the northern and eastern part, which reduced water exchange with the North Sea as well as fresh water inflow from rivers (Nienhuis \& Smaal 1994). The barrier is closed only during extreme storm floods, hence the tidal characteristics have been maintained despite current velocities and nutrient inflow decreasing and water residence time and light transparency increasing. Annual primary production was maintained for the first 10 years but lower values have been estimated recently (Smaal et al. 2013b). Chlorophyll-a concentrations typically fluctuated between 2 and $5 \mathrm{mg} \mathrm{m}^{-3}$ and TPM concentrations ranged from 4 to $10 \mathrm{mg} \mathrm{l}^{-1}$ (Smaal et al. 2013 b). Throughout history the area has been known for the culture of mussels and flat oysters; the latter has been replaced by culture of the Pacific oysters (Crassostrea gigas). In 
the Oosterschelde, culture plots with a total surface of 2250 ha are spread over the estuary. Mussel seed originates mainly from the fishery in the Wadden Sea or from seed mussel collectors (SMCs); incidentally, there have been fisheries on mussel seed in the Oosterschelde, recently in 2001, 2005 and 2009. Mussel seed and half-grown mussels are transported from the Wadden Sea for further culture in the Oosterschelde. In the vicinity of the mussel auction in Yerseke, there are 500 ha of rewatering plots for storage and maintenance of trade stocks. Mussels are generally relayed there for a short time after sale at the auction in Yerseke. All cultivated mussels within the Netherlands have to pass the auction. The registration of amount and quality delivers an extensive dataset on culture characteristics. In addition to bottom culture suspended culture (longlines) is carried out on a limited scale by nine companies.

\subsection{Mussel culture cycle}

Mussel bottom culture is dependent on mussel seed (o-year class mussels) as input resource for the culture . Mussel seed is dredged from natural subtidal mussel beds in a fishery in Autumn $\left(F_{\text {aut }}\right)$ and in Spring $\left(F_{s p r}\right)$, on mussel beds that have developed in areas where fishing is permitted. Natural spat fall shows large year-to-year fluctuations and is primarily limited to the Wadden Sea. Mussel seed is also collected from floating seed mussel collectors (SMCs). Mussel seed $\left(2-3 \mathrm{~cm}\right.$, Seed $\left._{m}\right)$ is relayed on culture plots (seeding) in the Wadden Sea or Oosterschelde. On the culture plots the mussels grow from seed to halfgrown size $\left(3-4.5 \mathrm{~cm}, H G_{m}\right)$ and until consumption size $\left(>4.5 \mathrm{~cm}, C_{m}\right)$, when they are harvested and sold at the mussel auction in Yerseke. During the growout phase mussels are often relayed between plots within the same system or from the more dynamic Wadden Sea to the Oosterschelde, where conditions are more sheltered and the risk of storm damage (dislodgement) is lower. However, food conditions are better in the Wadden Sea, which means the farmers have their strategy to optimize stock management. Transplantation of mussels 
between the Oosterschelde and Wadden Sea was historically not allowed, but this policy changed recently as part of the agreement between culture, NGOs and the government. Yet, transplants from Oosterschelde to Wadden Sea are limited and closely monitored to avoid the introduction of invasive species in the Wadden Sea. There are a few mussel plots where growth conditions are high enough to harvest mussels of the first year class. The majority of the mussels from the Wadden Sea and a minority from the Oosterschelde are harvested when in their second year class. The mussels remaining from culture plots the Wadden Sea and the majority of mussels from the Oosterschelde are harvested when in their third year class, and the remainder in the fourth year class. Mussel production is schematized in Figure 2.4.

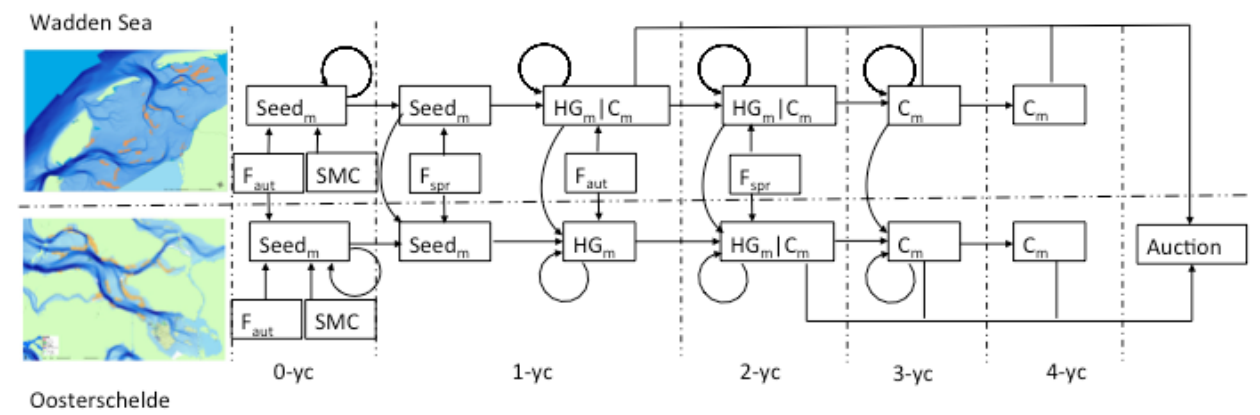

Figure 2.4 Schematic overview of mussel bottom culture production in the Netherlands, see text for explanation

Mussel seed can also be produced in hatcheries. This method does not currently seem to be a viable alternative to obtain resource material given the higher costs compared to mussel seed from fishery on natural beds or SMCs (Kamermans et al. 2013). When the costs of resource material increases, as they do for SMC seed, out-growing can also be carried out on submerged lines, as in longline culture or raft culture. Production efficiency in longline culture is often higher than in bottom culture; for example 4-12 kg harvest from kg seed depending on stocking density (Ferreira et al. 2009). In the Netherlands production on 
longlines is marginal (1\%), due to limitations in culture infrastructure, spatial planning, and market structure (bottom-grown mussels are more popular).

\section{Mussel seed fishery}

Figure 2.5 shows the biomass of mussels, fished from natural mussel beds in the Netherlands for relay on culture plots (2000-2012). The large year-to-year variability is primarily caused by year-to-year variability in natural spat fall (note the large variation in autumn fishery) and on spatial restrictions for fishery.

\section{Mussel seed fishery}

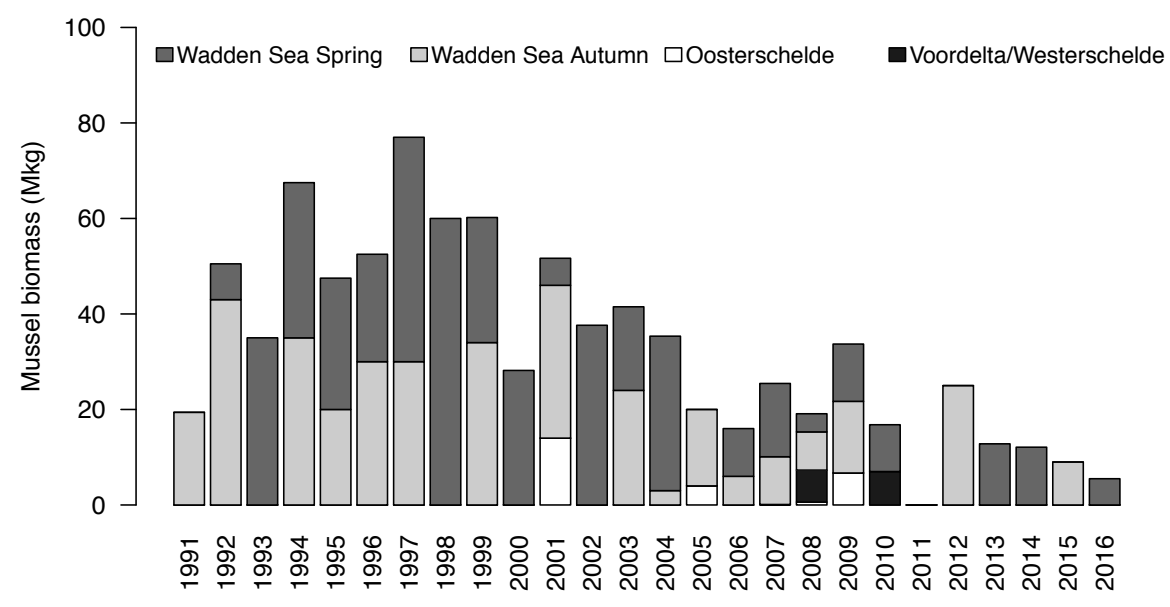

Figure 2.5 Mussel biomass fished from natural mussel beds for relay to culture plots from 2000-2012 for Wadden Sea (Autumn fishery and Spring fishery), Oosterschelde and Voordelta/Westerschelde

\section{Harvest from seed mussel collectors (SMCs)}

Mussel seed collection with floating collectors is a recent development and has increased steadily to almost 20 million $\mathrm{kg}$ in 2015 (Figure 2.6). Production on 
SMCs takes place in Oosterschelde, Voordelta, and the Wadden Sea (Figure 2.3). Majority of mussel seed is collected in the Wadden Sea, where spat fall is more abundant and growth rates of the spat are higher (Van Stralen 2016).

\section{SMC harvest}

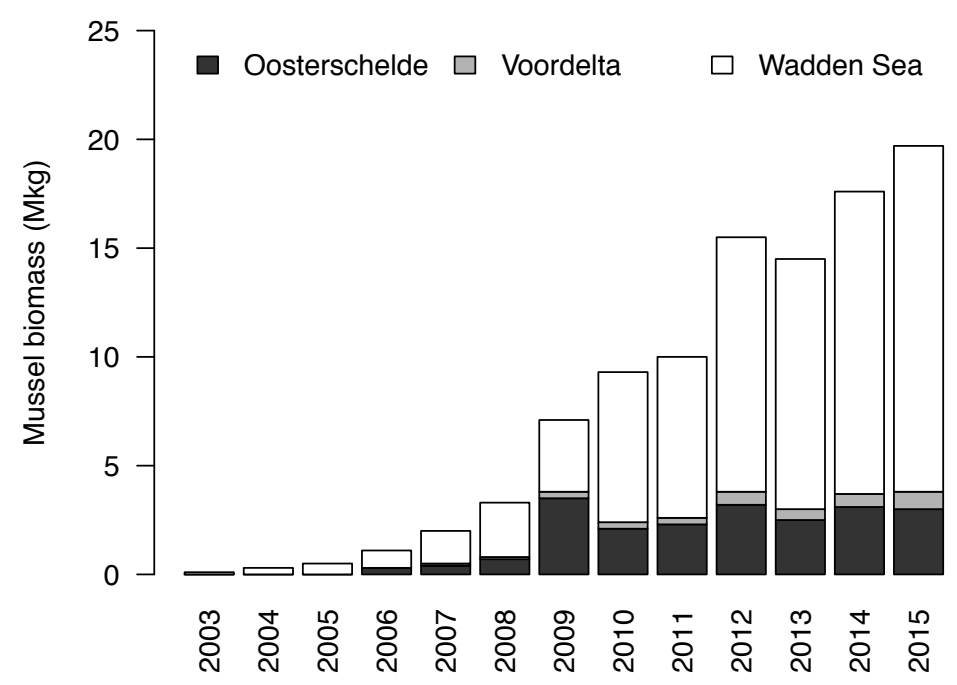

Figure 2.6 Harvest from SMCs in the Voordelta (near shore North Sea), Wadden Sea and Oosterschelde until 2015

\section{Auction deliveries and landing value development}

Figure 2.7 shows auction deliveries over the last 25 years. Mussel deliveries have decreased noticeably since 2000. Note that most of the mussels delivered from the Oosterschelde are originally from the Wadden Sea and have been transplanted as seed or as half-grown mussels. The average mussel landing value per season, recorded at the auction is included since 1997/1998 (www. agrimatie.nl). This value fluctuates between approximately 0.5 Euro per $\mathrm{kg}$ and 2 Euro per kg, reflecting variation in landings among other things. Other 
aspects that determine selling price are the quality of the mussels, competition between buyers and deliveries from other countries, especially Germany and Ireland (Nguyen 2012).

\section{Mussel landings and selling price}

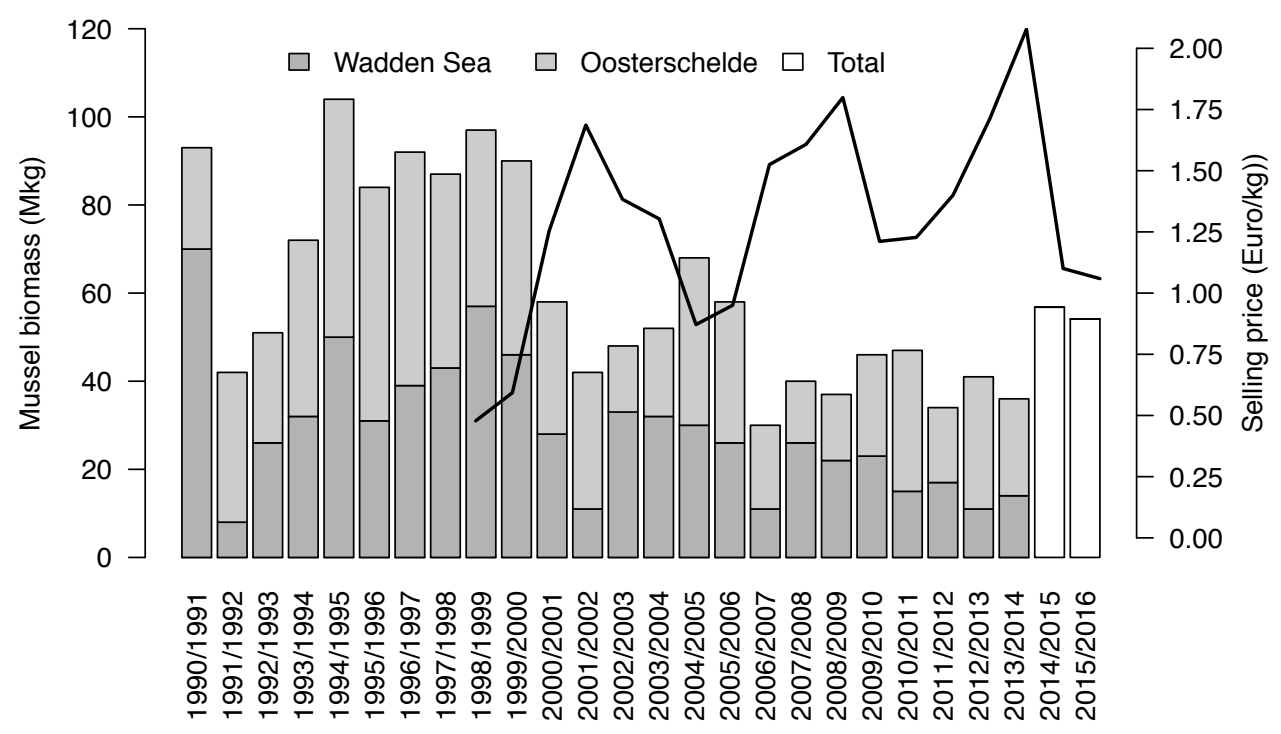

Figure 2.7 Auction deliveries since 1990 from Oosterschelde and the Wadden Sea

\subsection{Culture techniques and regulations}

Production efficiency of the mussel culture cycle is expressed by the relative biomass production ratio (RBP), which is synonymous to average physical product (APP) and is the number of units of mussel biomass harvested per unit of mussel biomass seeded (Ferreira et al. 2007a). The production efficiency can 
be improved to an extent that it takes less resource material (mussel spat) to produce a similar harvest (consumption mussels). The need to improve culture efficiency is set within the framework of culture techniques and regulations for three more or less distinctive periods for mussel farming in the Netherlands.

\section{Culture techniques and regulations in the 1970s and 1980s}

Traditionally, seed fishing was allowed from sunrise to sunset on subtidal mussel beds in autumn and in spring. In practice the opening of the fisheries started a competitive race for mussel seed, which was originally considered as a spectacular event. However, it raised questions about the non-efficient use of this resource as a lot of spillages occurred (that can be viewed at https:// www.youtube.com/watch?v=4UZyA6rqM5Q). Although fisheries were mainly focused on subtidal beds, quite a large amount of mussel seed was harvested from intertidal beds. Mussel beds in the intertidal zone could only be fished with a minimum water level to allow the vessels to dredge, which was during springtide or with enhanced water level due to winds from the northwest. Intertidal mussel seed is generally preferred over subtidal mussel seed due to its higher yields, probably because of a thicker shell that makes it less attractive for predation (Beadman et al. 2003).

The dredges were raised to the side of the ship where the content was rinsed and emptied by hand; a very labor-intensive method that included, extensive 'seed spills'. According to mussel farmers, these mussel spills often developed into mature mussel beds over time that could sometimes be harvested the year after. A method to empty the nets mechanically was implemented on mussel vessels around 1970, yielding higher efficiency and less seed spillage. Seeding on culture lots was done by hand, by shoveling seed through shafts (15-20 tons $\left.\mathrm{h}^{-1}\right)$ or by conveyer belts that transported the seed to the shafts $(25-40$ tonnes $\mathrm{h}^{-1}$ ). From 1978 till 1989 several inventions improved fishing and seeding 
efficiency. Larger ships with stronger engines, improved winches and a low draught were built. Seeding methods were improved (both in terms of time and labor) in 1979 by a system based on water pressure that washed mussels out through holes below the water line (Westbroek 1979). Seeding by means of water pressure proved to be a fast method, as seeding time could be reduced to half an hour (Dijkema 1997).

In the 1980s, oyster vessels that participated in the mussel seed fishery were replaced by cockle vessels with a draught of $60-80 \mathrm{~cm}$ that were better equipped to fish on intertidal seed beds. Large mussel companies hired cockle boats for seed fishing. Some cockle farmers did dredge for mussel seed on their own permits and competition between companies increased.

Prior to 1989 , few changes were made in the regulations for the mussel seed fishery. In the early 1980 os fishing time was limited from 7 a.m. till 7 p.m. and in the late 1980 a limit was placed on the number of fishing days. The eastern part of the Dutch Wadden Sea was only open to fishing after three weeks of fishing in the western part.

\section{Culture techniques and regulations in the 1990s and into the 2000s}

In the Netherlands in 1991, a seed quota system was introduced that divided the available seed over the licenses, with some extra quota based upon the size of the companies. After internal protests (due to the fact that some companies owned more licenses), it changed into a quota system that took auction deliveries from the past 25 years into account.

Low shellfish stocks, the disappearance of intertidal mussel beds and eider duck mass mortalities, gave rise to a new policy in 1993 (Sea and Coastal Fishery Policy) (LNV 1993). Twenty-six percent of intertidal mudflats and adjoined 
gullies were closed for fisheries by government and some others by the mussel sector as a token of good will (PV 1993). Furthermore, it was decided to enforce reduction of fishery on intertidal mudflats in years with low shellfish stocks, with the aim of preserving 10.1 million $\mathrm{kg}$ of mussels, which was estimated to be needed by over-wintering molluscivorous birds. At that time, no enforcements were formulated for the fishery on subtidal mussel beds. Agreements within the sector should take care of an efficient use of seed resources. One of these agreements was a yearly spring and autumn inventory of the natural mussel stocks in the Wadden Sea. These surveys have been carried out since 1992.

\section{Present culture techniques, regulations and economics}

Seed dredging on subtidal natural mussel beds in the Dutch Wadden Sea in autumn is currently limited to subtidal beds that are estimated to have a high physical instability or are subject to high predation pressure. For this purpose a stability index was developed (Alterra 2005). Stability is based on expert judgment that takes into account the cumulative effect of (sea star) predation and wave or current dislodgement. The stability index is a semi-quantitative value that evaluates the probability of the development of perennial natural mussel beds at a specific location. The stability index varies between 1 (low probability) and 5 (high probability). The total allowable catch is set before every fishery and is dependent on available mussel seed biomass in unstable (1-3) classes. The spatial map of the stability index is displayed in Figure 6.1b.

Mussel farmers started experimenting with floating SMCs in the early 2000 s and started using SMCs on an annual increasing scale (Figure 2.6). Companies started developing their own systems and harvesting techniques, which resulted in the development and use of several distinct SMC systems (Figure 2.8). Simultaneously, different harvest techniques are used, depending on the type of system, but are often custom made by the individual company. The 
majority of harvests are carried out on mussel vessels that are specially equipped for that occasion. Some (larger sized) companies have a custom-made vessel specifically (re)designed for SMC related work.

Harvest statistics and efficiency of the different systems are reported annually. The efficiency for 2015, expressed per unit substrate and per unit area is summarized in Table 2.1 (Van Stralen 2016). It shows that longlines are most productive in the Wadden Sea, while tubes with nets are most productive in the Voordelta, probably due to more exposed conditions there and the better attachment to nets than to ropes. Nets on rafts are less productive per unit substrate than nets on tubes; however, density of this system is much higher resulting in the highest production per unit area. Production per unit area seems more affected by location than by type of system.

The introduction of SMCs caused substantial changes in management of companies and in the cost and profit structure. The cost of mussel seed from SMCs and from fishery on natural mussel beds is dependent on the volume of the harvest. Prices are lower when more mussels are harvested. The increase in scale over time in SMC systems also reduces prices. 

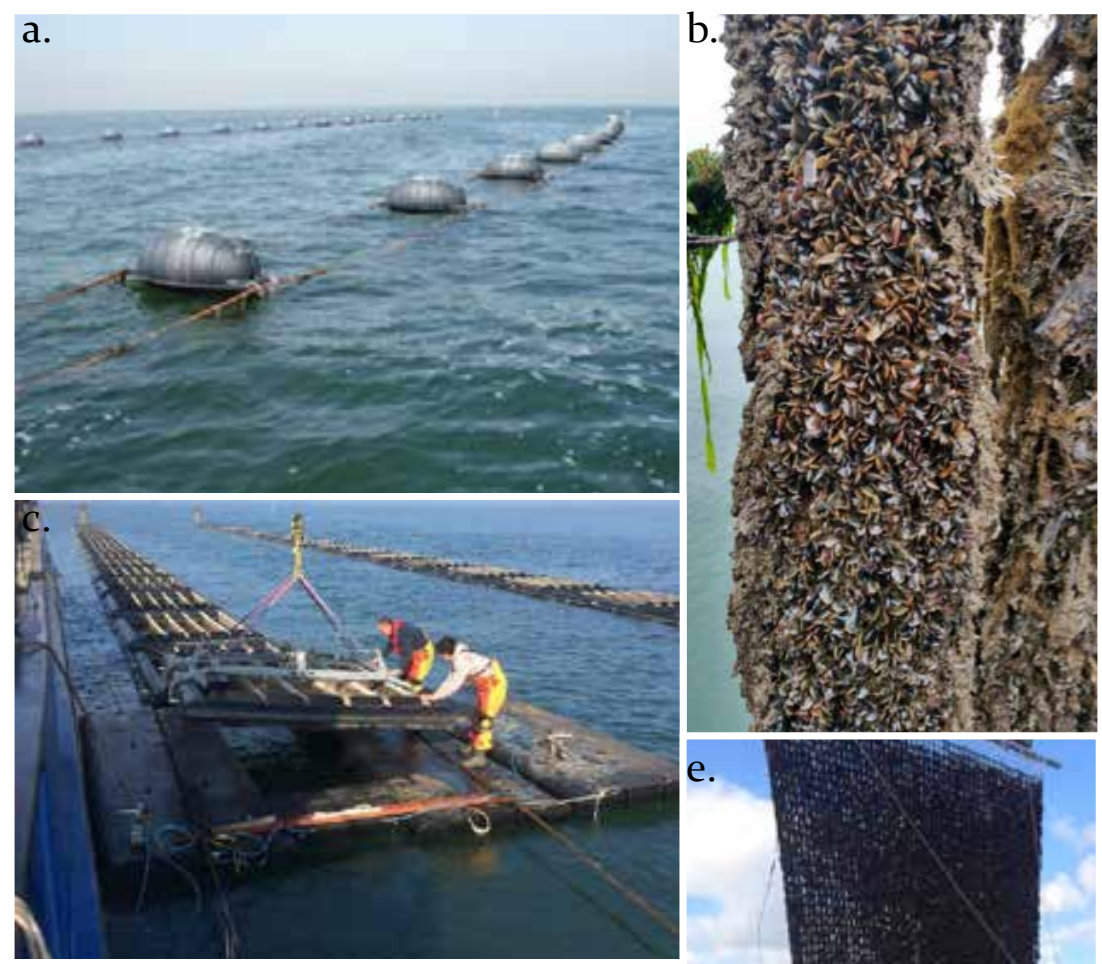

e.
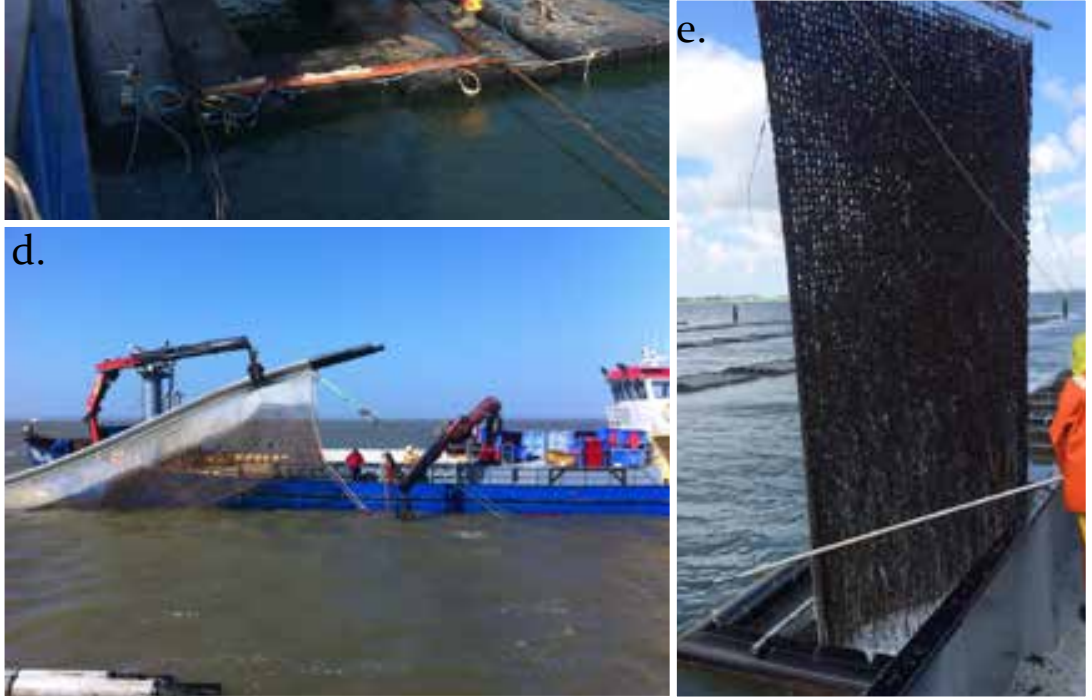

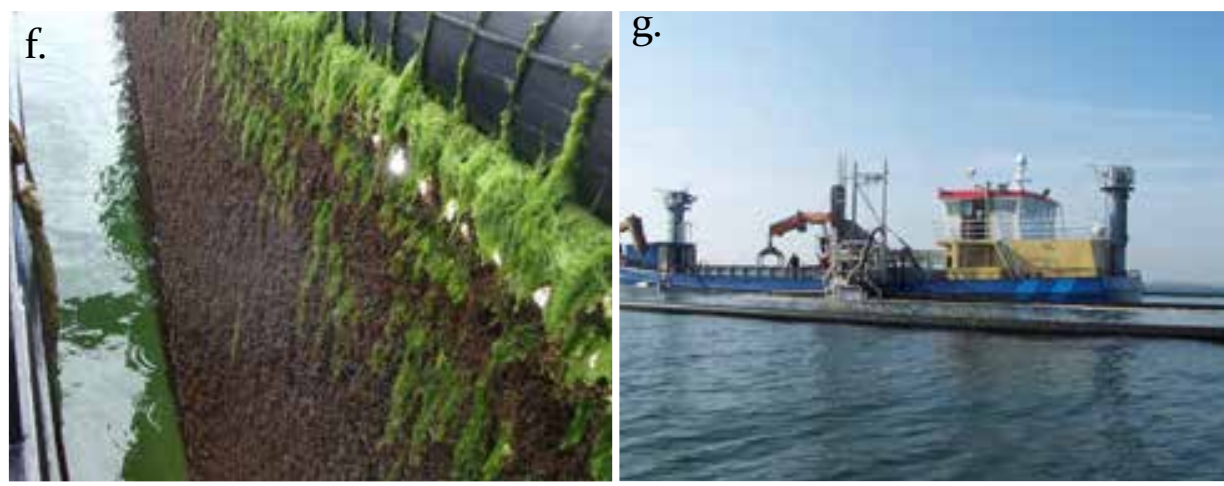

h.
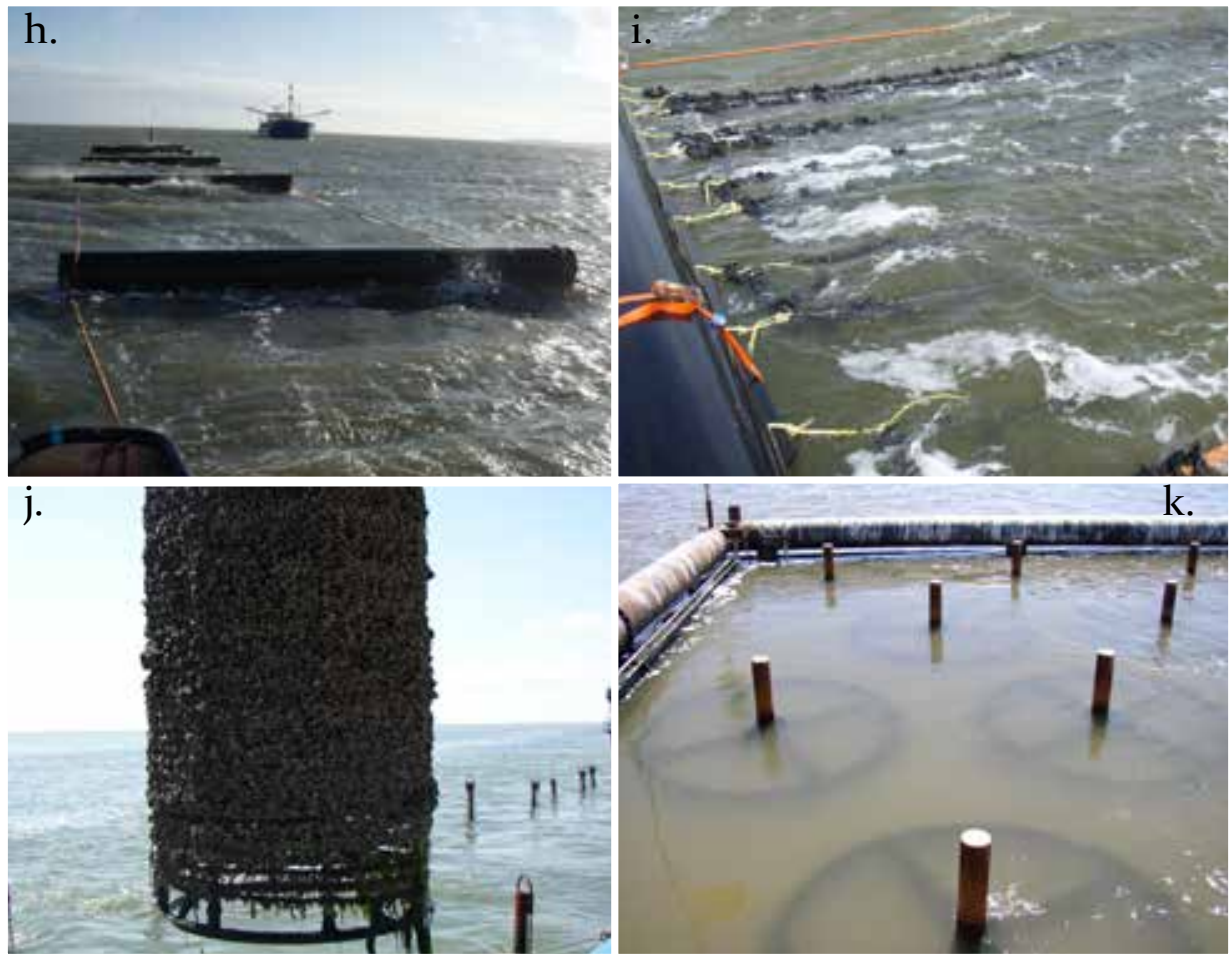
Figure 2.8 (previous pages) SMC systems used in the Netherlands: $\mathbf{a} / \mathbf{b}$ : longline system, consisting of endless ropes (default) or drop-down ropes; longlines are used to a depth of ca. $12 \mathrm{~m}$, harvested by hand, scrapers, or venturi pumps; endless ropes are harvested once per year; on dropping lines a thinning out harvest can first be applied; longlines are the most commonly used system (photo C. Otte). c/d: Rafts ( $3 \times 4 \mathrm{~m})$ with five nets deployed to a depth of $5 \mathrm{~m}$, one net has a surface area of $82 \mathrm{~m}^{2}$, harvest by brushing, rafts are used by one company (photo's J. Vane). e/f/g: Tubes with nets, approximately $100-110 \mathrm{~m}$ long to a depth of 3-4 m; different systems are in use: Smartfarm (maze: $17.5 \times 17.5 \mathrm{~cm}$ ), Easy farm and Emergo folding longline (maze: $4.5 \times 4.5 \mathrm{~cm}$ ), a thinning out harvest can first be applied, harvest by brushing using a custom made harvester (g.) (photo's M. Padmos). h/i: IMOTH $-6 \mathrm{~m}$ tubes of with horizontal ropes used in shallow waters, used by few companies (photo's M. van Stralen). j.: Cages: Wietex (k/j.)50 cm off-bottom, $360 \mathrm{~m}$ rope per cage, fitted in fixed pipes (k.). Cages are used by one company (photo's M. van Stralen)

Table 2.1 Production on the different categories of SMC systems in 2015 expressed per unit substrate and per hectare for the different locations in which the SMC systems were placed (data from Van Stralen (2016)).

\begin{tabular}{llll}
\hline \multicolumn{1}{c}{ Type of system } & \multicolumn{1}{c}{ Location } & \multicolumn{1}{c}{$\begin{array}{c}\text { Production per } \\
\text { unit substrate }\end{array}$} & \multicolumn{1}{c}{$\begin{array}{c}\text { Production per } \\
\text { hectare }\end{array}$} \\
\hline Longline & Oosterschelde & $2.4 \mathrm{Kg} \mathrm{m}^{-1}$ & 43900 \\
& Voordelta & $2.7 \mathrm{Kg} \mathrm{m}^{-1}$ & 48000 \\
& Wadden Sea & $3.4 \mathrm{Kg} \mathrm{m}^{-1}$ & 71200 \\
\hline IMOTH & Oosterschelde & $1.4 \mathrm{Kg} \mathrm{m}^{-1}$ & 33000 \\
& Wadden Sea & $1.9 \mathrm{Kg} \mathrm{m}^{-1}$ & 56700 \\
\hline Tubes with nets & Oosterschelde & $22.1 \mathrm{Kg} \mathrm{m}^{-2}$ & 35100 \\
& Voordelta & $63.8 \mathrm{Kg} \mathrm{m}^{-2}$ & 56600 \\
& Wadden Sea & $39.6 \mathrm{Kg} \mathrm{m}^{-2}$ & 40000 \\
\hline Rafts with nets & Oosterschelde & $13.1 \mathrm{Kg} \mathrm{m}^{-2}$ & 140000 \\
\hline
\end{tabular}

Development of mussel seed price estimated by Wageningen Economic Research (WER) based on expert judgment and calculations (Taal \& Turenhout 2013) are shown in Table 2.2. 
Table 2.2 Relation between harvest volume and seed costs for seed from fishery and from SMCs (data from: www.agrimatie.nl)

\begin{tabular}{lll}
\hline $\begin{array}{c}\text { Harvest volume } \\
\left(\mathrm{Mkg} \mathrm{y}^{-\mathbf{s}}\right)\end{array}$ & \multicolumn{1}{c}{$\begin{array}{c}\text { Seed costs fishery } \\
\left(\text { Euro } \mathbf{k g}^{-1}\right)\end{array}$} & \multicolumn{1}{c}{$\begin{array}{c}\text { Seed costs SMC } \\
\left(\text { Euro kg- }^{-1}\right)\end{array}$} \\
\hline $0-5$ & 0.07 & 0.7 \\
$5-10$ & 0.07 & 0.65 \\
$10-18$ & 0.06 & 0.6 \\
$18-26$ & 0.05 & 0.55 \\
$26-34$ & 0.04 & - \\
$34-42$ & 0.03 & - \\
\hline
\end{tabular}

The results from Table 2.2 were extrapolated by WER on recent harvest data to estimate average cost of mussel seed per year, depending on the harvested biomass from SMCs and fishery. Prices are clearly higher for SMC seed (factor 10 with seed from fishery), which means that the average cost is higher when the larger part of the seed originates from SMC's

Table 2.3 Harvest biomass and harvest biomass-dependent cost of mussel seed 2008-2015 (data from: www.agrimatie.nl)

\begin{tabular}{llllll}
\hline Year & $\begin{array}{c}\text { SMC seed } \\
\text { harvest } \\
(\mathbf{M k g})\end{array}$ & $\begin{array}{c}\text { Fishery seed } \\
\text { harvest }(\mathbf{M k g})\end{array}$ & $\begin{array}{c}\text { Total seed } \\
\text { harvest }(\mathbf{M k g})\end{array}$ & $\begin{array}{c}\text { Price } \\
\left(\mathbf{M} € \mathbf{~ y}^{-1}\right)\end{array}$ & $\begin{array}{c}\text { Price } \\
\left(€ \mathbf{~ k g}^{-1}\right)\end{array}$ \\
\hline 2008 & 4.3 & 8.2 & 12.5 & 3.6 & 0.29 \\
2009 & 7.9 & 27.0 & 34.9 & 6.2 & 0.18 \\
2010 & 9.4 & 20.0 & 29.4 & 7.1 & 0.24 \\
2011 & 10.1 & 0.0 & 10.1 & 6.0 & 0.60 \\
2012 & 15.3 & 40.9 & 56.1 & 10.4 & 0.18 \\
2013 & 14.2 & 20.1 & 34.3 & 9.5 & 0.28 \\
2014 & 17.5 & 20.0 & 37.5 & 11.5 & 0.31 \\
2015 & 19.6 & 15.0 & 34.6 & 11.7 & 0.34 \\
\hline
\end{tabular}


Table 2.3 provides insight in the price development of mussel seed. An illustration of how this fits into the total cost structure of mussel production is provided in a case study by WER for 2014 and is summarized in Table 2.4.

Table 2.4 estimated a net positive result of 12.5 M€ over the entire sector, that consisted of 55 vessels and 152 FTE (in 2014). Major costs are in wages and resource provisioning. Revenues are sales from mussel that were seeded in previous years the majority from 2012, when there was a substantial fishery; auction prices were relatively high in 2014 (Figure 2.7). Fluctuations between years and external factors have a large impact on the development of revenues, which means that information in Table 2.4 cannot be generalized.

Table 2.4 Costs and revenues of Dutch mussel sector estimated for 2014 (data from: www. agrimatie.nl)

\begin{tabular}{ll}
\hline Costs $(\mathbf{M} \boldsymbol{)})$ & \\
\hline Wages & 11 \\
Gasoline & 5 \\
Maintenance & 6 \\
Operational costs & 8 \\
Fixed costs & 6 \\
Seed costs & 11.5 \\
Interest & 3 \\
Divestments & 2 \\
\hline Total & 52.5 \\
\hline Revenues (M€) & \\
\hline Mussel sales & 63 \\
Other revenues & 2 \\
\hline \hline Total & 65 \\
\hline
\end{tabular}




\subsection{Synthesis and future developments}

This chapter has provided an overview of the mussel bottom culture sector in the Netherlands. We have addressed the relationship between developments in culture techniques and the need to optimize production efficiency. Relation between technology and production efficiency has developed over time and resulted in several changes. These changes were characterized by three more or less distinctive time periods with changes that affected culture technology. Therefore, it is expected that each step between these periods will also have implications for production efficiency. This link between technology and production efficiency is characterized in Table 2.5 .

Table 2.5 Steps in the relation between technological developments in the Dutch mussel bottom sector and implications for production efficiency

\begin{tabular}{|c|c|c|c|}
\hline Period & Characteristics & Steps & $\begin{array}{l}\text { Implications for } \\
\text { production efficiency }\end{array}$ \\
\hline$<1970 s$ & $\begin{array}{l}\text { Seeding and } \\
\text { harvesting by } \\
\text { hand }\end{array}$ & & \\
\hline 1970s-200os & Mechanization & Bulk production & External limits \\
\hline 20oos-present & $\begin{array}{l}\text { System } \\
\text { innovation }\end{array}$ & SMCs & $\begin{array}{l}\text { Limits on production } \\
\text { efficiency }\end{array}$ \\
\hline $\begin{array}{l}\text { Future } \\
\text { prospective }\end{array}$ & Chain innovation & $\begin{array}{l}\text { Efficiency } \\
\text { improvement }\end{array}$ & $\begin{array}{l}\text { Stepwise approach in } \\
\text { increasing production } \\
\text { efficiency }\end{array}$ \\
\hline
\end{tabular}

Mussel bottom culture in the Netherlands has made its first major technological transition from labor-intensive to mechanized from the 1960 os to the 1980 . This included more efficient fishery and innovations that made it possible to process high mussel biomasses in a short amount of time. This reduction in manual 
labor and the effort to increase fishing efficiency when resources were abundant became the driver for technological improvement. The developments resulted in a bulk production, frequently with levels up to $100-150 \mathrm{Mkg}$ in the period from 1970-200o. Production was mainly limited by external factors: limitation, of space, temporal depletion and limited of resources, together with increasing competition between fishermen

Policy following environmental concern, has led to a substantial reduction in resource (spat) availability through fisheries since the 1990 and a further reduction has been initiated since 2009 in the transition process from dependency on seed fishery to the development of other methods to obtain resources. Since 2000 production dropped to levels of 40-60 Mkg of mussels. Environmental concern has become a driver for technological improvements that led to a major system innovation, specifically the extensive use of SMC technology for resource provisioning. The higher efforts and costs of using SMCs compared to seed fishery, have increased the production costs of the resource. Hence, efficiency improvement through better seed use is now of major concern for the sustainability of culture.

When one part of the technology changes, there is a need to improve other technological parts, as requirement for balanced technological development. For example, productivity of seed from SMCs needs to increase by implementing better seeding techniques to become cost efficient. This stresses the need for innovations that obtain higher control on each step in the production chain from seeding to harvest. Steps in the production chain can be summarized by seeding and repetitive relay (see Figure 2.4), complemented by maintenance activities such as predator control and substrate manipulation (such as mud removal, providing attachment substrate). A higher control per production step will rely on better understanding the relation between culture techniques and population dynamics of mussels throughout the culture chain. This contradicts 
the vision proposed in Table 22 in Lane et al. (2014) where it is estimated that the use of technology in production will decrease for mussel bottom culture until 2030. It can be expected that culture plot positions and vessel design that were created or developed under a different set of (environmental and regulative) conditions need to be re-evaluated in this process now that production conditions has shown a considerable change in the recent period. 


\section{Chapter 3}

\section{Spatial organisation and biomass development after relaying of mussel seed}

Jacob J. Capelle, Jeroen W.M. Wijsman, Tim Schellekens, Marnix R. van Stralen, Peter M.J. Herman, Aad C. Smaal (2014) Spatial organisation and biomass development after relaying of mussel seed.

Journal of Sea Research 85:395-403 


\section{Chapter 3}

\section{Abstract}

It is not known whether and by what factors spatial heterogeneity in mussels (Mytilus edulis L.) affects mussel production in human-created mussel beds. In a field experiment, the same number of mussels was relayed on four different areas within plots of the same size, resulting in four treatments with different mussel densities. Density, individual weight and spatial structure of mussels were followed per treatment. The uniformly placed mussels on different areas redistributed into new patches, but mussels did not spread out over a larger area. Initial mussel density affected redistribution and mussel survival. At high densities mussels redistributed into a uniform matrix or in a few larger patches, that showed larger losses than at low densities, where mussels redistributed into a high number of patches. Growth rate and condition index of the mussels did not differ between treatments and no relation was found between treatment and number of foraging shore crabs, which was the major predator of mussels in this experiment. We hypothesize that the relation between initial mussel density and mussel loss after relaying is associated with redistribution, with less competition for space when mussels are positioned at the edge of a mussel patch. The very high mussel losses that we observed in the experiment within four weeks after relaying were the major factor in biomass development. Mussel bed formation concerns mussel growers and managers involved in natural mussel bed restoration. Initial mussel survival determines the success of these activities. The present study shows the effects of mussel relaying on spatial redistribution for the first time under field conditions, and underlines the importance of edge effects in understanding mussel loss in redistribution. Mussel survival after relaying will be higher when the mussels are distributed homogeneously and in relatively low density. 


\section{Chapter 3}

\subsection{Introduction}

Mussel beds on soft bottom substrate show a hierarchal spatial structure (Snover \& Commito 1998, Commito et al. 2006). On a large scale, in natural mussel beds that can stretch out over several square kilometres, mussels are found in banded or fractal structures (Van de Koppel et al. 2005, Crawford et al. 2006). Within a bed, mussels are found uniformly in net-like structures or scattered in loose patches (Svane \& Ompi 1993, Commito \& Rusignuolo 200o).

At the scale of $\mathrm{cm}$ to $\mathrm{dm}$, De Jager et al. (2011b) found that individual mussels actively search for substrate to attach to. On soft bottoms, substrate consists mainly of conspecifics and therefore they aggregate into clumps (aggregation of a few mussels) or strings that make patches. According to Van de Koppel et al. (2012), processes that occur on an individual scale define small-scale organisation into structures like clumps and patches, while physical forcing on landscape scale defines large-scale organisation into spatially-organised mussel beds.

Mussel growth, condition and reproductive output decrease, going from edge to centre at the scale of mussel beds (Knights 2012), patches (Newell 1990, Svane \& Ompi 1993) and clumps (Okamura 1986). Okamura (1986) showed furthermore that growth, reproductive output and condition, when averaged over a clump, decrease with clump size. This shows that the spatial aggregation of mussels increases competition for food at an individual level on all scales. On group level, however, food availability can be improved by increasing near bed turbulence (Newell \& Shumway 1993, Van de Koppel et al. 2005, Liu et al. 2012).

Spatial structure affects mussel loss, and relations between spatial structure and predation are particularly well documented. The aggregation of mussels decrease predation rates (Dolmer 1998, Frandsen \& Dolmer 2002), which are 


\section{Chapter 3}

higher in solitary mussels than in aggregated individuals and higher in mussels located at the edges of patches than in those in the centres (Burch \& Seed 2000, Brown et al. 2011). In the absence of predators, patches become larger (Okamura 1986, Reusch \& Chapman 1997). This suggests that at lower food levels, food availability affects success at the edges of a patch more than predation does, whereas at high food levels, food availability is also high for mussels within the patch that are less affected by predation. Consistent with general theories on trade-offs between food availability and mortality in group aggregations, the optimal situation for an individual is to be at the edges of an aggregation when food levels are intermediate (Morrell \& Romey 2008).

The profitability of positioning at the edge of a patch can change over an individual's lifetime, because, for example, predation decreases with size, meaning that mussels at the edge can outgrow crab predation sooner, with crabs being major predators on intertidal mussel beds (Bertness \& Grosholz 1985, Okamura 1986, Smallegange \& Van Der Meer 2003, Murray et al. 2007b). However, fast-growing mussels will be quicker to reach the prey size preferred by shellfish-eating birds like oystercatchers in the intertidal and eider ducks in the sub-tidal area (Ens et al. 1996, Hamilton et al. 1999).

Besides the effects of individual positioning on growth and mortality, the size of patches and amount of coverage affects dislodgement risk by waves and currents. Mussels attach to the substrate and to each other with their byssus threads. In an aggregation, mussels profit from having neighbours to attach to and this provides a refuge against hydrodynamic forces (Denny 1987, AveniDeforge 2007). Positioning within a patch can therefore be understood as a trade-off between food limitation and predation/bed stability in relation to hydrodynamic forces.

Humans create mussel beds in mussel bed restoration and in on-mussel bottom culture. Restoration can occur when mussel beds are endangered or 


\section{Chapter 3}

contaminated. For example in the Wadden Sea the area of mature natural mussel beds has declined over the last 3 decades (Nehls 2009), opportunities to restore mussels beds are studied (Donker et al. 2012) and in Alaska mussel beds were restored after oil spillage (Carls et al. 2004).

In on-mussel bottom culture, mussel seed dredged from natural seed beds or collected from spat mussel collectors, is positioned at intertidal or sub-tidal lease sites, where they are harvested when they reach commercial size (Dijkema 1997, Smaal 2002, Dolmer et al. 2012). Commercial beds are laid at high tide by mussel vessels which flush the seed (juvenile mussels) through shafts below water level (seeding). While seeding, the vessel moves in circular patterns. As a result mussels are distributed on multiple plots in concentric patterns. Seeding of high biomasses (up to 150 metric tonnes) is done as fast as possible around slack tide, to prevent mussels flushing out from the lease site by tidal currents. This results in highly concentrated mussel formations (Figure 3.1), that might be multi-layered within seeding tracks, especially where seeding tracks overlap. The spatial structure that forms by redistribution might affect production through individual position effects and dislodgement risk (Okamura 1986, Newell 1990, Reusch \& Chapman 1997, Widdows et al. 2002).

When the density of mussels increases, the amount of mussels will be sufficient to form a uniform matrix. When the density of mussels is lower we can expect a threshold to be reached, after which there will not be enough mussels to form a uniform matrix, and instead they will redistribute into smaller patches. Therefore, we hypothesise that mussels in high densities will show low levels of redistribution in different patches, whereas those in lower densities will redistribute into a number of small patches. This can affect production because of a higher perimeter-to-area ratio in smaller patches. Based on the effects reviewed here, a higher perimeter will increase predation risk but also food availability, while a larger patch size will decrease vulnerability to dislodgement 


\section{Chapter 3}

by hydrodynamic forces (Reusch \& Chapman 1995, Widdows et al. 2002) but increase density-dependent loss (Newell 1990).

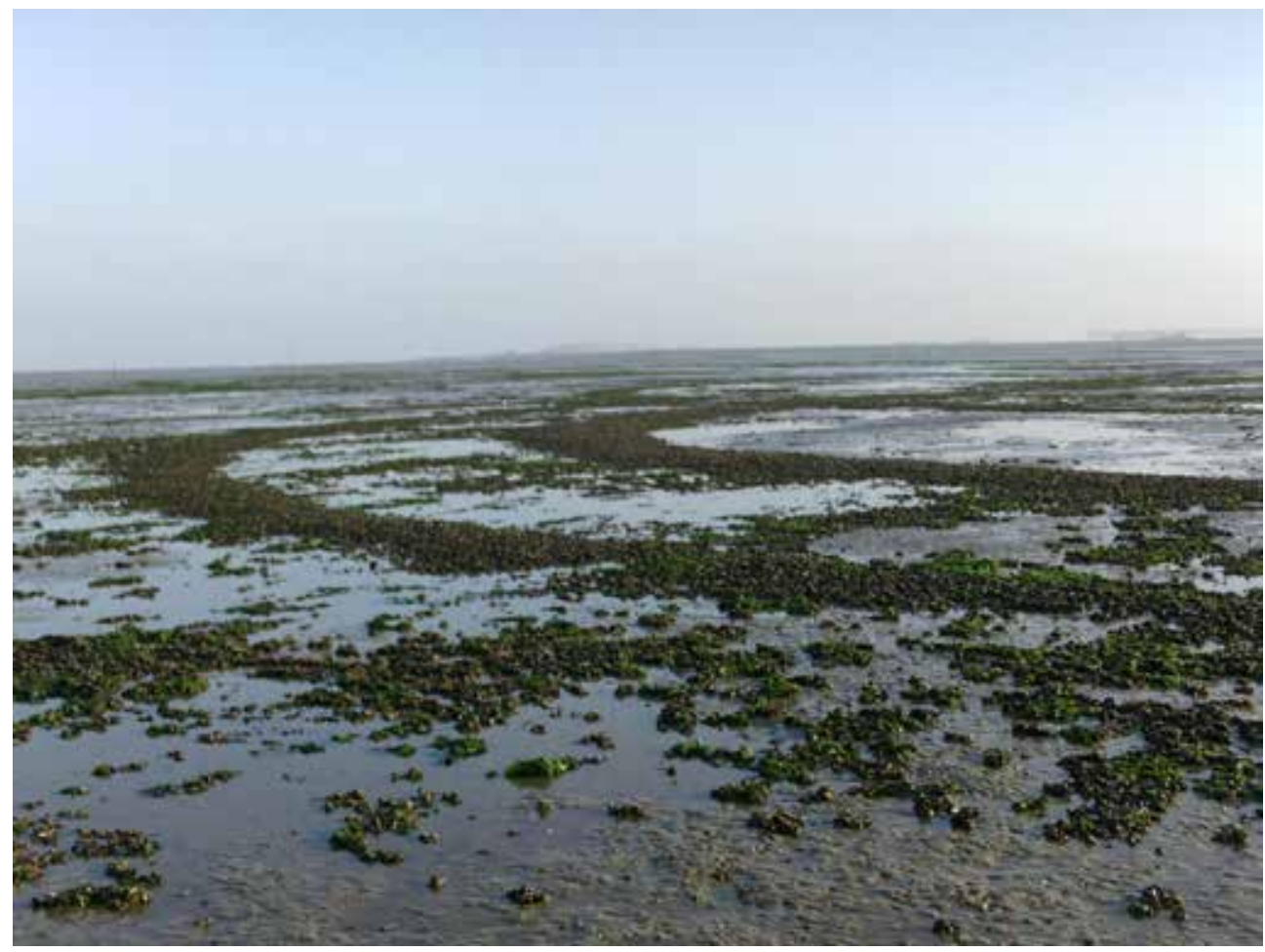

Figure 3.1 Mussels laid at an intertidal lease site at the Oosterschelde estuary.

To investigate the occurrence and relative importance of these processes for production in the period after relaying, we studied the redistribution of mussels at several experimental plots with different mussel densities, and measured growth and survival over a three month period. Results can be applied in situations where mussels are repositioned especially for seeding optimisation in on-mussel bottom culture, and in improving mussel bed restoration success. 


\section{Chapter 3}

\subsection{Material and methods}

\section{Location}

We executed a field experiment on an intertidal lease site from 16 August 2011 to 2 November 2011.This site is located in a sheltered area of the Oosterschelde estuary in the Netherlands (Figure 3.2). The entire site spans a total area of $112,500 \mathrm{~m}^{2}, 35.6 \%\left(40,000 \mathrm{~m}^{2}\right)$ of which was laid with mussel seed by a mussel grower on 11 August 2011. The mussel seed used originated from spat mussel collectors (SMC, Figure 3.2) and was harvested the same day it was laid. In total an estimated amount of $40,000 \mathrm{~kg}$ of mussel seed was laid over an area of $40,000 \mathrm{~m}^{2}$.

\section{Experimental design}

The experimental area on the lease site covered 1,200 $\mathrm{m}^{2}$ (30 $\mathrm{m} \mathrm{x} 40 \mathrm{~m}$ ) and was divided into 12 experimental plots $(7.9 \mathrm{~m} \times 7.9 \mathrm{~m})$ in a randomized blocks design (Figure 3.3), to rule out position advantages for food supply (Dolmer 200o). The experimental plots were air exposed for an average of 4.6 hours per day. In the middle of each experimental plot $62.5 \mathrm{~kg}$ of mussels, assumed to have an equal number of mussels given the small variation in individual size, were placed in four different densities randomly assigned to the blocks, by varying the areas on which they were placed (treatments, Table 3.1). By placing an equal number of mussels on experimental plots of variable size, we assumed that on this scale food availability and numbers of predators are equal per individual mussel. However, within these constraints we created different densities to test for density effects. 


\section{Chapter 3}

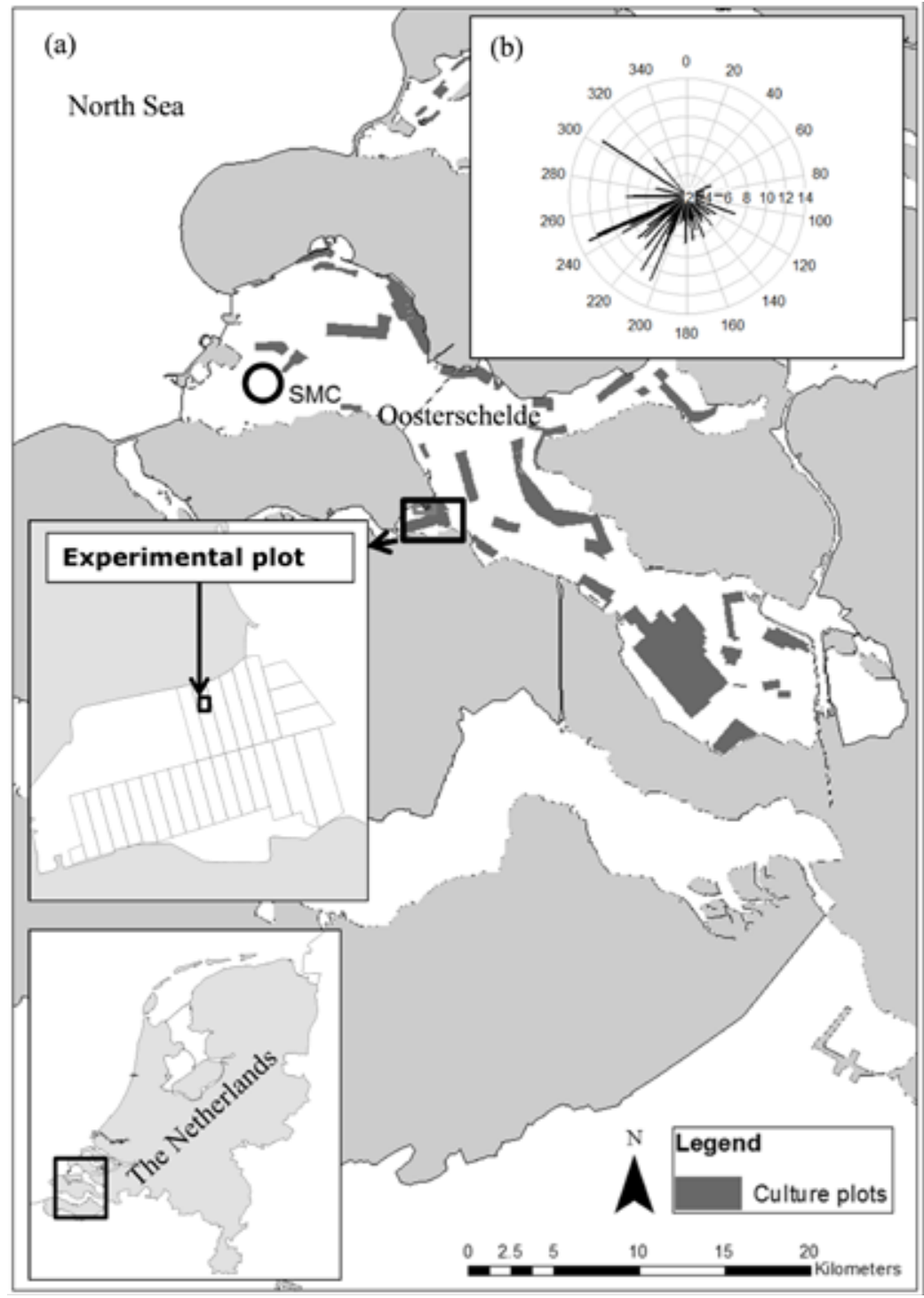

Figure 3.2a Location of experiment, origin of the seed (Spat Mussel Collector, SMC) and $\mathbf{b}$. wind speed ( $\mathrm{m} \mathrm{s}-1)$ and direction for the experimental period. 


\section{Chapter 3}

Each area was marked at the corners with bamboo sticks. Mussels were collected at low tide with buckets and homogeneously distributed over the designed areas in each experimental plot using rakes. They were weighted with a spring balance per bucket and weight was corrected for associated fauna, macroalgae and shell debris. A random subsample $(\mathrm{n}=493)$ was taken to measure initial mussel conditions (for analysis see section 2.4). Mean mussel length at start was $14.33( \pm 3.08) \mathrm{mm}$ and mean condition index $5.00 \pm 0.29 \mathrm{mg} \mathrm{cm}^{-3}$. We set up a buffer zone $(2.1 \mathrm{~m})$ with no mussels around each experimental plot to prevent migration of mussels between treatments (Figure 3.3). The typical density of an average (lease site scale) seeding density in Dutch mussel growing practice is $2.5 \mathrm{~kg} / \mathrm{m} 2$. In our experimental set-up we chose densities commonly found as average densities on lease sites. Within laying tracks on the lease site however, higher mussel densities can often be found. To include highest mussel plot densities we evaluated mussel dynamics at visually extreme high densities on a lease site. Three plots of $1 \mathrm{~m}^{2}$ with a high mussel density (visual estimation of $100 \%$ cover) were selected on the lease site directly after seeding and marked by bamboo sticks. Starting densities per plot were estimated to be $20.91 \mathrm{~kg}$ fresh wt $\mathrm{m}^{-2}, 11.44 \mathrm{~kg}$ fresh $\mathrm{wt} \mathrm{m}^{-2}$ and $19.96 \mathrm{~kg}$ fresh $\mathrm{wt} \mathrm{m}^{-2}$. These plots were sampled and measured according to the same method and at the same moment as samples on the experimental plots.

Table 3.1 Treatments with resulting density and biomass at start of the experiment.

\begin{tabular}{lllll}
\hline Treatment & $\begin{array}{c}\text { Initial number of } \\
\text { mussels (plot) }\end{array}$ & $\begin{array}{c}\text { Area } \\
\left(\mathbf{m}^{2}\right)\end{array}$ & $\begin{array}{c}\text { Initial number } \\
\text { of mussels }\left(\mathbf{m}^{-2}\right)\end{array}$ & $\begin{array}{c}\text { Initial biomass } \\
\text { density } \\
\left(\mathbf{k g ~ m}^{-2}\right)\end{array}$ \\
\hline I & 201613 & 62.5 & 3226 & 1 \\
II & 201613 & 25 & 8065 & 2.5 \\
III & 201613 & 12.5 & 16129 & 5 \\
IV & 201613 & 6.25 & 32258 & 10 \\
\hline
\end{tabular}




\section{Chapter 3}

\section{Spatial organisation}

Aerial photographs were taken of all experimental plots every two weeks in order to follow the spatial redistribution over time. This was done with a sealife mini 2 camera (9 mpx), attached to a kite. The camera automatically took a picture every $30 \mathrm{~s}$ and was secured to an adjustable rig attached to the line just below the kite. Stability of the camera was improved by attaching it to a Picavet suspension. This suspension consists of a rigid cross with a single line that runs through small pulleys at the points of the cross to keep it into level position. Images were geo-referenced using the bamboo sticks and analysed by converting mussel cover into polygons by following the outline of patch shapes with the polygon tool by hand, within ArcGIS 10. We obtained DGPS coordinates of the corners of each experimental square for geo-referencing of the photographs. For each individual plot, the number of patches, individual size of all patches $\left(\mathrm{m}^{2}\right)$, perimeter per patch $(\mathrm{m})$ and perimeter-to-area ratio $\left(\mathrm{m}^{-1}\right)$ were calculated with Fragstats 3.4 (McGarigal et al. 2002).

\section{Biomass development}

We obtained the weights, length and numbers of mussels at four-week intervals. Total area of mussel patches, $\left(A_{m}, m^{2}\right.$ patch) was estimated prior to sampling from aerial photographs for each experimental plot. Within this area, (total area covered with mussels), three random cylindrical core samples (diameter 7.5 $\mathrm{cm}$ ) were taken from each experimental plot to measure mussel density within mussel patches $\left(\mathrm{C}_{\mathrm{p}}, \# \mathrm{~m}^{-2}\right.$ patch). Total number of mussels per experimental plot $\left(N_{e}\right)$ was calculated as $A_{m}$ x $C_{p}$. Mussel density per experimental plot $\left(\mathrm{C}_{\mathrm{e}}\right.$, $\# \mathrm{~m}^{-2}$ ) was calculated based on experimental plot area on which mussels were initially placed $\left(A_{e}, m^{2}\right)$, as: $N_{e} / A_{e}$. All core samples were sieved (mesh size 1.6 $\mathrm{mm}$ ) and mussels retrieved. The mussels were counted; obtaining number of mussels per core $\left(\mathrm{N}_{\mathrm{c}^{\prime}}\right.$ \# core $\left.{ }^{-1}\right)$ and individual length was measured with a 
digital calliper (accurate to $0.1 \mathrm{~mm})$. The wet weight of mussels per core ( $\mathrm{WW}_{\mathrm{c}^{\prime}}$ g core $^{-1}$ ) was measured, accurate to $1 \mathrm{mg}$. The dry weight of mussel meat per core $\left(\mathrm{DW}_{\mathrm{c}^{\prime}} \mathrm{g}\right.$ core $\left.^{-1}\right)$ was obtained by drying at $70^{\circ} \mathrm{C}$ until the change in weight of each sample was less than $1 \%$ per $0.5 \mathrm{hr}$. Ash weight $\left(\right.$ Ash $_{c^{\prime}} \mathrm{g}$ core $\left.^{-1}\right)$ was obtained by heating at $560{ }^{\circ} \mathrm{C}$ until the change in weight of each sample was less than $0.1 \%$ per 0.5 hr. Individual mussel shell length $\left(\mathrm{L}_{\mathrm{c}}\right.$, mm core $\left.{ }^{-1}\right)$ was measured with a digital calliper accurate to $0.1 \mathrm{~mm}$. Wet weight per mussel $\left(\mathrm{WW}_{\mathrm{i}}, \mathrm{g}\right)$ was calculated for each plot as $\mathrm{WW}_{\mathrm{c}} / \mathrm{N}_{\mathrm{c} .}$ Average ash-free dry-weight $\left(\right.$ AFDW $\left._{\mathrm{i}}, \mathrm{g}\right)$ per mussel was calculated for each experimental plot as $\left(\mathrm{DW}_{\mathrm{c}}\right.$ Ash $\left.{ }_{c}\right) / N_{c}$. Shell length per mussels $\left(L_{i}\right)$ was calculated for each experimental plot by taking the average of all individual shell lengths $\left(\mathrm{L}_{\mathrm{c}}\right)$ per plot. We took and analysed samples as described on 17 August, 13 September, 13 October and 9 November. Mussel biomass density per square metre $\left(B, \mathrm{~g} \mathrm{~m}^{-2}\right)$, was obtained for each plot as $\mathrm{WW}_{\mathrm{i}} \mathrm{x} \mathrm{C}_{\mathrm{e}}$. Note that we will use the term 'biomass density' when we mean the amount of living mass per unit of surface, and the term 'total plot biomass' to indicate the total amount of living mass per experimental plot. Both are not equivalent because the plot sizes differ. Growth rates, condition index and loss rates could therefore be calculated over three time intervals (Periods 1, 2 and 3). Growth rates ( $\mathrm{GR}, \mathrm{g} \mathrm{d}^{-1}$ ) were calculated based on the change in mean individual ash-free dry weight of the mussels $\left(\right.$ AFDW $\left._{i}, g\right)$ : $\left(\right.$ AFDW $_{i}$ end $-\mathrm{AFDW}_{\mathrm{i}}$ start $) / \Delta \mathrm{t}$. Mussel growth can be described by a Von Bertalanffy function (Munch-Petersen \& Kristensen 2001), but over the short time frame of the experiment ( 85 days) growth will approximately be linear. Condition index (CI, $\mathrm{mg} \mathrm{cm}^{-3}$ ) was calculated for each plot as $\mathrm{AFDW}_{\mathrm{i}} / \mathrm{L}_{\mathrm{i}}^{3}$ (Beukema \& De Bruin 1977). Mussel loss rates $\left(\mathrm{r}, \mathrm{d}^{-1}\right)$ were calculated by the change in mussel density $\left(\mathrm{N}_{\mathrm{e}}, \# \mathrm{~m}^{-2}\right)$, assuming a constant mortality by exponential population decline: $\ln \left(\mathrm{N}_{\mathrm{e}}\right.$ start $)-\ln \left(\mathrm{N}_{\mathrm{e}}\right.$ end $)$ divided by $\Delta \mathrm{t}$. 


\section{Chapter 3}

\section{Predation by crabs}

On 19 October an underwater video camera was placed above each experimental plot, covering $0.11 \mathrm{~m}^{2}$ and recording for 1.5 hours. Cameras were attached 0.5 $\mathrm{m}$ above sediment onto a fixed iron pole. When plots became accessible a motorboat was anchored 15 metres from the side of the experimental plots and cameras were attached to a computer by an optical cable. Electricity needed for equipment was provided by a hand-portable engine-generator. Recording was finished $30 \mathrm{~min}$ before high tide. We used these videos to estimate the average density of foraging shore crabs (Carcinus maenas L.) per experimental plot to compare between treatments. The number of crabs is given in average number of individuals per $\mathrm{m}^{2}$ per hour. Predation pressure is expressed as number of foraging crabs per $\mathrm{m}^{2}$ per hour. Foraging crab density is related to mussel density that was measured six days before recording.

\section{Data analysis}

Spatial variables were tested for change in patch area, perimeter and perimeterto-area ratio per experimental plot. Effects of treatment were tested on the final values of growth rates and condition index on the final values of loss rates and on the final values of total mussel biomass per experimental plot. These variables were analysed according to the random block design, with a two way analysis of variance with block as covariate. If a block effect was not pronounced and a treatment effect was suggested, relation between change in variables and treatment was analysed with a one way analysis of variance with a post hoc Bonferroni correction. Change in number of patches per treatment over the entire experimental period, were analysed as count data, with a generalised linear model, with block as covariate, fitted with a log-link and Poisson errors. To test underlying assumptions for all linear models, we visualised underlying distribution of residuals in a Q-Q plot, linearity between the dependent 


\section{Chapter 3}

variable and independent variables by plotting residuals versus predicted values and homoscedasticity by plotting residuals verses fitted values together with conditional boxplots of residuals, influential data points were visualised by plotting Cook's distances (Zuur et al. 2007). We tested the differences between variation in numbers of crabs foraging by a modified robust Brown-Forsythe Levene-type test, and computed differences between means with a Kruskal Wallis test. All tests were performed with a significance level of 0.05. Statistical analysis was carried out in R (R Core Team 2016).

\subsection{Results}

\section{Spatial organisation}

Figure 3.3 shows how mussels redistributed over time from the initial situation. The first map (17 August) shows how the mussels were distributed. One experimental plot is missing (\# 3, Figure 3.3) as we did not obtain a clear photograph of it. However, this unit is included in the map of 24 August, where on the other experimental plots no clear differences with 17 August are observed. The maps show that the mussels were equally spread over each treatment plot at the start of the experiment. Maps in Figure 3.3 show that the mussels were redistributed into larger patches within four weeks while many small patches disappeared, especially at lower densities where they were initially more dispersed.

After four weeks, the patches occupied fixed spatial positions. Part of the change in patch size from day 36 to day 62 can be explained by the settlement and growth of sea lettuce (Ulva lactuca L.) on the mussel shells that could affect patch size by enlarging patches and filling gaps. However, because mussels were the only hard substrate available the lettuce was always associated with mussels underneath. The sea lettuce only disappeared at the end of October. 


\section{Chapter 3}

Sea lettuce fouling did not disturb the contrasts of mussel patches on sediment until day 36 or after day 62 .

We compared the spatial variables of mussel patches at the start of the experiment (day 1) with patches at the end of the experiment (day 78, Table 3.2). No block effect was significant for any of the spatial variables. In none of the treatments did we observe a change in total patch area per experimental plot ( $p>0.05$ ) during this period. However, we did observe a decrease in perimeter $(\mathrm{p}=0.006)$ and perimeter-to-area ratio $(\mathrm{p}=\mathrm{o.03})$ between the start and the end of the experiment. This decrease was much stronger in the low-density than in the high-density treatments. Also the number of patches decreased over the entire experimental period and again this decrease was strongest in the low-density treatments. Because the initial number of patches decreased, while total patch area per experimental plot did not change, patches became larger.

Table 3.2 also allows comparing the final spatial configurations for the different treatments. At the end of the experiment the number of patches differed between the two lowest and the two highest levels of initial mussel density $(\mathrm{p}=\mathrm{o.002}$ ). Final perimeter differed between both of the two lowest and both of the two highest levels of initial mussel density ( $\mathrm{p}=\mathrm{o.003}$ ), while total patch area per experimental plot did not differ. Final perimeter-to-area ratio differed between the two lowest and the two highest levels of initial mussel density ( $\mathrm{p}=\mathrm{o.003}$ ). These parameters suggest that from an initial four levels of mussel density, mussels redistribute into two different spatial structures. At the two lowest levels of initial mussel density, the mussels redistributed in more patches, with a higher perimeter ratio, than at the two highest levels of initial mussel density where they redistributed around a large patch (Figure 3.3, Table 3.2) with a lower perimeter. 


\section{Chapter 3}

Table 3.2 Average spatial variables and differences ( \pm sd) at first (day 0 ) and last (day 78) measurement for each treatment.

\begin{tabular}{|c|c|c|c|}
\hline Treatment & Start & End & Difference \\
\hline \multicolumn{4}{|c|}{ Number of patches } \\
\hline I & $169 \pm 28$ & $26 \pm 11$ & $-143 \pm 39$ \\
\hline II & $104 \pm 7$ & $16 \pm 6$ & $-88 \pm 4$ \\
\hline III & $38 \pm 19$ & $6 \pm 2$ & $-32 \pm 19$ \\
\hline IV & $4 \pm 2$ & $6 \pm 4$ & $2 \pm 5$ \\
\hline \multicolumn{4}{|c|}{ Area $\left(\mathrm{m}^{2}\right)$} \\
\hline $\mathrm{I}$ & $4.84 \pm 45.34$ & $4.14 \pm 191.86$ & $-1.81 \pm 0.46$ \\
\hline II & $5.72 \pm 50.67$ & $5.80 \pm 290.83$ & $0.082 \pm 3.01$ \\
\hline III & $5.53 \pm 15.49$ & $4.04 \pm 107.64$ & $-1.48 \pm 1.16$ \\
\hline IV & $6.77 \pm 42.19$ & $3.97 \pm|43.6|$ & $-2.80 \pm 1.75$ \\
\hline \multicolumn{4}{|c|}{ Perimeter $(\mathrm{m})$} \\
\hline $\mathrm{I}$ & $12.22 \pm 0.19$ & $4.56 \pm 1.12$ & $-8.24 \pm 0.50$ \\
\hline II & $10.45 \pm 0.54$ & $4.43 \pm 1.66$ & $-6.02 \pm 1.18$ \\
\hline III & $7.46 \pm 0.60$ & $2.52 \pm 0.037$ & $-4.94 \pm 0.63$ \\
\hline IV & $4.41 \pm 0.67$ & $2.25 \pm 0.46$ & $-2.16 \pm 1.08$ \\
\hline \multicolumn{4}{|c|}{ Perimeter-to-area ratio $\left(\mathrm{m}^{-1}\right)$} \\
\hline $\mathrm{I}$ & $2.53 \pm 0.20$ & $1.18 \pm 0.29$ & $-1.22 \pm 0.43$ \\
\hline II & $1.84 \pm 0.20$ & $0.81 \pm 0.14$ & $-1.03 \pm 0.27$ \\
\hline III & $1.35 \pm 0.12$ & $0.66 \pm 0.19$ & $-0.69 \pm 0.12$ \\
\hline IV & $0.66 \pm 0.14$ & $0.64 \pm 0.30$ & $-0.021 \pm 0.41$ \\
\hline
\end{tabular}




\section{Chapter 3}
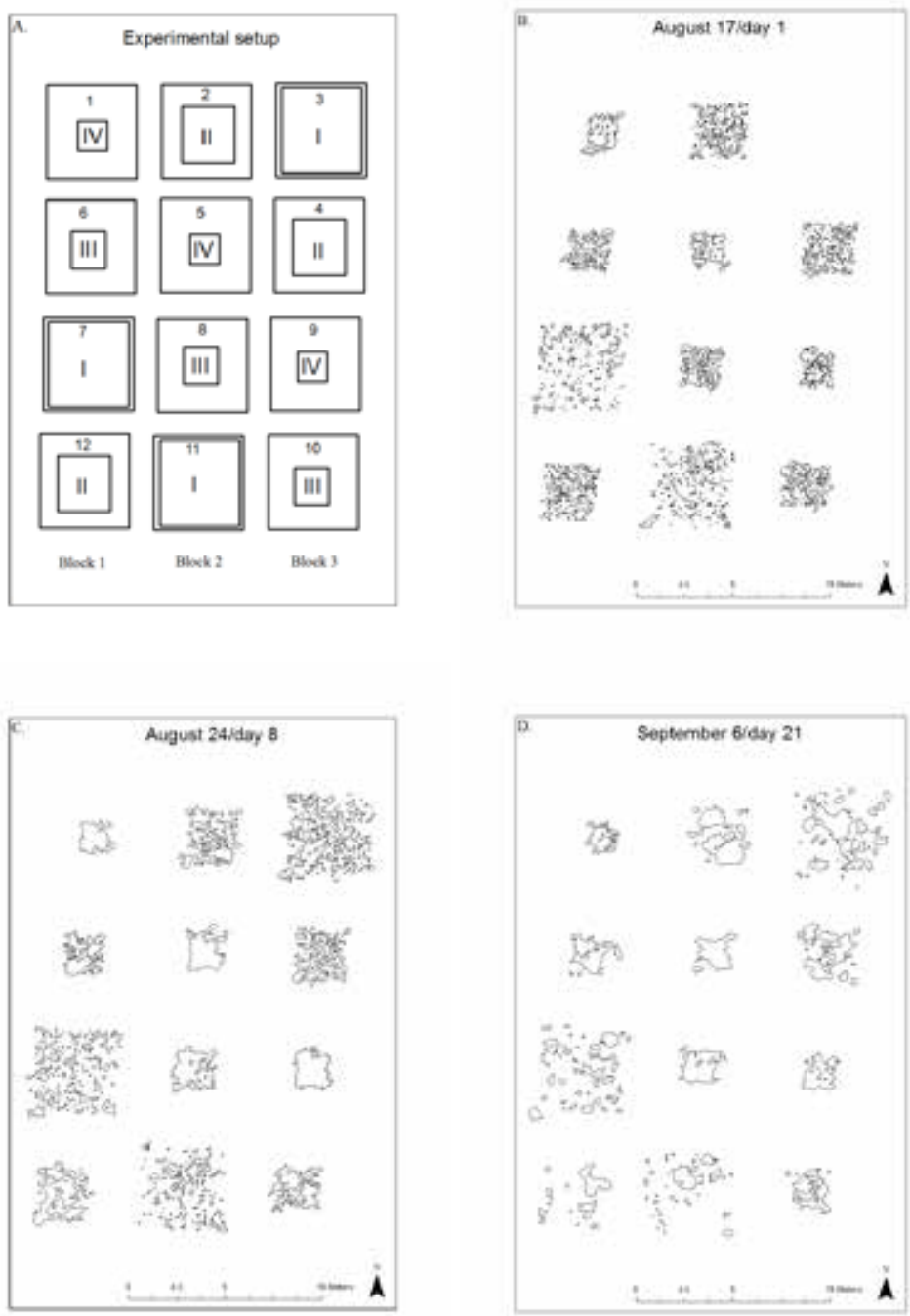


\section{Chapter 3}
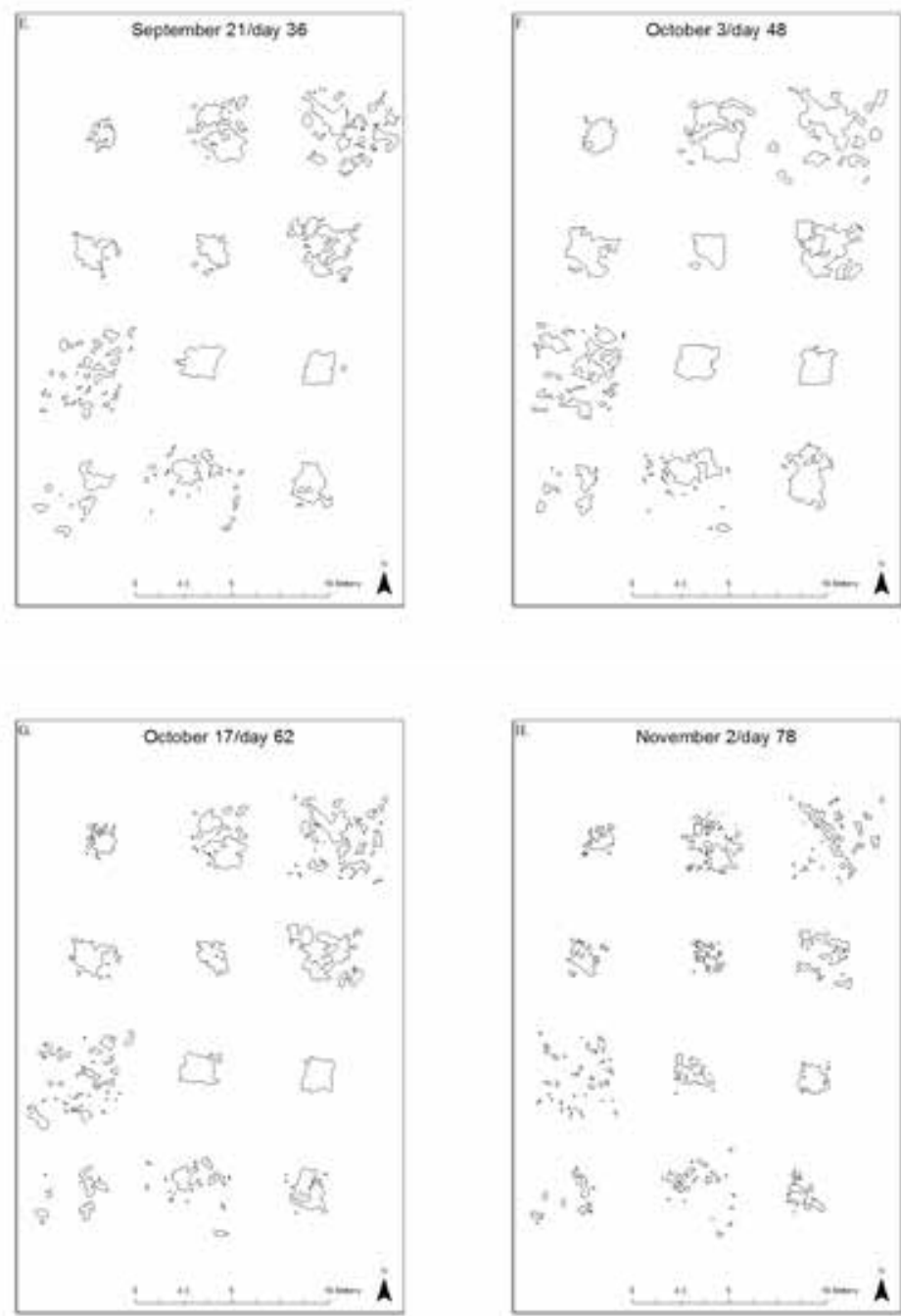

Figure 3.3 Development of mussel patches over the experimental period (Figure 3.3-H), from different densities as shown in the experimental set-up (Figure 3.3A); at the start, the same number of mussels (2x105) were equally spread in each experimental plot (squares 1-12) on four different areas (treatments: squares I-IV). 


\section{Chapter 3}

\section{Growth rate}

Differences in growth rates between treatments over the experimental period were not found, and tissue growth shows high variability within treatments (Figure 3.5a). No block effect was significant between growth rates. Growth rates declined over the measured periods ( $\mathrm{p}<\mathrm{0.001}$ ), which follows a seasonal trend related to decreasing food level (Troost et al. 2010). The growth rate did not show a relationship to perimeter-to-area, number of patches or perimeter at the end of each of the three periods. Condition index decreased over the experimental period from $5.00 \pm 0.29 \mathrm{mg} \mathrm{cm}^{-3}$ at day 1 to $4.80 \pm 0.15 \mathrm{mg} \mathrm{cm}^{-3}$, at day 85 . Condition index at the end of the experiment (Figure 3.4) did not differ between treatments ( $p>0.05)$.

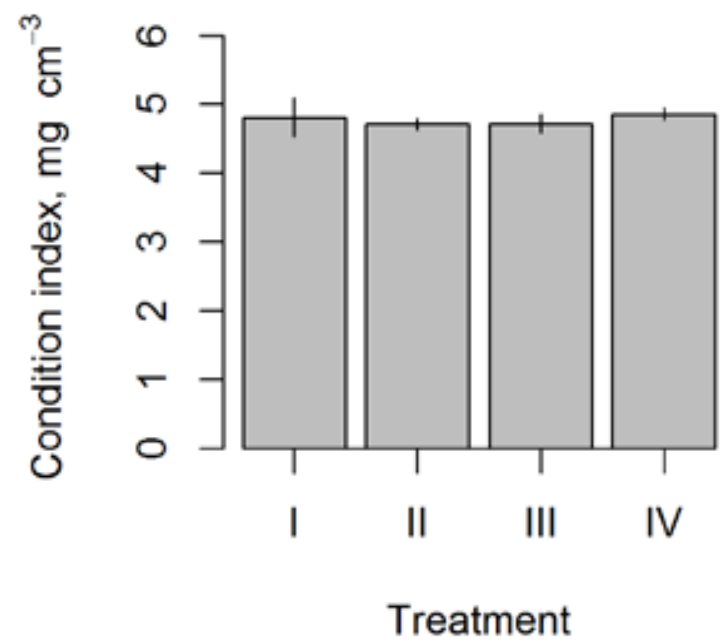

Figure 3.4 Mean mussel condition index $(\mathrm{Cl} \pm \mathrm{sd}$ ) at the end of the experimental period ( 85 days) ; treatments represent increasing mussel density. Mean $\mathrm{Cl}$ does not differ ( $p>0.05)$ between treatments. 


\section{Chapter 3}

(a) Growth - AFDW

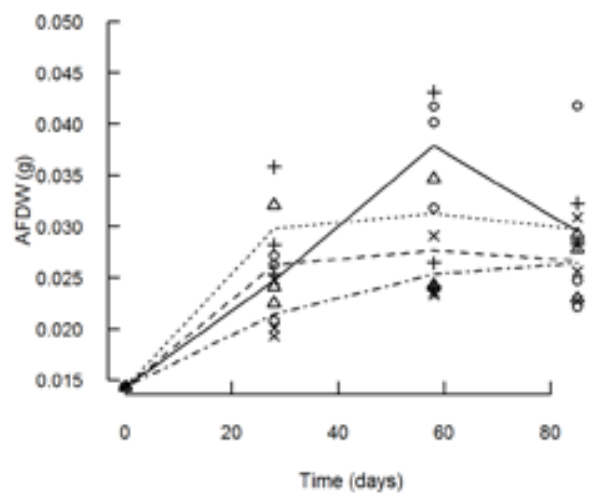

(b) Mussel survival

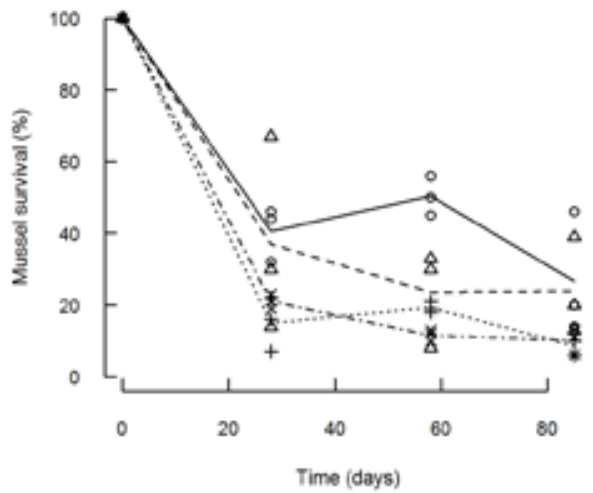

Treatment $\begin{array}{ll}-0-1 & ++\cdot 111 \\ -A-I I & * *-N\end{array}$

Figure 3.5a Mussel weight AFDW, g over time and b. mussel survival (\%) over time per treatment, with measured values (points) and average values (lines); treatments represent increasing mussel density. 


\section{Chapter 3}

\section{Loss rate}

Major changes in density occurred within the first period after seeding (Figure 3.5b). No block effect was significant for mussel loss. Loss rate increased with initial density ( $\mathrm{p}=0.02$, Table 3.1). Loss rate showed no relation to perimeterto-area ratio or number of patches, but was inversely related to perimeter after Period $1\left(\mathrm{R}^{2}=0.32, \mathrm{~F}=6.23, \mathrm{p}=0.03\right)$ and again after Period 3, with an increased goodness-of-fit $\left(\mathrm{R}^{2}=0.70, \mathrm{~F}=26.16, \mathrm{p}<0.001\right)$. When the plots with high densities on the lease site (described in section 3.2.2) are tested together with mussel loss rates for treatments, with starting density as independent variable, relation between loss rates and initial density remains significant $(\mathrm{p}=0.009)$ over the experimental period.

\section{Total plot biomass}

Total plot biomass after a three month period after seeding Figure 3.6), was log-transformed to normalize residuals and shows no significant block effect and a negative relation with initial mussel density ( $\mathrm{p}=0.038)$.

\section{Predation}

In one hour we counted $120 \mathrm{crabs}^{-2}$ averaged over all experimental plots, of which 70 crabs $\mathrm{m}^{-2}$ were foraging. Average carapax width of all crabs observed was $30.32 \mathrm{~mm} \pm 9.01 \mathrm{~mm}$. We could not find any relation between treatment or block with mean numbers and variation between numbers of foraging crabs. 


\section{Chapter 3}

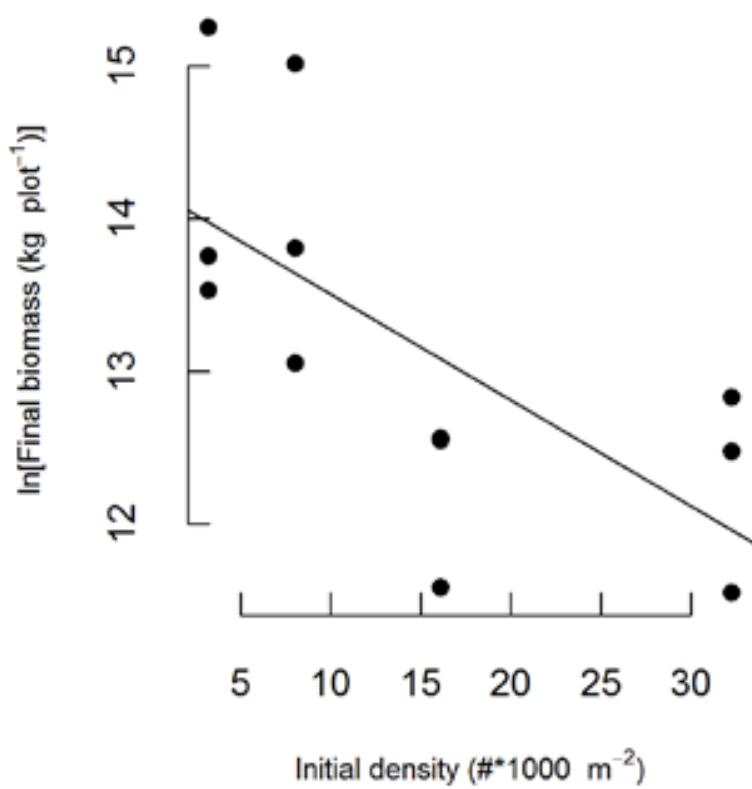

Figure 3.6 Ln final total plot biomass at initial densities within the area with mussels (4 treatments, column 3 in table 2$)$, line indicates significant relation $(p=0.01)$, starting value of the total plot biomass was the same for all subplots (62.5 kg plot-1).

\subsection{Discussion}

In field measurements on mussel beds, mussel biomass and mussel densities are directly related to each other. In this experiment we kept mussel biomass per experimental plot equal but varied area on which mussels were placed within the experimental plots, which resulted in different mussel densities. Because of this set-up, density effects and area effects could, in principle, both affect the results. The experiment differs in this regard from a set-up where only density or area would be varied. The choice for this set-up was based on the practical consideration that is dominant in culture or restoration practice: given a fixed amount of seed mussels (usually the limiting resource), how should they be distributed in space for an optimal biomass yield? 


\section{Chapter 3}

\section{Factors in biomass development}

The results show for situations with a similar initial total plot biomass that 1) a higher mussel density increased short term loss after laying, 2) that uniformly placed mussels on different areas redistributed into new patches, but that mussels did not spread out over a larger area, 3) that loss of mussels was the major factor in defining final total plot biomass and hence 4) that an increase in initial mussel density decreased total plot biomass at the end of the experiment.

Several factors as identified in the introduction might explain this relation. An increase in mussel density decreases the number of edges in mussel patches, while edges increase predation pressure (Burch \& Seed 2000). An increase in mussel density results in larger patches which are better protected against the hydrodynamic forces that might cause dislodgement (Bertness \& Grosholz 1985, Widdows et al. 2002). When mussel density increases, more mussels are positioned within larger patches after redistribution. This increases crowding, which may result in food shortage and could result in density-dependent mortality (Bertness \& Grosholz 1985, Newell 1990, Fréchette et al. 1992, Svane \& Ompi 1993).

The primary predators of intertidal mussels in the Oosterschelde estuary are birds when the mussels are exposed during low tide and shore crabs when they are under water. Herring gulls, which feed on small mussels, and oystercatchers, which feed on larger mussels (Hilgerloh et al. 1997), are the main predatory birds found on tidal flats in the Oosterschelde estuary. On the intertidal plot where the experiment was embedded, mussel growers stood guard in the first 2-3 weeks after laying at low tides during day time and chased the birds away. This activity was not undertaken during night-time. Oystercatchers, however, may continue feeding at low tides during the night (Zwarts et al. 1996). Nocturnal feeding behaviour of herring gulls is not described for this area. However, at Walney Island, UK herring gulls feeding on intertidal mussels 


\section{Chapter 3}

during low tides did not show nocturnal feeding behaviour (Sibly \& McCleery 1983). This reduces bird predation as an important factor in mussel loss. Shore crabs are important predators of mussel seed. Murray et al. (2007b) estimated that shore crabs are responsible for $10 \%$ of mussel loss, from laying until harvest on lease sites in the Menai Strait in Wales. In an extreme case, McGrorty et al. (1993) observed $96 \%$ mussel loss in a single tide as a consequence of crab predation. Presence of crabs can also decrease mussel growth and condition index, by disturbing filtration activity and increasing mussel aggregation (Dolmer et al. 2012) and references therein). High crab abundances during high tide suggest that a substantial fraction of total mussel loss could have been caused by crab predation. It is suggested that predation pressure is higher at edges compared to the centre of patches (Bertness \& Grosholz 1985, Okamura 1986, Burch \& Seed 200o). Our results show that loss was lower in plots with a higher perimeter-to-area ratio and also that crab foraging was not affected by treatment, although this latter result is indicative, because it is only based on one period of observation. Therefore, we found no indications that crab predation was a major factor explaining the higher mussel loss when mussels were more concentrated.

Even though experimental plots were designed to rule out position effects based on current direction as much as possible, wind direction can have an even greater influence (Hunt \& Scheibling 2002). Mussels could be dislodged from experimental plots at the south-western edge of the experimental area and retained at experimental plots upwind (the dominant wind direction was SW). However, this would have resulted in differences between blocks and no effect of block was shown for spatial variables or for growth rate and mussel loss. Changes in mussel numbers are therefore not dependent on mussel transfer between plots and must be explained by other factors.

Average area over all treatments did not change during the experimental 


\section{Chapter 3}

period, but the number of patches decreased, showing that smaller patches redistributed into larger ones. Figure 3.3 shows that major redistribution took place within 21 days after initialisation and that position did not change substantially thereafter. Furthermore, the more mussels were concentrated the less redistribution occurred and the more they remained in their initial positions. It follows that if dislodgement was an important loss factor it was more prevalent at lower mussel densities. However, because area did not substantially change and mussel loss was higher at higher mussel densities, it is unlikely that dislodgement was a major factor in explaining the higher mussel loss at higher mussel densities.

Results show that redistribution decreased with mussel density, mussels did not spread out over a larger area when density was high. Food competition therefore increased when area decreased. Mussel weight increased over the experimental period, especially up to half way through September. Differences in growth rates between treatments were not found. Since growth rates showed a high level of variation, this may have been an effect of mussel position within a patch and patch density, as found by Newell et al. (1990). If so, this did not result in differences between treatments. Condition index at the end of the experiment did not differ between the different initial densities; this suggests no food limitation with initial mussel density. No data was found on the condition index of intertidal mussels from the Oosterschelde estuary. Data from sampled mussel beds in the western Wadden Sea show an average condition index of 5.85 $\mathrm{mg} / \mathrm{cm}^{2}$ for intertidal mussel beds in autumn (Steenbergen et al. 2005). This is around $1 \mathrm{mg} / \mathrm{cm}^{2}$ higher than average condition index found in the present study, but the Wadden Sea is known to be a more productive area compared with the Oosterschelde estuary (Smaal 2002). Therefore, it is unlikely that food limitation was an important factor in explaining differences in biomass production and it is unlikely that food competition was an important factor in explaining the differences in loss between treatments. 
Differences between changes in total plot biomass were therefore primarily caused by differences in mussel loss. Mussel loss was highest in the first period, the first four weeks after relaying. This is the same period when major redistribution of the mussels took place (Figure 3.3), which suggests that loss rates were not associated with spatial effects after redistribution but rather with the redistribution process itself. This resulted in an increased loss rate at higher densities that are related to spatial structure and the amount of aggregation and competition that comes with it. Increased loss levels at higher densities that come with this redistribution, can be caused by the positioning of individuals within this spatial structure, because loss is correlated with perimeter. With more mussels positioned at theedges, individuals have less negative intraspecific interaction effects with conspecifics (crowding). Competition for space has been previously studied in field conditions, where it increased with patch size (Bertness \& Grosholz 1985, Svane \& Ompi 1993). In those cases mussels were physically hindered by conspecifics, causing deformed individuals (Bertness \& Grosholz 1985) and decreased shell gape in neighbours (Fréchette et al. 1992, Newell \& Shumway 1993). In the present experiment the effects became evident within one month after seeding, meaning that the survival of an individual mussel during redistribution was likely to be higher when it was positioned at the edge compared to within a patch. Within a patch, individual mussels use byssus threads to climb on top of each other; indeed, growth is higher when mussels are elevated (Liu et al. 2012). However, this process smothers those mussels positioned below. Within a patch mussels aggregate on top of each other in string-like structures, and those located at the edge of a patch are already in a favourable position to feed (Newell 1990, Svane \& Ompi 1993). Plots with high densities on the lease site (section 3.3) confirm these results.

\section{Implications for mussel relaying}

The relaying of mussels occurs on a large scale in on-mussel bottom culture 


\section{Chapter 3}

and, to a lesser extent, in mussel bed restoration. A reduction in mussel loss will increase production per unit of mussel seed available in on-mussel bottom culture or optimise restoration success in mussel bed restoration. Our results show that substantial losses occur in the period after relaying. These losses explain the decreased mussel biomass found in a short time period after relaying, but these losses can be reduced by an even spread of mussels.

If mussel loss rates in redistribution are lower for mussels in the edges of patches, a threshold in mussel loss can be expected, where density becomes large enough for mussels to redistribute into a uniform matrix with few edges. We showed that mussel loss increases when mussel density increases. When mussels redistribute into a uniform matrix at high initial density (treatments III and IV in Figure 3.3), mussel loss will be higher than when they redistribute into smaller patches (treatments I and II in Figure 3.3). Because it takes a minimum mussel density to redistribute into a uniform matrix, this density will be a threshold after which mussel loss increases. Our data suggest this threshold falls between an initial biomass density within the area covered with mussels (seeding tracks) of $2.5 \mathrm{~kg} / \mathrm{m}^{2}$ and $5 \mathrm{~kg} / \mathrm{m}^{2}$ for the mussel sizes used. Figure $3.5 \mathrm{~b} \&$ Figure 3.6 suggest that mussel loss rates are similar for the lowest two initial densities and for the highest two initial densities.

Table 3.2 also shows that perimeter at the end of the experiment is also similar for the lowest two and for the highest two initial densities. Both observations are in line with the hypothesis of a threshold density in the important processes. Experimental evidence to support this threshold hypothesis will require further research.

After redistribution a mussel bed or plot will develop further. In mussel culture, yield is only defined after harvesting, which is often one to three years after relaying. Previous studies also suggest that further mussel bed development will be most profitable when mussels are organised in smaller patches and in a 


\section{Chapter 3}

lower density (e.g. (Okamura 1986, Newell 1990, McGrorty et al. 1993, Newell \& Shumway 1993). Development in small patches after spreading at low densities will therefore probably be profitable in terms of production in the longer term as well as in the short term.

The present study has shown the effects of mussel relaying on spatial redistribution for the first time, and has underlined the importance of edge effects in understanding mussel loss in redistribution. The very high losses (up to $75 \%$ ) observed in the experiment within four weeks after relaying show the importance of this process in mussel dynamics of human-created mussel beds. 


\section{Chapter 4}

\section{Effect of seeding density on bio- mass production in mussel bot- tom culture}

Jacob J. Capelle, Jeroen W.M. Wijsman, Marnix R. van Stralen, Peter M.J. Herman, Aad C. Smaal (2016) Effect of seeding density on biomass production in mussel bottom culture.

Journal of Sea Research 110:8-15 


\section{Chapter 4}

\section{Abstract}

Effects of seeding density on biomass production in mussel bottom culture are investigated by detailed monitoring of culture practice in the western Wadden Sea, The Netherlands. The seed originates from different sources. The seeds differ in size and farmers apply seeding techniques dependent on the seed size resulting in different seed densities on the culture plots. We hypothesise growth to be density dependent and that biomass production is primarily determined by survival and is therefore a function of seed density which is related to the activities of the farmers. Data was collected from 42 different culture plots over a three year period (June 2009 - June 2012). During this period, 66 sub-populations were followed from seeding until harvest. Seeding at the start of the culture resulted in an instantaneous drop in biomass production, caused by large losses in mussel number. These losses were on average $42 \%$ of the mussels seeded. This seeding loss decreased with mussel size and increased with seeding density. A subsequent density dependent loss of 1.8 mussels per day was found for smaller mussels (<30 mm), and a non-density dependent loss of o.8 mussels per day for larger mussels $(>30 \mathrm{~mm}$ ) during grow out. Overall loss from seeding to harvest was high, from $92 \%$ for the smallest seeds collected from spat collectors, to $54 \%$ for half-grown mussels fished from natural beds in spring. No indication was found that growth or mussel condition was affected by culture plot scale density. Growth was dependent on mussel size and age, and this largely determined the differences in biomass production between seed sources. The density dependent seeding loss associated with seeding activities largely determined survival, and hence overall biomass production. 


\section{Chapter 4}

\subsection{Introduction}

About $50 \%$ of the aquaculture production of Mytilus edulis L. in Europe is produced in bottom cultures (Smaal 2002, FAO 2015). In mussel bottom culture, juvenile mussels (seed) are collected from natural beds or by using suspended seed mussel collectors (SMCs, Kamermans, et al., 2002). Mussels are seeded on subtidal or intertidal culture plots, where mussels grow for a period of 1 to 3 years until they reach consumption size (Gosling 2003). Relative biomass production (RBP) is the ratio between mussel biomass $\left(\mathrm{kg} \mathrm{m}^{-2}\right)$ at any given point in the culture cycle, and mussel biomass seeded $\left(\mathrm{kg} \mathrm{m}^{-2}\right)$. RBP is thus the product of the relative growth and survival between these two points in time. RBP over the entire period from seeding to harvest is defined as the average physical product (APP), discussed in Ferreira et al. (2007b).

Mussel bottom culture is an extensive culture as it depends on natural resources for feed, seed and space. Abiotic conditions vary between areas where culture plots are located, which causes differences in growth and survival (Brinkman et al. 2002). Cultivation techniques seem to have limited influence on the fate of the product during the culture cycle. Mussel farmers have to work within the static spatial boundaries of their culture plots and use these differences in environmental characteristics for strategic translocation of mussels between areas throughout the culture cycle. The RBP of extensive mussel culture from seeding to harvest is on average $1.5^{-2.5} \mathrm{~kg}$ harvested per $\mathrm{kg}$ seeded in the Wadden Sea, and is even often below $1 \mathrm{~kg}$ harvested per kg seeded in Ireland (Dijkema 1997, Bult et al. 2004, Wijsman et al. 2014, Calderwood 2015). However, at the scale of individual plots, RBP shows more variation and a maximum RBP of $6 \mathrm{~kg}$ harvested per kg seeded has been reported for the Wadden Sea (Dijkema 1997) and for Strangford Loch (Northern Ireland), a maximum of $7 \mathrm{~kg}$ harvested per $\mathrm{kg}$ seeded has been demonstrated (Ferreira et al. 2007b). The source of the large variability in RBP is often not clear. 


\section{Chapter 4}

Relative biomass production on a culture plot will only be larger than one as long as growth can compensate for losses in mussel number (Petraitis 1995a). Growth depends mainly on natural factors such as food supply at a given mussel density (Ferreira etal. 2007b). Survival of individual mussels in extensive bottom culture is a result of natural factors such as predation, mussel dislodgement and competition. Yet, survival also depends on culture techniques, in particular seeding techniques (e.g. Munch-Petersen, Kristensen, 2001; Seed, 1976; Seed, Suchanek, 1992; Smaal, 2002). In a previous study, we showed that the spatial organisation of mussels on culture plots is affected by seeding such that high local densities result in a density-related seeding loss, with maximum values of $75 \%$ within four weeks (Capelle et al. 2014).

In the Netherlands, mussels are cultured on bottom plots in the Oosterschelde estuary (ca. $20 \mathrm{~km}^{2}$ ) and in the western part of the Wadden Sea (where ca. $33 \mathrm{~km}^{2}$ of culture area is used). Fishing seed from natural seed beds is the traditional method used for the mussel culture cycle. Seed fishing in the Netherlands occurs mainly in autumn, but only in areas that are considered unstable for sustainable natural mussel beds. In spring, seed beds outside unstable areas can be fished (Smaal 2002). Meanwhile, the amount of mussel seed obtained from an alternative resource, SMCs, is sharply increasing (from $8 \mathrm{Mkg}$ in 2009 to $15 \mathrm{Mkg}$ in 2012). This increase is a result of a covenant signed by the government between environmental NGOs, and the mussel producers' trade organisation (Van Hoof 2012). With the covenant, the mussel producers' trade organisation has agreed to cooperate in the protection of natural mussel seed beds by a gradual transition from seed fisheries on natural mussel beds, to SMCs for mussel seed as input resource for the culture cycle. SMCs are harvested from July until October, and are a reliable source of mussel spat. However, seed origin can affect survival as, for example, SMC seed has a thinner shell that makes it more vulnerable to predation (Kamermans et al. 2009). However, after transplantation, SMC seed tends to aggregate more than mussels from 


\section{Chapter 4}

seedbeds, resulting in better survival (Christensen et al. 2015).

While cultivation techniques seem to have a limited effect on RBP, previous studies showed that cultivation techniques do affect survival of the mussel seed. In the culture cycle, the farmers make use of the different seed resources. Those resources differ in size and farmers apply seeding techniques dependent on seed size, which may result in different seed densities on the culture plots. We hypothesise growth to be density dependent, and that biomass production is primarily determined by survival and is therefore a function of seed density which is related to the activities of the farmers. We tested this by analysing the culture cycle for a number of years in an extensive number of culture plots to account for spatial and temporal variability.

\subsection{Methodology}

\section{Sampling}

A sampling procedure closely following routine culture methods was set-up to describe mussel growth and losses from subtidal culture plots in the western part of the Wadden Sea. Sampling of the mussels from culture plots was undertaken in collaboration with seven mussel-growing companies. The size of the company, by the number of culture plots a company leases in the Wadden Sea, may affect culture practices and since we want our data to be representative for the whole sector, we therefore pre-selected two small companies $(<10$ culture plots), three medium companies (between 10 and 20 culture plots) and three large companies (>20 culture plots). These companies reported after each fishery and SMC harvest within the period 2009-2011 on: (a) where mussels were seeded, which was pinpointed through GPS coordinates of the seeded area; (b) mussel size, measured by the typical mussel-farmer's method $\left(N_{\text {vol }}\right.$, amount of fresh mussels fitting in a $88 \mathrm{o} \mathrm{ml} \mathrm{tin} \mathrm{can);} \mathrm{(c)} \mathrm{biomass} \mathrm{seeded,} \mathrm{with}$ 


\section{Chapter 4}

an estimation of the debris and associated flora/fauna percentage (tare); when this was not estimated we assumed a tare of $40 \%$ for seed from fishing, $15 \%$ for seed from SMCs, and $25 \%$ for mussels larger than $30 \mathrm{~mm}$, following Wijsman et al. (2014); and (d) after mussels had been seeded: when translocation of the mussels and management measures took place. All areas on the culture plots in which mussels had been seeded by the selected companies, from spring 2009 until autumn 2011, were sampled four times per year, in February, June, September and at the end of November/beginning of December, resulting in four sampling periods. The measurements in June and November/December were carried out after the spring and autumn fishery, respectively.

In total, 42 unique culture plots were sampled from June 2009 until June 2012 (Figure 4.1). From these plots, 66 series were obtained (a series being mussels seeded on a culture plot area and sampled repeatedly until harvest). Some plots were used for more than one series. These 66 series included 22 plots with SMC-seed, 11 plots with seed from the autumn fishery, 18 plots with seed from the spring fishery and 15 plots with seed relayed from other culture plots. In all, 190 measurements were obtained.

Each measurement consisted of 70 random samples taken with a Van Veen grab $\left(0.0552 \mathrm{~m}^{2}\right)$ within the seeded area on a culture plot. Each individual sample was sieved using a $5 \mathrm{~mm}$ sieve, and the number of mussels was counted. From the 70 samples, the mean and standard deviation $(s)$ of the number of mussels per square meter was calculated.

The mussels from the 70 grab samples were pooled and homogenized. A volumetric subsample of one litre was taken from the pooled sample. The subsample was weighed to the nearest mg and the mussels counted and cooked in order to measure cooked meat weight. In the lab, the individual lengths of the mussel shells were measured with a digital calliper (accurate to o.1 $\mathrm{mm}$ ). Dry weight of mussel meat per plot was obtained by drying at $70^{\circ} \mathrm{C}$ in a prepASH 


\section{Chapter 4}

(prepASH ${ }^{\circledR} 340$ series, http://prepash.com) until the change in weight of each sample was less than $1 \%$ per $0.5 \mathrm{hr}$. Ash weight was obtained by heating at $540^{\circ} \mathrm{C}$ in a prepASH until the change in weight of each sample was less than $0.1 \%$ per $0.5 \mathrm{hr}$. Ash free dry weight $(A F D W)$ was calculated as the net difference between dry weight and ash weight. Average weight was calculated by dividing the total weight by the number of mussels in the sample.

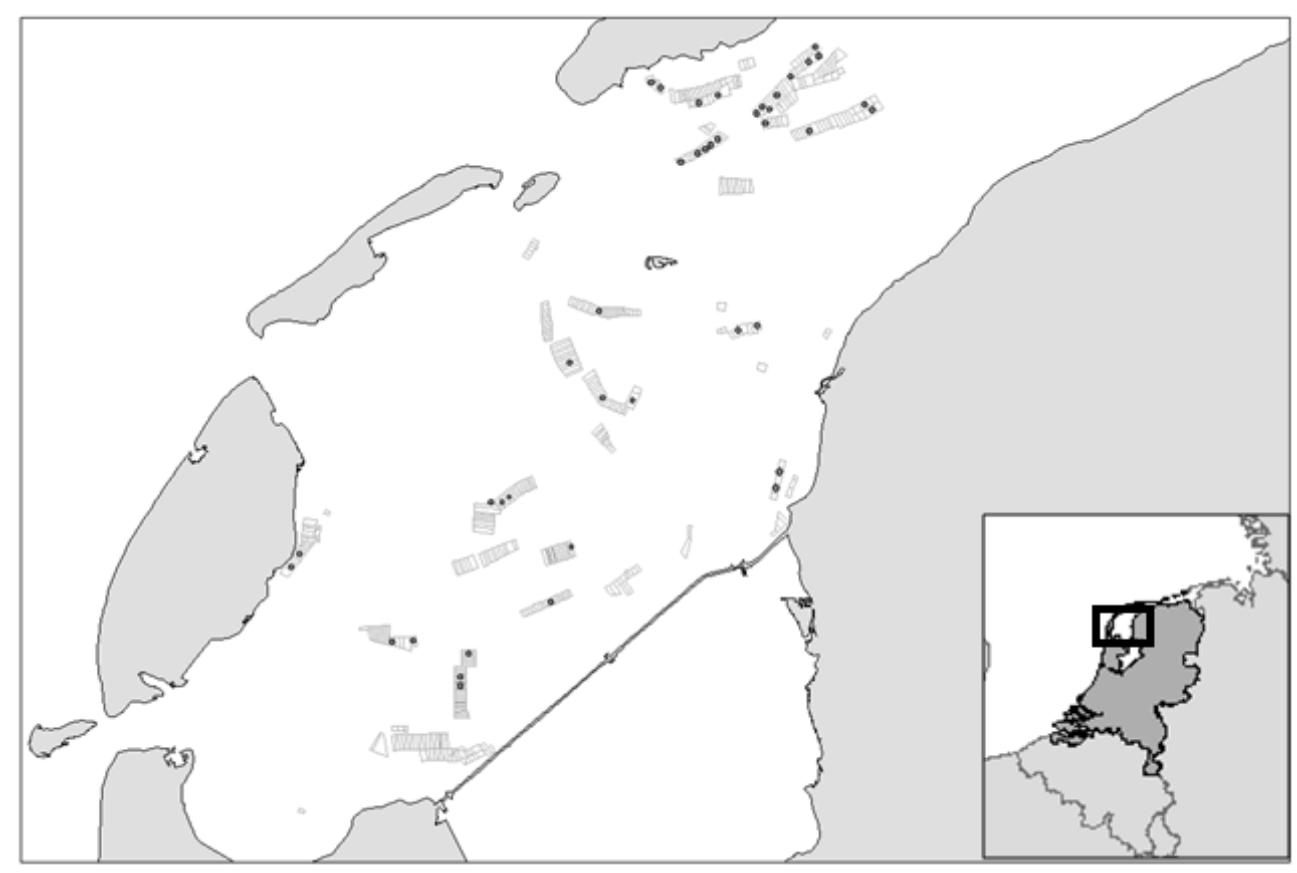

Figure 4.1 Location of on-mussel bottom culture plots in the western Wadden Sea, the Netherlands. Dots indicate culture plots sampled over the period 2009-2012.

\section{Growth}

Mussel weight was fitted to mussel age by the Von Bertalanffy growth equation, with a sinusoidal correction for seasonal growth fluctuations (Somers 1988). 


\section{Chapter 4}

$$
W_{t}=W_{\infty}\left[1-e^{-K\left(t-t_{0}\right)-\frac{c K}{2 \pi} \sin 2 \pi\left(t-t_{s}\right)}\right]^{b}
$$

Parameters $W_{\infty} K, t_{o}, C$ and $t_{s}$ were estimated with a non-linear model using the generalized least squares method from the nlme library for $\mathrm{R}$ software (Pinheiro et al. 2014). The model was fitted based on the average weight per sampling station and per sampling moment. Mussel age was calculated using the known year class of mussels from the culture plots. The $b$ parameter (2.89, with standard error: $0.0496, \mathrm{n}=190$ ) was calculated from the relation between length and weight, assuming the allometric relationship:, and $=a^{* b}\left(a=1.43 \times 10^{-}\right.$ ${ }^{4}$, with standard error: $2.79 \times 10^{-5}$ ), following von Bertalanffy (1938) and fitted with a non-linear model using generalized least squares method from the nlme library for R software (Pinheiro et al. 2014).

The condition index $\left(\mathrm{CI}, \mathrm{mg} \mathrm{cm}^{-3}\right)$ was calculated for each sample according to: $A F D W / L^{3}$, where $L$ is average mussel shell length $(\mathrm{cm})$. The average individual mussel wet weight at seeding $\left(W_{\text {seed }}, \mathrm{g}\right)$ was calculated from the volumetric index $\left(N_{v o l}\right.$, ind $\left.880 \mathrm{ml}^{-1}\right)$ as: $W_{\text {seed }}=663.46 N_{\text {vol }}{ }^{-0.996}\left(R^{2}=0.97\right)$ estimated from 91 different samples. Seeded biomass per square meter $\left(B_{\text {seed }} \mathrm{g}\right.$ $\mathrm{m}^{-2}$ ) was obtained per plot from the total net biomass seeded $\left(\mathrm{g} \mathrm{plot}^{-1}\right)$ divided by plot area $\left(\mathrm{m}^{2}\right)$. Seeding density $\left(D_{\text {seed }}\right.$, ind $\left.\mathrm{m}^{-2}\right)$ per plot was calculated as $B_{\text {seed }}$ divided by $W_{\text {seed }}$.

\section{Losses}

Previous work has shown that seeding loss is associated with seeding technique and is density dependent within the space occupied by the mussels (Theisen 1968, Capelle et al. 2014). In order to investigate whether seeding loss occurred, and whether there was a relationship with mussel density, we tested the log$\log$ relation between densities estimated at first sampling $\left(\ln D_{1}\right.$, ind $\left.\mathrm{m}^{-2}\right)$ as the dependent variable, against the number seeded $\left(\ln D_{\text {seed }}\right.$ ind $\left.\mathrm{m}^{-2}\right)$ as the 


\section{Chapter 4}

independent variable, using linear regression. When significant $(p<0.05)$, we calculated whether the slope of this linear model differed from 1. $D_{\text {seed }}$ and $D_{1}$ are derived from two independent estimations: the mussel-farmer method was used to estimate $D_{\text {seed }}$, while $D_{1}$ was estimated from sampling. Two independent methods were also used with $D_{\text {seed }}$ derived from the total biomass seeded, and $D_{1}$ was estimated from sampling. Because of the log-log relation, a slope larger than 1 indicates a positive density effect; a slope smaller than 1 indicates a negative density effect; and a slope that does not differ from 1 means that no density effect is indicated.

For the different sampling periods (Feb-Jun, Jun-Sep, Sep-Nov/Dec, Nov/DecFeb), density-dependent loss was also evaluated by testing the log-log relation between mussel densities at the start of a period $\left(\ln D_{s}\right)$, against mussel density at the end of a period $\left(\ln D_{e}\right)$, by means of a linear model.

Mussels were classified according to three categories based on shell length, which was measured at the start of a sampling period: (1) mussel seed: $\leq 30$ mm; (2) half-grown: > $30 \mathrm{~mm} \mathrm{\&} \leq 45 \mathrm{~mm}$; and (3) consumption: $>45 \mathrm{~mm}$. (Wijsman et al. 2014). Relative loss rates $\left(r, \mathrm{~d}^{-1}\right)$ were calculated over this period in days $(\mathrm{t})$ using the change in mussel density, which was measured at the start of a cohort $\left(D_{s}\right)$, and at the end of a cohort $\left(D_{e}\right)$, assuming a constant loss rate described by exponential population decline.

$r_{\text {cohort }}=-\frac{\ln \left(D_{e}\right)-\ln \left(D_{S}\right)}{t}$

Change in mussel density over time is expressed as:

$$
d D / d t=r_{\text {cohort }} \cdot D
$$

With $D_{\text {seed }}$ as the state variable and $r_{\text {cohort }}\left(\mathrm{d}^{-1}\right)$ as the cohort-specific variable; 


\section{Chapter 4}

depending on mussel length, this was calculated from Equation 1 for every time step (d).

\section{Biomass}

From the above, biomass $\left(B, \mathrm{~g} \mathrm{~m}^{-2}\right)$ for each culture plot was estimated over time $\left(\mathrm{d}^{-1}\right)$ as:

$B_{t-} W_{t} \cdot D_{t}$

(Equation 4.4)

Growth (wet weight, $\mathrm{g}$ ), density (ind $\left.\mathrm{m}^{-2}\right)$ and biomass $\left(\mathrm{g} \mathrm{m}^{-2}\right)$ were estimated over time based on the seeding parameters (age, $\left.D_{\text {seed }}, W_{\text {seed }}\right)$ for mussels of different origin: seeded from seed mussel collectors (SMC-seed), mussels seeded in autumn (autumn seed) and mussels seeded in spring (spring seed). The models were solved using the 'ode' function within the deSolve package in $\mathrm{R}$ (Soetaert et al. 2010). RBP was calculated as $B_{t} / B_{\text {seed }}$. To evaluate the sampling method, RBP values calculated from the model output, with culture-plotspecific state variables derived from sampling, were compared with RBP values derived from the mussel -farmers harvest data. The mussels in this case were either harvested to sell at auction, or for transplanting to other plots. RBP values obtained from the mussel -farmers were compared with RBP values calculated from the sampling results.

\section{Statistical analysis}

Cooked mussel meat is expressed as a function of growth rate calculated from the sampling period prior to cooked-meat measurements. Growth rate (GR,

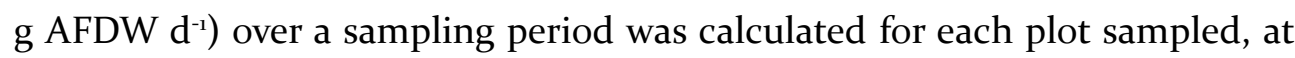
the start $\left(t_{\text {start }}, \mathrm{d}\right)$ and at the end $\left(t_{\text {end }}, \mathrm{d}\right)$ of a sampling period, as: $\left(A F D W_{\text {end }}{ }^{-}\right.$ $\left.A F D W_{\text {start }}\right) /\left(t_{\text {end }}-t_{\text {start }}\right)$. Cooked meat weight as a function of GR over the preceding growing period was fitted using a linear model. 


\section{Chapter 4}

The effects of mussel density on mussel growth rates were analysed using a multiple ANOVA, with GR $\left(\mathrm{g} \mathrm{d}^{-1}\right)$ over each sampling period as a function of mussel origin, mussel density at the start of the sampling period and mussel size at start of the sampling period. GR was subjected to a power ( 0.43 ) transformation prior to analysis to gain constant error variance.

The effects of mussel density on mussel condition were analysed using a twoway ANOVA, with $\mathrm{CI}\left(\mathrm{mg} \mathrm{cm}^{-3}\right)$ as a function of mussel density and mussel size.

Arcsine-transformed seeding-loss ratios $\left(D_{I} / D_{\text {seed }}\right)$ were compared between seeds from different origins (autumn fishing, spring fishing, SMCs and relaying), by means of a pairwise t-test with Bonferroni correction ( $\alpha=0.05)$.

\subsection{Results}

\section{Growth}

The relation between the cooked meat weight and the growth rate (GR) for all plots that were measured at the start and the end of each sampling period is shown in Figure 4.2.

Cooked meat weight increased with GR from the preceding period according to: o.18•GR+16.24 (adj. $R^{2}=0.53, p<0.001$ ). Preceding periods were: June-September (summer), September-November (autumn), November-February (winter), February-June (spring), and are indicated by the different symbols in Figure 4.2. Figure 4.2also indicates that GR increases from winter to summer. 


\section{Chapter 4}

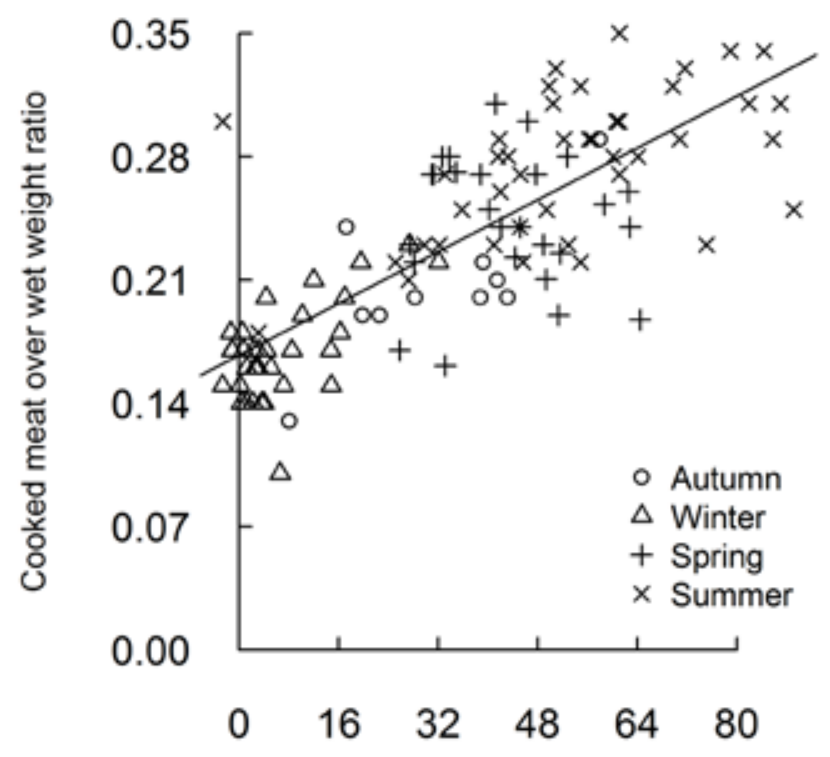

Growth rate, mg per day

Figure 4.2 Relation of the ratio between cooked mussel meat weight ratio and total wet weight and growth rate, calculated over the period before cooked weight was measured. Summer: Jun-Sep (2009-2011), autumn: Sep-Nov (2009-2011), winter: Nov-Feb (20092012), Spring: Feb-Jun (2009-2012).

Mussel GR was significantly related to mussel size ( $p<0.001)$, but not to mussel density or mussel origin. There was also no significant interaction between dependent variables. Therefore, mussel growth is described only as a function of mussel age and no distinction is made between density and seed origin. Growth in wet weight $(\mathrm{g})$ is shown in Figure 4.3. 


\section{Chapter 4}

\section{A. Growth}

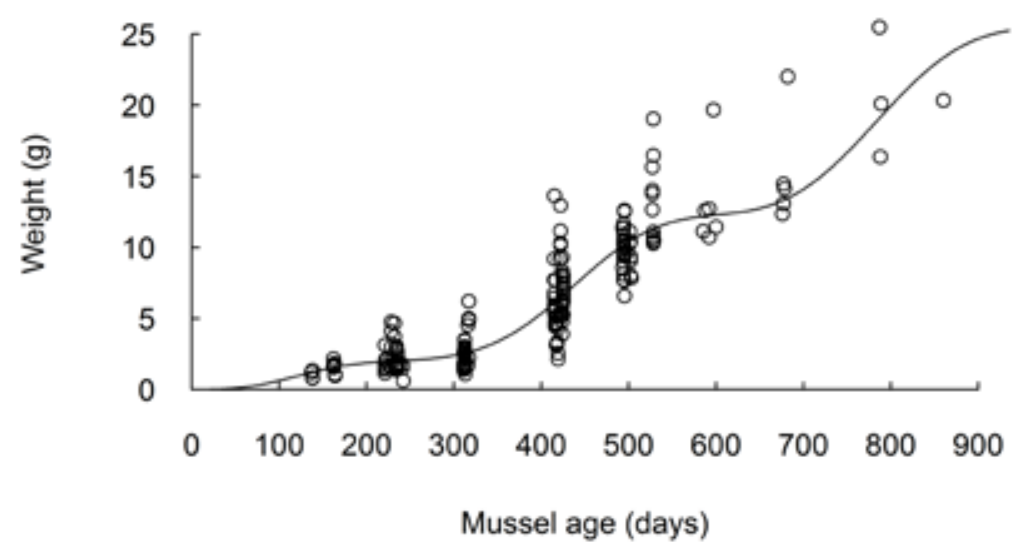

B. Relative growth rate

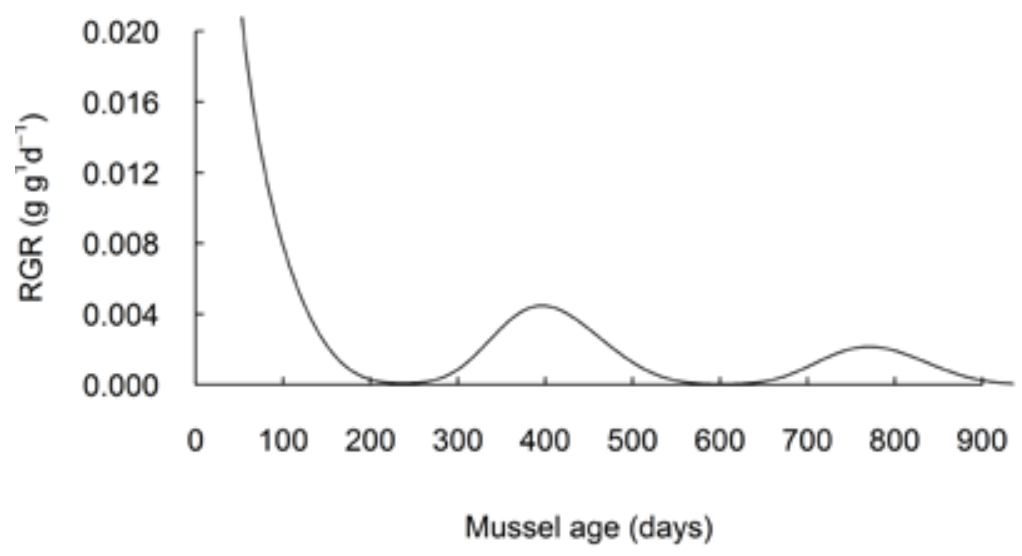

Figure 4.3 (a) Observed (dots) mussel weight (g) at different mussel ages and fitted Von Bertalanffy function (line), from 66 different subtidal areas seeded in the period 2009-2012 in the western Wadden Sea. (b) Relative growth rate (RGR, $\left.\mathrm{g} \mathrm{g}^{-1} \mathrm{~d}^{-1}\right)$ derived from fitted Von Bertalanffy growth equation as: $\ln \left(W_{t+1}\right)-\ln \left(W_{t}\right)$ for each time step of 1 day. 


\section{Chapter 4}

Table 4.1 Parameter estimates of Von Bertalanffy growth function, with oscillating sinusoidal correction, for mussels on culture plots in the western Wadden Sea.

\begin{tabular}{lll}
\hline Parameter & Value & SE \\
\hline$K\left(\mathrm{y}^{-1}\right)$ & 0.63 & 0.15 \\
$W_{\infty}(\mathrm{g})$ & 41.74 & 11.25 \\
$t_{o}(\mathrm{y})$ & -0.010 & 0.076 \\
$C_{\text {weight }}\left(\right.$ day $\left.^{-1}\right)$ & 0.67 & 0.17 \\
$t_{s}(\mathrm{y})$ & 1.10 & 0.037 \\
\hline
\end{tabular}

The estimated parameters of the Von Bertalanffy functions are presented in Table 4.1. Growth rates, as derivatives from the fitted Von Bertalanffy function, showed seasonal fluctuations (Figure 4.3). Also, the relation between CI (mg $\mathrm{cm}^{-3}$ ) and mussel density (ind $\left.\mathrm{m}^{-2}\right)$ is not significant $(p=1.0)$ when corrected for mussel size (shell length).

\section{Mussel loss}

\section{Seeding loss}

The average period between seeding and first sampling is shown in Table 4.2 for the different seed sources.

Table 4.2 Seeding loss for different seed sources. $t_{1}$ and $t_{\text {seed }}$ in days. $.^{a}=$ significantly different from ${ }^{b}$

\begin{tabular}{llll}
\hline Seed source & Seeding loss (mean \%) & Seeding loss (sd \%) & $\begin{array}{c}\mathbf{t}_{\mathbf{1}}-\mathbf{t}_{\text {seed }} \\
(\mathbf{s d})\end{array}$ \\
\hline SMC seed & $69 \mathrm{a}$ & 22 & $58(43)$ \\
Autumn fishery & $39 \mathrm{~b}$ & 28 & $49(17)$ \\
Spring fishery & $41 \mathrm{~b}$ & 23 & $20(11)$ \\
Relayed & $44 \mathrm{~b}$ & 19 & $52(28)$ \\
\hline
\end{tabular}

Seeding loss from all culture plots was on average $53 \pm 26 \%$ (SD). Seeding loss 


\section{Chapter 4}

will be overestimated because of the time lag between seeding $\left(t_{\text {seed }}\right)$ and first sampling moment $\left(\mathrm{t}_{1}\right)$. When the average loss rate is extrapolated over the time lag for the different seed types (shown in

Table 4.2 as: $\mathrm{t}_{1}-\mathrm{t}_{\text {seed }}$ ), it can be estimated at $9 \%$. As a result, average seeding loss is estimated to be $42 \%$ of mussels seeded.

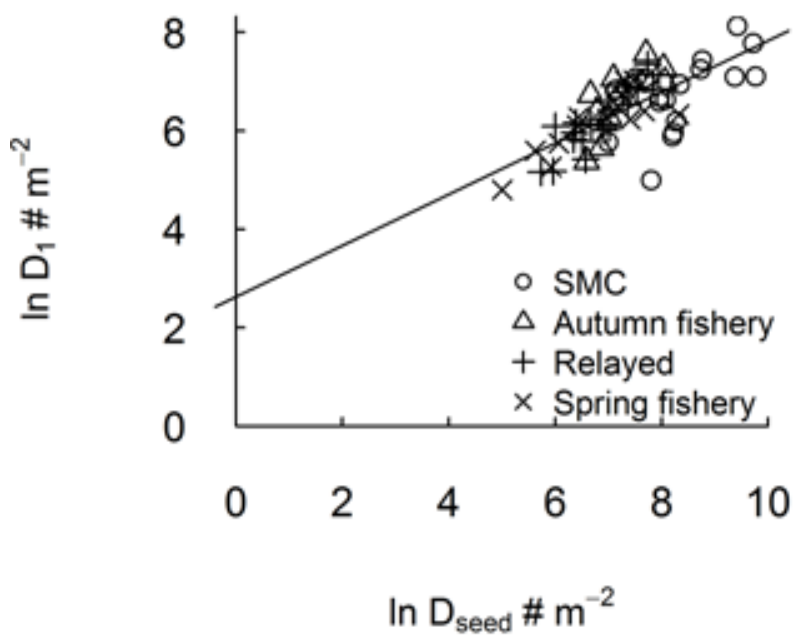

Figure 4.4 Log-log relation between mussel density at first sampling $\left(D_{1}\right)$ and mussel density at seeding $\left(D_{\text {seed }}\right)$ from mussel plots in the western Wadden Sea from culture plots from 2009-2012.

The $\log -\log$ relation between $D_{1}$ and $D_{\text {seed }}\left(\ln D_{1}=0.52 \pm 0.064(\mathrm{SE}) \cdot \ln D_{\text {seed }}+2.62\right.$ \pm 0.48 (SE), $\mathrm{F}=65.42, \mathrm{df}=60, \mathrm{p}<0.001, \mathrm{R}^{2}=0.51$ ) is shown in Figure 4.4. Since the slope is smaller than $1,(0.52, p<0.001), D_{1}$ decreases faster when $D_{\text {seed }}$ increases, which indicates that loss rates increase with mussel density. $D_{\text {seed }}$ was correlated with individual seed size $\left(W_{\text {seed }}, r=-0.86\right.$, between $\ln \left[D_{\text {seed }}\right]$ and $\left.\ln \left[W_{\text {seed }}\right]\right)$, so 


\section{Chapter 4}

seeding loss was also negatively related to $W_{\text {seed }}$. The only differences were between seeding loss ratios for SMC seed, which were higher than for mussel seed from autumn fishing ( $p=0.003)$, spring fishing $(p=0.001)$, or seed sown after transplantation between plots ( $p=0.003$,Table 4.2$)$.

\section{Cohorts}

Estimations of the relative loss rates for the different cohorts suggest that the average loss rates decreased with mussel size, but this size effect is not significant (ANOVA, $p>0.05$ ). The average loss rate for all size classes was 0.0019 $\pm 0.0031(\mathrm{SD}) \mathrm{d}^{-1}$. The slope is lower than 1 for the seed-size cohort only, with: $\ln \left(\mathrm{D}_{\mathrm{e}}\right)=0.77 \pm 0.068(\mathrm{SE}) \cdot \ln \left(\mathrm{D}_{\mathrm{s}}\right)+1.30 \pm 0.45(\mathrm{SE})$, which indicates an increase in loss rates at higher densities. For half-grown and consumption-sized mussels, the slope did not differ from 1, which indicates that losses were not density related for mussels $>30 \mathrm{~mm}$.

The RBP calculated from mussel -farmers' data at harvest versus RBP calculated from sampling data is included in Table 4.3 per seed type.

Overall, the mean RBP was underestimated in the calculations (mean calculated $=1.5 \mathrm{~kg} \mathrm{~kg}^{-1}$ mean observed $=1.8 \mathrm{~kg} \mathrm{~kg}^{-1}$ ). Table 4.3 displays the age at seeding, $\mathrm{D}_{\text {seed }}$ and $\mathrm{W}_{\text {seed }}$ for SMC seed, autumn seed and spring seed. Harvest date and harvest biomass was obtained for each cohort followed and from this data, RBP was calculated over the entire period from seeding to harvest as shown in Table 4.3, averaged for each origin as the harvest based RPB. RBP was also calculated for the harvest date using Equation 4.4 and these results are shown in Table 4.3 as the sampling based RBP. Figure 4.5 shows the RBP $\left(\mathrm{B}_{\mathrm{t}} / \mathrm{B}_{\text {seed }}\right)$ for three model outputs with input values based on the average seed size, seeding density and age at seeding of SMC seed, autumn seed and spring seed, modelled over time up to a mussel age of 1460 days (four years), with input values from Table 4.3. Maxima of curves in Figure 4.5 are shown in Table 4.3 as the max RBP. 


\section{Chapter 4}

Table 4.3 Model input consisting of seeding data (Origin, Seeding period, $D_{\text {seed }}$ Age at seeding and $\left.W_{\text {seed }}\right)$; RBP averaged per seed origin as obtained from mussel-farmers at harvest; RBP averaged per seed origin derived from calculations based on sampling results and extrapolated to the time of harvest and the maximum RPB from RPB curves as a result of model input

\begin{tabular}{|c|c|c|c|c|c|c|c|}
\hline Origin & $\begin{array}{l}\text { Seeding } \\
\text { period }\end{array}$ & $\begin{array}{c}D_{\text {seed }} \\
\text { (ind } \mathrm{m}^{-2} \text { ) }\end{array}$ & $\begin{array}{l}\text { Age at } \\
\text { seeding } \\
\text { (d) }\end{array}$ & $\begin{array}{c}W_{\text {seed }} \\
(\mathrm{g})\end{array}$ & $\begin{array}{c}\text { Harvest } \\
\text { based } \\
\text { RBP }\end{array}$ & $\begin{array}{c}\text { Sampling } \\
\text { based } \\
\text { RBP }\end{array}$ & $\begin{array}{c}\text { Max } \\
\text { RBP } \\
\text { (model } \\
\text { output) }\end{array}$ \\
\hline \multirow{3}{*}{$\begin{array}{l}\text { SMC } \\
\text { seed }\end{array}$} & Aug 2010 & 3088 & 120 & 0.47 & & & \\
\hline & Sep 20II & 3290 & 130 & 0.60 & & & \\
\hline & Average & 3189 & 125 & 0.54 & 1.9 & 1.5 & 2.8 \\
\hline $\begin{array}{l}\text { Autumn } \\
\text { Seed }\end{array}$ & Oct 2009 & 1474 & 181 & 1.49 & 1.7 & 1.7 & 1.9 \\
\hline \multirow{3}{*}{$\begin{array}{l}\text { Spring } \\
\text { seed }\end{array}$} & May 2009 & 1124 & 394 & 2.85 & & & \\
\hline & Apr 2010 & 1236 & 367 & 3.72 & & & \\
\hline & Average & $1 / 80$ & 381 & 3.29 & $I$ & 0.7 & 1.3 \\
\hline
\end{tabular}

\subsection{Discussion}

\section{Growth}

In our study we hypothesized that mussel growth, as well as survival, are affected by seeding density and we therefore expected to find a lower growth and survival at higher seed density. However, results indicate that growth on the subtidal culture plots was primarily determined by mussel size and mussel age, and not by mussel density or seed type. In a recent study on culture plots in Denmark, no indications of density dependent growth were found for mussels seeded at similar densities as in the present study (Dolmer et al. 2012).

With regard to growth rate, it has been demonstrated that density dependent growth of mussels occurs at different scales. Newell (1990) describes reduced 


\section{Chapter 4}

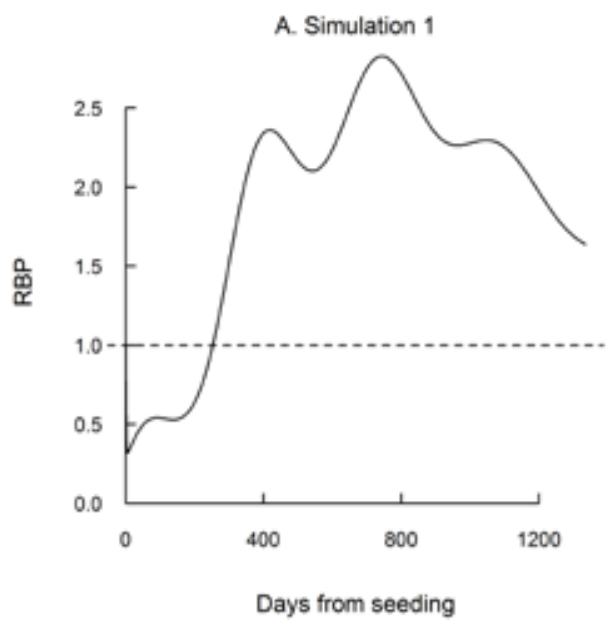

C. Simulation 3

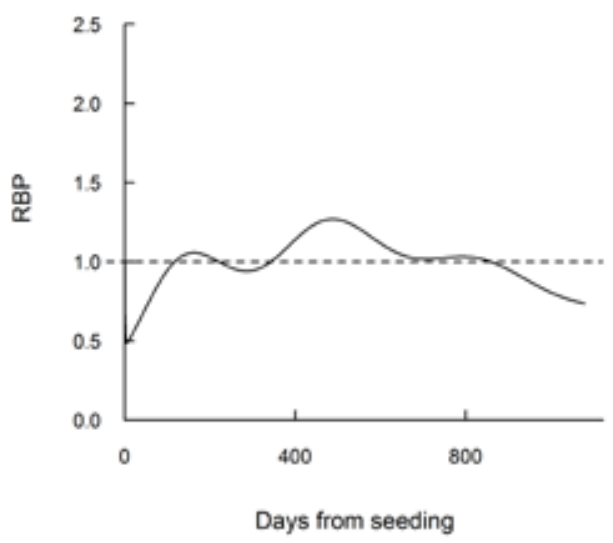

B. Simulation 2

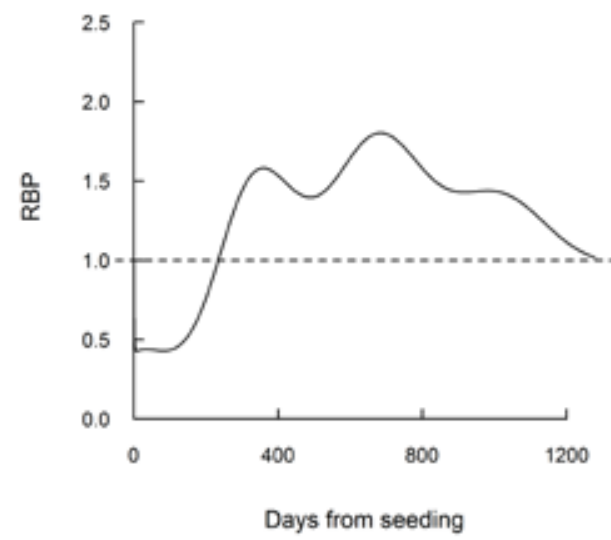

Figure 4.5 RBP $\left(B_{t} / B_{\text {sed }}\right)$ curves for different seed sources for mussels seeded on culture plots in the Wadden Sea between June 2009 and June 2012. Lines are model outputs, with input variables of: (A) averaged for SMC seed: age at seeding (from $t_{0}=17$ April) $=125 \mathrm{~d}, D_{\text {seed }}=3189$ ind $\mathrm{m}^{-2}, W_{\text {seed }}=0.54 \mathrm{~g}$; (B) averaged for autumn seed: age at seeding $=181 \mathrm{~d}, D_{\text {seed }}=1474$ ind $\mathrm{m}^{-2}, W_{\text {seed }}=1.49 \mathrm{~g}$; (C) averaged for spring seed: age at seeding $=381 \mathrm{~d}, D_{\text {seed }}=$ 1180 ind $\mathrm{m}^{-2}, W_{\text {seed }}=3.29 \mathrm{~g}$. 


\section{Chapter 4}

growth in the middle of a mussel patch, and Knights, (2012) found a reduced growth in the middle of a culture plot. Due to the gregarious behaviour of mussels after seeding, patch densities are much higher than average plot densities (Capelle et al. 2014). Growth rates in our study were calculated based on pooled samples taken from 70 random sampling points from a culture plot. As a result, effects at the scale within a culture plot or within space occupied by mussels might be more dominant than effects on the average plot scale. Another source of variation is the large spatial variation in growth rates between plots in the Wadden Sea.

Mussel condition can be used as indicator of growth deprivation at high density in bivalves (Alunno-Bruscia et al. 2000, Lauzon-Guay et al. 2005, Rosland et al. 2011). CI is an instantaneous parameter giving information about the state of the mussels at sampling, while growth provides information over a longer period. Also, no indication of an effect of plot scale density on mussel condition was found in the present study.

The strong correlation between mussel meat content and GR shows that meat content, which is relatively easy to measure, can be used as a reliable proxy for growth. Similar relations between meat content in autumn and food availability in the summer were found in culture plots in the Oosterschelde estuary (Smaal \& Van Stralen 1990, Van Stralen \& Dijkema 1994). Figure 4.2 suggests that this relation between meat content and growth in the preceding season is also applicable for other periods of the year, and growth rates were linearly related to meat content after each respective season.

\section{Mussel loss}

Consumption-sized mussel of $20 \mathrm{~g}$ (around a mussel age of $800 \mathrm{~d}$, Figure 4.3) equate to 37 times the average weight of SMC-seed, 13 times the average weight of autumn seed and 6 times the average weight of spring seed. These values are 


\section{Chapter 4}

the theoretical maximum RBP at harvest without loss and are already showing that size at seeding will affect RBP. Results from Equation 3 show that at that time ( $800 \mathrm{~d}$ ) the actual average losses in mussel number over the culture cycle was $92.4 \%$ for SMC seed, $85.4 \%$ for autumn seed and $53.8 \%$ for spring seed, with an overall average of $77 \%$. This demonstrates that RBP is primarily determined by survival.

Of all mussels seeded, an estimated $42 \%$ were lost in the seeding process. We called this loss the seeding loss and showed that this major loss factor is density and size dependent. Seeding loss is most probably a combination of several different loss factors. Mussels can be washed away by the current during seeding, mussels might be damaged because of handling, losses can be stress related and mussels are lost as a result of intraspecific competition in the aggregation process.

In practice, farmers plan their seeding activities during slack tide to prevent too much loss because of currents. However, some mussels will contain air inside and float. This can be seen during seeding but accounts for only a very small number of mussels.

We could find no figures giving estimates of the amount of damage and stress related to handling. However, it has been shown that physical disturbance affects mussel performance and increases mortality (Honkoop et al. 2003, Newell 2007). The physiological condition of the mussels declines when mussels are kept in the hold for a period longer than 24 hours (Calderwood et al. 2014), which does in fact sometimes occur in culture practice.

Losses due to currents, or stress and damage related losses are primarily density independent, although stress might have secondary effects by affecting mussel performance after seeding. Intraspecific competition following aggregation is density dependent. During seeding, mussels are flushed through seeding shafts 


\section{Chapter 4}

with the use of water pressure below the water level inside the mussel vessel's hold. This seeding technique results in a heterogeneous spread of mussels in seeding tracks with mussels in high densities. Effects of heterogeneity in the spreading of mussel seed were investigated in a previous study (Capelle et al. 2014), where the same mussel biomass of similar sized mussels were distributed in different densities. Results showed that mussel loss increased with mussel density within four weeks after seeding, resulting in a maximum seeding loss of $75 \%$. A reduction of losses through a reduction in within plot-scale mussel density by using better spreading at seeding has been mentioned as a major improvement in Newell et al. (2007). Higher losses at higher densities might be caused by the smothering of mussels in the under layers, in multi-layered mussels at high densities or as an effect of the re-organisation process (Liu et al. 2013, Capelle et al. 2014). This type of loss acts at the scale of the area occupied by the mussels and is probably also related to the speed and time at which the mussels are flushed out of the vessel.

After the seeding activity, mussels on the culture plots are subjected to natural loss factors. Loss was found to be particularly density dependent at seeding and for the seed cohort of size <30 mm. Similar effects were found by McGrorty et al. (1990) within intertidal natural mussel beds, where only small densityrelated loss rates were found in older mussels as a fine-tune mechanism that kept the mussel densities within a close range, following large density-related losses in the first year cohort over winter. Natural loss factors in culture plots are predation, by shore crabs, starfish and eider ducks and dislodgement, typically of mussel seed (Seed 1976, Swennen et al. 1989, Saier 2001, Kats 2007, Murray et al. 2007b, Kamermans et al. 2009, van Leeuwen et al. 2010). Mussel losses of $50-60 \%$ over summer in the Limfjorden, Denmark (Dolmer et al. 2012) or losses of $70 \%$ and higher over the entire culture cycle in Northern Ireland (Ferreira et al. $2007 \mathrm{~b}$ ) are comparable to the numbers we found, although we showed that the major loss is concentrated around seeding. Loss rates for seed found in our 


\section{Chapter 4}

study are comparable to loss rates loss rates from subtidal mussel populations in the Danish Wadden Sea $\left(0.002 \mathrm{~d}^{-1}\right)$. However, losses for mussels larger than $25 \mathrm{~mm}$ decreased considerably in the study of Theisen (1968), where with o.ooog $\mathrm{d}^{-1}$ only half of what was found in the present study, no difference in loss rates between size cohorts was found. Loss factors which act more on larger mussels are predation by eider ducks, which are known to be an important loss factor for mussels in culture plots in the western Wadden Sea. A relatively stable wintering eider duck population of 40,000-50,00o individuals forage in this area and might even be dependent on mussels from culture plots in the western Wadden Sea (Kats 2007, Smaal et al. 2010, Cervencl et al. 2015).

\section{Biomass production}

Cultivation techniques seem to have a limited effect on RBP. In the Wadden Sea, bottom culture has been practiced since 1949 (Korringa 1976). Cultivation techniques have developed based on trial and error and variations in RBP are often associated to external variables by mussel farmers. Such external variables include environmental factors such as storms, temporal and spatial variation in food availability and include other natural factors such as predation. At the same time, as this study clearly shows, mussel farmers rely on techniques that may simultaneously affect RBP.

The maximum RBP in this study averaged per seed source (Table 4.3) decreased from SMC seed $\left(2.8 \mathrm{~kg} \mathrm{~kg}^{-1}\right)$, to autumn seed $\left(1.9 \mathrm{~kg} \mathrm{~kg}^{-1}\right)$ to spring seed $(1.3 \mathrm{~kg}$ $\mathrm{kg}^{-1}$ ) (Figure 4.5). The average RBP we calculated and extrapolated from the sampling results slightly underestimated the average RBP the mussel farmers calculated based on seed and harvest data. This underestimation might result from an overestimated RBP by mussel-farmers, or from an underestimation due to the sampling methods.

Figure 4.5 show that growth quickly compensates mussel losses. When seeded 


\section{Chapter 4}

in autumn, loss is compensated by growth in the following spring. In winter, growth rates decrease (Bayne \& Worrall 1980) and cannot compensate for losses, resulting in a decrease in biomass (Figure 4.5). Production of biomass increases again in spring following the phytoplankton spring bloom (Philippart et al. 2010). Relative biomass production is at a maximum in September-October in the second year cohort (mussel age ca. 8oo d, Figure 4.5) and after this peak, RBP starts to decrease. Growth rates cannot compensate for losses because relative growth rates decrease (Figure 4.3), total biomass comes from a small number of mussels, and individual losses ad up to a substantial total loss. Petraitis (1995a) referred to this process as boom and bust cycles - high productivity after recruitment because of high growth rates, and a rapid decrease in productivity after growth rates cannot compensate loss rates anymore.

The RBP in Figure 4.5 steeply declines at seeding; this decline is the result of seeding loss and is highest for small seed. After this decline, RBP increases again because of growth, at the same time, the mussels decline in number in a density dependent manner for seed smaller than $30 \mathrm{~mm}$. For mussels larger than 30 $\mathrm{mm}$ the decline in numbers is constant. Similar results were found for mussels in suspended culture, where stocking density reduces survival in mussel seed, but not in larger (half-grown) mussels (Lauzon-Guay et al. 2005). It follows that around seeding, RBP is determined by survival. Growth is only significantly affected by size and age and losses for mussels larger than $30 \mathrm{~mm}$ are constant, therefore differences between RBP after seeding are primarily determined by mussel size and age. This is shown by the different models outputs given in Figure 4.5, where RBP also shows seasonal fluctuations, mirroring the growth pattern (Figure 4.3). During grow out; mussel farmers can try to enhance growth and survival by placing the mussels in the right environment and to reduce loss factors such as starfish predation. Mussel culture activities affect RBP primarily at seeding. 


\section{Chapter 4}

The results of this study clearly show that yield improvements will be most effective when mussel-farmers invest in reducing seeding loss for small seed. Possible ways to achieve this are to reduce plot-scale seeding densities (this study), reduce heterogeneity in local mussel density (Capelle et al. 2014), increase substrate complexity (Christensen et al. 2015) and reduce handling stress (Calderwood et al. 2014).

In conclusion, we have shown that variation in RBP is affected by environment, but also by cultivation techniques primarily at seeding. Seeding is the start of the culture cycle and results in an instantaneous drop in RBP, following large losses. In this study, these losses were on average $42 \%$ of the mussels seeded and this substantially determined the RBP. This loss was size dependent, and because farmers apply seeding techniques dependent on seed size, also density dependent. Losses remained density dependent for mussel seed of <30 mm. During grow out; when the mussels became larger than $30 \mathrm{~mm}$, they were subjected to a constant loss. No indication was found that growth or mussel condition was affected by plot scale density. Growth was dependent on mussel size and age, and these largely determined differences in biomass production between seed sources. The density dependent seeding loss associated with seeding activities largely determined survival, hence also the overall biomass production. 


\section{Chapter 5}

\section{The role of shore crabs and mussel density in mussel losses at a commercial intertidal mus- sel plot after seeding}

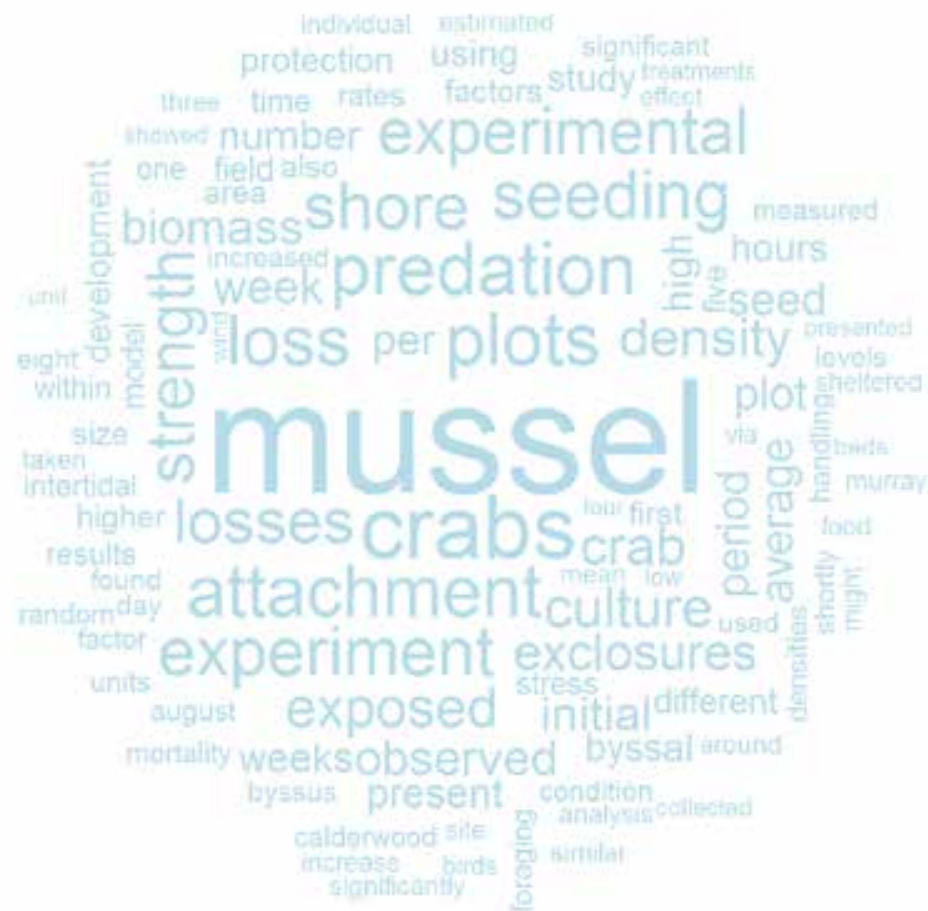

Jacob J. Capelle, Gerard Scheiberlich, Jeroen W.M. Wijsman \& Aad C. Smaal (2016) The role of shore crabs and mussel density in mussel losses at a commercial intertidal mussel plot after seeding.

Aquaculture International:1-14 


\section{Chapter 5}

\section{Abstract}

Mussel losses peak after relaying seed on culture plots. The present paper is an attempt to examine the role of shore crab predation and initial mussel density on mussel losses in mussel bottom culture using an intertidal culture plot as a case study. Because of their small size and loose attachment, mussels are particularly vulnerable to predation at this stage, as well as to handling stress and intraspecific competition. In the experimental field plots $(1 \times 1 \mathrm{~m})$ in the intertidal Oosterschelde, three different densities (1, 5 and $10 \mathrm{~kg} \mathrm{m-2}$ ) of mussel seed is laid, with half of the experimental plots protected from predation by means of exclosures. Duration of the experiment was five weeks (Aug-Sep 2012) post seeding. Protection was the major factor accounting for biomass production, followed by mussel density. Loss rates increased with mussel density, both in the exclosures and on the exposed plots. Losses in the exclosures with the lowest density were still $45 \%$. There are indications that handling stress prior to the start of the experiment played a major role in these losses. At the higher densities in the exclosures, losses increased to $72.1 \%$, and were not significantly different between 5 $\mathrm{kg} \mathrm{m}-2$ and $10 \mathrm{~kg} \mathrm{~m}-2$. About one third of the total loss (32.6\%) was attributed to shore crab predation. The number of shore crabs observed on the plots did not differ between treatments. Byssal thread development during the experimental period was followed, and was found to be a slow process that was insufficient to protect mussels from crab predation at the sheltered experimental location. 


\subsection{Introduction}

The seeding of mussel seed dredged from natural beds or collected from submerged seed mussel collectors (SMC) in the water column is the most critical step in the mussel bottom culture cycle (Calderwood et al. 2014, Capelle et al. 2014). Most of the mussel seed does not survive the cycle from seeding to harvest. Average survival of SMC-seed, or seed relayed from natural mussel beds in autumn over the culture cycle is $8 \%$ and $15 \%$, respectively (Capelle et al. 2016). A substantial part of the losses is associated with seeding (Theisen 1968, Capelle et al. 2014, Capelle et al. 2016). Such losses are a significant factor in biomass production (Capelle et al. 2016).

Losses on culture plots associated with or following seeding are clearly density dependent (Gascoigne et al. 2005, Capelle et al. 2014, Capelle et al. 2016). Seeding practice in bottom culture leads to a highly heterogeneous distribution of mussels on culture plots, with high mussel densities within the space occupied by mussels (Capelle et al. 2014). Mussels are gregarious organisms and aggregate in patches, thereby competing for food and space (Fréchette \& Bourget 1985, Liu et al. 2012).

Other factors that account for such losses are damaged mussels, handling stress (Calderwood et al. 2014) and predation. The main predators of young mussels are starfish in the subtidal area (Gallagher et al. 2008), and birds and tidal-moving shore crabs in the intertidal zone (Hilgerloh et al. 1997, Silva et al. 2014).

The shore crab (Carcinus maenas) is a well-studied predator of juvenile mussels. The feeding rate of shore crabs depends on the predator-prey size ratio, where the predation rate shows a rapid decrease with increasing mussel size (Crothers 1968, Mascaró \& Seed 2001, Murray et al. 2007b, Kamermans et al. 2009). The impact of crab predation over the entire culture cycle has been estimated to 


\section{Chapter 5}

range from 9.5\% (Murray et al. 2007b) to 52\% mussel loss (Grosholz et al. 2011). These data are extrapolations of laboratory results on feeding rates to estimated field abundances. Exclusion of shore crabs from an intertidal culture plot (8oo $\mathrm{m}^{2}$ ) via installation of fences improved the yield by a factor of 4 to 5 for the entire culture cycle (Davies et al. 1980).

Mussels display several defense mechanisms against predation. In response to chemical cues from crabs, mussels increase their shell thickness, which significantly increases the handling time for foraging crabs (Freeman 2007). Mussels also increase the production of byssal thread in the presence of predators, thereby being more firmly attached and leading to reduced predation rates. This defense is widely used and has been known with regard to Homarus sp., C. maenas and Cancer sp. feeding on M. edulis (Côté 1995, Reimer \& Tedengren 1997, Garner \& Litvaitis 2013), Callinectes sapidus feeding on Ischadium recurvum (Brown et al. 2011) and Acanthocylus gayi feeding on Perumytilus purpuratus and Semimytilus algosus (Caro et al. 2008), where $A$. gayi was selecting the mussels with the weakest attachment. Since shore crabs display competitive behaviour for food, dense mussel aggregations increase the intraspecific interactions between the crabs that might lead to a decrease in the predator-prey interactions in the field (Sneddon et al. 1997, Smallegange \& Van Der Meer 2007). Interference between crabs is also indicated by experiments of Kamermans et al. (2009) where the rate at which $20 \mathrm{~mm}$ mussel seed was consumed, decreased from 6 seeds/day/crab to 3 seeds/day/crab when two crabs were placed together in one cage. However, when this hypothesis was tested on cockles, it was observed that the aggregation level had no effect on predation success of shore crabs (Whitton et al. 2012). When mussels were presented as a group rather than as a sequence of single individuals, predation rates increased, as the shore crabs were able to select smaller-sized individuals of a group more easily (Burch \& Seed 200o). 


\section{Chapter 5}

Mussels attach to conspecific organisms using their byssus threads. The attachment strength of mussels increases with time, and depends on the number of byssal threads that are produced (Kangeri et al. 2014). If shore crab predation rates are dependent on byssus attachment strength, mussels are most vulnerable during the short period after seeding, when the mussels redistribute (Capelle et al. 2014) and need to develop their attachment strength. Furthermore, damaged mussels or dead mussels, as a result of the seeding process (Calderwood et al. 2014) emit cues that enable shore crabs (which orientate themselves mainly via chemoreception) to locate a culture plot from a long distance shortly after seeding (Crothers 1968). Damaged or dead mussels are easy prey for shore crabs.

Losses peak on intertidal (Capelle et al. 2014) and subtidal plots (Capelle et al. 2016) shortly after seeding. The contribution of different loss factors to this loss is not known. It is hypothesised that density-dependent losses and shore crab predation are the major loss factors for mussel seed on intertidal culture plots.

We expect that shore crab predation will contribute significantly to losses shortly after seeding because of the small mussel size, weak byssal attachment and the high chemical attraction of damaged mussels. Therefore, the role of byssal attachment strength shortly after seeding as a protection mechanism against loss was also investigated.

\subsection{Materials and methods}

A field experiment was conducted in order to estimate losses during the first five weeks post seeding. In this experiment, the effects of mussel density and protection against predation on mussel condition and survival were measured. 


\section{Chapter 5}

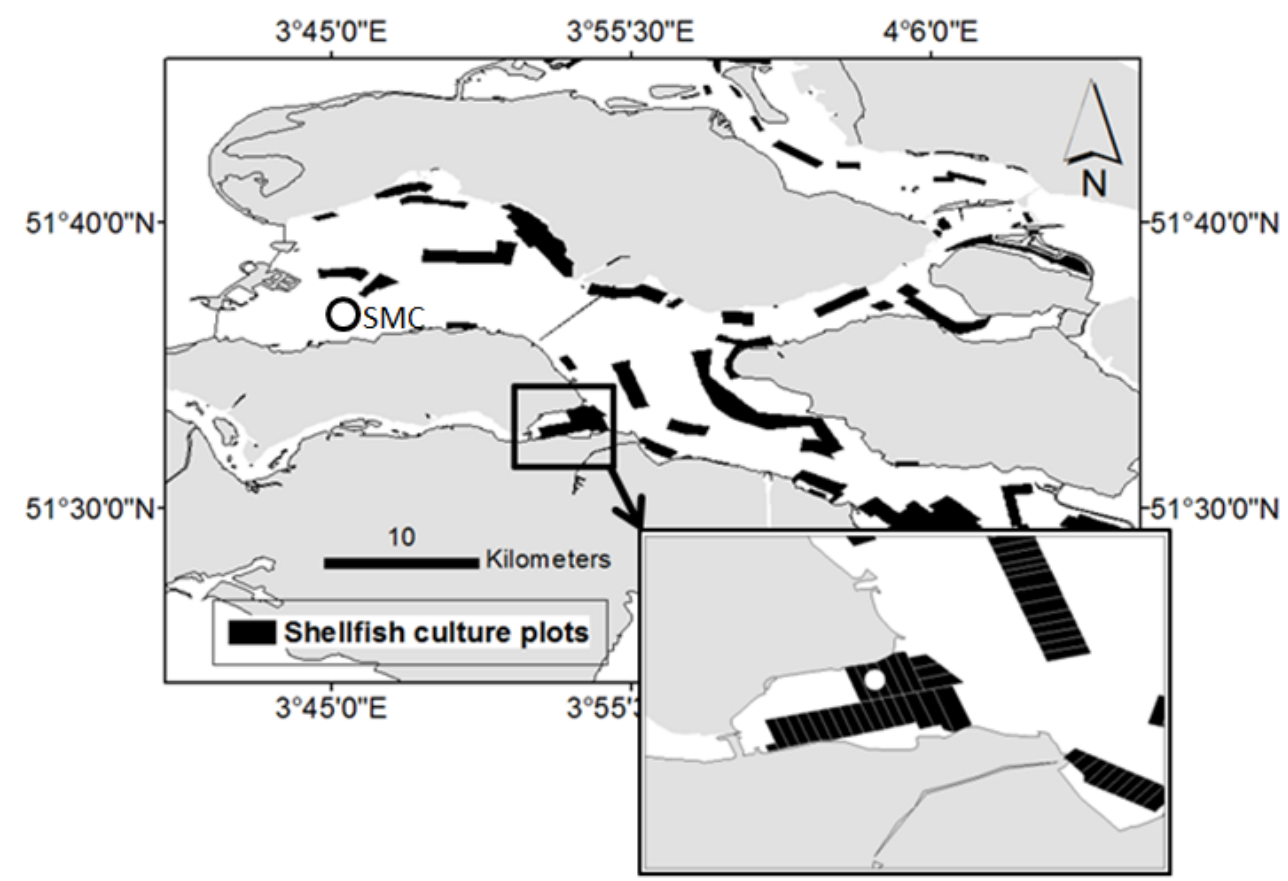

Figure 5.1 Location of field experiment (white dot, 51 $\mathrm{N} 33.193^{\prime}, 3^{\circ} \mathrm{E} 53.327^{\prime}$ ) and location of seed mussel collector (SMC) where mussel seed was collected prior to seeding on the experimental plot.

\section{Site and experimental set-up}

The field experiment was undertaken on an intertidal commercial mussel plot $\left(51^{\circ} \mathrm{N} 33.193^{\prime}, 3^{\circ} \mathrm{E} 53.327^{\prime}\right)$ from the $15^{\text {th }}$ of August 2012 to the $20^{\text {th }}$ of September 2012. The site is located at a sheltered location within the Oosterschelde estuary in the Netherlands (Figure 5.1). A section of this mussel plot was laid with mussel seed by a mussel farmer during high tide on the $14^{\text {th }}$ of August 2012. Mussel seed used was harvested from seed mussel collectors (SMC) from the western part of the Oosterschelde (Figure 5.1) a day previously and was held overnight without water in the hold of a mussel vessel prior to seeding. A total of eighteen experimental units were set out in three rows, with six experimental 


\section{Chapter 5}

units of $1 \mathrm{~m} \times 1 \mathrm{~m}$ per row, with one metre between each experimental unit. The experimental units were located approximately $10 \mathrm{~m}$ northeast of the area where the mussels were laid by the mussel farmer. Within each experimental unit of $1 \mathrm{~m}^{2}$, mussels that were collected from the culture plot were evenly distributed in three different biomass densities over the experimental plots a day after seeding: $1 \mathrm{~kg} \mathrm{~m}^{-2}, 5 \mathrm{~kg} \mathrm{~m}^{-2}$ and $10 \mathrm{~kg} \mathrm{~m}^{-2}$, which corresponded to approximate mussel densities of 3000 mussels $\mathrm{m}^{-2}$, 15000 mussels $\mathrm{m}^{-2}$ and 30000 mussels $\mathrm{m}^{-2}$, respectively. Half of the experimental units from each density were protected by cages Figure 5.2). The cages were constructed using wooden frames $(1 \mathrm{~m} \times 1 \mathrm{~m} \times 0.5 \mathrm{~m})$ that were wrapped with chicken wire mesh (size: $0.8 \mathrm{~mm}$ ). All the treatments (density and exclosure) were randomly assigned to the experimental units in triplicate. During the course of the experiment, due to an unknown reason, one of the exclosures of an initial biomass of $1 \mathrm{~kg}$ $\mathrm{m}^{-2}$ of mussels was lost between the third and fourth week. At the start of the experiment, a random sub-sample $(n=424)$ was taken from the culture plot in order to measure the length and the byssal attachment strength of the mussels. For a period of four weeks, three core samples $(\mathrm{d}=75 \mathrm{~mm})$ were taken from each experimental unit haphazardly, once every week, and the collected mussels were pooled per experimental unit. In the fifth week of the experiment, all the remaining mussels were collected from each of the experimental units and were weighed for biomass, after which a random volumetric (100 ml) sub-sample was taken for analysis.

Byssal attachment strengths of all the individual mussels, both within the sub-sample and within the intermediate core samples, were measured using a digital gauge (Sauter FK-10, o-10 N). This device was attached to plastic tick tweezers, which were positioned around an individual mussel and pulled in a $180^{\circ}$ direction from the point of attachment of the byssus threads until the mussel became loose. The force gauge displayed the maximum force $(\mathrm{N})$ that was used during the experiment. 


\section{Chapter 5}

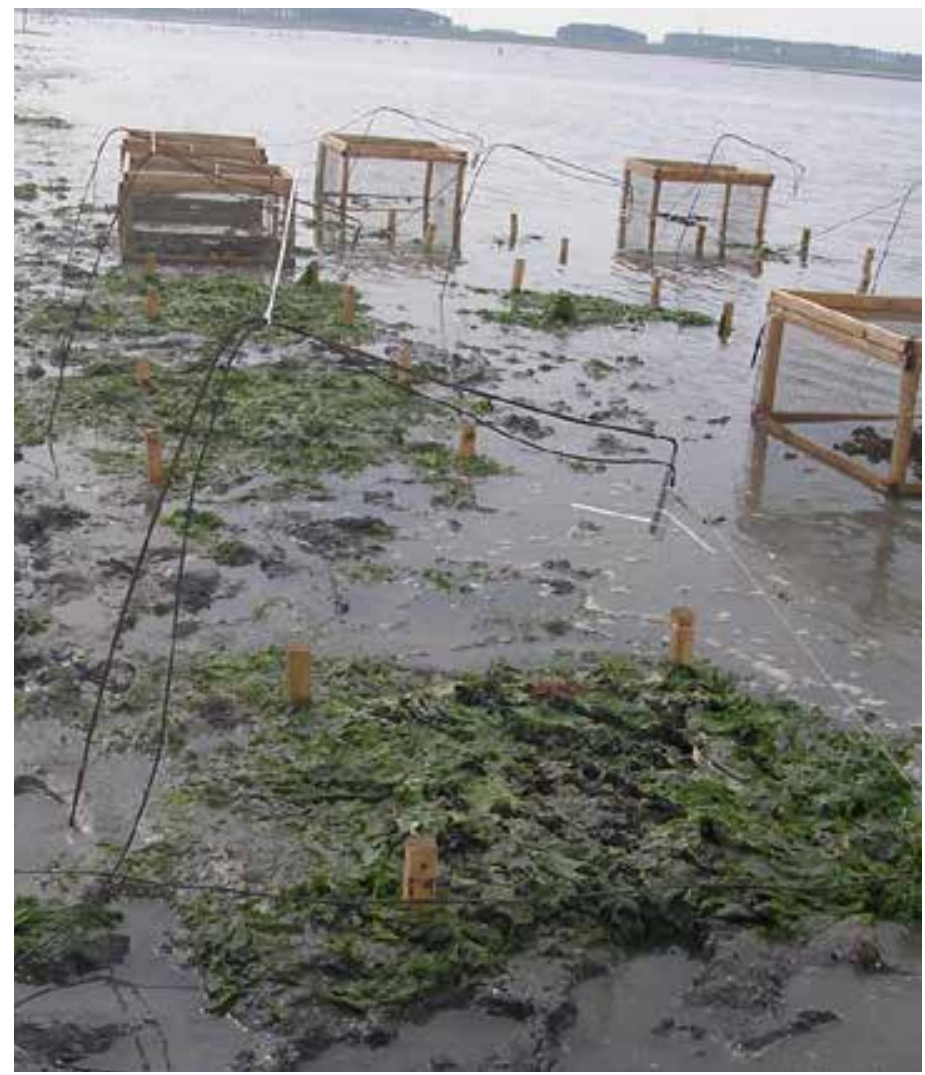

Figure 5.2 Picture of experimental design, showing cages as exclosures, open plots marked by wooden poles and L-shaped frames to which cameras were attached.

The length of the individual mussel $(L)$ was measured using a digital calliper (accurate to $0.1 \mathrm{~mm}$ ), while the ash-free dry weight (AFDW) per sample was obtained by drying the sample at $80{ }^{\circ} \mathrm{C}$ and ashing it at $560^{\circ} \mathrm{C}$ in a prepASH ${ }^{\circledast}$ 340 series until the difference in weight was observed to be less than $1 \%$ per 30 minutes. Relative mussel loss rates $\left(\mathrm{r}, \mathrm{d}^{-1}\right)$ were calculated for each of the experimental units as $\left(\ln \left(N_{\text {end }}\right)-\ln \left(N_{\text {start }}\right)\right)$ divided by the time of the experiment (days), where $\mathrm{N}$ is the number of mussels $\mathrm{m}^{-2}$. A Condition Index $(C I, \mathrm{mg}$ 


\section{Chapter 5}

$\mathrm{cm}^{-3}$ ) was calculated for each experimental unit via $A F D W / L^{3}$ (Beukema 1976). Biomass development over the experiment was expressed as $B_{\text {end }} / B_{\text {start }}$, where $B$ is biomass $\left(\mathrm{kg} \mathrm{m}^{-2}\right)$

Eight video cameras (wide-angle waterproof surveillance cameras) were placed above the exposed plots on the $22^{\text {nd }}$ of August and nine cameras on the $29^{\text {th }}$ of August, each covering an area of $0.6-0.7 \mathrm{~m}^{2}$. Cameras recorded the activities on the plots continuously for $\mathbf{2 . 2}$ hours, during high tide. The videos were used to estimate the average density of foraging shore crabs on the exposed plots in order to evaluate the relationship between the numbers of shore crabs and the mussel density, as well as to estimate the shore crab predation pressure. The crabs were counted and expressed as average number of individuals per $\mathrm{m}^{2}$ per hour. Predation pressure was expressed as the number of foraging crabs per $\mathrm{m}^{2}$ per hour. A crab was considered to be foraging when it stayed in one place for at least 30 seconds. Food processing movements were also observed in most such cases.

Average water temperature was $18{ }^{\circ} \mathrm{C}$ during the experimental period. Average wind speed was $4.0 \mathrm{~m} \mathrm{~s}^{-1}$ (Beaufort 3); the maximum wind speed during the experimental period was recorded as $9.2 \mathrm{~m} \mathrm{~s}^{-1}$ (Beaufort 5) on one day during the experiment (day 17 from the start). Wind direction was observed to range between $120^{\circ}$ and $340^{\circ}$, with an average of $223^{\circ}$ north. Experimental plots were completely dry only at water levels below about -1.50 m NAP (Amsterdam Ordnance Datum), which occurred for about two hours out of every 24 hours on average. No shore crabs were found in the exclosures at the end of the experiment.

In addition, we carried out a small predation experiment in the laboratory in which pre-aggregated mussels (four tanks) and loose mussels (four tanks) were exposed to an individual shore crab for a period of eight hours - the crabs had carapace width of 60-70 $\mathrm{mm}$, and mussels ranged from $20-25 \mathrm{~mm}$ in shell 


\section{Chapter 5}

length, from a different batch than used in the field experiment and were fished from a subtidal commercial mussel plot. The experiment was repeated eight times over a period of five weeks using different crabs and mussels for each run. Average attachment strength of the pre-aggregated mussels was found to be $2.0 \pm 1.0 \mathrm{~N}(\mathrm{n}=185)$, and mussels that were presented loose developed an attachment strength of $1.0 \pm 0.7 \mathrm{~N}(\mathrm{n}=83)$ over the course of the eight hours for which the experiment lasted.

\section{Data analysis}

The field experiment was set up as a random design. Differences in loss rates, biomass development and $\mathrm{CI}$ between treatments at the end of the experimental period were analysed using a two-way analysis of variance (ANOVA), with the factors of initial biomass and protection as response variables. The analyses were followed by a post-hoc Tukey HSD (honest significant difference). The quantity of crabs that was measured from the video observations was tested against the initial mussel biomass (as factor) via the Kruskal-Wallis test. The level of significance was 0.05 for each analysis. Normality and homogeneity of the variances of the residuals were evaluated for all models by following Zuur et al. (2010).

The development of the attachment strength of the mussels over time was first analysed via a repeated-measures ANOVA; however, because of the heterogeneity of residual variances, a linear mixed-effects model (LME) was applied using 'Ime' from the nlme library (Pinheiro et al. 2014). In this model, the mussel density, protection and time (number of weeks) were taken as fixed effects, and time nested in subject as a random effect. Model selection was carried out according to Zuur et al. (2009), and non-significant ( $\mathrm{P}>0.05)$ interactions were removed in a reverse stepwise manner. Restricted maximum likelihood (REML) estimators were used to estimate whether random structures improved 


\section{Chapter 5}

model fit. When the model was improved via a random structure, the optimal fixed-effect structure was determined (with the same random structure) using maximum likelihood (ML) estimators. The final model was presented using an REML estimation. Normalized residuals of this fit were visually checked for normality using a histogram, and were plotted against fitted values and against each explanatory variable to validate the model. The residuals closely followed a normal distribution and no violation of homogeneity was indicated at this point. When significant overall effects were found, pairwise comparisons were made by means of a Tukey HSD test.

The number of mussels consumed by each shore crab per eight hours in the lab experiment was analysed using a generalised linear model (GLM), with the response factor $(\mathrm{Y})$ containing the proportion dead and live mussels per observation, and a quasi-binomial variance model to account for overdispersion. All analyses were carried out using R software (R Core Team 2016).

\subsection{Results}

Video observations in the first week (22nd of August) showed significantly more $(\mathrm{F}(1,11)=8.33, P=0.01)(5.4 \pm 2.8)$ shore crabs foraging for mussels (11.8\% of all passing crabs) than in the second week (29th of August, $1.7 \pm 1.8$ shore crabs, $7.4 \%$ of all passing crabs). No statistical association between the number of foraging crabs and the initial mussel density was observed. Since crabs migrate with the tide, the measurements obtained during high tide will probably reflect the peak in numbers within each day. 


\section{Chapter 5}

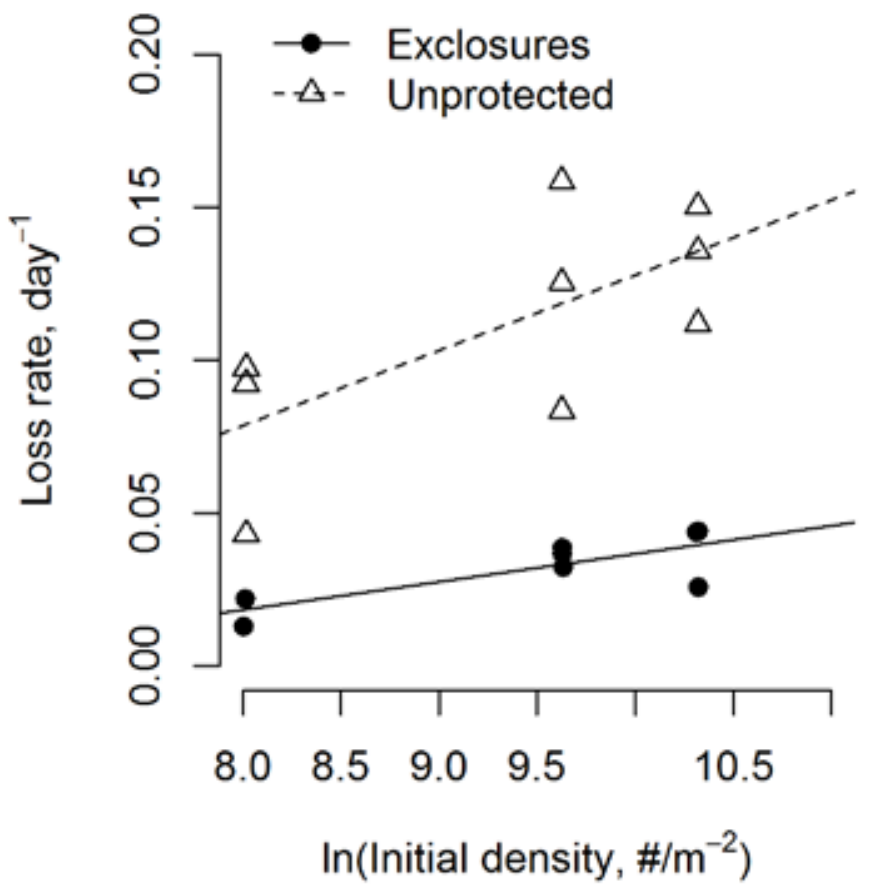

Figure 5.3 Mussel loss rates over a five-week field experiment at three different initial densities on exclosures and unprotected plots. Lines $(y=a x+b)$ show a significant relationship for exclosures $\left(r^{2}=0.57, F(1,6)=10.37, P=0.018\right)$ and unprotected plots $\left(r^{2}=0.41, F(1,7)=6.51\right.$, $P=0.038)$.

Loss rates differed significantly between exclosures and exposed plots $(F(1,13)=80.38, P<0.001)$ and between levels of initial density $(F(2,13)=8.71$, $P=0.003$, Figure 5.3); protection and levels of initial density showed no significant interaction. Loss increased with (In) initial density. The differences in mussel loss between the exclosures and the exposed plots are expressed as percentages in Table 5.1. 


\section{Chapter 5}

Table 5.1 Percentage of mussel loss and differences for exclosures and exposed plots with different initial densities over a five-week period after seeding.

\begin{tabular}{|c|c|c|c|}
\hline $\begin{array}{c}\text { Initial } \\
\text { density } \\
\mathrm{Kg} \mathrm{m}^{-2} \\
\end{array}$ & $\begin{array}{c}\text { A. Exclosure } \\
\%(S D)\end{array}$ & $\begin{array}{c}\text { B. Exposed plots } \\
\%(S D)\end{array}$ & $\begin{array}{c}\text { B-A } \\
\%\end{array}$ \\
\hline 1 & $44.8(12.2)$ & $90.2(10.7)$ & $45 \cdot 4$ \\
\hline 5 & $71.2(3 \cdot 3)$ & $97.7(2.7)$ & 26.5 \\
\hline 10 & $72.1(11.1)$ & 98.9 (o.8) & 26.8 \\
\hline
\end{tabular}

Biomass development, calculated as final mussel biomass/initial biomass over the five-week experimental period, was affected by the factors of initial density $(F(2,11)=16.22, P<0.001)$ and protection $(F(1,11)=99.19, P<0.001)$. However, there was a significant interaction effect $(F(2,11)=4.25, P=0.04)$ between the factors, indicating that the biomass development was higher on the protected plots (exclosures) than it was on the exposed plots (Figure 5.4). In the exclosures, mussel biomass increased in five weeks with a factor of 1.5; this ratio was below 1 in all the plots with higher initial biomasses. 


\section{Chapter 5}

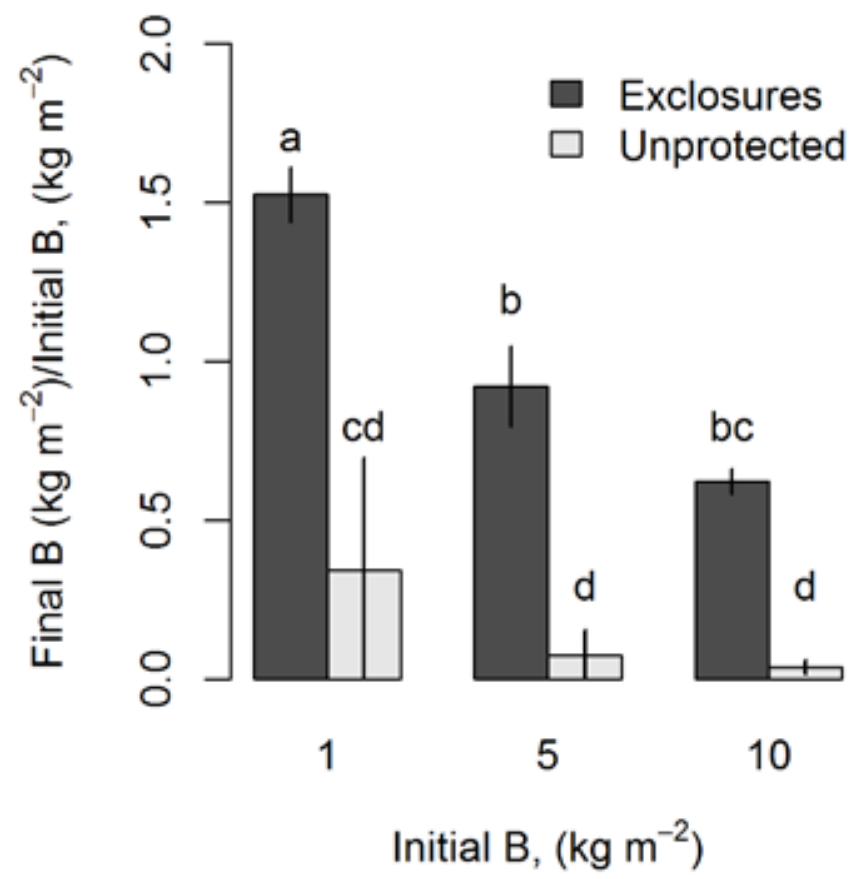

Figure 5.4 Average biomass development after five weeks as a ratio between the final biomass (Final $\mathrm{B}, \mathrm{kg} \mathrm{m}^{-2}$ ) and the initial biomass (Initial $\mathrm{B}, \mathrm{kg} \mathrm{m}^{-2}$ ), shown for the different treatments; $a, b, c$ and $d$ are statistically different from each other (Tukey HSD, $P<0.05$ ).

Condition indices of the mussels from all the treatments (Figure 5.5) were subjected to a two-way analysis of variance test, with two levels of protection and three levels of initial density. However, the effects were not statistically different. 


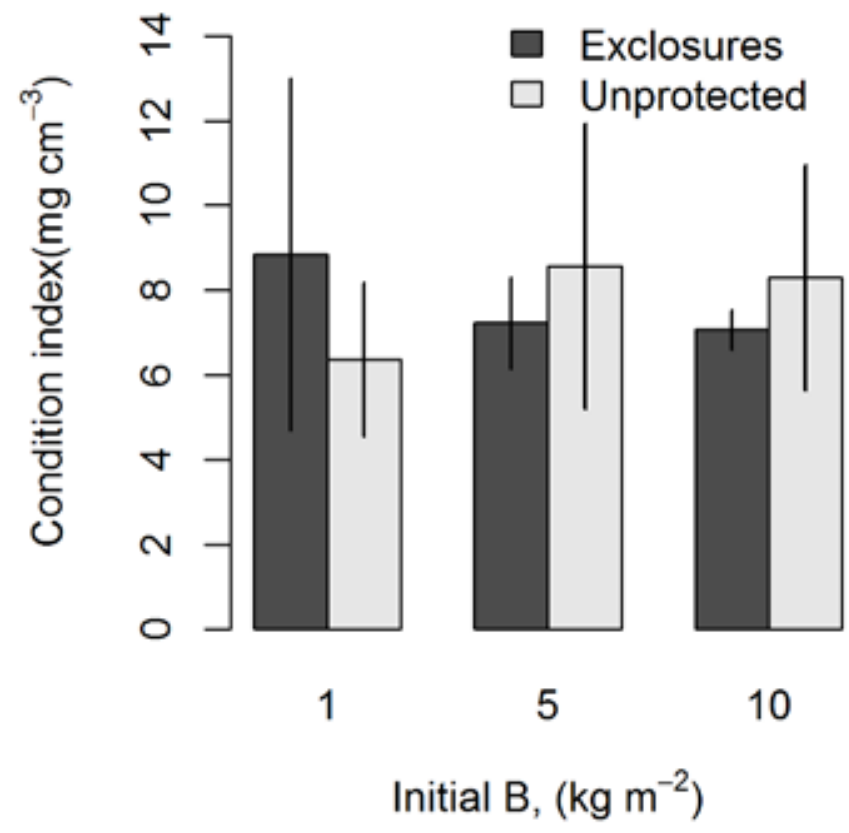

Figure 5.5 Average condition index $\left(\mathrm{mg} \mathrm{cm}^{-2}\right)$ at the end of the experiment, shown per treatment as the initial biomass (B); treatments are not significantly different from each other (two-way ANOVA, $P>0.05$ ).

Attachment strength increased over time (Figure 5.6) and was significantly affected by protection (Table 5.2). A regression tree model showed that protection did not matter before the $5^{\text {th }}$ week. In other words, within the exclosures, byssal attachment strength of the mussels did not increase, whereas on the exposed plots, it increased in the fifth week. The initial biomass was found to have no effect on attachment strength. Results of the additional (controlled) lab experiment showed that the number of mussels consumed by each shore crab per eight hours (mean: $10.15 \pm 5.53$ ) did not differ between the pre-aggregated or the loose mussels (GLM, P>0.05). Average attachment 


\section{Chapter 5}

strength of the pre-aggregated mussels was $2.0 \pm 1.0 \mathrm{~N}$ ( $\mathrm{n}=185)$, and the mussels that were presented loose developed an attachment strength of $1.0 \pm 0.7 \mathrm{~N}$ $(n=83)$ over the course of the eight hours that the experiment lasted. This shows that mussel attachment strength that developed in the first week in the field was not sufficient to protect them from crab predation.

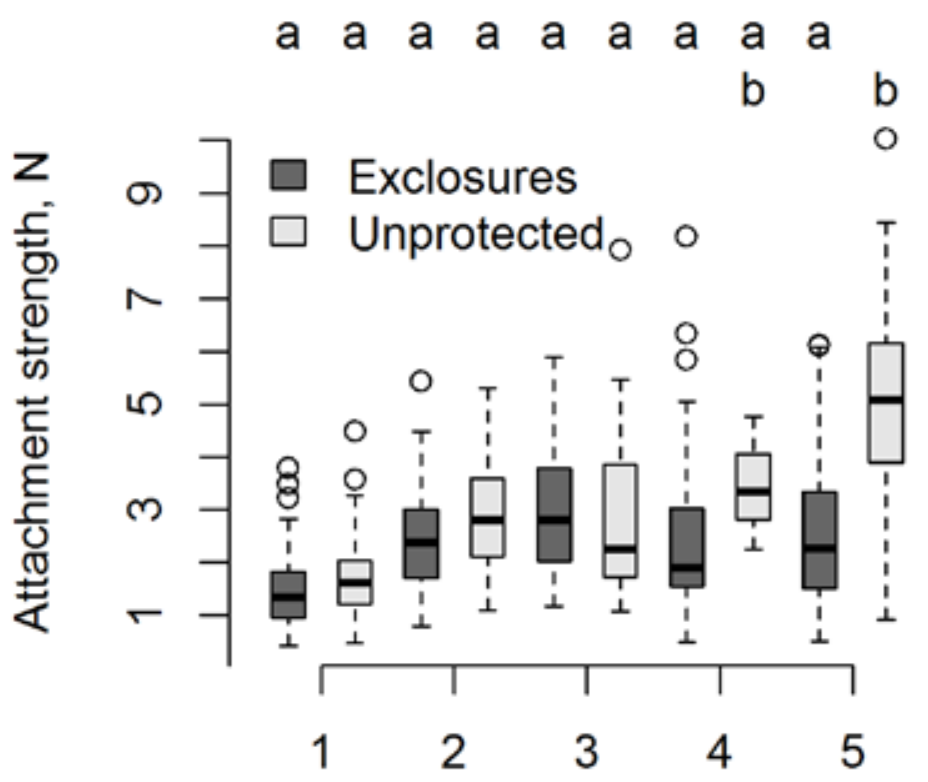

\section{Week}

Figure 5.6 Boxplot of the development of byssal attachment strength ( $\mathrm{N}$ per mussel) of mussels from exclosures and exposed plots over the experimental period; $a$ and $b$ are statistically different (Tukey HSD, $P<0.05$ ). 
Table 5.2 LME results for the development of attachment strength $(N)$ in exclosures and on exposed plots

\begin{tabular}{lcccc}
\hline \multicolumn{2}{c}{ Source of variation } & $\boldsymbol{d} f$ & $\boldsymbol{F}$ & $\boldsymbol{P}$ \\
& Dependent variable: log & attachment & strength $(N)$ & \\
\hline Treatment & 1 & 15.44 & 0.001 \\
Time & 4 & 11.87 & $<0.001$ \\
\hline
\end{tabular}

\subsection{Discussion}

The present study closely followed mussel performance on an intertidal commercial mussel plot for a five week period after seeding. Effects of initial mussel density and crab predation (through use of exclosures) on mussel survival were estimated. Overall losses were extremely high, particularly when compared to earlier tests as is detailed below.

\section{Potential loss factors}

The present study confirmed earlier findings that mussel loss is very high shortly after seeding and that mussel loss increases with mussel density (Theisen 1968, Capelle et al. 2014, Capelle et al. 2016). Differences between the exclosures and the exposed plots can be used to distinguish between the loss factors. In the exclosures, mussel loss was probably due to mortality associated with handling stress (Calderwood et al. 2014) and intraspecific competition. At the lowest density ( $\left.1 \mathrm{~kg} \mathrm{~m}^{-2}\right)$, where intraspecific completion was assumed to be low, mortality was still $45 \%$ after five weeks. We could not find any studies on mussel bed performance as a function of density by means of exclosures. However, because $1 \mathrm{~kg} \mathrm{~m}^{-2}$ is a low density in common mussel culture practice (Capelle et al. 2014), this $45 \%$ is regarded as background mortality that might show losses following handling stress. At higher densities of $5 \mathrm{~kg} \mathrm{~m}^{-2}$ and $10 \mathrm{~kg} \mathrm{~m}^{-2}$, 


\section{Chapter 5}

mortality was observed to be $71 \%$ and $72 \%$ respectively, during the experiment. This mortality increase can be attributed to intraspecific competition at higher densities. The difference between mussel mortality in the exclosures and the losses on the exposed plots is due to dislodgement, and to predation by birds and shore crabs. This difference was in the range of $27 \%-45 \%$ (average $32.6 \%$; Table 5.1), which resulted in a final mussel biomass range of $0.3-0.4 \mathrm{~kg} \mathrm{m-2}$ on the exposed plots for each treatment.

\section{Mussel loss on the exposed plots}

Exclosures not only protected mussels against crab predation, but also against dislodgement and bird predation. Both bird predation and dislodgement are known factors contributing to loss on mussel beds (Nehls \& Thiel 1993, Ens \& Alting 1996, Hilgerloh et al. 1997). Herring gulls feed on small mussels (of around $20 \mathrm{~mm}$ ), and oystercatchers feed on larger mussels (30-45 mm; Meire and Ervynck, 1986). These birds are the main predators of mussel seed on intertidal flats (Hilgerloh et al. 1997). The experimental area was embedded in a culture plot on which the same mussel seed was seeded. On that culture plot, mussel farmers were present at low tides every day during the daytime and actively chased the birds away. This activity stopped after the first three weeks of the experiment because of the low number of birds observed in the area, and subsequently on the culture plot. Exposure of the experimental area during low tides was relatively short and occurred, on average, only two hours in every 24 hours. Such circumstances led to speculation that bird predation might not be a significant loss factor on the exposed plots. The other major mussel predator in this area is starfish (Asterias rubens), however their distribution is limited to the subtidal zone (Saier 2001). Also no starfish were observed on the video. It has been observed that the intertidal mussel beds are destroyed by dislodgement as a result of the effect of severe storms, but they remain relatively stable in sheltered locations (Nehls \& Thiel 1993). The experimental site for 
the present study was located within a sheltered area in the Oosterschelde (Figure 5.1), where the wind speed did not peak above $9.2 \mathrm{~m} \mathrm{~s}^{-1}$ throughout the duration of the experiment. The dominant direction of the wind during the five weeks of the experimental period was southwest. No mussel seed was found in the area around the (seeded) culture plot. These circumstances during the experimental period did reduce dislodgement risk, and were important factors in the evaluation of the mussel loss. Thus, only predation by crabs remained as a factor to analyse the primary difference in mussel loss between the exclosures and the exposed plots.

\section{Mussel loss caused by handling stress}

In contrast to a similar experiment that was performed a year earlier on the same culture plot, with $60-85 \%$ loss four weeks after relaying on exposed plots, mussel loss was observed to be higher at the exposed plots in the current study with 90-99\% loss (Capelle et al. 2014). Furthermore, in the present study, the mussel loss was also higher than the losses that are generally experienced after seeding (around 50\%) (Theisen 1968, Capelle et al. 2016). According to mussel farmers, such high mussel loss may be due to the possibility that the mussels were kept in the vessel for too long from the time of harvest to seeding, especially because the day was very hot and sunny, and it has been reported that such conditions might cause some kind of stress that decreases survival after relay (Calderwood et al. 2014). It might be a satisfactory explanation for the very high mussel losses (Table 5.1), because the condition index of the seed, a day after seeding, was high $\left(8.08 \mathrm{mg} \mathrm{cm}^{-3}\right)$. In the similar experiment that was performed a year earlier on the same culture plot with mussels from similar origin and size, condition index of mussels at start was only $5.00 \mathrm{mg}$ $\mathrm{cm}^{-3}$ (Capelle et al. 2014) and condition index of mussels of a similar size transplanted in Denmark ranged between 3.8-5.2 $\mathrm{mg} \mathrm{cm}^{-3}$ (Dolmer et al. 2012). These losses, due to handling stress also explain the total losses (95.6\%), the 


\section{Chapter 5}

resulting loss levels were at the levels that are normally expected after seeding (about 50\%, Table 5.1).

It has been reported that handling stress also has an impact on byssal thread production shortly after seeding (Calderwood et al. 2014). However, in spite of similar stress experienced by the mussels in each treatment and on the entire culture plot, mussel losses found in the present study were higher than those observed under normal conditions. The results support the suggestion by Calderwood et al. (2014) that mussels should not be kept out of the water for more than 24 hours.

\section{Development of attachment strength}

Byssal attachment strength increased to a mean strength of $4.9 \mathrm{~N} \pm 0.2 \mathrm{~N}$ (SE) $\mathrm{n}=9$ during the fifth week at the exposed plots, while it remained at the same level for the protected mussels (mean: $2.5 \mathrm{~N} \pm 0.2 \mathrm{~N}$ (SE), $\mathrm{n}=8$ ). Previous studies showed that the presence of shore crabs (effluent) stimulates the creation of byssus (Reimer \& Tedengren 1997, Leonard et al. 1999) at a speed that can results in 10 byssus threads after six hours and, in the field, to attachment strengths (after 30 days) of about $16 \mathrm{~N}$ (Côté 1995), which was twice as high as it was when no crabs were present (Leonard et al. 1999). Attachment strength is related to the sum of individual byssal threads (Bell \& Gosline 1996), and mussels that are more strongly attached are less likely to be taken by crabs (Lin 1991). However, the byssus production on the exposed plots over time did not increase in the period after seeding, which is when the majority of the losses occur (Capelle et al. 2016). During the first week in the field, the mussels developed an average attachment strength of $1.6 \mathrm{~N} \pm 0.1 \mathrm{~N}$ (SE). The results of the lab experiment indicated that mussel attachment strength of around $2 \mathrm{~N}$ is not sufficient to protect a mussel from crab predation.

Byssal attachment strength, which was measured both in established and in 


\section{Chapter 5}

transplanted (after 30 days) mussel aggregations at exposed rocky shores in the study conducted by Leonard et al. (1999), was much higher (about 10-35 N) than it was in the present study. The byssal attachment strength measured after re-attachment under laboratory conditions (Lee et al. 1990, Dolmer \& Svane 1994, Babarro \& Reiriz 2010) was much lower than that which was reported in the findings by Leonard et al. (1999), and was lower than values measured in the present study. The experimental site at which the present experiment was carried out was a sheltered area of the Oosterschelde. Site conditions are strong determinants of attachment strength (Bell \& Gosline 1996), and formation of byssus is costly ( $8 \%$ of carbon and nitrogen in the total production in summer (Hawkins \& Bayne 1985). Sheltered site conditions might, therefore, be more relevant for explaining the development of attachment strength than the presence of shore crabs, and may also play a role in protection against shore crab predation.

\section{Crab predation}

It is estimated that about one third (average 32.6\%; Table 5.1) of mussel loss in the one-month period after seeding can be attributed to crab predation. These results are in line with the Plass-Johnson et al. (2010), who attributed 35\% of the mussel losses to predation and with estimations of Grosholz et al. (2011) who extrapolated results from Beal and Kraus (2002) and from (Beal 2006) where predation losses varied between $13 \%$ and $55 \%$. Murray et al. (2007b) estimated that losses as a result of shore crab predation are $9.5 \%$ over 12 months in the Menai Street in Wales, which is substantially lower than in the present study. However, predation rates were based on mean number of crabs per square meter on mussel beds in Wales which was lower than in the present study with on

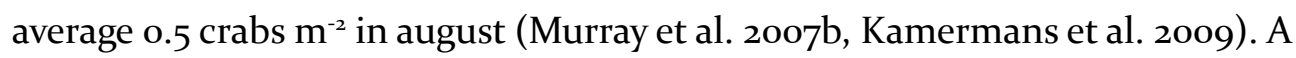
peak in foraging crabs can be expected closely after relaying. However, detailed observations from the first weeks after relaying are scarce, but the present study 


\section{Chapter 5}

indicates such an effect. Crab abundance was much lower in the second week after seeding than it was in the first week after seeding, probably due to the attraction of the crabs to the smell of dead or damaged mussels during and shortly after seeding. Losses in mussel bottom culture are determined by high losses following seeding (Capelle et al. 2016). Mussels in Week 1 and Week 2 were between 16 to $18 \mathrm{~mm}$ in size. Murray et al. (2007b) reported that the number of mussels consumed decreased as the mussel size increased. An individual shore crab can consume 21-36 mussels of $20 \mathrm{~mm}$ (minimum size presented) per 24 hours depending on the size of the crab (Murray et al. 2007b, Kamermans et al. 2009). It is assumed that for mussels of between 16 and $18 \mathrm{~mm}$, the average food intake is around 1.25 mussels per hour, a similar food intake was observed in the small predation experiment and in Kamermans et al. (2009); thus, the amount of crabs observed would have eaten about 286-1676 (mean $\pm \mathrm{sd}$ ) mussels $/ \mathrm{m}^{2}$ within the first two weeks: $730( \pm 355)$ mussels $/ \mathrm{m}^{2}$ in the first week and 216 $( \pm 229)$ mussels $/ \mathrm{m}^{2}$ in the second week. At the exposed plots with the highest density, 7000 mussels $/ \mathrm{m}^{2}$ were lost in a period of five weeks. With the estimated food intake, it would have taken between four and 24 weeks to consume such a high number of mussels with regard to the number of crabs that was observed. The amount of variation shows that such estimations can only be regarded as a rough estimate; however, it does show that the number of shore crabs observed could explain the observed mussel losses.

\section{Conclusions}

Based on the present analysis, it can be concluded that mussel losses were high (mean: 95.6\%) in a short period (about one month) after seeding on an intertidal culture plot, particularly when compared to previous studies. We observed high and unexpected background mortality, which was the largest relative proportion ( $45 \%$ ) of all losses. Handling stress caused by the culture process could have played a major role in this loss. Moreover, (18\%) higher 


\section{Chapter 5}

losses were observed at the higher stocking densities $\left(5^{-10} \mathrm{~kg} \mathrm{~m}^{-2}\right)$ than at the low mussel density ( $1 \mathrm{~kg} \mathrm{~m}^{-2}$ ). Remaining losses (about one third; 32.6\%) were attributed to crab predation. No correlation was found between the number of shore crabs and the density of mussels. The development in attachment strength of the mussels at the sheltered location was observed to be a slow process and was thus unlikely to serve as protection against predation. 


\section{Chapter 6 \\ Population dynamics of subtidal mussels (Mytilus edulis L.) and the impact of cultivation}

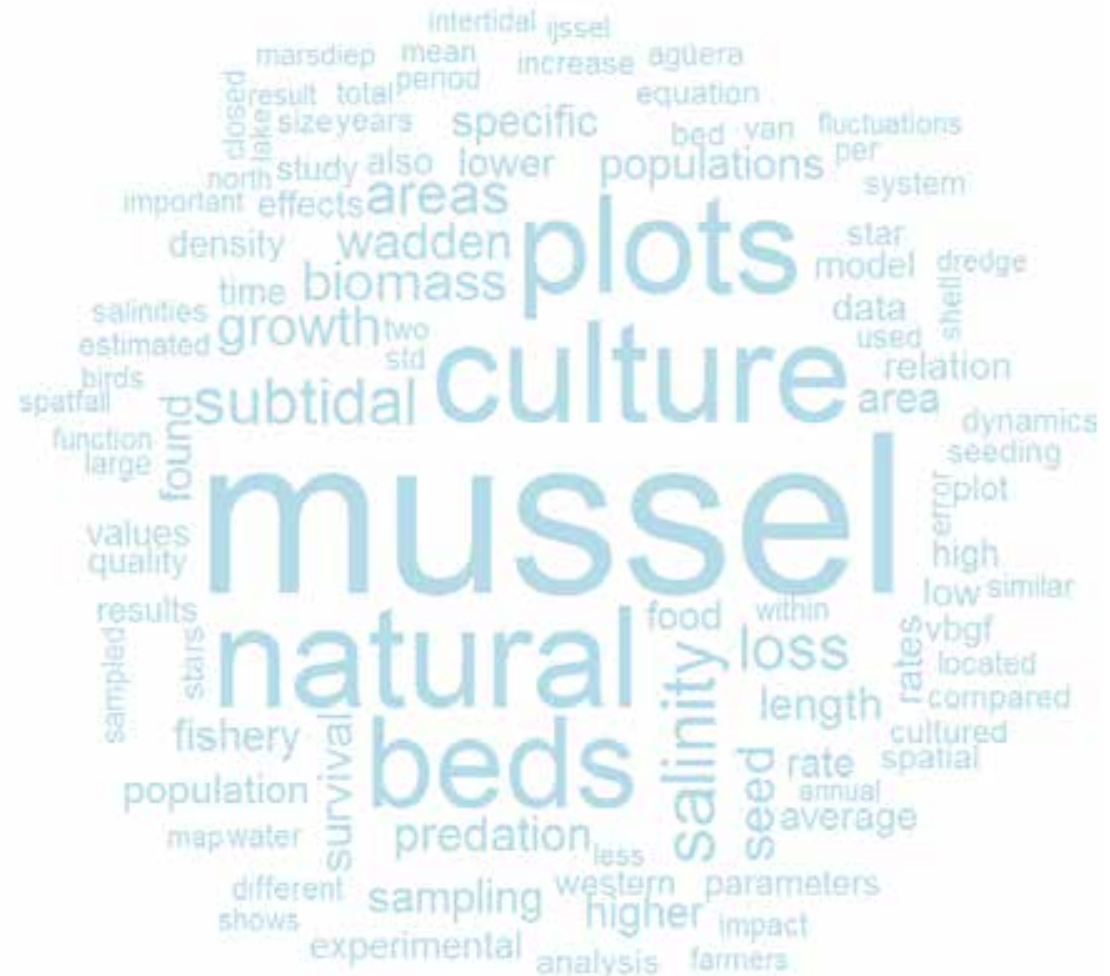

Jacob J. Capelle, Marnix R. van Stralen, Jeroen W.M. Wijsman, Peter M.J. Herman \& Aad C. Smaal

Submitted for publication 


\section{Chapter 6}

\section{Abstract}

Fishery on subtidal mussel beds and subsequent relying on culture plots in the same system is a common practice in mussel bottom culture. We address factors that determine the population dynamics of subtidal mussels and in how far, total (natural plus cultured) subtidal mussel biomass in the system is affected by fishery practices. Mussel size and density of spatially segregated natural and cultured subtidal mussel populations in the western Wadden Sea were measured over time in two field studies. Spatial patterns in survival rates show better spat survival in areas with lower salinity. This suggests that mussel survival is negatively related to sea star distribution which is to a large extent controlled by salinity. Natural beds that escape predation are found at lower salinities and mussels on these beds showed low growth rates, also because of a lower food quality in these areas. Mussel culture is strongly affecting the population dynamics of the subtidal mussel population, through relay of mussels from natural mussel beds to culture plots. This activity increased mussel growth and survival, because food quality on culture plots is high and predation is controlled. Despite harvesting, mussel biomass production on culture plots was higher than on natural mussel beds, enhancing total subtidal mussel stock. 


\subsection{Introduction}

Bottom culture of mussels is an extensive large scale form of aquaculture, which is practiced in shallow subtidal and intertidal sand/mud flats in coastal areas (Gosling 2003). The overall impact of this type of culture is in general low compared to other more intensive forms of aquaculture (Davenport et al. 2009). However, the shallow sand/mudflats are habitats for ecologically important habitat creating communities (e.g. mussel, sea grass, oyster, Sabellaria) and vital foraging areas for birds and fishes (Lenihan \& Micheli 2001, Van de Kam et al. 2004). These ecological values may be impacted by the culture activities, which include the translocation of juvenile mussels from natural beds (mussel seed) to culture plots.

Major concerns about the environmental impacts of mussel culture include the effects on predatory birds in subtidal areas, especially the Eider duck, and to a lesser extent the Greater Scaup (Dankers \& Zuidema 1995, Smit et al. 1998, Piersma \& Camphuysen 2001, Smaal et al. 2001b, Stillman et al. 2001, Laursen et al. 2009). Effects of mussel seed fishery on benthic biodiversity, habitat structure and natural mussel stocks are also debated (Dolmer et al. 1999, Herlyn \& Millat 2000, Smith \& Shackley 2004, Murray et al. 2007a, Dolmer et al. 2012). Mussel beds are considered one of the most diverse temperate communities (Suchanek 1992). Effects of mussel dredging on soft sediment include the removal of larger substrates such as shell debris and gravel (Frandsen et al. 2015). Experiments in the Limfjorden showed that abundance of several taxa (sponges, echinoderms, anthozoans, molluscs, crustaceans, and ascidians) were still reduced 4 months after dredging (Dolmer et al. 2001). Most of these species are associated with hard substrate, such as mussel shells, provided by the mussel bed. Apart from removing mussels with associated flora and fauna, impact of dredging on biodiversity seems habitat specific, in more exposed and sandy environments effects are less pronounced (Kaiser et al. 2006). 


\section{Chapter 6}

Mussels are ecosystem engineers that provide important ecosystem functions, such as benthic pelagic coupling, food and habitat for other species (Borthagaray \& Carranza 2007, Gutiérrez et al. 2011). Most studies on mussel populations have been carried out on intertidal mussel beds, probably because they are more abundant and more accessible than subtidal mussel beds. Intertidal beds can persist on the same spots for decades, re-establishing periodically with new spat fall (McGrorty et al. 1990, Brinkman et al. 2002, Büttger et al. 2008, Commito et al. 2014, Folmer et al. 2014). In contrast, subtidal beds and to some extent intertidal beds at exposed locations are often described as ephemeral as a result of sea star predation or dislodgement during storms (Nehls \& Thiel 1993, Reusch \& Chapman 1997, Beadman et al. 2003, Agüera 2015). Indeed, there are concerns on the impact of mussel culture on subtidal seed beds, specifically to what extent fishery prevents the development of viable subtidal mussel beds (Dankers \& Zuidema 1995, Kaiser et al. 1998, Asmus \& Asmus 2002, Lotze et al. 2005). Yet, factors determining the resilience of subtidal mussel beds are often unknown and the effects of extensive aquaculture on the population dynamics of subtidal mussels are not clear (Commito \& Dankers 2001, Nehls et al. 2009).

In this study we address which factors determine the population dynamics of subtidal mussels and in how far the total (natural plus cultured) subtidal mussel biomass in the system is affected by fishery practices, such as mussel seed dredging, relaying and subsequent harvest. We compare mussel biomass development on both natural beds and culture plots within the western Wadden Sea, the largest mussel bottom culture area in Western Europe. Culture takes place on 7700 ha of leased culture plots, of which 4000 ha is effectively used by about 60 mussel-producing companies. The Wadden Sea is also a globally important area for nature conservation (N200o). Mussel seed in the Wadden Sea is traditionally dredged from subtidal natural beds and translocated to culture plots within the same system. A substantial amount of mussel seed is also obtained from floating seed mussel collectors (SMCs). 
Here, we test whether mussel culture is an important factor in determining the population dynamics of the subtidal mussel population, because, due to management measures by the farmers, cultured mussels display higher growth and survival rates than mussels on natural subtidal beds that are subject to predation, physical factors such as waves and currents, and low site specific recruitment. Mussel cohort dynamics on natural mussel beds and on culture plots were monitored over time. To test differences in growth and survival, mussel cohorts on natural mussel beds and culture plots were monitored for 6 years and 4 years respectively, results are integrated in a biomass production model, to compare mussel biomass development between natural and cultured mussel populations.

\subsection{Methodology}

\section{Study area}

The Wadden Sea is a shallow intertidal area of about $6000 \mathrm{~km} 2$, stretching over three countries, The Netherlands, Germany and Denmark. It is separated from the North Sea by a range of barrier islands and from the mainland by dikes. The western part of the Wadden Sea (Figure 6.1) is a very dynamic area, which receives a yearly average fresh water input of ca. $450 \mathrm{~m}^{3} \mathrm{~s}^{-1}$ from lake IJssel (Duran-Matute et al. 2014) and connects to the North Sea through three major inlets (Marsdiep, Eierlandse gat and Vliestroom) in the north. The water volume exchange between the different tidal basins of the Wadden Sea is limited compared to the volume exchanged with the North Sea (Ridderinkhof et al. 1990). All mussel culture plots in the Dutch Wadden Sea are found in the western part (Figure 6.1a). 


\section{Chapter 6}
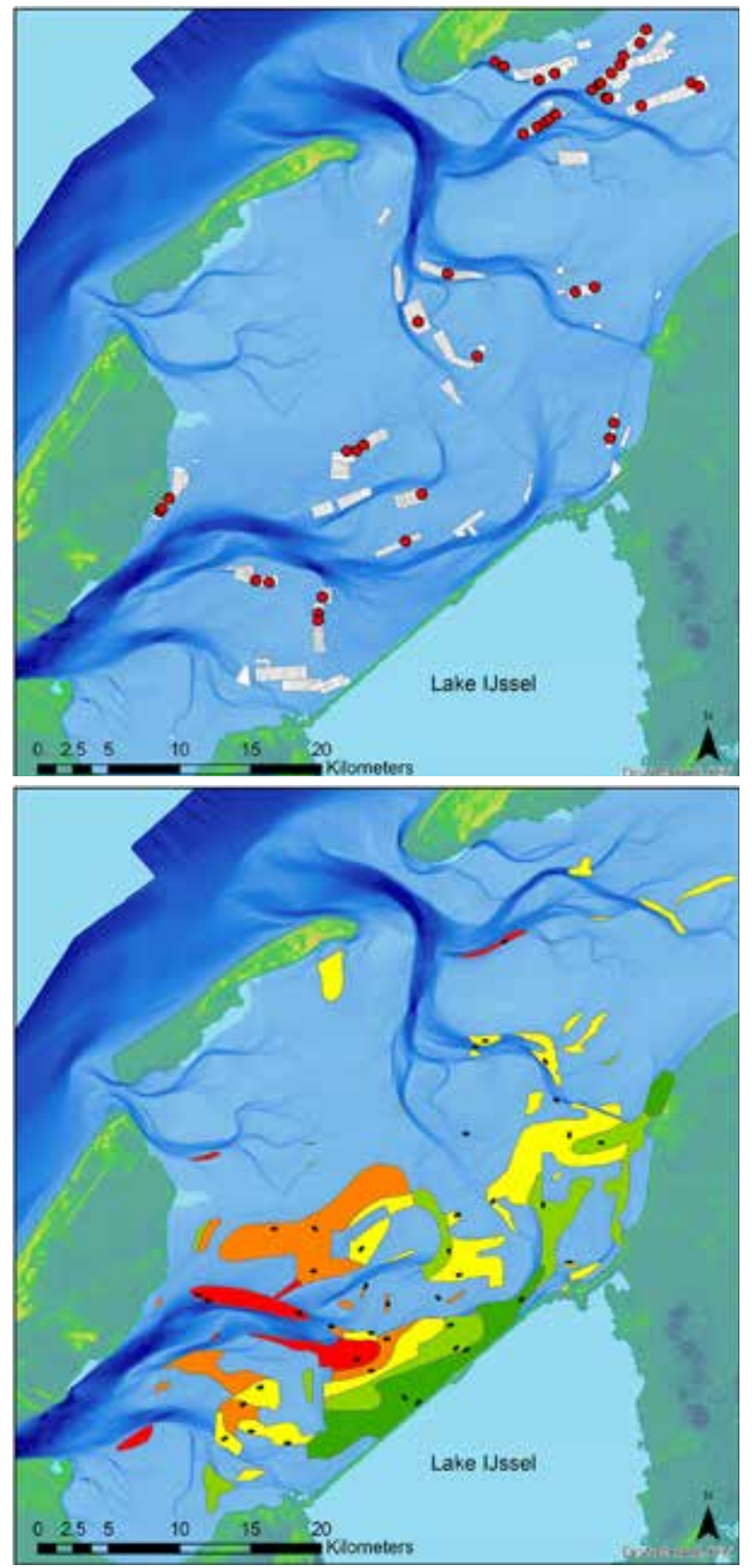

Figure 6.1a Map of areas with culture plots, dots show sampling locations b Map of areas where natural subtidal mussel beds are regularly formed, including five classes of relative stability (Alterra 2005) based on expert judgment, where red, being relatively stable, to green, being relativity unstable, black dots are experimental 8 ha plots 


\section{Chapter 6}

Figure 6.1b (Alterra 2005) displays the areas in the same system where subtidal natural mussel beds were regularly observed from 1992-2005. Fishery on natural mussel beds is carried out in autumn and spring, and collects small ('seed') mussels to be relayed on the culture plots. Culture plots are located in areas where natural seedbed formation seldom occurs, since farmers like to avoid spat fall on culture plots, because it causes an undesirable mixing of different size classes. As a result, culture plots are spatially separated from areas where the majority of natural mussel beds are found (Figure 6.1). Natural mussel populations are found in areas with lower salinities (close to lake IJssel - Marsdiep area) whereas the majority of the culture plots are located in areas with higher salinities (Close to the North Sea -Vlie area) (Drent \& Dekker 2013). Suspended particulate matter (SPM) is also higher in Marsdiep area compared with Vlie area (on average respectively about $50 \mathrm{~g} \mathrm{~m}^{-3}$ and $30 \mathrm{~g} \mathrm{~m}^{-3}$, Figure 9 in De Jonge et al. (1996)), because of discharges from lake IJssel (De Jonge \& De Jong 2002).

\section{Sampling of natural subtidal mussel beds}

Growth and specific loss rates of mussel populations on natural subtidal beds were determined from a sampling program designed to investigate the effects of mussel seed fishery on biodiversity and natural mussel stock (Van Stralen et al. 2013).

Natural mussel seed beds originate from natural spat fall and appear during summer. In autumn of every year from 2006-2009, all newly formed mussel seed beds were studied by the creation of experimental plots of 8 ha in the newly established mussel seed bed (Figure 6.1b). The experimental plots were split in two (split-plot design), with one half ( $4 \mathrm{ha}$ ) closed and the other half open for mussel seed fishery. Within the two $200 \times 200 \mathrm{~m}(4 \mathrm{ha})$ subplots inside the experimental plot, a buffer zone of $50 \mathrm{~m}$ was created at the edges, leaving an 


\section{Chapter 6}

area of $100 \times 100 \mathrm{~m}$ in the centre of the subplots. In total 40 experimental plots were created this way. Sampling was carried out in the period 2006-2012 and continued beyond 2012 until the natural beds formed between 2006 and 2012 were all gone. In the present study only data collected between 2006 and 2012 are used. This set-up provided large scale quantitative information on mussel growth and specific loss rates on plots closed for fishery, which can be seen as representative for all major natural seedbeds formed in the western Wadden Sea between 2006 and 2012.

Sampling of experimental plots was done with a suction dredge or, when water depth was more than 8 meter, with a trawled dredge. Two transects of about 100 x $0.2 \mathrm{~m}$ (suction dredge) or about 100 x $0.1 \mathrm{~m}$ (trawled dredge) each, were sampled per experimental subplot open for fishery and similarly two similar sized transects per closed subplot. Actual sampling track lengths were measured with handheld GPS for the suction dredge, while a rotating wheel with a magnetic counter was used for the trawled dredge. Experimental plots within new seedbeds or on which a new seedbed was re-established during the course of the experiment were always sampled before and after fishery in autumn and spring. Experimental plots with mussels aged $>1$ year were always sampled in spring. In the majority of cases only one year-class remained per experimental plot. However, when new spat fall occurred on an existing plot, separate year-classes were considered in the analysis. An extensive schedule of sampling events per location can be found in the study of Van Stralen et al. (2013).

Average mussel density and mussel biomass per square meter was calculated by dividing total number of mussels and total mussel wet weight by sampled area. Year-classes of mussels used in the present study were followed by this method until April 2012.

We assume that sampled plots are representative for the natural beds on which 
the plots were created. Hence, fishing activities around the area (4 ha) closed for fishery should not have a measurable effect on the experimental plots. This was tested by Van Stralen et al. (2013) by investigating gradients in mussel density on a $50 \mathrm{~m}$ buffer zone and on a $100 \times 100 \mathrm{~m}$ inner plot. In this analysis, it was assumed that if fishing activities had any effect on mussels in experimental plots closed for fishery, it would have created gradients in mussel density from the edge to the middle of the plot. Results of the analysis showed that no such patterns could be found and suggests no effect of fishing activities in the area surrounding the plots closed for fishery.

\section{Sampling of subtidal culture plots}

Estimates of mussel growth and mortality rates from culture plots were obtained from a sampling program in which 66 mussel cohorts were followed over time on 42 different culture plots in the western Wadden Sea using a methodology published by Capelle et al. (2016). Mussels on the plots originated from fishery on natural beds $(\mathrm{n}=29)$ and from seed harvested from submerged SMCs $(\mathrm{n}=$ $22)$, or with seed relayed from other culture plots $(n=15)$.

\section{Data analysis}

\section{Growth}

A von Bertalanffy growth function (VBGF), with sinusoidal correction for seasonal temperature fluctuations (Somers 1988) was fitted to the length measurements $(\mathrm{L}, \mathrm{mm})$ from the culture plots and natural seed beds:

$$
L_{t}=L_{\infty}\left(1-e^{-\left[K\left(t-t_{0}\right)+S(t)-S\left(t_{0}\right)\right]}\right), \text { with } S(t)=\frac{C K}{2 \pi} \sin \left(2 \pi\left(t-t_{s}\right)\right) \quad \text { Equation 6.1) }
$$

with $\mathrm{K}$ as growth coefficient, $\left(\mathrm{d}^{-1}\right), \mathrm{L}_{\infty}$ the asymptotic length $(\mathrm{mm}), \mathrm{L}_{\mathrm{t}}$ the length $(\mathrm{mm})$ at age $\mathrm{t}(\mathrm{d}), \mathrm{C}$ as constant (-) determining magnitude of 


\section{Chapter 6}

oscillation, $\mathrm{t}_{\mathrm{s}}$ defining beginning of sine wave (with a wave length of one year) and $t_{o}$ theoretical age where $L_{t}$ is zero (Somers 1988). Fitting the model to the measured length data with Equation 1 was achieved by a generalised nonlinear least square routine, GNLS, from the nlme library (Pinheiro et al. 2014) for the software R (R Core Team 2016), by which heterogeneous errors were accounted and assumptions of the full model (fitted on data from natural beds and culture plots together) were met by the data.

Growth between mussels on natural beds and culture plots are compared following the likelihood methodology of Kimura (1980) and its implementation in Ogle (2015a), with the help of the FSA package for R (Ogle 2015b). In this method a complex model with all parameters of the VBGF different for natural beds and culture plots are compared to simpler nested models, with one or more VBGF parameters in common. Models are compared with a likelihood ratio test and this process stops when a more complex model is significantly different from every simpler nested model. Resulting best model was fitted to the data over a period of 2.5 years, because mussels on culture plots were not followed for longer than 2.5 years.

\section{Mussel loss}

Specific loss rates (r, d-1) of the mussels on the natural mussel beds and culture plots, were calculated by the change in mussel density $\left(D, \# m^{-2}\right)$ over time $(t, d)$ assuming an exponential population decline. Specific loss rates were calculated as the change in mussel density found between the first sampling $\left(D_{1}\right)$ and subsequent second sampling $\left(\mathrm{D}_{2}\right)$, with t as time interval in days.

$r=-\frac{\ln \left(D_{2}\right)-\ln \left(D_{1}\right)}{t}$

(Equation 6.2)

Densities of mussels older than 2.5 years were excluded from the analysis, because mussels on culture plots were not followed for longer than 2.5 years. 


\section{Chapter 6}

Measurements were excluded from the analysis if both $\mathrm{D}_{1}$ and $\mathrm{D}_{2}<10$ ind $\mathrm{m}^{-2}$ to prevent inflation of $\mathrm{r}$. Average mussel length () was calculated for each $\mathrm{r}$ as: $\left(\mathrm{L}_{2}-\mathrm{L}_{1}\right) / 2$, with $\mathrm{L}_{1}$ and $\mathrm{L}_{2}$ corresponding to $\mathrm{D}_{1}$ and $\mathrm{D}_{2}$ respectively. Culture plots are located in areas with higher salinity, while natural mussel beds are found in areas where average salinity is lower with more fluctuations (Drent \& Dekker 2013 \& Figure 7.2 in Agüera et al. 2015). Annual average salinity values for each culture plot and for each experimental plot on the natural beds were calculated (data RIKZ, Haren, summarized in Figure 6.2). Salinity in the Wadden Sea shows seasonal fluctuations, with lowest values in Winter and highest values in Summer, in van Aken (2008) maximum and minimum values in the Marsdiep area (western part of the Wadden Sea) differed by ca. $2 \mathrm{mg} \mathrm{l}^{-1}$.

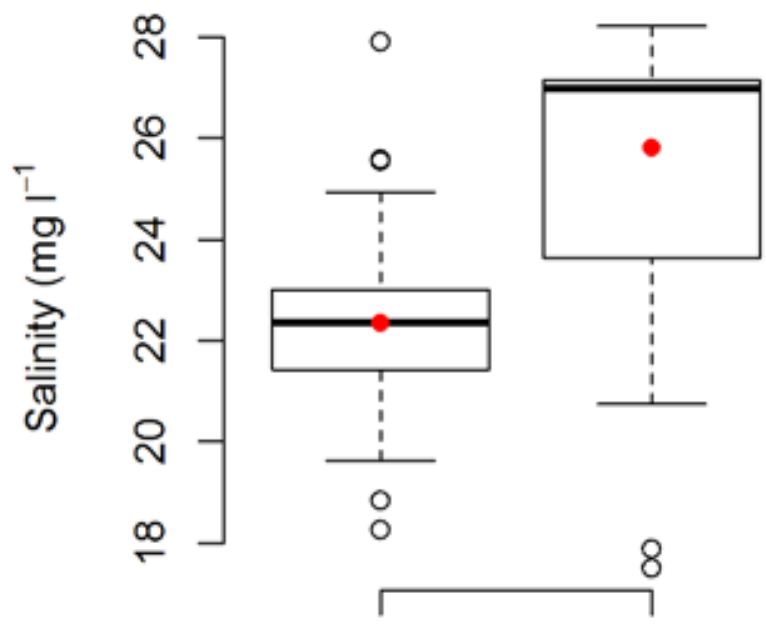

Natural beds Culture plots

Figure 6.2 Boxplot with averaged yearly salinity values for natural mussel beds and culture plots that were sampled in this study, red dots represent mean values (data RIKZ, Haren) 


\section{Chapter 6}

Specific loss rates as a function of salinity and were investigated for natural mussel populations and for mussel on culture plots. We used a generalized least-squares (GLS) model with the varIdent function in R allowing for different variances for each type (Pinheiro et al. 2014).

Spatial variation in specific loss rates were visualised by plotting $r$ in graduated symbols on a map of the area for culture plots and natural beds respectively. Spatial variation in salinity is indicated in the same map with contour lines.

\section{Biomass}

Biomass $\left(\mathrm{B}, \mathrm{kg} \mathrm{m}^{-2}\right)$ on culture plots and natural mussel beds is simulated over time, using the output of Equation 1 and 2 as:

$$
B_{t}=W_{t} \cdot D_{t}
$$

With $\mathrm{W}_{\mathrm{t}}(\mathrm{g})$ obtained by converting mussel length as output of Equation 1 to mussel wet weight according to: (Capelle et al. 2016). $\mathrm{D}_{\mathrm{t}}$ was obtained from change in mussel density over time:

$$
D_{t}=D_{0} \cdot e^{-r t}
$$

(Equation 6.4)

With $r$ as either $r_{\text {culture }}$ or $r_{\text {natural }}$ as a constant, or as function of length and salinity when regression analysis indicated a significant relation. Additionally, the loss is corrected for density-dependent seeding loss estimated by:(Capelle et al. 2016), where $D_{t 1}$ is mussel density on the culture plot after seeding, and $D_{\text {seed }}$ is seeding density. So, total mussel loss on culture plots is the combination of $\mathrm{r}_{\text {culture }}$ and a density depending loss directly after seeding. 


\section{Chapter 6}

\subsection{Results}

Data is summarized in Figure 6.3, with the biomass distribution $\left(\mathrm{g} \mathrm{m}^{-2}\right)$ of mussels at the subsequent sampling moments on natural mussel beds and on culture plots.

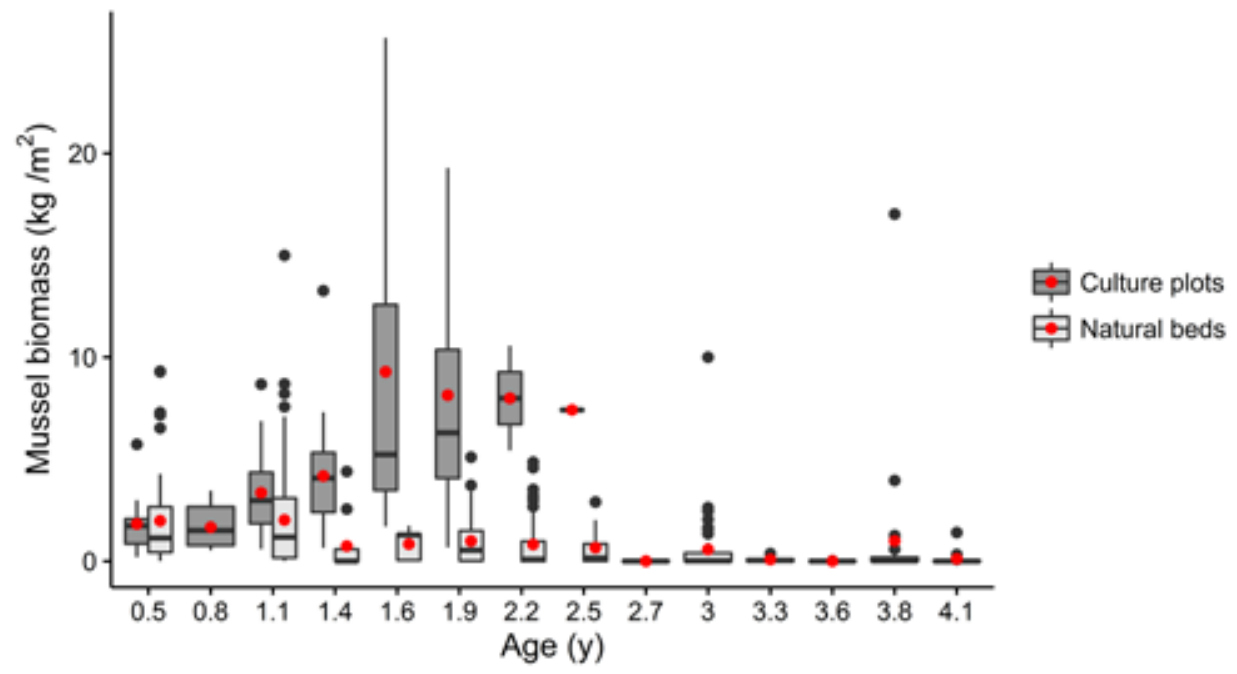

Figure 6.3 Box-an-whiskers plot of accumulated mussel biomass found on culture plots and on natural mussel beds in the Wadden Sea for different mussel ages, reference date of age 0 is April $17^{\text {th }}$, red dots represent mean values.

\section{Mussel growth}

The likelihood ratio test between VBGF with separate versus common parameters for mussel growth provides evidence that VBGF parameters differ between mussels on natural beds and mussels on culture plots. The most parsimonious model had separate VBGF parameters $\mathrm{L}_{\text {inf }}$ and $\mathrm{C}$ between groups (Table 6.1). The difference between this 'best model' and the model with all VBGF parameters in common $\left(X^{2}=108.69, \mathrm{p}<0.001\right)$ confirms that differences between groups exist and that the difference is only evident for the $\mathrm{L}_{\mathrm{inf}}$ and $\mathrm{C}$ 


\section{Chapter 6}

parameters in Equation 6.1.

Table 6.1 Estimated parameters of the VBGF for culture plots and natural mussel beds

\begin{tabular}{lllll}
\hline \multicolumn{1}{c}{ VBGF } & \multicolumn{2}{c}{ Culture plots } & \multicolumn{2}{c}{ Natural mussel beds } \\
Parameter & Estimate & Std. error & Estimate & Std. error \\
\hline $\mathrm{L}_{\infty}$ & 69.86 & 2.28 & 60.20 & 1.59 \\
$\mathrm{~K}$ & 0.82 & 0.072 & 0.82 & 0.072 \\
$\mathrm{t}_{\mathrm{o}}$ & 0.13 & 0.029 & 0.13 & 0.029 \\
$\mathrm{C}$ & 0.95 & 0.11 & 0.68 & 0.096 \\
$\mathrm{~T}_{\mathrm{s}}$ & 0.19 & 0.018 & 0.19 & 0.018 \\
\hline
\end{tabular}

Growth fitted with two VBGFs for natural mussel beds and culture plots, with parameter estimates from Table 6.1, is displayed in Figure 6.4. Cultured mussels reached a higher asymptotic length and a faster growth than mussels on natural beds. The length difference between the two groups was in the order of $20-25 \%$

\section{Mussel loss rate}

Average specific loss rate for natural beds was $r_{\text {natural }}=1.05 \cdot 10^{-2} \pm 1.40 \cdot 10^{-2}(\mathrm{sd})$. However, for the natural mussel population, loss rate was significantly related with shell length and salinity (Figure 6.5), with negative linear relation between specific loss rate and shell length: $\mathrm{r}_{\text {natural }}=-2.65 \cdot 10^{-4} \cdot L+1.95 \cdot 10^{-2}$ (with std. error slope $=9.0510^{-5}$, std. error intercept: $\left.3.6310^{-3}, p=0.004, R^{2}=0.05\right)$ and a positive linear relation with annual averaged salinity according to: $r_{\text {natural }}=2.96 \cdot 10^{-3}$ $\cdot$ Salinity $-5 \cdot 57 \cdot 10^{-2}$ (with std. error slope $=6.77 \cdot 10^{-4}$, std. error intercept: $1.49 \cdot 10^{-2}$, $\left.p<0.001, R^{2}=0.11\right)$. No such relation was found for mussels on culture plots. The averaged specific loss rate for the culture plots was $r_{\text {culture }}=2 \cdot 71 \cdot 10^{-3} \pm 5 \cdot 01 \cdot 10^{-3}(\mathrm{sd})$. 


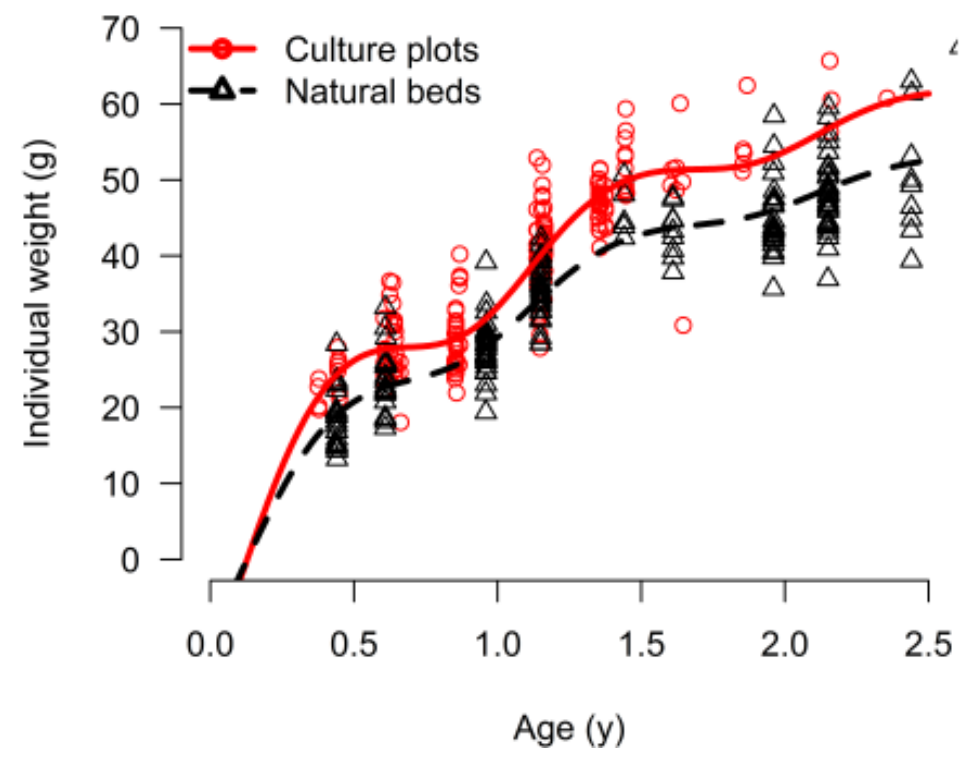

Figure 6.4 Mean individual mussel weight from culture plot sampling (2009-2012) and natural mussel bed sampling (2006 - 2012), data are fitted with a von Bertalanffy growth equation with sinusoidal correction for season oscillations.

The effects of shell length $(L)$ and salinity on specific loss rate for the natural mussel population were further investigated using a combined model, according to: $\mathrm{r}_{\text {natural }}=\mathrm{a}+\mathrm{b} \cdot L+\mathrm{c} \cdot$ Salinity $+\mathrm{d} \cdot L \cdot$ Salinity, with estimated coefficients (std. error): $a=-0.16\left(4.70 \cdot 10^{-2}\right), b=2.80 \cdot 10^{-3}\left(1.18 \cdot 10^{-3}\right), c=8.23 \cdot 10^{-3}\left(2.10^{\circ} \cdot 10^{-3}\right), d=$ $-1.37 \cdot 10^{-4}\left(5.26 \cdot 10^{-5}\right)$. 


\section{Chapter 6}
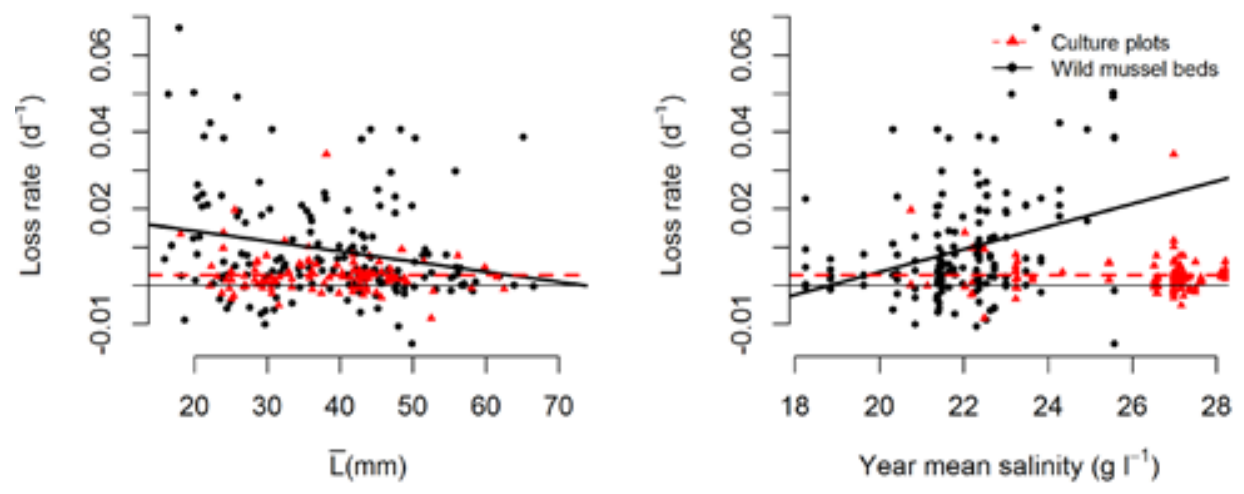

Figure 6.5a Relation between specific loss rate and mean length of the mussels in the corresponding time interval. b. relation between specific loss rate and annual averaged salinity of the sampling location. Both relations are significant for natural mussel beds, but not for culture plots.

Table 6.2 Statistical result of ANOVA performed to examine relation between specific loss rates on natural mussel beds with shell length and salinity and their interaction, $\mathrm{df}=\mathrm{degrees}$ of freedom, $*=0.01 \leq \mathrm{p}<0.05 ; * *=0.001 \leq \mathrm{p}<0.01 ; * * *=\mathrm{p}<0.001$

\begin{tabular}{llrrl}
\hline Variable & df & \multicolumn{1}{c}{ MS } & F & \multicolumn{1}{c}{$\mathbf{p}$} \\
\hline & 1 & $1.5610^{-3}$ & 10.09 & o.002 $^{\text {** }}$ \\
$S$ & 1 & $3.3610^{-3}$ & 21.72 & $<0.001^{* * *}$ \\
$L: S$ & 1 & $1.0610^{-3}$ & 6.83 & $0^{*} .01^{*}$ \\
Residuals & 152 & $1.5510^{-4}$ & & \\
\hline
\end{tabular}

The significance of the model parameters was tested with an analysis of variance (ANOVA), the results of which are summarized in Table 6.2. Shell length (L) and Salinity were very weakly correlated $(\mathrm{r}=-0.05)$. Specific loss rate from plots on natural mussel beds (Figure 5 ) shows a general pattern that is very similar to the map of annual mean salinity (Duran-Matute et al. 2014) while for culture 


\section{Chapter 6}

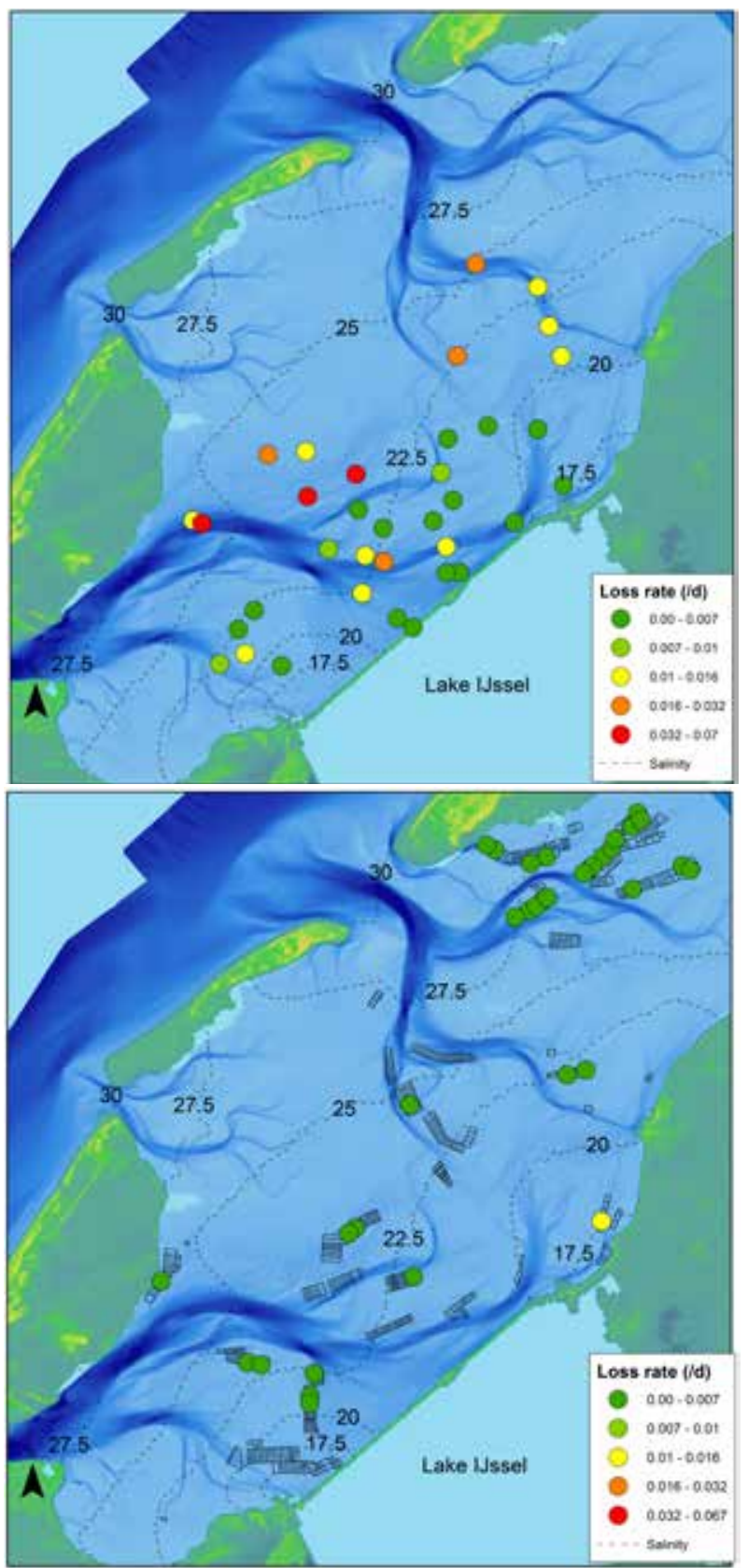

Figure 6.6a Spatial patterns in mussel loss $\left(d^{-1}\right)$ per natural mussel bed, showing only sampling stations that were used in the analysis. b Average specific loss rates per $=$ culture plot, that were used in the analysis according to the same legend as in 'a'. Annual averaged salinity is indicated with contour lines 


\section{Chapter 6}

plots no obvious spatial relation appeared, although mussel losses seem a little higher towards lake IJssel, than towards the North Sea (Figure 6.6). Salinity contours on the map confirm that no viable natural mussel populations were found at high salinity zones, or at the extreme low salinity zones $(<17.5 \mathrm{mg}$ $\left.\mathrm{l}^{-1}\right)$, while the majority of the cultured population is found within the higher salinity zones.

\section{Biomass simulation}

A biomass simulation with $1 \mathrm{~kg} \mathrm{~m}^{-2}$ of mussel seed on culture plots over time was performed based on VBGF growth parameters found for culture plots (Figure 6.7) and with a constant specific loss rate of $2.7110^{-3} \mathrm{~d}^{-1}$ (Figure 6.7). Seeding mortality results, on average, in a loss of $28 \%$ of the mussel seed. This causes the initial biomass on culture plots to be lower than on natural beds.

A biomass simulation of $1 \mathrm{~kg} \mathrm{~m}^{-2}$ of mussel seed on a natural mussel bed over time was performed with specific loss rate related to salinity and to shell length and with shell length estimated from the VBGF with parameters for the natural mussel population (Table 6.1). In Figure 6.7 an average biomass simulation is plotted with $r_{\text {natural }}$ estimated by using the average salinity of all sampled plots on natural mussel beds $\left(22.35 \mathrm{mg} \mathrm{l}^{-1}\right)$. The average biomass on natural mussel beds shows a continuous decrease, whereas an overall increase of biomass is predicted for culture plots, this is also evident from observations (Figure 6.3). Both curves intersect after about 90 days after 'seeding' (at a mussel age of 240 days), around the end of the year, when mussels are still in their o year-class. In the following spring season, increase in growth rates on culture plots, and especially lower mortality on these plots compared to natural beds, cause a divergence of the curves. 


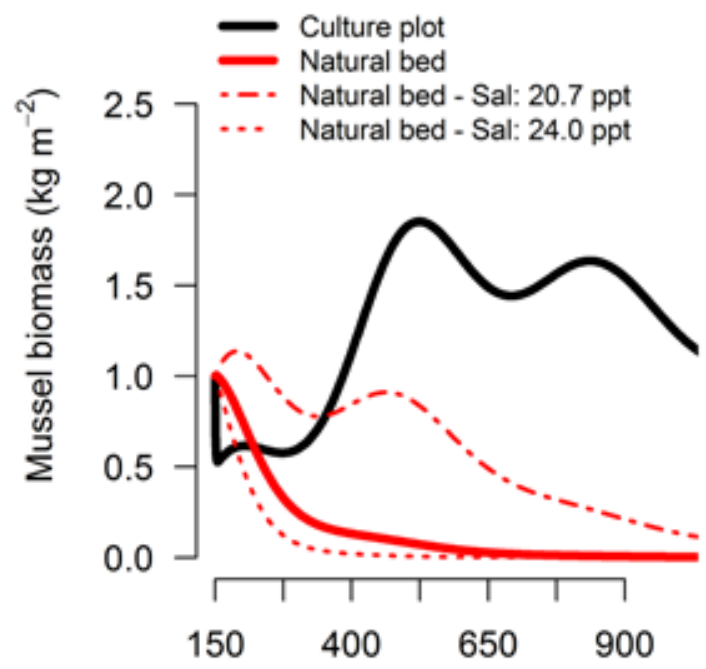

Mussel age (d)

Figure 6.7 Simulation of mussel biomass, with average loss and growth values calculated from sampling on natural mussel beds and culture plots, including seeding (handling) loss on culture plots; same state variables are used for natural mussel beds and culture plots, dotted lines represent biomass simulations for natural beds with the lower value (mean-sd $20.7 \mathrm{mg} \mathrm{l}^{-1}$ ) and upper value (mean+sd: $24.0 \mathrm{mg} \mathrm{l}^{-1}$ ) salinity distribution from all natural beds (mean: $22.4 \mathrm{ppt}$ )

The dotted lines in Figure 6.7 represent biomass simulation for natural beds with relatively low salinity (mean $-\mathrm{sd}=20.7 \mathrm{mg} \mathrm{l}^{-1}$ ) and relatively high salinity (mean $+\mathrm{sd}=24 \mathrm{mg} \mathrm{l}^{-1}$ ). At low salinity, mussel biomass development is similar to development on culture plots, but with a decreasing trend. At high salinity, loss processes dominate and the biomass shows a fast exponential decline. These results demonstrate the high sensitivity of mussel biomass development to salinity, caused by the relation between loss rate and salinity. 


\section{Chapter 6}

\subsection{Discussion}

The sampling program on culture plots was dependent on cooperation with the mussel farmers and followed their activities. On natural mussel beds monitoring was set-up to test fishery effects, sampling was limited to natural beds in the areas where they were established. Because of these limitations an experimental approach was not feasible. For example, it would have been interesting to experimentally manipulate mussels in the natural populations (relay seed, control for predation), in order to determine the pure effects of location, salinity and predation control in natural and culture plots. This manipulation, however, was not permitted. Nonetheless, the combined sampling programs made it possible to collect a considerable amount of unique data on subtidal mussels populations from natural beds and from culture plots. Both populations were compared and results give insight in the survival, growth and impact of cultivation in the dynamics of subtidal mussel populations.

Factors that determine mussel survival on natural mussel beds and culture plots

There are no indications that the lack of recruitment in the high-salinity zone where the culture plots are located, is caused by a lack of larvae in the water or by a lack of natural spat fall. Harvest from mussel seed collectors at various locations shows that spat fall does occur on a yearly basis outside the seed bed establishment areas. Also the availability of substratum is not a limiting factor (Brinkman et al. 2002). Extensive research mostly on intertidal mussel populations showed that the survival of soft bottom mussel beds in their early phase depends on the magnitude of physical disturbance and predation pressure (Seed \& Suchanek 1992, Nehls \& Thiel 1993, Hilgerloh et al. 1997, Reusch \& Chapman 1997, Herlyn \& Millat 2000, Brinkman et al. 2002, Beukema \& Dekker 2007, Van der Heide et al. 2014). 


\section{Chapter 6}

In general, the areas where the culture plots are located, are subject to stronger current and wave action than the areas where most of the natural mussel beds are found, as dominant winds are from SW in the Wadden Sea, and best performing natural beds are found in areas protected for long-fetch waves such as areas at the downstream end of the tidal channel system (Figure 6.1). The higher survival rate on the culture plots cannot be attributed to higher physical disturbance on natural mussel beds. Furthermore, in the present study mussel survival was monitored when seedbeds were already established. Mussel seed on these beds have reached a size refuge against predation by fish and shrimps that are major predators on newly settled mussel spat (Dare, Beukema et al. 1998b). Also the impact of crab predation reduces with mussel size (McGrorty et al. 1993, Murray et al. 2007b). Sea star (Asterias rubens) predation, however, is a very likely cause for the spatial pattern in survival success in the natural beds (Figure 6.6). Notably, a reduction in salinity results in a reduction of sea star feeding activity, or can even diminish the effects of sea stars completely (Agüera et al. 2015). Sea stars can wipe out entire mussel beds in a short period of time (Kristensen \& Lassen 1997, Agüera 2015), but are less tolerant to changes or low values in salinity than mussels are (Binyon 1976, Shumway 1977, Saranchova \& Flyachinskaya 2001). Monitoring data, published in (Ens et al. 2007) and summarized in Figure 7.2 and 7.3 in (Agüera 2015), showed that the frequency of sea stars in a sample (y) increased with salinity $(\mathrm{x})$ according to the power function: $y=0.00016 x^{1.34}$. Abundance of sea stars in the study area is lower in winter, which is attributed to the lower salinity in winter (Agüera 2015). High temporal fluctuations in salinity occur in regions where water from Lake IJssel enters the Wadden Sea (Duran-Matute et al. 2014). Areas with high temporal fluctuations in salinity are the areas where we find natural mussel beds (Figure 6.6). Especially further away from these fluctuations at higher salinities, natural subtidal mussel beds were absent or only survived for a short period (Van Stralen et al. 2013). Hence, better survival of mussels on natural beds in 


\section{Chapter 6}

the vicinity of fresh water inputs is explained by the lower sea star predation pressure in these areas.

Culture plots are located in areas with substantially higher salinities (Figure 6.6 and Figure $6.5 \mathrm{~b}$ ), but are less affected by sea star predation, because sea stars are actively removed by the mussel farmers (Barkhouse et al. 2007). This is also observed in other culture areas. Sea stars are found in large numbers on mussel beds in areas where mussel bottom culture or mussel fishery is practiced: in Wales (Gallagher et al. 2008), the German Wadden Sea (Saier 2001), and Denmark (Kristensen \& Lassen 1997). In these areas sea star control is common practice.

For large mussels (around $6 \mathrm{~cm}$ shell length) the survival is similar in natural subtidal beds and culture plots (Figure 6.5a). The positive relation between mussel length and survival in natural mussel populations can be the result of a reduction in sea star predation pressure when mussels are larger (Sommer et al. 1999). Survival of a natural bed would require the bed to pass through the bottleneck of intense predation during several years, which despite their location in low-salinity zones has a low probability (see generally higher loss rate of natural beds in Figure 4, but note that some natural beds do have low loss rate). It can be hypothesized that size-dependence could lead to persistence of the natural beds once a threshold of size-dependent predation is passed. Interestingly, the relation between mussel length and survival was not found on culture plots, which is consistent with the hypothesis that the presence of sea stars promotes length-dependent increase in survival. Similar effects were suggested for the relation between the starfish Pisaster ochraceus and the mussel $M$. californianus, where the coexistence of predator and prey was only possible when mussels reach a size refuge against sea star predation (Paine 1976b). The Pisaster-Mytilus relation (in Washington state USA), is similar to the AsteriasMytilus relation (NW Europe), to the extent that it regards subtidal populations, 
with dynamics that are determined by predation and physical disturbance. Furthermore, Asterias seems to have the same keystone predatory function on M. edulis as $P$. ochraceus has on M. californianus (Paine 1976a, Agüera 2015). The mechanism is worked out by Menge and Sutherland (1987), assuming that environmental stress has a higher impact on mobile consumers than on sessile organisms. Their theory predicts that in high stress environments (e.g. at low salinities) consumers and sessile organisms are absent or not active. In more moderate environments, sessile organisms are less affected by environmental stress than consumers, resulting in the establishment of sessile populations. In benign environments, sessile organisms can only thrive when they pass through an intense predation bottleneck. This theory is consistent with the Asterias-Mytilus relation in the Wadden Sea, where mussel populations can most likely only persist in benign environments if they pass the predation bottleneck through mediation of the mussel farmer. Furthermore, Figure 6.6 shows that viable mussel populations were also absent at the very low saline regions $\left(<17.5 \mathrm{mg} \mathrm{l}^{-1}\right)$. Yet, the outcome of the long-term monitoring on the plots closed to fishery is that all mussels have disappeared in a period of 7 years (Van Stralen et al. 2015). Therefore, the question remains to what extent longer term survival of a natural mussel population in the subtidal zone of the Western Wadden Sea is probable. In the period when natural beds were monitored, large scale recruitment regularly resulted in new mussel seed beds (Van Stralen et al. 2015). When frequent recruitment on older mussel beds does not take place, the longevity of a cohort is limited, in our study to about 7 years. Hence, the long term survival of subtidal natural mussel populations appears recruitment driven.

On culture plots, other loss factors may be more dominant than sea star predation, such as loss associated with relaying or density dependent losses (Gascoigne et al. 2005, Capelle et al. 2016). The loss rate of mussels surviving the initial seeding is uncorrelated with length or salinity, and is notably less 


\section{Chapter 6}

variable than loss rate in natural beds (Figure 4). This constancy may be the result of measures by mussel farmers (e.g. adjusting seeding density, mud removal), and are reflecting the quality-based selection of the culture plots.

\section{Effects of relay on mussel growth}

Figure 6.4 and underlying data indicate that growth rates of natural mussels, even when they persist for longer periods, is lower than on culture plots. This is ascribed to lower salinity and a higher turbidity near lake IJssel (Piersma \& Camphuysen 2001, De Jonge \& DeJong 2002, Drent \& Dekker 2013, Duran-Matute et al. 2014) that can both or jointly reduce growth. Mussels remain smaller and display low growth rates at places where salinity is low or strongly fluctuating (Bøhle 1972, Almada-Villela 1984, Gruffydd et al. 1984, Westerbom et al. 2002, Riisgård et al. 2012, Riisgård et al. 2013). However, in Maar et al. (2015) significant reductions in growth were only observed at salinity values below $15 \mathrm{mg} \mathrm{l}^{-1}$. This value is well below the average values found at the mussel bed locations (Figure 6.2); we therefore expect that differences in growth are more related to spatial differences in food quality. Spatial variability in chlorophyll a in the Marsdiep basin is not very well described, but appears to be limited, based on long-term monitoring data of Rijkswaterstaat. It is expected that variability in food quality mainly depends on the spatial variability in suspended particulate matter (SPM), as the ratio of chlorophyll a to SPM is a well-documented measure of food quality. Hawkins et al. (1996) found that mussels are able to cope with high silt concentrations and mussels can adapt to (short term) changes in siltrelated food quality, by altering their feeding behaviour (Bayne 1998, Hawkins et al. 1998). This adaptability was demonstrated for a range of SPM levels (10$90 \mathrm{mg} \mathrm{l}^{-1}$ ) that is very similar to the natural range reported for the Marsdiep area in the Wadden Sea (De Jonge et al. 1996). Although mussel populations can persist under these conditions, inorganic matter reduces food quality and thus mussel growth rates in shellfish production (Newell et al. 1998, Scholten 
\& Smaal 1999). Furthermore, high SPM levels can reduce primary production in estuaries by limiting light penetration through the water column (Wilson 2002).

\section{Impact of cultivation}

Traditional culture relies on the relay of mussel seed from natural mussel beds to culture plots. Results point out that culture potentially leads to an increase of mussel biomass within the Wadden Sea. Mussels from culture plots are harvested after they reach market size, or even before when transplanted to culture plots outside the Wadden Sea, notably the Oosterschelde, resulting in a short turnover time of mussel biomass. Nonetheless, it was estimated over the period 2004-2012 that mussel culture for this period results on average in 1.27 times more mussels than there would be in the absence of culture, in a study based on a budget calculation approach using mussel stock estimations, seed fishery statistics, harvest and transplantation data (Wijsman et al. 2014). An increase in mussel biomass may reduce the carrying capacity of the system for (other) shellfish, such as cockles, an important food source for birds. Model calculations in Kamermans et al. (2014) predicted that when mussel numbers increase because of an increase in mussel seed collectors, some negative effect on shellfish biomass can be expected for confined areas in the western Wadden Sea, although due to spatial differences in the distribution of shellfish stocks effects are less probable for areas where culture plots are located.

Bivalve aquaculture is providing ecosystem goods and services (Smaal et al. 2001a, Newell 2004, Saurel et al. 2014, Ferreira \& Bricker 2016). These include among others, reducing eutrophication, increase water column visibility and provide habitat and food for higher trophic levels (Suchanek 1992, Inglis \& Gust 2003, Newell \& Koch 2004, Rönnbäck et al. 2007, Diana 2009). A healthy mussel population, by means of extensive mussel culture supports more 


\section{Chapter 6}

subtidal biodiversity, and provides a food source for birds (Buschbaum et al. 2009, Ysebaert et al. 2009). In fact species richness on subtidal culture plots in the western Wadden Sea was not lower than on natural mussel beds (Drent \& Dekker 2013), but this study noted that species richness generally increased with salinity, so that the effect could partly be caused by the higher salinity at the location of the culture plots, compared to the natural beds. Furthermore, cultured mussels are a suitable food source for birds not only because of the size of the stock, but also because better growth conditions on culture plots will result in mussels with more meat (Capelle et al. 2016). Consistently, bird counts confirm that culture plots are vital foraging grounds for eider ducks (Smaal et al. 2010, Cervencl et al. 2015). Eider ducks prefer medium and large sized mussels above other food sources and are therefore also an important predator on culture plots, annual mussel consumption from culture plots between 2008 and 2011 was estimated to range between 4.5 and $8.2 \mathrm{Mkg}$ fresh weight mussels (Cervencl et al. 2015).

\section{Conclusions}

Survival of mussels on natural beds in the Wadden Sea was lower than on culture plots except for larger mussel sizes that probably reached a size refuge for predation. Survival of natural mussel populations decreased with salinity. Natural mussel populations in this region are limited to areas with low and strongly fluctuating salinities. This pattern is consistent with the explanation that the natural subtidal mussel population is controlled by sea star predation. Sea stars are keystone predators on subtidal mussels in the Wadden Sea, but have a lower tolerance for low or strongly fluctuating salinities than mussels. The vast majority of culture plots are situated in areas with a relative high salinity and food quality, benign to sea stars and mussels, that explains why natural mussel beds seldom establish in that area. However, the cultured mussel population can pass through the predation bottleneck by mediation of the 


\section{Chapter 6}

mussel farmers who actively remove sea stars from the culture plots. On culture plots mussel growth was higher, growing conditions were more favourable than on natural mussel beds that cope with lower food quality. Mussel culture affects the population dynamics of the subtidal mussels in the system by relaying mussels from natural mussel beds to culture plots. This activity results in a higher mussel biomass production on culture plots than on natural mussel beds. This activity enhances the total subtidal mussel stock within the system, favouring ecosystem services such as the provision of subtidal biodiversity and a high quality food source for birds. 


\section{Chapter 7 \\ General discussion}

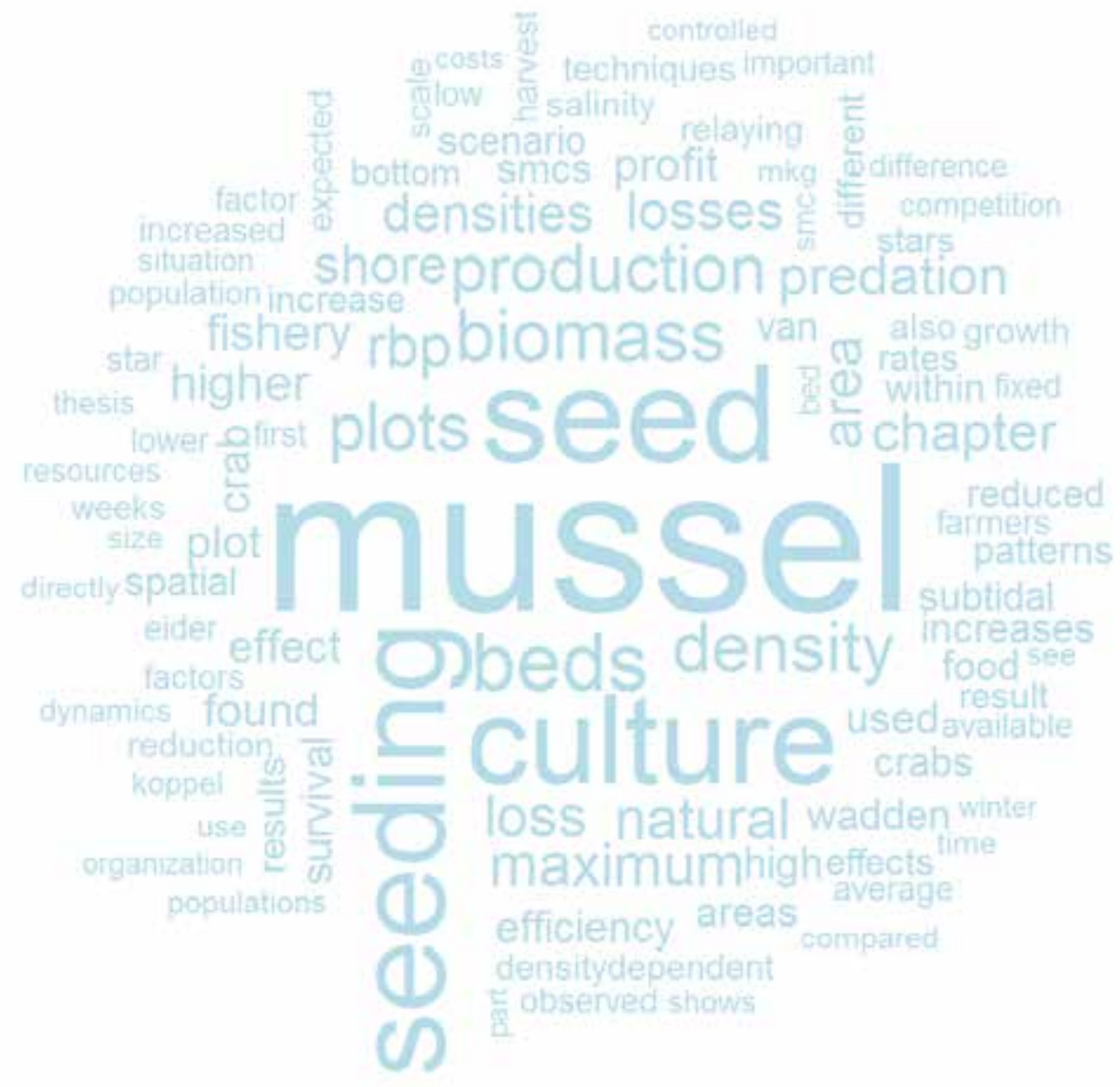




\section{Chapter 7}

In mussel bottom culture, mussels are relayed on intertidal or subtidal plots in a natural environment. The environmental factors determine the growth and survival of the mussels. In order to increase production efficiency, mussel farmers manipulate environmental factors by such means as removing predators or modifying mussel density in relation to food availability. Mussel bottom culture is essentially 'farming with nature'. A focus on the factors that determine mussel growth and survival on culture plots with the interfering activities of culture can provide further insights into the population dynamics of mussel populations.

This thesis focuses on the dynamics of subtidal mussel populations, and the impact of mussel culture activities on these dynamics. The aims of this thesis are (1) to better understand the population dynamics of subtidal mussel populations and (2) to analyse which factors determine production efficiency in mussel bottom culture and how this efficiency can be improved.

In Chapter 1, several research questions were formulated to address these aims. These questions are discussed throughout the following sections.

\subsection{Effects of seeding on mussel performance}

Seeding or relaying results in a redistribution of mussels on a culture plot. Close monitoring of these processes increases our understanding of the relation between spatial organisation and density-dependent processes in mussel populations.

\section{Spatial organisation}

Mussels are gregarious organisms that actively aggregate and interconnect with byssal threads. The resulting spatial organisation of mussel beds is an important feature that enhances mussel growth and survival at different scales 


\section{Chapter 7}

(Van de Koppel et al. 2005, Van De Koppel et al. 2008, Widdows et al. 2009). It can be expected that spatial organisation in redistribution after seeding affects biomass production. Mussels show self-organisation, which is defined by Van De Koppel et al. (2012) as "small-scale, localized interactions among the components of a system that generate complex spatial structures at large spatial scales". On natural mussel seed beds at high-energy sites, this organisation can result in large (meter)-scale wave-banded patterns. The banded patterns result from an interplay of negative feedbacks by food competition when mussels are homogeneously distributed and positive feedback by enhanced food delivery when mussels are heterogeneously distributed (Gascoigne et al. 2005, Van de Koppel et al. 2005, Van De Koppel et al. 2008). At a smaller (centimetre) scale within the banded structure, competition between mussels drives organisation in net-like structures (Liu et al. 2014). When mussel beds get older and density decreases, or at low-energy sites, mussels may organise in patches that develop in a fractal power-law pattern (Snover \& Commito 1998, Commito et al. 2006, Commito et al. 2014).

Mussel seed beds with banded patterns were observed in intertidal mussel beds; see Figure 1 in (Van de Koppel et al. 2005). Very similar patterns are observed in an aerial photograph from a subtidal mussel bed in the Wadden Sea (Figure 7.1a). It is expected that these patterns enhance growth and survival.

After relaying on culture plots, mussels redistribute and re-establish by crawling together after disturbances (Geesteranus 1942, De Jager et al. 2011b, Commito et al. 2014, Kangeri et al. 2014). During seeding the vessel circles above the culture plot, as a result, mussels on culture plots are laid in concentric patterns (Figure 7.1b). 


\section{Chapter 7}
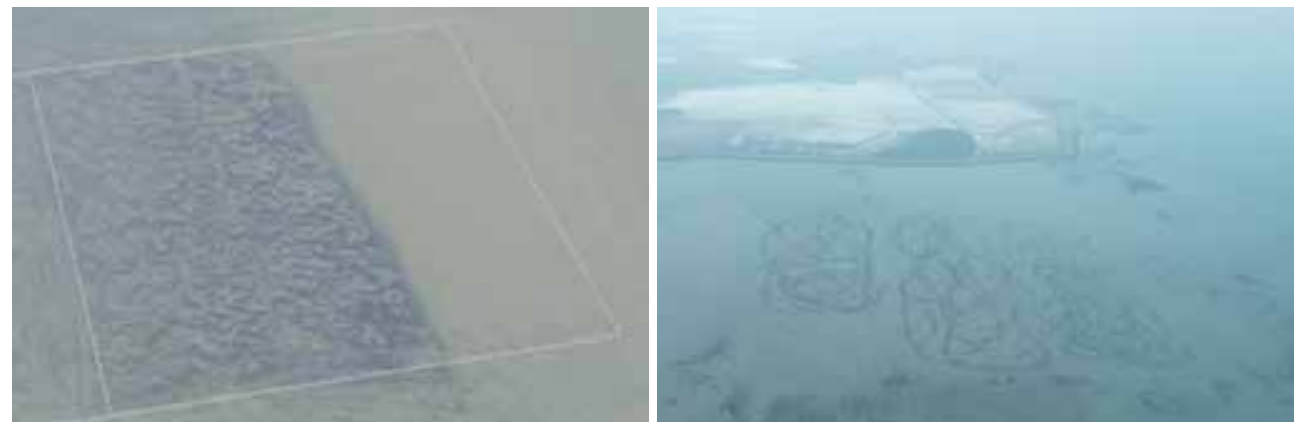

Figure 7.1a Aerial photographs of a natural subtidal mussel bed at Breesem, Wadden Sea, Netherlands (taken from (Van Stralen et al. 2013)); light square $(200 \mathrm{~m} \times 200 \mathrm{~m}$ ) indicates contour of experimental site (see also Chapter 3 ) and $\mathbf{b}$ from an (intertidal) mussel culture plot after seeding at Zandkreek Oosterschelde, Netherlands (right pane, photo by D. van der Ende).

Mussel densities can be very high in the seeding tracks; for example, at the most densely packed location within the tracks on the littoral plot described in Chapter 3 it could be as high as $21 \mathrm{~kg} \mathrm{~m}^{-2}$. Concentrating mussels has several implications for survival; we found that mussels redistribute into shapes depending on the initial density. Mussels at low densities re-organise within four weeks in a higher number of patches than at higher densities. We hypothesized that the possibility of re-organizing into a high number of patches reduced competition and promoted the survival of mussels and increased biomass production.

Competition forces mussels to move away from crowded situations and is a driver to self-organise in small-scale patterns (Liu et al. 2014). At high densities, however, mussels cannot avoid crowding and competition will result in high losses (up to $75 \%$ within four weeks after relaying in Chapter 3 ).

Self-organisation increases the resilience of mussel beds and increases food availability for the mussels in the bed (Van De Koppel et al. 2008, Van De Koppel 


\section{Chapter 7}

et al. 2012, Liu et al. 2014). In particular, mussel seed displays active searching behaviour for conspecifics (de Jager et al. 2011a). Therefore, it can be expected that a uniform spreading of mussel seed in low densities will facilitate spatial organisation in self-organised patterns and will ultimately result in a mussel distribution that resembles the spatial patterns found in natural mussel beds.

\section{Density dependent processes}

When mussels on natural subtidal mussel seed beds in the Wadden Sea were fished in autumn (2009, o-yearclass) for relaying on culture plots, mussel density on natural mussel bed was on average $2216 \mathrm{~m}^{-2} \pm 3162 \mathrm{~m}^{-2}$ (sd); mussel density on culture plots after relaying was on average $1549 \mathrm{~m}^{-2} \pm 929 \mathrm{~m}^{-2}$ (sd). On natural mussel beds in spring (2009 \& 2010) after winter losses, the average density was reduced to $323 \mathrm{~m}^{-2} \pm 521 \mathrm{~m}^{-2}$ (sd), while the average mussel density on culture plots after relaying was $1236 \mathrm{~m}^{-2} \pm 1006 \mathrm{~m}^{-2}$ (sd). Therefore, fishing and subsequent relaying on culture plots reduced mussel density and variation in mussel density in autumn and increased mussel density in Spring. It can be hypothesized that over several decades of trial and error, mussel farmers relay mussels in densities that will optimize production. However, we observed density-dependent losses on culture plots. This may also be because culture techniques are more driven by harvesting maximum biomasses than on improving production efficiency (7.4.1). Density dependent losses were observed first directly after and probably associated with seeding (seeding loss), and also over the first winter when mussels were $<30 \mathrm{~mm}$ (Chapter 4 ). Seeding loss increased with density, measured on a hectare scale (Chapter 4 ). In an experiment performed on a metre scale (Chapter 3), where we redistributed mussels in different densities, we showed that the seeding techniques that results in high local mussel densities are probably the major explanatory factor for the observed seeding loss. Within mussel patches, suffocation occurs when mussels are outcompeted by other mussels (Bertness \& Grosholz 1985). 


\section{Chapter 7}

On natural subtidal mussel beds, density-dependent mortalities are also expected, especially in the establishment phase. However, our sampling program was not designed to monitor density changes before the first winter. In studies on natural intertidal mussel beds, density-dependent mortalities are observed on o-yearclass mussel seed; hence, survivors at 1 year of age vary in numbers within relative narrow density limits (McGrorty et al. 1990, McGrorty \& Goss-Custard 1991, 1993, Stillman et al. 2000). Average densities on natural mussel beds in the Wadden Sea in spring were much lower than in autumn (see previous paragraph), but the very high losses on natural mussel beds are attributed to other factors, especially sea star predation (Agüera 2015).

Density-dependent growth on the patch scale is commonly observed because mussels in the middle of patches are competing for food and show reduced growth compared to the edges of the plot (Okamura 1986, Newell 1990, Svane \& Ompi 1993). On a plot scale, similar spatial differences (better performance at the edges compared to the middle) were found by Knights (2012). Our studies found no evidence for density-dependent growth. However, we calculated with plot averages from the monitoring described in Chapter 4 and missed out spatial differences within the plot scale or even within the patch scale.

A theoretical frame that is used to quantify density dependent mortality is the self-thinning theory, which was developed in plant science and has been repeatedly applied to sessile animals, including mussels (Begon et al. 1986, Hughes \& Griffiths 1988, Fréchette \& Lefaivre 1995, Guiñez 2005). Self-thinning is a mortality (thinning) applied on itself; when individuals in a cohort grow, the average size increases, often accompanied by a reduction in density (Westoby 1984). In the experiment presented in Chapter 3, mussel density and mussel cover were successively sampled for a period of three months on a square meter scale. We might estimate the self-thinning relation, plotting mussel density $(\mathrm{N})$ and mussel dry weight $(\mathrm{m})$, using the effective density (number of mussels 


\section{Chapter 7}

per occupied area, hence dismissing the area on the plot without mussels), following the same method (reduced major axis (RMA) regression) as Filgueira et al. (2008). The slope of the axis after four weeks was -0.41 with ' $95 \% \mathrm{CI}$ : [-0.23,0.71 and at the end of the experiment after 12 weeks it was -0.36 with $95 \% \mathrm{CI}$ : [-0.19,-0.68]. According to the self-thinning theory, there is no evidence that the population was regulated through or moving towards either classical food regulated self-thinning (FST, expected slope towards $-3 / 2$ ) or space regulated self-thinning (SST, expected slope towards $-4 / 3$ ), as the slope did not decrease over time and was well above -1 (Hughes \& Griffiths 1988, Fréchette \& Lefaivre 1990, Fréchette \& Bacher 1998). However, we observed density-dependent loss rates $\left(\mathrm{d}^{-1}\right)$ in this experiment, with the highest loss rates observed within the first four weeks. The question is whether the self-thinning theory can be applied to soft-sediment mussel populations under field conditions. Even under controlled conditions in a food regulated setting without other loss factors, and while competition between mussels was observed, no classical self-thinning relation was found (Alunno-Bruscia et al. 200o). On culture plots there are various other natural factors that determine variation in survival, which makes it difficult to find regular patterns in biomass-density relations (Fréchette et al. 2005). In Chapter 5, density-dependent losses occurred (ca. 20\%) in exclosures on an intertidal culture plot alongside shore crab predation (ca. 30\%) and other loss factors.

We can conclude that seeding results in a high density-dependent loss rate, and we expect that the density dependency is caused by high competition that is enhanced by seeding techniques that concentrates mussels in tracks on the plots. The heterogeneity in mussel distribution on a plot limits the facilitation ability through self-organisation. 


\section{Chapter 7}

\subsection{Effects of mussel bottom culture on mussel predators}

Predator control techniques consist of shore crab exclusion or removal and sea star mopping. Reported effects of controlling shore crab predation on yields show that only the exclusion of crabs by means of exclosures has proven successful (Davies et al. 1980). Sea stars are eliminated using fresh water exposure after fishing (Dijkema 1997). In addition, sea star removal with mops seems to be an effective method for removing sea stars from the culture plots (Calderwood et al. 2016b).

\section{Shore crabs}

Quite a lot of research has been done on the biology and behaviour of shore crabs (Carcinus maenas), under different environmental conditions (Crothers 1968, Sanchez-Salazar et al. 1987, Beukema 1991, Sneddon et al. 1997, Calderwood et al. 2016a). Shore crabs are important predators starting with bivalve spat right after settlement (van der Veer et al. 1998). At the same time, mussel beds are preferred habitats for shore crabs in all life stages of the crabs (Moksnes 2002). Estimation of effects of shore crab predation on biomass production relies on extrapolation of size-dependent predation to crab abundances in the field. Feeding rates of shore crabs on mussels decrease with mussel size and larger crabs can handle larger mussels (Elner \& Hughes 1978). Murray et al. (2007b) used this relation to predict the effect of shore crabs as a loss factor over the mussel culture cycle, based on shore crab counts on culture plots; the same study estimated shore crab contribution to losses from seeding to harvest at about $10 \%$.

Shore crabs exhibit diel and - at least in intertidal areas - tidal migration patterns in search of food (Crothers 1968, Reid \& Naylor 1993). They find their 


\section{Chapter 7}

food by chemoreception from receptors located on their legs and antennae (Crothers 1968). Freshly relayed mussels will elucidate strong cues, originating from mussels damaged in the seeding process and from mussel losses due to density-dependent mortality. It can be expected that the appearance of a food source during mussel seeding will result in local aggregation of crabs (Sneddon et al. 1997). Although shore crabs show competitive behaviour over food to an extent that limits food uptake, competitive behaviour is reduced when food is abundant (Sneddon et al. 1997, Sneddon et al. 2000, Smallegange \& Van Der Meer 2007). In Chapter 5 we tested the effect of shore crab predation on mussel biomass production in the period following seeding. We found that shore crab abundance peaked in the first week after seeding and about one-third of mussel (seeding) losses after five weeks could be attributed to shore crab predation. Furthermore, feedback mechanisms of the mussels such as shell thickness (Freeman 2007) and attachment strength (Côté 1995), did either not develop in such a short time, or was not strong enough to serve as protection.

Our results show that shore crabs take a substantial share in the seeding losses and suggest that the effect of shore crab predation on mussel biomass production is higher than previous studies would suggest (Murray et al. 2007b, Grosholz et al. 2011). Effect sizes, such as the $10 \%$ suggested by Murray et al. (2007b), may apply to already established mussel populations on culture plots, or on natural mussel beds. Chapter 5 suggests that seeding as culture activity presents a situation where a substantial fraction (in our case one-third) of the seed is consumed within a few weeks after seeding Including this crab predation peak in the estimation of the effect of total crab predation on biomass production, crab-related losses may sum up to about $40 \%$ over the entire culture cycle on culture plots. This peak is probably absent on natural mussel beds were values of about $10 \%$ might apply over the same period.

It is concluded that mussel culture will most likely increase the effect of 


\section{Chapter 7}

shore crab predation because seeding will cause strong cues that will attract shore crabs and presents an easy-to-obtain prey. Failure to include the effect of seeding activities will lead to a substantial underestimation of the effect of shore crab predation on production efficiency in mussel bottom culture.

\section{Sea stars}

Although we did not study the effects of sea stars on the mussel populations directly, we have provided evidence of the strong structuring effect of sea stars on the subtidal mussel population in the Wadden Sea and the role of culture therein. These findings are consistent with observations on effects of sea stars (Pisaster) on subtidal Mytilus californianus beds in Maine (Paine 1976b, a). Locations where natural mussel beds are found in the Wadden Sea and the survival rates of these beds suggest that salinity plays an important role in the success of establishment; this finding is consistent with results found in a controlled experiment by (Agüera et al. 2015). In the Wadden Sea a strong salinity gradient is found from Lake IJssel towards the North Sea (DuranMatute et al. 2014). No mussel beds are found at low-salinity sites (mean annual salinity $<17.5 \mathrm{mg} \mathrm{l}^{-1}$ ); mussel beds that show the highest survival rates are found in intermediate sites (mean annual salinity $17.5-22.5 \mathrm{mg} \mathrm{l}^{-1}$ ); at high-salinity sites (mean annual salinity $>\mathbf{2 2 . 5} \mathrm{mg} \mathrm{l}^{-1}$ ), mussel beds with low survival rates or no mussel beds at all are found (Figure 6.6a). It is highly likely that these patterns are caused by the relative intensity of sea star predation in the different zones. Mussels are more tolerant to salinity variation than sea stars (Bøhle 1972, Binyon 1976, Agüera et al. 2015) and the only mussel beds in the high salinity areas that have high survival rates, are found on culture plots. Here, sea star predation is controlled by the mussel farmers. The Asterias-Mytilus relation in the Wadden Sea is a good example of the concept that environmental stress determines the successes of the prey by affecting the prey-predator relationship (Menge \& Sutherland 1976, Menge et al. 1996). 


\section{Eider ducks}

We did not directly study the effects of mussel culture on eider ducks in this thesis. However, we did find that mussel culture increased system-scale subtidal mussel biomass and probably increased the carrying capacity for eider ducks; this is because eider ducks forage extensively on culture plots and prefer mussels above other food items (Cervencl et al. 2015). It is suggested in Chapter 6 that the overall positive effect of mussel culture on system scale subtidal biomass compared to natural mussel beds is largely the effect of successful removal of sea stars. This leads to the hypothesis that, at system scale, active removal of one predator (sea star) by culture activities strongly enhances the population of another predator (eider duck). It is unclear how this interaction relates to production efficiency. It can be argued that the effect of eider duck predation is reduced when sea stars are not controlled on culture plots. The annual mussel consumption of eider ducks from culture plots is substantial, between 2008 and 2011 it was estimated to range between 4.5 and 8.2 million $\mathrm{kg}$ fresh weight of mussels (Cervencl et al. 2015). This translates to $23 \%$ and $42 \%$ of the landings from the Wadden Sea in that period. Direct data on the effect of sea star removal on production efficiency are not available. However, it is expected that the effect of sea stars on a mussel population exceeds the effect of eider duck predation. Sea stars do rarely migrate and are very effective predators on mussel beds, under optimal conditions able to eliminate entire mussel populations in a couple of days (Agüera et al. 2012). Eider ducks are foraging on a larger area and are exerting a thinning out effect on the cultured mussel population. There are frequent reports from mussel farmers who experienced $100 \%$ mortality on their plot due to starfish predation. From areas with high sightings of eider ducks only reduced harvests are reported. 


\section{Chapter 7}

\subsection{Integrated effect of mussel bottom culture on system-scale biomass production}

At present, mussel seed fishery in the Wadden Sea in autumn is limited to subtidal areas, which are a priori estimated to have a low probability of survival (unstable beds). After the first winter, the remainder of the seed beds in areas open for fishing are fished in spring (stable beds, see also Figure 6.1b). A large-scale study in the Wadden Sea was not able to find significant effects of mussel fishery on mussel bed area or natural mussel biomass in unstable subtidal mussel beds (Van Stralen et al. 2013). In stable mussel beds, fishery induced reduction of mussel bed area and mussel biomass, measurable up to maximum of two years after fishery. The stability map of mussel beds, illustrated in Figure 6.1b, shows a similar pattern as the loss rates in Figure 6.6a. In areas where survival is low, natural dynamics outweigh the effects of fishery. Natural dynamics that affect mussel survival are predation, dislodgement and competition (Seed \& Suchanek 1992, Gosling 2003). The spatial pattern in losses on natural mussel beds found in the study period were attributed in Chapter 6 to sea star predation, which is limited in its distribution by salinity (Binyon 1976, Agüera et al. 2015). At the same time, on mussel seed beds and culture plots in shallow areas, high losses can occur during (winter) storms. However, in the period during which mussel beds were monitored, no significant storms occurred (Smaal et al. 2013a). Mussel beds that escape the intense sea star predation will become more sensitive to dislodgment when ageing as a thick mud layer develops underneath the mussels; see, for example, Figure 21 in Theisen (1968). Culture practice reduces these loss factors, as predicted in Figure 1.1 and further elaborated in the text in Chapter 1, by top-down control. Mussel farmers remove sea stars and relay mussels to sheltered plots before winter or when mud build-up underneath the mussels makes them prone to dislodgment. As a result of these activities, mussels can be cultured in areas 


\section{Chapter 7}

where the establishment of natural mussel beds is very limited. Therefore, seed bed establishment on an existing mussel plot, or smothering of older mussels by new recruits, which is yet another loss factor on mussel beds (Theisen 1968), has lower prevalence in culture areas, where mussels are cultured in monocohorts. Furthermore, mussel farmers can optimize growth rates through site selection. It is concluded in Chapter 6 that, as a result of these culture activities, the net mussel biomass on culture plots increases from seeding to harvest (Figure 1.1). The majority of natural subtidal mussel beds in the Wadden Sea were ephemeral (see also Figure 6.7), which is consistent with observations on subtidal mussel beds in other parts of the world (Paine 1976b, a, Seed 1976, Seed \& Suchanek 1992, Maguire et al. 2007, Davenport et al. 2009).

System-scale biomass production in the Wadden Sea is increased by relaying from natural seed beds to culture plots. However, mussel culture is extracting mussel biomass from the system through harvest or through transplantation to the Oosterschelde. On culture plots from the dataset used in Chapter 6, mussels were harvested before the age of 2.5 years. Furthermore, fishing for seed mussels on natural beds in the Wadden Sea resulted in a reduction of mussel biomass on these beds, although it did not completely remove all mussels Van Stralen et al. (2013). Areas with a mussel biomass $<150 \mathrm{~g} \mathrm{~m}^{-2}$ showed a reduction of $<10 \%$, while areas with a biomass of $150-1000 \mathrm{~g} \mathrm{~m}^{-2}$ showed a reduction of $40 \%$ and areas with a mussel biomass of $1000-2000 \mathrm{~g} \mathrm{~m}^{-2}$ showed a reduction of $60 \%$, compared to the control (unfished) areas directly after fishing. Considering all these factors in a budget model approach, mussel culture resulted in $\mathbf{1 . 2 7}$ more mussel biomass in the Wadden Sea than in a situation without culture (Wijsman et al. 2014). 


\section{Chapter 7}

\subsection{Culture techniques that affect production efficiency of mussel bottom culture}

Culture practices that affect production efficiency are seeding, predator control, relay and harvest. The parameter used in this thesis to express culture efficiency is relative biomass production (RBP), which is the ratio between biomass harvested and biomass seeded at a culture plot.

Harvesting occurs by dredging; when the plot is empty, dredging may continue to remove the accumulated silt layer from the plot. Relaying is seeding of mussels fished from culture plots that were seeded there before. Data collected for the analysis of seeding effects included both seeding of mussels from seed harvest as from relaying.

\section{Seeding techniques}

Mussel mortality shortly after seeding is an important variable determining the overall production efficiency. Thus, the techniques used for seeding may be a key to improving the efficiency. Seeding techniques differ in seed type used, seed size, seeding density and spatial distribution of the seed. Techniques currently in use were developed in the 1970s. Mussels are flushed out through pipes below the water level from the hold of the mussel vessel (Westbroek 1979, Dijkema 1997). This technique, which results in a heterogenic spatial seeding pattern with very high local densities, affects mussel production (see Chapters 3 and 4). The associated losses largely determine the production efficiency and are systematically quantified for the first time in this thesis.

An important recent transition in the Netherlands is the use of seed mussel collectors (SMCs) to obtain sufficient resources for the culture cycle, as a compensation for the closure of fishing areas (LNV 2009a). Use of SMCs resulted in a higher and more reliable provision of resource biomass, but also increased 


\section{Chapter 7}

costs and efforts. It was expected that the higher growth rates of mussels on the SMCs compared to the bottom would result in thinner shells, which would make seed from SMCs more prone to predation (Palmer 1981, Leonard et al. 1999). Kamermans et al. (2009) tested the assumption that SMC seed is more prone to predation by presenting mussel seeds from SMCs and bottom seed to shore crabs and sea stars. She could not find a difference in consumption rates between seed from SMCs and bottom seed. In a comparative study, seed from SMCs aggregated more and more quickly than bottom seed after relaying (Christensen et al. 2015). Seed from SMCs is harvested earlier in the year (July-September) than seed from fishery (October-November). Therefore, seed from SMCs is, on average, smaller at seeding than seed from fishery (Table 4.3). Smaller seed experiences higher mortalities but the high growth rates and higher number per kilogram can compensate this mortality (Petraitis 1995a). In the culture plot monitoring program, that forms the basis of this thesis and is presented in Chapter 4, we found that smaller seed increases the RBP, regardless of culture practices.

RBP increases with decreasing mussel size. It can be hypothesized that when the seed becomes very small; RBP might become low again because of the high vulnerability of the very small seed. Small seed is preyed upon intensively by different predators (shrimp, crab, and fish) and moreover the very small seeds are unable to aggregate in stable mussel aggregations (Dare 1976, Beukema 1991, 1992, van der Veer et al. 1998, Van der Heide et al. 2014). Data from the logbook of a mussel farmer (2001-2010) showed a low RBP on the occasions when very small seed was used (dotted line in Figure 7.2). Unfortunately, this trend is only based on two data points, it would be interesting to find more data to support this hypothesis. 


\section{Chapter 7}

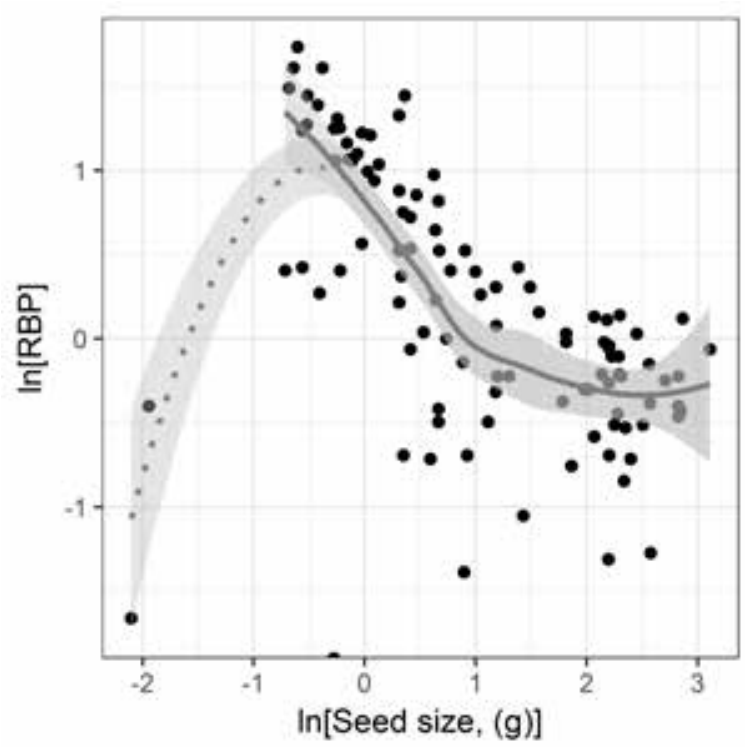

Figure 7.2 RBP at different seeding densities; data digitalized from the logbook of a mussel farmer (A. Nieuwenhuize) who compiled the data between 2001 and 2010. The RBP was calculated on a plot scale as the biomass harvested divided by the biomass seeded; mussel size was recorded as 'bustal', which refers to the number of mussels fitting in a $880 \mathrm{ml}$ tin can and translated to mussel size as described in Paragraph 2.2.2.

Seed size, the first factor affecting production efficiency, can only be controlled in culture practices by timing of the seed harvest. A second factor, seeding density, is also important and can more readily be controlled. Production efficiency is higher at lower seeding density (Chapter 4). Reducing seeding density requires more space per unit of seed resource. Mussel farmers have to deal with a yearly variable but uncontrollable amount of seed mussels and a fixed area of culture plots. Their choice is to leave some fraction of the available resource out, or to leave some fraction of the plot area out, in order to optimize profit. This question is discussed with the aid of a simulation based on the results presented in this thesis (Box 7.1). 


\section{Chapter 7}

Box 7.1 Maximum RBP, maximum harvest and maximum profit of seed from SMCs and fishery, simulated at different seeding densities, with a fixed amount of seed mussels and a fixed amount of culture area.

- The first scenario represents a (historic) situation where resources for a specific mussel farmer are obtained from fishery only and with abundant seed availability, fixed at $0.2 \mathrm{Mkg}$.

- The second scenario represents a situation in which $50 \%$ of the fishery is closed (as an estimation arising from the closure of littoral areas in the 1990s and the recent closure of subtidal areas under the transition; see also Chapter 2); resources are fixed at 0.1 Mkg of seed from fishery.

- The third scenario represents years in which the $50 \%$ reduction in fished biomass is supplied with seed from SMCs (mirroring the current state of affairs). Hence, resources are fixed at $0.1 \mathrm{Mkg}$ of seed from fishery and $0.1 \mathrm{Mkg}$ of seed from SMCs.

All three simulations are performed at a range of different seeding densities $\left(0.5-4 \mathrm{~kg} \mathrm{~m}^{-2}\right)$ and on a fixed available culture area of 10 ha. $\left(100,000 \mathrm{~m}^{2}\right)$ of a similar quality, suitable for the culture from seed to consumption.

Simulations are performed under the following assumptions:

- Harvest takes place when RBP is at a maximum (maxima in Figure 4.5; this will result in an overestimation of the RBP, compared to average culture practice).

- Biomass development is calculated with the method presented in Paragraph 4.2.4.

- $\quad$ Size and age of bottom and SMC seed is taken from Table 4.3.

- Cost price of seed from fishery in the first scenario, with abundant seed, is 0.05 Euro; cost price of seed from fishery in the second simulation is 0.07 Euro, when seed is scarcer, such as in situation 2; and cost prize of seed from SMCs in simulation 3 is 0.70 Euro. These prices are based on Table 2.2.

- Operating costs on top of resource provisioning are estimated at $63 \%$, based on Table 2.4 where these costs are estimated over 2014.

- Selling price is set at 1.11 Euro, which was the average selling price at the auction in 2014 (Figure 2.7).

Results of the simulations are plotted in Figure 7.3. 


\section{Chapter 7}
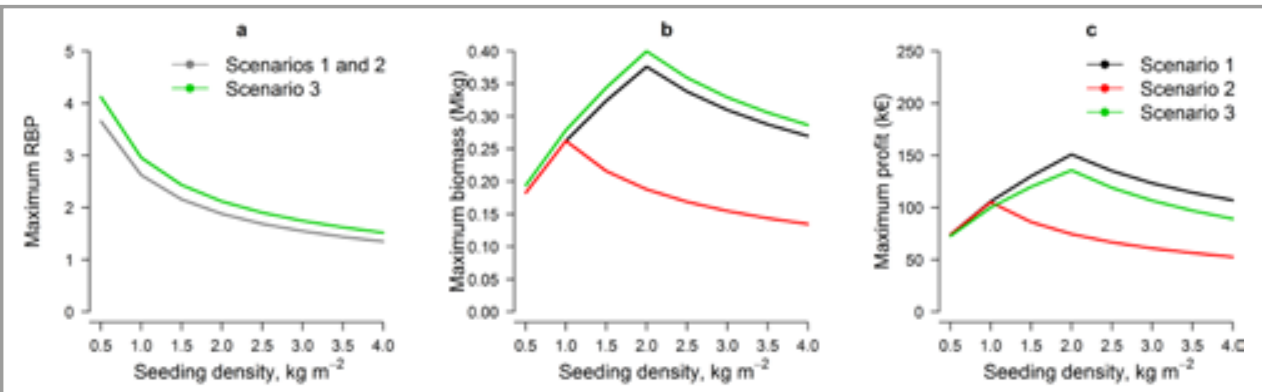

Figure 7.3a difference in RBP at different seeding densities for seed from SMCs and from fishery used in the simulations; $\mathbf{b}$ maximum biomass at the different RBP for the different seeding densities and at a maximum area of $10 \mathrm{ha}$; $\mathrm{c}$ is the profit at different densities and at a maximum area of $10 \mathrm{ha}$. When the slopes in a and b are positive, not all seed is used; when slopes are negative, not all area is used. Scenario 1: max 0.2 Mkg of seed from fishery, Scenario 2: max $0.1 \mathrm{Mkg}$ of seed from fishery, Scenario 3: max $0.1 \mathrm{Mkg}$ of seed from fishery and $0.1 \mathrm{Mkg}$ of seed from SMCs.

Figure 7.3a illustrates the higher maximum RBP for the 50:50 mixture of SMC seed and seed from fishery used in Scenario 3. This translates into a higher maximum biomass in Figure $1 \mathrm{~b}$ than for seed from fishery only (Scenario 1 and Scenario 2). However, because of the higher cost price of seed from SMCs, profit for the 50:50 mixture of SMC seed and seed from fishery is lower than when the same amount of seed from fishery is used (Figure 7.3c).

From the lowest density until the maximum values in the curve in Figure 1.1b and Figure $1.1 c, 100 \%$ of the area is effectively seeded. After the maximum values until the highest seeding density, only part of the available area is used; here, seed is concentrated to obtain the different densities. This means when the slope is positive area is fixed and part of the seed is not fished or part of the SMCs are not used. When the slope is negative, seed availability is fixed, but only part of the area is seeded. Because RBP decreases when seeding density increases, maximum biomass and maximum profit decreases when seed availability is fixed and density increases. In Scenario 2 only half of the seed is available compared to Scenarios 1 and 3 . When this amount is spread over all the available area, the maximum seeding density is half of the maximum seeding densities that can be obtained in Scenarios 1 and 3. 


\section{Chapter 7}

The results indicate that it is always profitable to use all of the available seed resources, even though RBP decreases at the higher seed density. However, the loss in profit is not directly proportional to the decrease in seed resources. A reduction of $50 \%$ in resource availability (difference between scenarios 1 and 2) leads to a decrease in profit of approximately $30 \%$. The supplement with SMC seed (difference between scenarios 2 and 3) results in higher biomass harvest and higher profit.

However, the higher costs for SMC seed will reduce profit increasingly with seeding density. With the 2014 situation (Table 2.4) used in the simulations, the use of SMC seed to replace half of the seed from fishery is profitable. However, profit is very sensitive to differences in auction prices. Use of SMC seed will not be profitable for all seeding densities when auction prices are similar to or lower than seed costs (€0.70 in Scenario 3 ).

When the space on the culture plots is not limited, profit increases when seeding densities are reduced, but in practice there are limits to this theoretical optimization. In culture practices, often only part of the potential area is used because of variation in quality between plots, or because mussel farmers are avoiding risks associated to seeding in overly low densities. Experience of mussel farmers is that mussels obtain safety in numbers, and thus that the increase in RBP with decreasing seeding density does not hold at very low density. This indicates a second trade-off between a situation where risk is avoided and only part of the available area is used, where mussels obtain safety in numbers or when risk is taken to seed mussels in lower densities over a larger area in an attempt to obtain a higher RBP.

Seeding losses were the major factor that determined the RBP over the entire production chain from seed to harvest. Reducing seeding losses will involve costs in terms of investments in time and in seeding techniques, it might also cause more stress for the mussels when seeding requires more time, on the 


\section{Chapter 7}

other hand a higher RBP will increase profit. Costs involved in a reduction of seeding loss are not in the scope of this thesis and requires further research and development. However, we can re-run the simulation for scenario 3 (Box 1), against a scenario where seedling losses are reduced by $50 \%$, to provide insight in the economic effects of a seeding loss reduction. Results of this simulation are shown in Figure 7.4, with for both scenarios: a) maximum RBP, b) difference between maximum biomass production and c) differences between maximum profit.
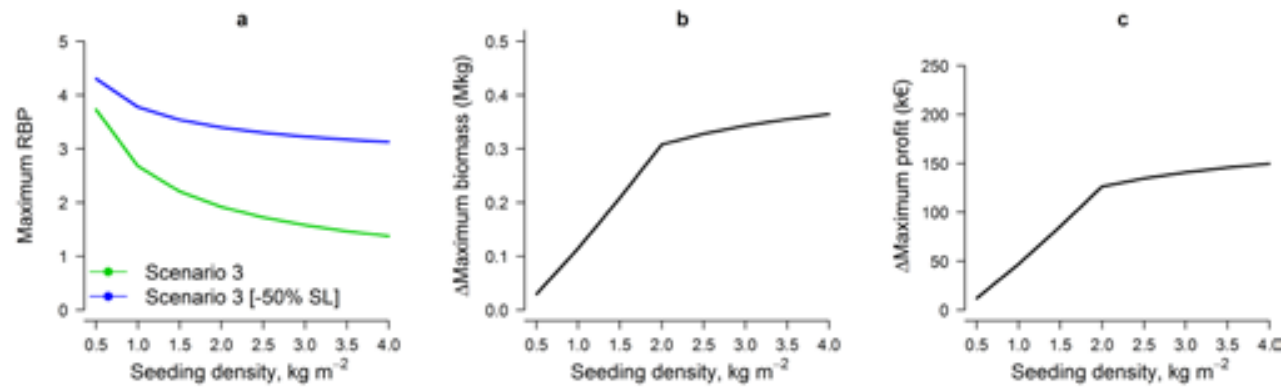

Figure 7.4a shows the difference in RBP for Scenario 3 (Box 1), together with a scenario where absolute seeding loss is reduced by $50 \%$ b shows the difference between maximum biomass for both scenarios and is the net biomass production when absolute seeding losses are reduced by $50 \%$; c shows the difference between maximum profit for both scenarios and is the net profit when absolute seeding losses are reduced by $50 \%$;

The results indicate that a $50 \%$ reduction in seeding loss results in an averaged $42 \%$ increase in RBP and maximum biomass production, while average profit increased by approximately $46 \%$. The differences in RBP between both scenarios increases with mussel density, because seeding loss is density dependent, hence the effect of seeding loss in RBP increases with seeding density. The increase in maximum profit illustrates a substantial scope for investments for the mussel farmers to prevent seeding loss.

In conclusion, biomass production per area and maximum profit can increase when the resources are used optimally within the designated area. This requires 
understanding of the population dynamics of the mussels and the effects of culture thereon. However, it is important to consider that when area is limited and/or resources are plenty, an increase in RBP will not necessarily result in an increase in biomass production per area or in profit. However, a more efficient seed use on the available area, by reducing seeding losses will increase RBP and maximum biomass production and increases maximum profit.

\section{How can production efficiency of mussel bottom culture be improved?}

An important result of this thesis is the strong evidence for a density-dependent seeding/relaying loss (Chapter 3-4). This has implications for the improvement of production efficiency. Seeding induced relatively high mortality (on average $42 \%$ ) of the mussels and was the major factor reducing biomass production over the culture period (Chapter 4 ). Seeding losses increased up to $69 \%$ when mussels were smaller and laid at a higher density. The biggest improvement of production efficiency can be obtained by reducing seeding loss. Chapter 3 shows that a better spreading of the seed will increase immediate survival; similar findings are reported by Newell (2007). A change in technology needs to be considered to balance technological developments which resulted from the transition in resource provisioning (Chapter 2). For example, in Chapter 3 we found that a better spreading reduced seeding losses, by $20 \%$ within 4 weeks in the experiment; this suggest that an increase in production efficiency through the developments of better seeding techniques that increases spatial homogeneity of mussels on culture plots is possible. Figure 7.4 shows that a change in technology that results in a reduction of seeding losses is followed by a scope for investments. In general, densities at culture plots in the monitoring campaign described in Chapter 4 can be reduced, because even after substantial seeding loss a density-dependent loss of mussel seed was found over the first winter. Chapter 5 suggests that handling can cause stress, which could 


\section{Chapter 7}

substantially increase seeding loss, as also pointed out in Calderwood (2015). Mussel farmers need to realize that this effect might occur, avoid unnecessary seed handling and invest in seed-friendly methods. In Chapter 5 we found that crab predation is a substantial loss factor (ca. 30\% within five weeks after seeding) and especially increased mussel losses directly after seeding. The effects of removing shore crabs from culture plots in the Wadden Sea was tested by Kamermans (2010), but no effect on crab distribution or biomass production was found on the culture plots. It can be expected that effects of exclusion or removal of crabs is maximized when this occurs directly after seeding.

\subsection{Main conclusions}

On natural mussel beds mussels organise in patterns that enhance food delivery and resilience of the bed. On culture plots mussels are seeded in concentric seeding patterns. Seeding techniques concentrate mussels locally within the culture plot area, resulting in high local mussel densities; this increases competition and limits the spatial re-organisation of mussels in the bed. Consequently, seeding on culture plots is followed by a large size and densitydependent seeding loss that ranges from about $40 \%$ for seed from fishery to $69 \%$ for smaller SMC seed. This loss was the major factor in determining the maximum RBP. Losses in the grow-out stage were substantially lower, a subsequent density dependent loss was found for smaller mussels $(<30 \mathrm{~mm})$, and a non-density dependent loss for larger mussels (>30 mm). Shore crab predation is an important factor contributing to the higher losses at seeding. The effect of shore crab predation on mussel biomass production is higher than expected from previous studies. In an experiment on an intertidal culture plot in the Oosterschelde, we observed that shore crab predation peaks directly after seeding and accounted for $33 \%$ of the total losses within five weeks after seeding. 


\section{Chapter 7}

Spatial patterns in the survival rates of natural mussel beds in the Wadden Sea show better seed survival in areas with intermediate salinity (mean annual salinity $17.5-22.5 \mathrm{mg} \mathrm{l}^{-1}$ ). This suggests that mussel survival is negatively related to sea star distribution, which is largely controlled by salinity. Natural beds that escape predation are found at lower salinities and mussels on these beds showed low growth rates, also because of a lower food quality in these areas. Mussel culture strongly affects the population dynamics of the subtidal mussel population, through relaying of mussels from natural mussel beds to culture plots. Culture plots are located in more saline regions of the Wadden Sea (mean annual salinity $25.8 \mathrm{mg} \mathrm{l}^{-1}$ ), compared to natural mussel beds. This activity increased mussel growth and survival because food quality on culture plots is high and predation is prevented. As a result, average biomass production is higher on culture plots than on natural mussel beds and this difference increases over time.

In culture practices there can be a trade-off between maximum harvest and maximum RBP at different seeding densities: when resources are not limited, higher harvestable biomasses are obtained at higher densities, despite a decrease in RBP. A second trade-off exists between a situation where risk is avoided and only part of the available area is used (mussels obtain a safety in numbers) and a situation where the risk is taken to seed mussels in lower densities over a larger area in an attempt to obtain a higher RBP. A more efficient seed use on the available area, that can be obtained by reducing seeding losses will increase RBP, maximum biomass production and increases maximum profit. Our results suggest that this can be achieved by seeding homogeneously in low densities. 


\section{References}

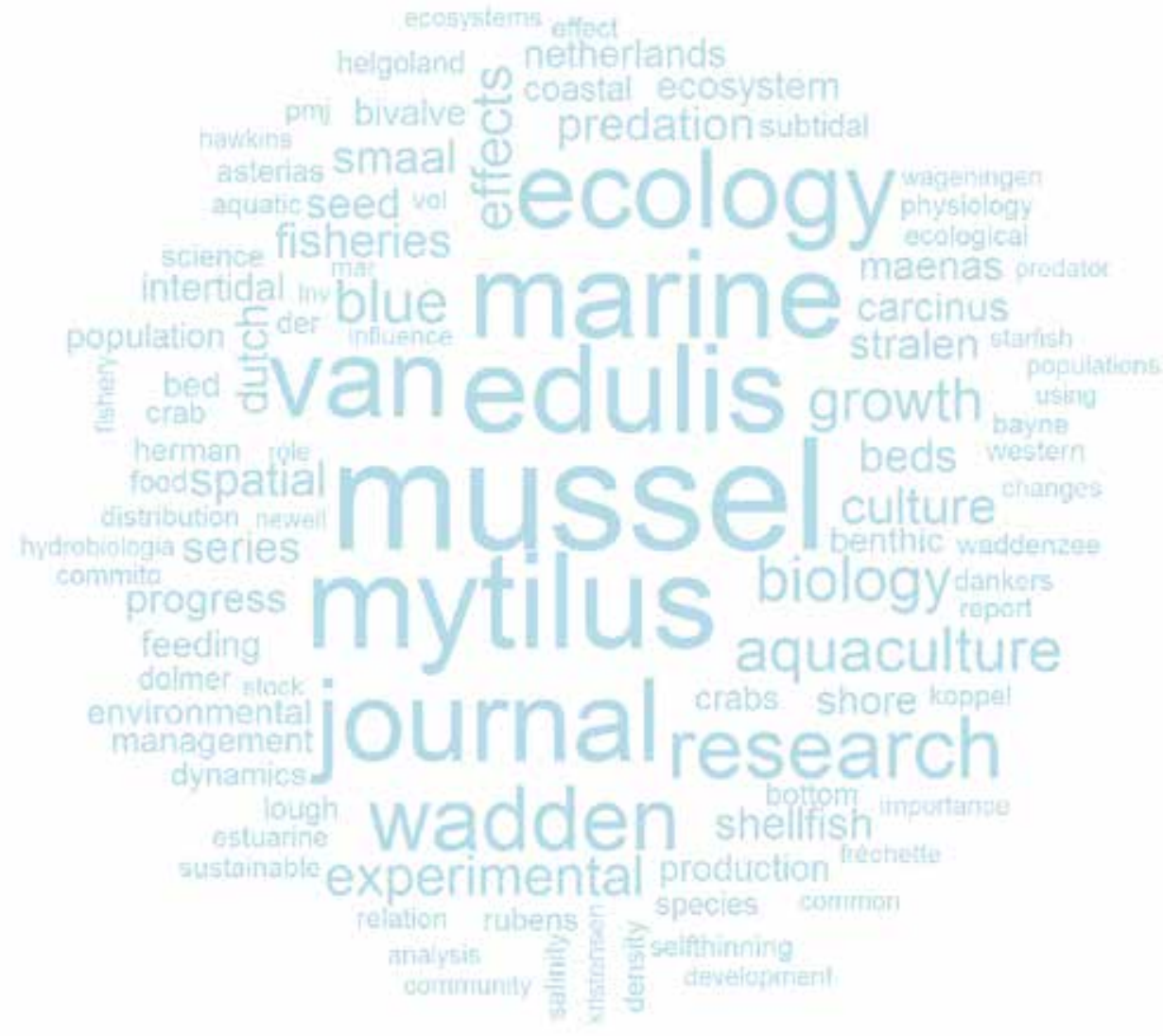




\section{References}

Agüera A (2015) The role of starfish (Asterias rubens L.) predation in blue mussel (Mytilus edulis L.) seedbed stability, PhD dissertation. Wageningen University, Wageningen

Agüera A, Schellekens T, Jansen JM, Smaal AC (2015) Effects of osmotic stress on predation behaviour of Asterias rubens L. Journal of Sea Research 99:9-16

Agüera A, Trommelen M, Burrows F, Jansen JM, Schellekens T, Smaal A (2012) Winter feeding activity of the common starfish (Asterias rubens L.): The role of temperature and shading. Journal of Sea Research 72:106-112

Almada-Villela PC (1984) The effects of reduced salinity on the shell growth of small Mytilus edulis. Journal of the Marine Biological Association of the United Kingdom 64:171-182

Alterra (2005) Passende Beoordeling sublitorale mosselzaadvisserij in de westelijke Waddenzee [Assessment of subtidal mussel fisheries in the western Wadden Sea], Alterra-Texel, RIVOYerseke.

Alunno-Bruscia M, Petraitis PS, Bourget E, Fréchette M (2000) Body size-density relationship for Mytilus edulis in an experimental food-regulated situation. Oikos 90:28-42

Asmus H, Asmus RM (2002) ECSA workshop: Community ecology of soft bottom mussel beds. Helgoland Marine Research 56:1-2

Aveni-Deforge K (2007) Aggregate Behaviour of the Blue Mussel, Mytilus Edulis, PhD dissertation, University of South Carolina

Babarro JMF, Reiriz MJF (2010) Secretion of byssal threads in Mytilus galloprovincialis: Quantitative and qualitative values after spawning stress. Journal of Comparative Physiology B: Biochemical, Systemic, and Environmental Physiology 180:95-104

Bailey G (2004) World prehistory from the margins: the role of coastlines in human evolution. Journal of Interdisciplinary Studies in History and Archaeology 1:39-50 


\section{References}

Barkhouse CL, Niles M, Davidson LA (2007) A literature review of sea star control methods for bottom and off bottom shellfish cultures. Canadian Industry Report of Fisheries and Aquatic Sciences 279

Bayne BL (1998) The physiology of suspension feeding by bivalve molluscs: An introduction to the Plymouth 'TROPHEE' workshop. Journal of Experimental Marine Biology and Ecology 219:1-19

Bayne BL (2004) Phenotypic flexibility and physiological tradeoffs in the feeding and growth of marine bivalve molluscs. Integrative and Comparative Biology 44:425-432

Bayne BL, Iglesias JIP, Hawkins AJS, Navarro E, Heral M, Deslous-Paoli JM (1993) Feeding behaviour of the mussel, Mytilus edulis: responses to variations in quantity and organic content of the seston. Journal of the Marine Biological Association of the United Kingdom 73:813-829

Bayne BL, Worrall CM (1980) Growth and production of mussels Mytilus edulis from two populations. Marine Ecology Progress Series 3:317-328

Beadman HA, Caldow RWG, Kaiser MJ, Willows RI (2003) How to toughen up your mussels: Using mussel shell morphological plasticity to reduce predation losses. Marine Biology 142:487494

Beal BF (2006) Relative importance of predation and intraspecific competition in regulating growth and survival of juveniles of the soft-shell clam, Mya arenaria L., at several spatial scales. Journal of Experimental Marine Biology and Ecology 336:1-17

Beal BF, Kraus MG (2002) Interactive effects of initial size, stocking density, and type of predator deterrent netting on survival and growth of cultured juveniles of the soft-shell clam, Mya arenaria L., in eastern Maine. Aquaculture 208:81-111

Beck MW, Heck Jr KL, Able KW, Childers DL, Eggleston DB, Gillanders BM, Halpern B, Hays CG, Hoshino K, Minello TJ (2001) The identification, conservation, and management of estuarine and marine nurseries for fish and invertebrates: a better understanding of the habitats that serve as nurseries for marine species and the factors that create site-specific variability in nursery quality will improve conservation and management of these areas. Bioscience 51:633-641

Begon M, Firbank L, Wall L (1986) Is there a self-thinning rule for animal populations? Oikos 46:122-124 


\section{References}

Bell E, Gosline J (1996) Mechanical design of mussel byssus: material yield enhances attachment strength. The Journal of Experimental Biology 199:1005-1017

Bertness MD, Grosholz E (1985) Population dynamics of the ribbed mussel, Geukensia demissa: The costs and benefits of an aggregated distribution. Oecologia 67:192-204

Beukema JJ (1976) Biomass and species richness on the macro-benthic animals living on the tidal flats of the Dutch Wadden Sea. Netherlands journal of Sea Research 10:236-261

Beukema JJ (1991) The abundance of shore crabs Carcinus maenas (L.) on a tidal flat in the Wadden Sea after cold and mild winters. Journal of Experimental Marine Biology and Ecology 153:97-113

Beukema JJ (1992) Dynamics of juvenile shrimp Crangon crangon in a tidal-flat nursery of the Wadden Sea after mild and cold winters. Marine Ecology Progress Series 83:157-165

Beukema JJ, Cadée GC, Dekker R (1998a) How two large-scale "experiments" illustrate the importance of enrichment and fishery for the functioning of the Wadden Sea ecosystem. Senckenbergiana Maritima 29:37-44

Beukema JJ, De Bruin W (1977) Seasonal changes in dry weight and chemical composition of the soft parts of the tellinid bivalve Macoma balthica in the Dutch Wadden Sea. Netherlands Journal of Sea Research 11:42-55

Beukema JJ, Dekker R (2007) Variability in annual recruitment success as a determinant of longterm and large-scale variation in annual production of intertidal Wadden Sea mussels (Mytilus edulis). Helgoland Marine Research 61:71-86

Beukema JJ, Honkoop PJC, Dekker R (1998b) Recruitment in Macoma balthica after mild and cold winters and its possible control by egg production and shrimp predation. Hydrobiologia 375-376:23-34

Binyon J (1976) The effects of reduced salinity upon the starfish Asterias rubens L. together with a special consideration of the integument and its permeability to water. Thalassia Jugoslavica 12:11-20

Bøhle B (1972) Effects of adaptation to reduced salinity on filtration activity and growth of mussels (Mytilus edulis L.). Journal of Experimental Marine Biology and Ecology 10:41-47 


\section{References}

Borthagaray AI, Carranza A (2007) Mussels as ecosystem engineers: Their contribution to species richness in a rocky littoral community. Acta Oecologica 31:243-250

Bouma TJ, Olenin S, Reise K, Ysebaert T (2009) Ecosystem engineering and biodiversity in coastal sediments: posing hypotheses. Helgoland Marine Research 63:95

Breuer M (2016) European Aquaculture, Fact Sheets on the European Union. Accessed 11/12/2016. http://www.europarl.europa.eu/atyourservice/en/displayFtu.html?ftuId=FTU_5·3.7.html

Brinkman A, Dankers N, Van Stralen M (2002) An analysis of mussel bed habitats in the Dutch Wadden Sea. Helgoland Marine Research 56:59-75

Brown KM, Aronhime B, Wang X (2011) Predatory blue crabs induce byssal thread production in hooked mussels. Invertebrate Biology 130:43-48

Bult TP, Stralen MRv, Brummelhuis EBM, Baars JMDD (2004) Mosselvisserij en -kweek in het sublitoraal van de Waddenzee [Mussel fisheries and culture in the subtidal Dutch Wadden Sea]. RIVO-CSO, Yerseke

Burch A, Seed R (200o) Foraging behaviour of Carcinus maenas on Mytilus edulis: The importance of prey presentation. Journal of the Marine Biological Association of the United Kingdom 80:799-810

Buschbaum C, Dittmann S, Hong JS, Hwang IS, Strasser M, Thiel M, Valdivia N, Yoon SP, Reise K (2009) Mytilid mussels: global habitat engineers in coastal sediments. Helgoland Marine Research 63:47-58

Büttger H, Asmus H, Asmus R, Buschbaum C, Dittmann S, Nehls G (20o8) Community dynamics of intertidal soft-bottom mussel beds over two decades. Helgoland Marine Research 62:23-36

Cadée G (2001) Herring gulls learn to feed on a recent invader in the Dutch Wadden Sea, the Pacific oyster Crassostrea gigas. Basteria 65:33-42

Calderwood J (2015) Developing Science-Based Management Strategies for Improving Yield of Blue Mussels, Mytilus edulis, in Benthic Cultivation, PhD Dissertation, The Queens University of Belfast, Belfast 


\section{References}

Calderwood J, O'Connor NE, Roberts D (2016a) Breaking and entering: Examining the role of stress and aerial exposure in predator-prey relationships between the common shore crab (Carcinus maenas) and cultivated blue mussels (Mytilus edulis). Aquaculture 452:217-223

Calderwood J, O'Connor NE, Roberts D (2016b) Efficiency of starfish mopping in reducing predation on cultivated benthic mussels (Mytilus edulis L). Aquaculture 452:88-96

Calderwood J, O'Connor NE, Roberts D (2015) The effects of transportation stress and barnacle fouling on predation rates of starfish (Asterias rubens) on mussels (Mytilus edulis). Aquaculture 444:108-113

Calderwood J, O’Connor NE, Sigwart J, Roberts D (2014) Determining optimal duration of seed translocation periods for benthic mussel (Mytilus edulis) cultivation using physiological and behavioural measures of stress. Aquaculture 434:288-295

Capelle JJ, Wijsman JW, van Stralen MR, Herman PM, Smaal AC (2016) Effect of seeding density on biomass production in mussel bottom culture. Journal of Sea Research 110:8-15

Capelle JJ, Wijsman JWM, Schellekens T, van Stralen MR, Herman PMJ, Smaal AC (2014) Spatial organisation and biomass development after relaying of mussel seed. Journal of Sea Research $85: 395-403$

Carls MG, Harris PM, Rice SD (2004) Restoration of oiled mussel beds in Prince William Sound, Alaska. Marine Environmental Research 57:359-376

Caro AU, Escobar J, Bozinovic F, Navarrete SA, Castilla JC (2008) Phenotypic variability in byssus thread production of intertidal mussels induced by predators with different feeding strategies. Marine Ecology Progress Series 372:127-134

Cervencl A, Troost K, Dijkman E, de Jong M, Smit C, Leopold M, Ens B (2015) Distribution of wintering Common Eider Somateria mollissima in the Dutch Wadden Sea in relation to available food stocks. Marine Biology 162:153-168

Christensen HT (2012) Area-intensive bottom culture production of blue mussels, Mytilus edulis (L.), PhD Dissertation. DTU aqua, Denmark

Christensen HT, Dolmer P, Hansen BW, Holmer M, Kristensen LD, Poulsen LK, Stenberg C, Albertsen CM, Støttrup JG (2015) Aggregation and attachment responses of blue mussels, Mytilus edulis-impact of substrate composition, time scale and source of mussel seed. Aquaculture $435: 245-251$ 


\section{References}

Commito JA, Commito AE, Platt RV, Grupe BM, Piniak WED, Gownaris NJ, Reeves KA, Vissichelli AM (2014) Recruitment facilitation and spatial pattern formation in soft-bottom mussel beds. Ecosphere 5:1-26

Commito JA, Dankers NMJA (2001) Dynamics of spatial and temporal complexity in European and North American soft-bottom mussel beds. Ecological Comparisons of Sedimentary Shores:39-59

Commito JA, Dow WE, Grupe BM (2006) Hierarchical spatial structure in soft-bottom mussel beds. Journal of Experimental Marine Biology and Ecology 330:27-37

Commito JA, Gownaris NJ, Haulsee DE, Coleman SE, Beal BF (2016) Separation anxiety: mussels self-organise into similar power-law clusters regardless of predation threat cues. Marine Ecology Progress Series 547:107-119

Commito JA, Rusignuolo BR (2000) Structural complexity in mussel beds: The fractal geometry of surface topography. Journal of Experimental Marine Biology and Ecology 255:133-152

Côté IM (1995) Effects of predatory crab effluent on byssus production in mussels. Journal of Experimental Marine Biology and Ecology 188:233-241

Crawford TW, Commito JA, Borowik AM (2006) Fractal characterization of Mytilus edulis L. spatial structure in intertidal landscapes using GIS methods. Landscape Ecology 21:1033-1044

Crothers JH (1968) The biology of the shore crab Carcinus maenas (L.). 2. The life of the adult crab. Field Studies 2:579-614

Dankers N, Brinkman AG, Meijboom A, Dijkman E (2001) Recovery of intertidal mussel beds in the Waddensea: Use of habitat maps in the management of the fishery. Hydrobiologia 465:21-30

Dankers N, Zuidema DR (1995) The role of the mussel (Mytilus edulis L.) and mussel culture in the Dutch Wadden Sea. Estuaries 18:71-80

Dare PJ (1976) Settlement, growth and production of the mussel Mytilus edulis L. in Morecambe Bay, England. Fish Invest Ser 2 28:1-25

Dare PJ (1982) Notes on the swarming behaviour and population density of Asterias rubens L. (echinodermata: Asteroidea) feeding on the mussel, Mytilus edulis L. J. Cons. Int. Explor. Mer. 40:112-118 


\section{References}

Dare PJ, Bell MC, Walker P, Banister RCA (2004) Historical and current status of cockle and mussel stocks in the Wash. CEFAS, Lowestoft

Dare PJ, Davies G, Edwards DB (1983) Predation on juvenile Pacific oysters (Crassostrea gigas Thunberg) and mussels (Mytilus edulis L.) by shore crabs (Carcinus maenas L.). Fisheries Research Technical Report - UK Ministry of Agriculture, Fisheries \& Food, Directorate of Fisheries Research 73

Dare PJ, Edwards DB (1976) Experiments on the survival, growth and yield of relaid seed mussels (Mytilus edulis L.) in the Menai Straits, North Wales. J. Cons. Int. Explor. Mer. 37:16-28

Dare PJ, Edwards DB (1981) Under water television observations on the tidal movements of shore crabs, Carcinus maenas, across a mudflat. Journal of the Marine Biological Association of the United Kingdom 61:107-116

Davenport JC, Black K, Burnell G, Cross T, Culloty S, Ekaratne S, Furness B, Mulcahy M, Thetmeyer H (2009) Aquaculture: the ecological issues. Blackwell Publishing, Oxford. 89 pp.

Davies GP, Dare PJ, Edwards DB (1980) Fenced enclosures for the protection of seed mussels (Mytilus edulis L.) from predation by shore crabs (Carcinus maenas L.). Fisheries Research Technical Report 56

De Jager M, Weissing FJ, Herman PM, Nolet BA, van de Koppel J (2011a) Lévy walks evolve through interaction between movement and environmental complexity. Science 332:1551-1553

De Jonge VN, Bakker JF, Van Stralen M (1996) Recent changes in the contributions of river Rhine and North Sea to the eutrophication of the western Dutch Wadden Sea. Aquatic Ecology 30:27-39

De Jonge VN, De Jong DJ (2002) 'Global change' impact of inter-annual variation in water discharge as a driving factor to dredging and spoil disposal in the River Rhine system and of turbidity in the Wadden Sea. Estuarine, Coastal and Shelf Science 55:969-991

Denny MW (1987) Lift as a mechanism of patch initiation in mussel beds. Journal of Experimental Marine Biology and Ecology 113:231-245

Diana JS (2009) Aquaculture production and biodiversity conservation. Bioscience 59:27-38

Dijkema R (1997) Molluscan fisheries and culture in the netherlands. NOAA Technical Report NMFS 129:115-134 


\section{References}

Dolmer P (1998) The interactions between bed structure of Mytilus edulis L. and the predator Asterias rubens L. Journal of Experimental Marine Biology and Ecology 228:137-150

Dolmer P (200o) Feeding activity of mussels Mytilus edulis related to near-bed currents and phytoplankton biomass. Journal of Sea Research 44:221-231

Dolmer P, Christensen HT, Hansen BW, Vismann B (2012) Area-intensive bottom culture of blue mussels Mytilus edulis in a micro-tidal estuary. Aquaculture Environment Interactions 3:81-91

Dolmer P, Kristensen PS, Hoffmann E (1999) Dredging of blue mussels (Mytilus edulis L.) in a Danish sound: Stock sizes and fishery-effects on mussel population dynamic. Fisheries Research 40:73-80

Dolmer P, Kristensen T, Christiansen M, Petersen M, Kristensen PS, Hoffmann E (2001) Shortterm impact of blue mussel dredging (Mytilus edulis L.) on a benthic community. Hydrobiologia 465:115-127

Dolmer P, Stenalt E (2010) The impact of the adult blue mussel (Mytilus edulis) population on settling of conspecific larvae. Aquaculture International 18:3-17

Dolmer P, Svane I (1994) Attachment and orientation of Mytilus edulis L.in flowing water. Ophelia 40:63-74

Donker JJA, van der Vegt M, Hoekstra P (2012) Wave forcing over an intertidal mussel bed. Journal of Sea Research

Drent J, Dekker R (2013) How different are subtidal Mytilus edulis L. communities of natural mussel beds and mussel culture plots in the western Dutch Wadden Sea? NIOZ-report 2013-6, Royal Netherlands Institute for Sea Research (NIOZ)

Duran-Matute M, Gerkema T, de Boer GJ, Nauw JJ, Gräwe U (2014) Residual circulation and freshwater transport in the Dutch Wadden Sea: a numerical modelling study. Ocean Sci 10:611632

Ekroos J, Fox AD, Christensen TK, Petersen IK, Kilpi M, Jónsson JE, Green M, Laursen K, Cervencl A, De Boer P (2012) Declines amongst breeding Eider Somateria mollissima numbers in the Baltic/Wadden Sea flyway. Ornis Fennica 89:81 


\section{References}

Elias E, Van der Spek A, Wang ZB, De Ronde J (2012) Morphodynamic development and sediment budget of the Dutch Wadden Sea over the last century. Netherlands Journal of Geosciences 91:293-310

Elner RW, Hughes RN (1978) Energy maximization in the diet of the shore crab, Carcinus maenas. Journal of Animal Ecology 47:103-116

Ens BJ, Alting D (1996) The effect of an experimentally created mussel bed on bird densities and food intake of the oystercatcher Haematopus ostralegus. Ardea 84:493-507

Ens BJ, Craeymeersch JAM, Fey FE, Smaal AC, Brinkman AG, Dekker R, Van derMeer JW, Van Stralen MR (2007) Sublitorale natuurwaarden in de Waddenzee [Natural values of the subtidal Wadden Sea]. Wageningen IMARES, Co77/o7

Ens BJ, Dirksen S, Smit CJ, Bunskoeke AJ (1996) Seasonal changes in size selection and intake rate of Oystercatchers Haematopus Ostralegus feeding on the bivalves Mytilus Edulis and Cerastoderma Edule. Ardea 84:159-176

Erlandson JM (1988) The role of shellfish in prehistoric economies: a protein perspective. American Antiquity 1:102-109

Essink K, Bos AH (1985) Growth of three bivalve molluscs transplanted along the axis of the Ems estuary. Netherlands Journal of Sea Research 19:45-51

FAO (2004) Cultured aquatic species information programme. Mytilus edulis. Text by Goulletquer, P. FAO Fisheries and Aquaculture Department [online] http://wwwfaoorg/fishery/ culturedspecies/Mytilus_edulis. Accessed 14/12/2016.

FAO (2012) The State of World Fisheries and Aquaculture 2012, Rome

FAO (2015) Fisheries \& aquaculture, Global Statistical Collection; http://www.fao.org/fishery/ statistics/en. Accessed 11/12/2016.

Ferreira J, Bricker S (2016) Goods and services of extensive aquaculture: shellfish culture and nutrient trading. Aquaculture International 24:803-825 


\section{References}

Ferreira J, Sequeira A, Hawkins A, Newton A, Nickell T, Pastres R, Forte J, Bodoy A, Bricker S (2009) Analysis of coastal and offshore aquaculture: application of the FARM model to multiple systems and shellfish species. Aquaculture 289:32-41

Ferreira JG, Hawkins AJS, Bricker SB (2007a) Management of productivity, environmental effects and profitability of shellfish aquaculture - the Farm Aquaculture Resource Management (FARM) model. Aquaculture 264:160-174

Ferreira JG, Hawkins AJS, Monteiro P, Service M, Moore H, Edwards A, Gowen R, Lourenco P, Mellor A, Nunes JP, Pascoe PL, Ramos L, Sequeira A, Simas T, Strong J (2007b) SMILE Sustainable Mariculture in northern Irish Lough Ecosystems - Assesment of carrying capacity for environmental sustainable shelfish culture in Carlingford Lough, Strangford Lough, Belfast Lough, Larne Lough and Lough Foyle. IMAR - Institute of Marine Research

Filgueira R, Peteiro LG, Labarta U, Fernandez-Reiriz MJ (2008) The self-thinning rule applied to cultured populations in aggregate growth matrices. Journal of Molluscan Studies 74:415-418

Folkard AM, Gascoigne JC (2009) Hydrodynamics of discontinuous mussel beds: Laboratory flume simulations. Journal of Sea Research 62:250-257

Folmer EO, Drent J, Troost K, Büttger H, Dankers N, Jansen J, van Stralen M, Millat G, Herlyn M, Philippart CJM (2014) Large-scale spatial dynamics of intertidal mussel (Mytilus edulis L.) Bed coverage in the German and Dutch Wadden Sea. Ecosystems 17:550-566

Frandsen RP, Dolmer P (2002) Effects of substrate type on growth and mortality of blue mussels (Mytilus edulis) exposed to the predator Carcinus maenas. Marine Biology 141:253-262

Frandsen RP, Eigaard OR, Poulsen LK, Tørring D, Stage B, Lisbjerg D, Dolmer P (2015) Reducing the impact of blue mussel (Mytilus edulis) dredging on the ecosystem in shallow water soft bottom areas. Aquatic Conservation: Marine and Freshwater Ecosystems 25:162-173

Fréchette M, Aitken AE, Page L (1992) Interdependence of food and space limitation of a benthic suspension feeder: consequences for self-thinning relationships. Marine Ecology Progress Series 83:55-62

Fréchette M, Alunno-Bruscia M, Dumais J-F, Sirois R, Daigle G (2005) Incompleteness and statistical uncertainty in competition/stocking experiments. Aquaculture 246:209-225

Fréchette M, Bacher C (1998) A modelling study of optimal stocking density of mussel populations kept in experimental tanks. Journal of Experimental Marine Biology and Ecology 219:241-255 


\section{References}

Fréchette M, Bourget E (1985) Food-limited growth of Mytilus edulis L. in relation to the benthic boundary layer. Canadian Journal of Fisheries and Aquatic Sciences 42:1166-1170

Fréchette M, Butman CA, Geyer WR (1989) The importance of boundary-layer flows in supplying phytoplankton to the benthic suspension feeder, Mytilus edulis L. Limnology \& Oceanography 34:19-36

Fréchette M, Lefaivre D (1990) Discriminating between food and space limitation in benthic suspension feeders using self-thinning relationships. Marine Ecology Progress Series 65:15-23

Fréchette M, Lefaivre D (1995) On self-thinning in animals. Oikos 73:425-428

Freeman AS (2007) Specificity of induced defenses in Mytilus edulis and asymmetrical predator deterrence. Marine Ecology Progress Series 334:145-153

Gallagher T, Richardson CA, Seed R, Jones T (2008) The seasonal movement and abundance of the starfish, Asterias rubens in relation to mussel farming practice: A case study from the Menai Strait, UK. Journal of Shellfish Research 27:1209-1215

Garner YL, Litvaitis MK (2013) Effects of injured conspecifics and predators on byssogenesis, attachment strength and movement in the blue mussel, Mytilus edulis. Journal of Experimental Marine Biology and Ecology 448:136-140

Gascoigne JC, Beadman HA, Saurel C, Kaiser MJ (2005) Density dependence, spatial scale and patterning in sessile biota. Oecologia 145:371-381

Geesteranus RM (1942) On the formation of banks by Mytilus edulis L. Archives neerlandaises de zoologie 6:283-326

Gosling E (2003) Bivalve Molluscs. Biology, Ecology and Culture, Blackwell Publishing, Oxford

Goulletquer P, Bachelet G, Sauriau PG, Noel P (2002) Open Atlantic coast of Europe-a century of introduced species into French waters. In: Leppa“koski, E., Gollasch, S., Olenin, S. (Eds.), Invasive Aquatic Species of Europe: Distribution, Impacts and Management. Kluwer Academic Publishers Dordrecht, The Netherlands

Goulletquer P, Heral M (1997) Marine molluscan production trends in France: from fisheries to aquaculture. NOAA Techical Report NMFS 129 


\section{References}

Grosholz E, Lovell S, Besedin E, Katz M (2011) Modeling the impacts of the European green crab on commercial shellfisheries. Ecological Applications 21:915-924

Gruffydd LD, Huxley R, Crisp DJ (1984) The reduction in growth of Mytilus edulis in fluctuating salinity regimes measured using laser diffraction patterns and the exaggeration of this effect by using tap water as the diluting medium. Journal of the Marine Biological Association of the United Kingdom 64:401-409

Guiñez R (2005) A review on self-thinning in mussels. Revista de Biologia Marina y Oceanografia 40:1-6

Gutiérrez JL, Jones CG, Byers JE, Arkema KK, Berkenbusch K, Commito JA, Duarte CM, Hacker SD, Lambrinos J, Hendriks I (2011) Physical ecosystem engineers and the functioning of estuaries and coasts, Elsevier, Amsterdam

Hamilton DJ, Nudds TD, Neate J (1999) Size-selective predation of blue mussels (Mytilus edulis) by common eiders (Somateria mollissima) under controlled field conditions. Auk 116:403-416

Havinga B (1960) De mosselteelt in de waddenzee [Mussel culture in the Wadden Sea]. Rapport aangeboden aan het College van Gedeputeerde Staten van de provincie Friesland

Hawkins A, Bayne B (1985) Seasonal variation in the relative utilization of carbon and nitrogen by the mussel Mytilus edulis: Budgets, conversion efficiencies and maintenance requirements. Marine ecology progress series 25:181-188

Hawkins AJS, Bayne BL, Bougrier S, Héral M, Iglesias JIP, Navarro E, Smith RFM, Urrutia MB (1998) Some general relationships in comparing the feeding physiology of suspension-feeding bivalve molluscs. Journal of Experimental Marine Biology and Ecology 219:87-103

Hawkins AJS, Smith RFM, Bayne BL, Héral M (1996) Novel observations underlying the fast growth of suspension- feeding shellfish in turbid environments: Mytilus edulis. Marine Ecology Progress Series 131:179-190

Herlyn M, Millat G (2000) Decline of the intertidal blue mussel (Mytilus edulis) stock at the coast of Lower Saxony (Wadden Sea) and influence of mussel fishery on the development of young mussel beds. Hydrobiologia 426:203-210 


\section{References}

Herman P, Middelburg J, Van de Koppel J, Heip C (1999) Ecology of estuarine macrobenthos. Advances in ecological research 29:195-240

Hilgerloh G, Herlyn M, Michaelis H (1997) The influence of predation by herring gulls Larus argentatus and oystercatchers Haematopus ostralegus on a newly established mussel Mytilus edulis bed in autumn and winter. Helgoland Marine Research 51:173-189

Honkoop PJC, Bayne BL, Underwood AJ, Svensson S (2003) Appropriate experimental design for transplanting mussels (Mytilus sp.) in analyses of environmental stress: An example in Sydney Harbour (Australia). Journal of Experimental Marine Biology and Ecology 297:253-268

Hughes RN, Griffiths CL (1988) Self-thinning in barnacles and mussels: the geometry of packing. American Naturalist 132:484-491

Hunt HL, Scheibling RE (2002) Movement and wave dislodgment of mussels on a wave-exposed rocky shore. Veliger 45:273-277

Inglis GJ, Gust N (2003) Potential indirect effects of shellfish culture on the reproductive success of benthic predators. Journal of Applied Ecology 40:1077-1089

Jones CG, Lawron JH, Shachak M (1997) Positive and negative effects of organisms as physical ecosystem engineers. Ecology 78:1946-1957

Kaiser M, Clarke K, Hinz H, Austen M, Somerfield P, Karakassis I (2006) Global analysis of response and recovery of benthic biota to fishing. Marine Ecology Progress Series 311:1-14

Kaiser M, Laing I, Utting S, Burnell G (1998) Environmental impacts of bivalve mariculture. Journal of Shellfish research 17:59-66

Kamermans P (2010) Rendement MZI zaad op percelen: effect van wegvissen van krabben perceelproef 2009 [Productivity of SMC seed on culture plots: effects of crab removal - experiment on culture plots 2009]. Wageningen Imares, Yerseke 


\section{References}

Kamermans P, Blankendaal M, Perdon J (2009) Predation of shore crabs (Carcinus maenas L.) and starfish (Asterias rubens L.) on blue mussel (Mytilus edulis L.) seed from wild sources and spat collectors. Aquaculture 290:256-262

Kamermans P, Brummelhuis E, Smaal AC (2002) Use of spat collectors to enhance supply of seed for bottom culture of blue mussels (Mytilus edulis) in the Netherlands. World Aquaculture 33:12-15

Kamermans P, Galley T, Boudry P, Fuentes J, Mccombie H, dos Reis Batista I, Garcia AB, Dominguez L, Cornette F, Pincot L (2013) Blue mussel hatchery technology in Europe. In: Allan G, Burnell G (Eds.) Advances in aquaculture hatchery technology Woodhead Publishing Ltd, Cambridge

Kamermans P, Smit CJ, Wijsman JWM, Smaal AC (2014) Meerjarige effect- en productiemetingen aan MZI's in de Westelijke Waddenzee, Oosterschelde en Voordelta: samenvattend eindrapport [Long term measurements on effects and production of SMCs in the western Wadden Sea]. IMARES Wageningen UR, Yerseke

Kangeri AK, Jansen JM, Barkman BR, Donker JJA, Joppe DJ, Dankers NMJA (2014) Perturbation induced changes in substrate use by the blue mussel, Mytilus edulis, in sedimentary systems. Journal of Sea Research 85:233-240

Kats R (2007) Common Eiders Somateria mollissima in the Netherlands, PhD Thesis. Rijksuniversiteit Groningen,

Kimura DK (1980) Likelihood methods for the von Bertalanffy growth curve. Fishery Bulletin 77:765-776

Knights AM (2012) Spatial variation in body size and reproductive condition of subtidal mussels: Considerations for sustainable management. Fisheries Research 113:45-54

Korringa P (1976) Mussel farming in the Netherlands. Development in aquaculture and fisheries, Vol 1, pp 50-102

Kristensen PS, Lassen H (1997) The production of relaid blue mussels (Mytilus edulis L.) in a Danish fjord. ICES Journal of Marine Science 54:854-865 


\section{References}

Lane A, Hough C, Bostock J (2014) The long-term economic and ecologic impact of larger sustainable aquaculture. In: Kelmelytė V (Eds.) Policy Department, Structural and Cohesion Policies. European Parliament.

Lassen J, Kortegård M, Riisgård HU, Friedrichs M, Graf G, Larsen PS (2006) Down-mixing of phytoplankton above filter-feeding mussels - Interplay between water flow and biomixing. Marine Ecology Progress Series 314:77-88

Laursen K, Asferg KS, Frikke J, Sunde P (2009) Mussel fishery affects diet and reduces body condition of Eiders Somateria mollissima in the Wadden Sea. Journal of Sea Research 62:22-30

Lauzon-Guay J-S, Dionne M, Barbeau MA, Hamilton DJ (2005) Effects of seed size and density on growth, tissue-to-shell ratio and survival of cultivated mussels (Mytilus edulis) in Prince Edward Island, Canada. Aquaculture 250:652-665

Lauzon-Guay JS, Scheibling RE, Barbeau MA (2008) Formation and propagation of feeding fronts in benthic marine invertebrates: A modeling approach. Ecology 89:3150-3162

Lee CY, Lim SSL, Owen MD (1990) The rate and strength of byssal reattachment by blue mussels (Mytilus edulis L.). Canadian Journal of Zoology 68:2005-2009

Lenihan, H. S. and F. Micheli. 2001. Soft-sediment communities. In: M. D. Bertness, S. D. Gaines, and M. E. Hay, (Eds.) Marine Community Ecology, pp. 253-287. Sunderland, MA: Sinauer Associates

Leonard GH, Bertness MD, Yund PO (1999) Crab predation, waterborne cues, and inducible defenses in the blue mussel, Mytilus edulis. Ecology 8o:1-14

Lin J (1991) Predator-prey interactions between blue crabs and ribbed mussels living in clumps. Estuarine, Coastal and Shelf Science 32:61-69

Liu Q-X, Doelman A, Rottschäfer V, de Jager M, Herman PMJ, Rietkerk M, van de Koppel J (2013) Phase separation explains a new class of self-organised spatial patterns in ecological systems. Proceedings of the National Academy of Sciences 110:11905-11910

Liu Q-X, Herman PMJ, Mooij WM, Huisman J, Scheffer M, Olff H, van de Koppel J (2014) Pattern formation at multiple spatial scales drives the resilience of mussel bed ecosystems. 5:5234 


\section{References}

Liu Q-X, Weerman EJ, Herman PMJ, Olff H, van de Koppel J (2012) Alternative mechanisms alter the emergent properties of self-organisation in mussel beds. Proceedings of the Royal Society B: Biological Sciences 279:2744-2753

LNV (1993) Vissen naar evenwicht [Fishing towards an equilibrium], Structuurnota Zee- en Kustvisserij. In. Ministerie van LNV, Den Haag

LNV (2009a) Hoofdpunten voorgenomen MZI-beleid [main issues in the proposed policy on the use of SMC seed]. Ministerie van LNV, Den Haag

LNV (2009b) Natuurlijk voorwaarts, Plan van Uitvoering convenant transitie mosselsector en natuurherstel Waddenzee [Plan of action convenant transition mussel sector and nature restoration in the Wadden Sea]. In. Ministerie van LNV, Den Haag

Lotze HK, Reise K, Worm B, van Beusekom J, Busch M, Ehlers A, Heinrich D, Hoffmann RC, Holm P, Jensen C, Knottnerus OS, Langhanki N, Prummel W, Vollmer M, Wolff WJ (2005) Human transformations of the Wadden Sea ecosystem through time: A synthesis. Helgoland Marine Research 59:84-95

Maar M, Saurel C, Landes A, Dolmer P, Petersen JK (2015) Growth potential of blue mussels ( $M$. edulis) exposed to different salinities evaluated by a Dynamic Energy Budget model. Journal of Marine Systems 148:48-55

MacKenzie Jr CL, Burrell jr. VG, Rosenfield A, Hobart WL, (Eds.) (1997) The history, present condition, and future of the molluscan fisheries of North and Central America and Europe, Volume 3, Europe. , Vol 129. U.S. Dep. Commer.

Maguire JA, Knights T, Burnell G, Smaal AC (2007) Management recommendations for the sustainable exploitation of mussel seed in the Irish Sea. Marine Environmental Health Series No 31

Mannino MA, Thomas KD (2002) Depletion of a resource? The impact of prehistoric human foraging on intertidal mollusc communities and its significance for human settlement, mobility and dispersal. World Archaeology 33:452-474

Mascaró M, Seed R (2001) Foraging behaviour of juvenile Carcinus maenas (L.) and Cancer pagurus (L.). Marine Biology 139:1135-1145 


\section{References}

McGarigal K, Cushman SA, Neel MC, Ene E (2002) FRAGSTATS: Spatial pattern analysis program for categorical maps. FRAGSTATS: Spatial Pattern Analysis Program for Categorical Maps

McGrorty S, Clarke RT, Reading CJ, Goss-Custard JD (1990) Population dynamics of the mussel Mytilus edulis: Density changes and regulation of the population in the Exe estuary, Devon. Marine Ecology Progress Series 67:157-169

McGrorty S, Goss-Custard JD (1991) Population dynamics of the mussel Mytilus edulis: spatial variations in age-class densities of an intertidal estuarine population along environmental gradients. Marine Ecology Progress Series 73:191-202

McGrorty S, Goss-Custard JD (1993) Population dynamics of the mussel Mytilus edulis along environmental gradients: spatial variations in density-dependent mortalities. Journal of Animal Ecology 62:415-427

McGrorty S, Goss-Custard JD, Clarke RT (1993) Mussel Mytilus edulis (Mytilacea) dynamics in relation to environmental gradients and intraspecific interactions. Netherlands Journal of Aquatic Ecology 27:163-171

Meire PM, Ervynck A (1986) Are oystercatchers (Haematopus ostralegus) selecting the most profitable mussels (Mytilus edulis)? Animal Behaviour 34:1427-1435

Menge BA, Daley B, Wheeler P (1996) Control of interaction strength in marine benthic communities. Food webs. Springer

Menge BA, Sutherland JP (1976) Species diversity gradients: Synthesis of the roles of predation, competition and temporal heterogeneity. The American Naturalist 110:351-369

Menge BA, Sutherland JP (1987) Community regulation: variation in disturbance, competition, and predation in relation to environmental stress and recruitment. The American Naturalist 130:730-757

Møhlenberg F, Riisgård HU (1978) Efficiency of particle retention in 13 species of suspension feeding bivalves. Ophelia 17:239-246

Moksnes PO (2002) The relative importance of habitat-specific settlement, predation and juvenile dispersal for distribution and abundance of young juvenile shore crabs Carcinus maenas L. Journal of Experimental Marine Biology and Ecology 271:41-73 


\section{References}

Morrell LJ, Romey WL (2008) Optimal individual positions within animal groups. Behavioural Ecology 19:909-919

Munch-Petersen S, Kristensen PS (2001) On the dynamics of the stocks of blue mussels (Mytilus edulis L.) in the Danish Wadden Sea. Hydrobiologia 465:31-43

Murray LG, Newell CR, Seed R (2007a) Changes in the biodiversity of mussel assemblages induced by two methods of cultivation. Journal of Shellfish Research 26:153-162

Murray LG, Seed R, Jones T (2007b) Predicting the impacts of Carcinus maenas predation on cultivated Mytilus edulis beds. Journal of Shellfish Research 26:1089-1098

Nauen CE (1978) The growth of the sea star, Asterias rubens, and its role as benthic predator in Kiel Bay. Kieler Meeresforschiungen 4:68-81

Nehls G (2009) Fishery. Thematic report No. 3.3. Quality Status Report 2009

Nehls G, Thiel M (1993) Large-scale distribution patterns of the mussel Mytilus edulis in the Wadden Sea of Schleswig-Holstein: Do storms structure the ecosystem? Netherlands Journal of Sea Research 31:181-187

Nehls G, Witte S, Büttger H, Dankers N, Jansen J, Millat G, Herlyn M, Markert A, Kristensen P, Ruth M (2009) Beds of blue mussels and Pacific oysters: Thematic report no. 11. Wadden Sea quality status report 2004/Common Wadden Sea Secretariat, Trilateral Monitoring and Assessment Group; Quality Status Report Group H Marencic \& J Vlas de (Eds) Wilhelmshaven: Common Wadden Sea Secretariat, Trilateral Monitoring and Assess

Newell CR (1990) The effects of mussel (Mytilus edulis, linnaeus, 1758 ) position in seeded bottom patches on growth at subtidal lease sites in Maine. Journal of Shellfish Research 9:113-118

Newell CR (2007) Case study 1 - Factors which influence mussel production on bottom leases. In: SMILE - Sustainable Mariculture in northern Irish Lough Ecosystems - Assesment of Carrying Capacity for Environmental Sustainable Shelfish Culture in Carlingford Lough, Strangford Lough, Belfast Lough, Larne Lough and Lough Foyle. IMAR - Institute of Marine Research

Newell CR, Campbell DE, Gallagher SM (1998) Development of the mussel aquaculture lease site model MUSMOD@: a field program to calibrate model formulations. Journal of Experimental Marine Biology and Ecology 219:143-169 


\section{References}

Newell CR, Shumway SE (1993) Grazing of natural particulates by bivalve molluscs: A spatial and temporal perspective. In: Dame RF (ed) NATO ASI Series Bivalve Filter Feeders, in Estuarine \& Coastal Ecosystems Processes, Book G33. Springer Verlag, Berlin

Newell RI, Koch EW (2004) Modeling seagrass density and distribution in response to changes in turbidity stemming from bivalve filtration and seagrass sediment stabilization. Estuaries 27:793806

Newell RIE (2004) Ecosystem influences of natural and cultivated populations of suspensionfeeding bivalve molluscs: A review. Journal of Shellfish Research 23:51-61

Nguyen T (2012) Implicit price of mussel characteristics in the auction market. Aquaculture International 20:605-618

Nienhuis PH, Smaal AC (1994) The Oosterschelde Estuary (The Netherlands): A case-study of a changing ecosystem [Special issue of 43 papers]. Hydrobiologia 282-3:1-597

Nilsson L (2005) Wintering diving duck populations in the Öresund, Southern Sweden, in relation to available food resources. Wildfowl 55:61-75

ODUS (2001) Uit de schulp-Visieop duurzameontwikkeling van de Nederlandse schelpdiervisserij ["Out of the Shell", Viewpoint on sustainable development of the Dutch shellfish sector]. Stichting Odus, Yerseke

Ogle DH (2015a) Chapter 12 - Individual Growth. In: Introductory Fisheries Analyses with R. CRC press

Ogle DH (2015b) FSA: Fisheries Stock Analysis. R package version o.8.4.

Okamura B (1986) Group living and the effects of spatial position in aggregations of Mytilus edulis. Oecologia 69:341-347

Paine R (1976a) Biological observations on a subtidal Mytilus californianus bed. Veliger 19:30

Paine R (1976b) Size-limited predation: an observational and experimental approach with the Mytilus-Pisaster interaction. Ecology 57:858-873 


\section{References}

Palmer AR (1981) Do carbonate skeletons limit the rate of body growth? Nature 292:150-152

Payne BS, Miller AC, Jin L (1995) Palp to gill area ratio of bivalves: a sensitive indicator of elevated suspended solids. Regulated Rivers: Research \& Management 11:193-200

Petersen AJK, Gislason H, Fitridge I, Saurel C, Degel H, Nielsen CF (2016) Fiskeri efter søstjerner i Limfjorden. Fagligt grundlag for en forvaltningsplan. In. Institut for Akvatiske Ressourcer, Danmarks Tekniske Universitet

Petersen JK, Maar M, Ysebaert T, Herman PMJ (2013) Near-bed gradients in particles and nutrients above a mussel bed in the Limfjorden: influence of physical mixing and mussel filtration. Marine Ecology Progress Series 490:137-146

Petraitis PS (1995a) The role of growth in maintaining spatial dominance by mussels (Mytilus edulis). Ecology 76:1337-1346

Petraitis PS (1995b) Use of Average vs. Total Biomass in Self-Thinning Relationships. Ecology $76: 656-658$

Philippart CJM, Van Iperen JM, Cadée GC, Zuur AF (2010) Long-term field observations on seasonality in chlorophyll-a concentrations in a shallow coastal marine ecosystem, the Wadden Sea. Estuaries and Coasts 33:286-294

Piersma T, Camphuysen CJ (2001) What can peak mortality of Eiders tell us about the state of the Dutch Wadden Sea Ecosystem. Wadden Sea Newsletter 2001:42-45

Pinheiro J, Bates D, DebRoy S, Sarkar D, Team RC (2014) nlme: Linear and Nonlinear Mixed Effects Models. R package version 3.1-117, http://CRAN.R-project.org/package=nlme.

Plass-Johnson JG, McQuaid CD, Porri F (2010) Top-down effects on intertidal mussel populations: assessing two predator guilds in a South African marine protected area. Marine Ecology Progress Series 411:149-159

Prins TC, Dankers N, Smaal AC (1994) Seasonal variation in the filtration rates of a semi-natural mussel bed in relation to seston composition. Journal of Experimental Marine Biology and Ecology 176:69-86

PV (1993) Beheersplan Kustvisserij Schelpdier Visserij [Managmentplan coastal shelfish fisheries]. Productschap Vis, Rijswijk 


\section{References}

R Core Team (2016) R: A language and environment for statistical computing. R Foundation for Statistical Computing, Vienna, Austria. ISBN 3-900051-07-o, URL http://www.R-project.org.

Reid D, Naylor E (1993) Different free-running periods in split components of the circatidal rhythm in the shore crab Carcinus maenas. Marine Ecology Progress Series 102:295-302

Reimer O, Tedengren M (1997) Predator induced changes in byssal attachment, aggregation and migration in the blue mussel, Mytulis edulis. Marine and Freshwater Behaviour and Physiology 4:251-266

Renault T, Le Deuff R-M, Cochennec N, Maffart P (1994) Herpesviruses associated with mortalities among Pacific oyster, Crassostrea gigas, in France-Comparative study. Revue de Médecine Vétérinaire 145:735-742

Reusch TBH, Chapman ARO (1995) Storm effects on eelgrass (Zostera marina L.) and blue mussel (Mytilus edulis L.) beds. Journal of Experimental Marine Biology and Ecology 192:257-271

Reusch TBH, Chapman ARO (1997) Persistence and space occupancy by subtidal blue mussel patches. Ecological Monographs 67:65-87

Ridderinkhof H, Zimmerman JTF, Philippart ME (1990) Tidal exchange between the North Sea and Dutch Wadden Sea and mixing time scales of the tidal basins. Netherlands Journal of Sea Research 25:331-350

Riisgård HU, Bøttiger L, Pleissner D (2012) Effect of salinity on growth of mussels, Mytilus edulis, with special reference to Great Belt (Denmark) Open Journal of Marine Science 2:167-176

Riisgård HU, Lüskow F, Pleissner D, Lundgreen K, López MÁP (2013) Effect of salinity on filtration rates of mussels Mytilus edulis with special emphasis on dwarfed mussels from the low-saline Central Baltic Sea. Helgoland Marine Research 67:591-598

Rönnbäck P, Kautsky N, Pihl L, Troell M, Söderqvist T, Wennhage H (2007) Ecosystem goods and services from Swedish coastal habitats: identification, valuation, and implications of ecosystem shifts. Journal of the Human Environment 36:534-544

Rosland R, Bacher C, Strand Ø, Aure J, Strohmeier T (2011) Modelling growth variability in longline mussel farms as a function of stocking density and farm design. Journal of Sea Research 66:318-330 


\section{References}

Saier B (2001) Direct and indirect effects of seastars Asterias rubens on mussel beds (Mytilus edulis) in the Wadden Sea. Journal of Sea Research 46:29-42

Sanchez-Salazar ME, Griffiths CL, Seed R (1987) The effect of size and temperature on the predation of cockles Cerastoderma edule (L.) by the shore crab Carcinus maenas (L.). Journal of Experimental Marine Biology and Ecology 111:181-193

Saranchova OL, Flyachinskaya LP (2001) The influence of salinity on early ontogeny of the mussel Mytilus edulis and the starfish Asterias rubens from the White Sea. Russian Journal of Marine Biology 27:87-94

Saurel C, Ferreira JG, Cheney D, Suhrbier A, Dewey B, Davis J, Cordell J (2014) Ecosystem goods and services from Manila clam culture in Puget Sound: a modelling analysis. Aquaculture Environment Interactions 5:255-270

Saurel C, Petersen JK, Wiles PJ, Kaiser MJ (2013) Turbulent mixing limits mussel feeding: direct estimates of feeding rate and vertical diffusivity. Marine Ecology Progress Series 485:105-121

Scholten H, Smaal AC (1999) The ecophysiological response of mussels (Mytilus edulis) in mesocosms to a range of inorganic nutrient loads: Simulations with the model EMMY. Aquatic Ecology 33:83-100

Seed R (1976) Ecology. In: Bayne BL (Eds.) Marine Mussels: Their Ecology and Physiology, Book 10. Cambridge University Press, Cambridge, England

Seed R, Suchanek TH (1992) Population and community ecology of Mytilus. In: Gosling E (Eds.) The Mussel Mytilus: ecology, physiology, genetics and culture. Elsevier, Amsterdam

Shumway SE (1977) The effects of fluctuating salinities on four species of asteroid echinoderms. Comparative biochemistry and physiology Part A, Molecular \& integrative physiology 58A:177179

Sibly RM, McCleery RH (1983) The distribution between feeding sites of herring gulls breeding at Walney Island, UK. Journal of Animal Ecology 52:51-68

Silva ACF, Boaventura DM, Thompson RC, Hawkins SJ (2014) Spatial and temporal patterns of subtidal and intertidal crabs excursions. Journal of Sea Research 85:343-348 


\section{References}

Smaal A, Van Stralen M, Schuiling E (2001a) The interaction between shellfish culture and ecosystem processes. Canadian Journal of Fisheries and Aquatic Sciences 58:991-1002

Smaal A, Verbagen J, Coosen J, Haas H (1986) Interaction between seston quantity and quality and benthic suspension feeders in the Oosterschelde, The Netherlands. Ophelia 26:385-399

Smaal AC (1991) The ecology and cultivation of mussels: new advances. Aquaculture 94:245-261

Smaal AC (2002) European mussel cultivation along the Atlantic coast: Production status, problems and perspectives. Hydrobiologia 484:89-98

Smaal AC, Brinkman AG, Schellekens T, Aguera A, Van Stralen MR (2013a) Ontwikkeling en stabiliteit van sublitorale mosselbanken, samenvattend eindrapport [Development and stability of subtidal musselbeds]. IMARES Wageningen UR, Yerseke

Smaal AC, Craemeersch J, Kamermans P, Van Stralen MR (20o1b) Is food shortage the cause of Eider duck mortality? Shellfish and crab abundance in the Dutch Wadden Sea 1994 - 1999. Wadden Sea Newsletter 1:35-38

Smaal AC, Haas HA (1997) Seston dynamics and food availability on mussel and cockle beds. Estuarine, Coastal and Shelf Science 45:247-259

Smaal AC, Schellekens T, Van Stralen MR, Kromkamp JC (2013b) Decrease of the carrying capacity of the Oosterschelde estuary (SW Delta, NL) for bivalve filter feeders due to overgrazing? Aquaculture 404-405:28-34

Smaal AC, Van Stralen MR (1990) Average annual growth and condition of mussels as a function of food source. Hydrobiologia 195:179-188

Smaal AC, Wijsman JWM, Van Stralen MR (2010) Mussel culture and subtidal mussel stock management in the western Wadden Sea: Are exploitation and conservation compatible? Wadden Sea Ecosystem 26:145-150

Smallegange IM, Van Der Meer J (2003) Why do shore crabs not prefer the most profitable mussels? Journal of Animal Ecology 72:599-607

Smallegange IM, Van Der Meer J (2007) Interference from a game theoretical perspective: Shore crabs suffer most from equal competitors. Behavioural Ecology 18:215-221 


\section{References}

Smallegange IM, Van Noordwijk CGE, Van der Meer J (2009) Spatial distribution of shore crabs Carcinus maenas in an intertidal environment in relation to their morphology, prey availability and competition. Marine Ecology Progress Series 392:143-155

Smit CJ, Dankers N, Ens BJ, Meijboom A (1998) Birds, mussels, cockles and shellfish fishery in the Dutch Wadden Sea: how to deal with low food stocks for eiders and oystercatchers? Senckenbergiana Maritima 29:141-153

Smith J, Shackley SE (2004) Effects of a commercial mussel Mytilus edulis lay on a sublittoral, soft sediment benthic community. Marine Ecology Progress Series 282:185-191

Sneddon L, Huntingford F, Taylor A, Orr J (2000) Weapon strength and competitive success in the fights of shore crabs (Carcinus maenas). Journal of Zoology 250:397-403

Sneddon LU, Huntingford FA, Taylor AC (1997) The influence of resource value on the agonistic behaviour of the shore crab, Carcinus maenas (L.). Marine and Freshwater Behaviour and Physiology 30:225-237

Snover ML, Commito JA (1998) The fractal geometry of Mytilus edulis L. spatial distribution in a soft-bottom system. Journal of Experimental Marine Biology and Ecology 223:53-64

Soetaert K, Petzoldt T, Woodrow Setzer R (2010) Solving Differential Equations in R: Package deSolve. Journal of Statistical Software 33:1-25

Somers IF (1988) On a seasonally oscillating growth function. Fishbyte 6:8-11

Sommer U, Meusel B, Stielau C (1999) An experimental analysis of the importance of body-size in the seastar-mussel predator-prey relationship. Acta Oecologica 20:81-86

Spångberg J, Jönsson H, Tidåker P (2013) Bringing nutrients from sea to land-mussels as fertiliser from a life cycle perspective. Journal of Cleaner Production 51:234-244

Sprung M (1984) Physiological energetics of mussel larvae (Mytilus edulis). I. Shell growth and biomass. Marine ecology progress series 17:283-293

Steenbergen J, Baars J, van Stralen M, Craeymeersch J (2006) Winter survival of mussel beds in the intertidal part of the Dutch Wadden Sea. Monitoring and Assessment in the Wadden Sea Proceedings from the 11 Scientific Wadden:107

Steenbergen J, Breen VP, Jol JG (2005) LNV bestek mosselen en eidereenden Deelproject 3 : een vergelijking van de kwaliteit van mosselen op percelen en in het wild [Comparison between 


\section{References}

mussel quality on culture plots and natural beds]. RIVO, IJmuiden

Stillman RA, Goss-Custard JD, West AD, Dit Durell SEALV, McGrorty S, Caldow RWG, Norris KJ, Johnstone IG, Ens BJ, Van Der Meer J, Triplet P (2001) Predicting shorebird mortality and population size under different regimes of shellfishery management. Journal of Applied Ecology 38:857-868

Stillman RA, McGrorty S, Goss-Custard JD, West AD (200o) Predicting mussel population density and age structure: The relationship between model complexity and predictive power. Marine Ecology Progress Series 208:131-145

Strasser M (2003) How predictable is high bivalve recruitment in the Wadden Sea after a severe winter? Journal of Sea Research 49:47-57

Suchanek T (1992) Extreme biodiversity in the marine-environment-mussel bed communities of Mytilus californianus. Northwest Environ J 8: 150-152.

Svane I, Ompi M (1993) Patch dynamics in beds of the blue mussel Mytilus Edulis L.: effects of site, patch size, and position within a patch. Ophelia 37:187-202

Swennen C, Nehls G, Laursen K (1989) Numbers and distribution of eiders Somateria mollissima in the Wadden Sea. Netherlands Journal of Sea Research 24:83-92

Taal K, Turenhout M (2013) Notitie Quick scan Mosselsector [Quick scan mussel culture sector]. In. LEI Wageningen UR, Den Haag

Theisen BF (1968) Growth and mortality of culture mussels in the Danish Wadden Sea. Medd Danm Fiskeri og Havunders NS 6:47-78

Troost TA, Wijsman JWM, Saraiva S, Freitas V (2010) Modelling shellfish growth with dynamic energy budget models: An application for cockles and mussels in the Oosterschelde (southwest Netherlands). Philosophical Transactions of the Royal Society B: Biological Sciences 365:35673577

Van Aken HM (2008) Variability of the salinity in the western Wadden Sea on tidal to centennial time scales. Journal of Sea Research 59:121-132 


\section{References}

Van de Kam J, De Goeij P, Moore SJ, Ens B, Piersma T, Zwarts L (2004) Shorebirds : an illustrated behavioural ecology. KNNV Publishers, Utrecht

Van De Koppel J, Bouma TJ, Herman PMJ (2012) The influence of local-and landscape-scale processes on spatial self-organisation in estuarine ecosystems. Journal of Experimental Biology 215:962-967

Van De Koppel J, Gascoigne JC, Theraulaz G, Rietkerk M, Mooij WM, Herman PMJ (20o8) Experimental evidence for spatial self-organisation and its emergent effects in mussel bed ecosystems. Science 322:739-742

Van de Koppel J, Rietkerk M, Dankers N, Herman PM (2005) Scale-dependent feedback and regular spatial patterns in young mussel beds. The American naturalist 165:66-77

Van der Heide T, Tielens E, van der Zee EM, Weerman EJ, Holthuijsen S, Eriksson BK, Piersma T, van de Koppel J, Olff H (2014) Predation and habitat modification synergistically interact to control bivalve recruitment on intertidal mudflats. Biological Conservation 172:163-169

Van der Veer HW, Cardoso JFMF, Van der Meer J (2006) The estimation of DEB parameters for various Northeast Atlantic bivalve species. Journal of Sea Research 56:107-124

Van der Veer HW, Feller RJ, Weber A, Ij. Witte J (1998) Importance of predation by crustaceans upon bivalve spat in the intertidal zone of the Dutch Wadden Sea as revealed by immunological assays of gut contents. Journal of Experimental Marine Biology and Ecology 231:139-157

Van Hoof L (2012) If you can't beat them; joint problem solving in Dutch fisheries management. Maritime Studies 11:1-16

Van Leeuwen B, Augustijn DCM, van Wesenbeeck BK, Hulscher SJMH, de Vries MB (2010) Modeling the influence of a young mussel bed on fine sediment dynamics on an intertidal flat in the Wadden Sea. Ecological Engineering 36:145-153

Van Stralen M (2002) De ontwikkeling van mosselbestanden op droogvallende platen en in het sublitoraal van de Waddenzee vanaf 1955 [Development of mussel stock in the litoral and sublitoral western Wadden Sea since 1955]. EVA-2 project F2: Habitatkaart mosselbanken. Marinx, Scharendijke

Van Stralen MR (2016) Invang van mosselzaad in MZI's. Resultaten 2015 [Musselseed collection with SMCs Results from 2015]. Marinx, Scharendijke 


\section{References}

Van Stralen MR, Craeymeersch J, Drent J, Glorius S, Jansen JM, Smaal AC (2013) Het mosselbestand op de PRODUS vakken en de effecten van de visserij daarop [Effects of fishery on mussel stock on experimental PRODUS plots] Effecten van mosselzaadvisserij op sublitorale natuurwaarden in de westelijke Waddenzee [Effects of mussel seed fishery on natural values of the subtidal western Wadden Sea]. Marinx, Scharendijke

Van Stralen MR, Dijkema RD (1994) Mussel culture in a changing environment: the effects of a coastal engineering project on mussel culture (Mytilus edulis L.) in the Oosterschelde estuary (SW Netherlands). Hydrobiologia 282/283:359-379

Van Stralen MR, Van den Ende D, Troost K (2015) Inventarisatie van het sublitorale wilde mosselbestand in de westelijke Waddenzee in het voorjaar van 2015 [Inventarization of natural subtidal mussel stock in the western Wadden Sea in the Spring of 2015]. Marinx, Scharendijke

Von Bertalanffy L (1938) A quantitative theory of organic growth (inquiries on growth laws. II). Human biology 10:181-213

Wang ZB, Hoekstra P, Burchard H, Ridderinkhof H, De Swart HE, Stive MJF (2012) Morphodynamics of the Wadden Sea and its barrier island system. Ocean \& Coastal Management 68:39-57

Waselkov GA (1987) Shellfish gathering and shell midden archaeology. Advances in archaeological method and theory 10:93-210

Westbroek L (1979) Technical research in Dutch mussel farming. Procedings of the 1oth annual shellfish conference, London

Westerbom M, Kilpi M, Mustonen O (2002) Blue mussels, Mytilus edulis, at the edge of the range: population structure, growth and biomass along a salinity gradient in the north-eastern Baltic Sea. Marine Biology 140:991-999

Westoby M (1984) The self-thinning rule. Advances in Ecological Research 14:167-225

Whitton TA, Jenkins SR, Richardson CA, Hiddink JG (2012) Aggregated prey and predation rates: Juvenile shore crabs (Carcinus maenas) foraging on post-larval cockles (Cerastoderma edule). Journal of Experimental Marine Biology and Ecology 432-433:29-36 


\section{References}

Widdows J, Donkin P, Salkeld PN, Cleary JJ, Lowe DM, Evans SV, Thompson PE (1984) Relative importance of environmental factors in determining physiological differences between two populations of mussels (Mytilus edulis). Marine Ecology Progress Series 17:33-47

Widdows J, Lucas JS, Brinsley MD, Salkeld PN, Staff FJ (2002) Investigation of the effects of current velocity on mussel feeding and mussel bed stability using an annular flume. Helgoland Marine Research 56:3-12

Wijsman JWM, Schellekens T, Van Stralen M, Capelle JJ, Smaal AC (2014) Rendement van mosselkweek in de westelijke Waddenzee [Efficiency of mussel culture in the western Wadden Sea]. In. IMARES Wageningen UR, Yerseke

Wiles PJ, van Duren LA, Häse C, Larsen J, Simpson JH (2006) Stratification and mixing in the Limfjorden in relation to mussel culture. Journal of Marine Systems 6o:129-143

Wilson JG (2002) Productivity, fisheries and aquaculture in temperate estuaries. Estuarine, Coastal and Shelf Science 55:953-967

Witman JD, Suchanek TH (1984) Mussels in flow: Drag and dislodgement by epizoans. Marine Ecology Progress Series 16:259-268

Wolff WJ (200o) Causes of extirpations in the Wadden Sea, an estuarine area in the Netherlands. Conservation Biology 14:876-885

Young G (1983) The effect of sediment type upon the position and depth at which byssal attachment occurs in Mytilus edulis. Journal of the Marine Biological Association of the United Kingdom 63:641-651

Ysebaert T, Hart M, Herman PMJ (2009) Impacts of bottom and suspended cultures of mussels Mytilus spp. on the surrounding sedimentary environment and macrobenthic biodiversity. Helgoland Marine Research 63:59-74

Zuur A, Ieno EN, Walker N, Saveliev AA, Smith GM (2009) Mixed effects models and extensions in ecology with R. Springer Science + Business Media, New York 


\section{References}

Zuur AF, Ieno EN, Elphick CS (2010) A protocol for data exploration to avoid common statistical problems. Methods in Ecology and Evolution 1:3-14

Zuur AF, Ieno EN, Smith GM (2007) Analysing Ecological Data. Springer Science + Business Media, New York

Zwarts L, Hulscher JB, Koopman K, Zegers PM (1996) Short-term variation in the body weight of Oystercatchers Haematopus ostralegus: Effect of available feeding time by day and night, temperature and wind force. Ardea 84:357-372 


\section{Summary}

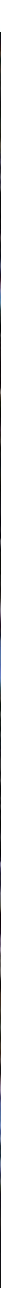

English - Nederlands 


\section{Summary}

\section{English summary}

Mussel bottom culture is an extensive type of aquaculture, it depends on natural resources for feed, seed and space. It consists of the translocation of juvenile mussels (seed) from natural beds to designated culture areas, where mussel farmers try to improve production efficiency. Production efficiency is expressed as the relative biomass production (RBP), which is the ratio between biomass harvested and biomass seeded.

The RBP increases over time due to growth and decreases due to mortality. Mussel bottom culture makes use of natural resources and depends on the natural environment. Cultured mussels are subject to similar environmental factors that influence growth and mortality on natural mussel beds, with additional effects of culture activities. In this thesis we focus on dynamics of mussel beds and the impact and effectiveness of culture activities on mussel production yield.

The theoretical framework of this thesis is introduced in Chapter $\mathbf{1}$ and the major objectives are stated as: (1) to better understand the population dynamics of subtidal mussel populations, (2) to analyze which factors determine production efficiency in mussel bottom culture and how this can be improved. In this chapter the population dynamics of mussels in the human-natural system of mussel bottom culture are reviewed. In Chapter 2 developments in culture techniques in relation to optimize production efficiency are reviewed for mussel bottom culture in the Netherlands. The Netherlands harbors the largest mussel bottom culture area in the world, with at total annual production of about $60 \mathrm{Mkg}$. In the Netherlands the transition from a labor intensive culture to a highly mechanized culture took place between 1960 to 1990. Technological innovations made it possible to increase fishing efficiency and process high mussel biomasses in a short amount of time. Policy measures such as closure 


\section{Summary}

of areas following environmental concern has led to a substantial reduction in resource availability since the 1990s. As a consequence of further pressure to reduce bottom seed fishery a second major technological change in system innovation has developed, specifically the introduction and extensive use of seed mussel collectors (SMCs) for resource provisioning. Implications for production efficiency are that scarcity and higher costs of resources drive the need to obtain higher production efficiency through better use of seed resources. We argue that major changes in technology urge for improved technology at other parts, for example, productivity of seed from SMCs needs to be increased by implementing better seeding techniques to become cost efficient.

Seeding of mussels at culture plots results in a spatial heterogeneity in mussel density that differs from the spatial patterns of mussels in natural beds,. The research question addressed in Chapter 3 is whether this spatial organisation of the mussels imposed at seeding, affects biomass production. In a field experiment we tested how mussel distribution in space affects biomass development by relying the same number of mussels on different areas, within plots of the same size. Aggregation, growth rates and loss rates at the different densities were monitored over a twelve-week period. Results show that mussels stayed within the area where they were initially laid, but redistributed differently dependent on initial density. At higher densities mussels aggregated into uniform matrices or in a few larger patches, at lower densities mussels aggregated into numerous small patches. Survival and biomass within a plot decreased with initial density. No differences in growth rates were found at the end of the experiment. Results suggest that the relation between mussel survival and mussel density is associated with the redistribution process, with less competition for space when mussels are positioned at the edges of mussel patches. Very high mussel losses (up to 75\%) were found in the first four weeks of the experiment and this was the major factor that determined biomass development. 


\section{Summary}

These findings suggest that seeding density is an important factor in determining the production efficiency in mussel bottom culture. The impact of mussel density on biomass production is further investigated in Chapter 4 . This was done by a monitoring program at mussel culture plots in the western part of the Dutch Wadden Sea. During three years, growth and survival of 66 mussel cohorts were monitored from seeding to harvest at 42 different culture plots. Additional data on seeding and harvest were provided by the mussel farmers. Seeding at the start of the culture cycle resulted in an instantaneous drop in biomass, caused by large losses in mussel numbers. These losses were on average $42 \%$ of the mussels seeded. This seeding loss decreased with mussel size and increased with seeding density. Losses during the grow-out phase were substantially lower, a subsequent density dependent loss of was found for smaller mussels $(<30 \mathrm{~mm})$, and a non-density dependent loss for larger mussels $(>30 \mathrm{~mm}$ ). Overall loss from seeding to harvest was high, from $92 \%$ for the smallest seeds collected from spat collectors, to $54 \%$ for larger, half-grown mussels fished from natural beds in spring. No relation between mussel density and growth rate was found. The density dependent seeding loss associated with seeding activities largely determined survival, and hence overall biomass production.

Mussel farmers apply predator control on culture plots to increase the production efficiency. Predators on subtidal mussel beds in the Wadden Sea are sea stars, molluscivorous ducks and shore crabs. The impact of sea stars and molluscivorous ducks on mussel dynamics in the Wadden Sea has recently been extensively investigated. However, shore crabs are also important predators on mussels, both intertidally and subtidally. In Chapter 5 the effect of shore crab predation on mussel biomass production was addressed. In a case study at an intertidal culture plot in the Oosterschelde using exclosures for crabs. The impact of predation was studied and provided an estimate on how the prevention of shore crab predation on the culture plot would affect production. 


\section{Summary}

During the first 5 weeks, about one-third of the total losses could be attributed to shore crab predation.

It can be expected that cultureactivities, that are directed to optimize production efficiency result in a higher overall biomass. However, part of the mussels are harvested and removed from the system. The extent to which mussel culture impact system-scale biomass mussel production is addressed in Chapter 6. In this chapter, we compare population dynamics of mussels on natural mussel beds with the population dynamics of mussels on culture plots in the Wadden Sea. Forty natural subtidal mussel populations in the western Wadden Sea were monitored over a seven-year period and compared with the results from culture plots as described in Chapter 4. Natural mussel beds and culture plots were to a large extent spatially segregated. Results show that culture activities strongly affects the population dynamics of the subtidal mussel population, through relay of mussels from natural mussel beds to culture plots. the activities increased mussel growth and survival. This effect is ascribed to the fact that culture plots are translocated to areas with relatively good food conditions while predation by sea stars is prevented by the farmers. Despite harvesting, RBP on culture plots was higher than on natural mussel beds, enhancing total subtidal mussel stock within the whole Wadden Sea.

The main part of this thesis provided insight in the (subtidal) mussel population dynamics and the effect of mussel culture on these dynamics. In the general discussion in Chapter 7 the results of this study are related to literature and discussed in a broader context to investigate the main factors that are affecting production efficiency in mussel bottom cultureand - given the factors identified, the best practice method for mussel farmers to increase production efficiency.

Chapter 3 and Chapter 4 show that seeding results in high density dependent loss rates on culture plots, which have a large effect on the production efficiency. It is expected that this density effect is caused by the high concentration of mussels 


\section{Summary}

as a result of seeding techniques. High mussel concentrations can limit the facilitation effect that mussels may have by the ability to self-organise in optimal patterns. Furthermore, seeding will result in a highly attractive situation for mobile predators such as shore crabs, due to the strong cues of damaged mussels and the presentation of a prey that is easy to obtain. Therefore, in Chapter 5 one third of the losses after seeding could be attributed to shore crab predation. In subtidal areas the intense predation of sea stars on young mussel beds limits the successes of those beds to develop into mature long lived subtidal mussel beds. Majority of mussel beds that escape this intense predation bottleneck are found in areas with low and strongly fluctuating salinities. Circumstances that are not optimal for mussels but where mussels are able to survive, while sea stars are avoiding these areas. On mussel culture plots the environment is benign to both mussels and sea stars, but sea star predation is prevented by the mussel farmer. Chapter 6 shows that transplanting mussels from natural mussel beds to culture plots improves growth and survival; average biomass production is higher on culture plots than on natural mussel beds. Despite harvesting, mussel biomass production on culture plots was higher than on natural mussel beds, enhancing total subtidal mussel stock. A more efficient seed use on the available area, that can be obtained by reducing seeding losses will increase RBP, maximum biomass production and increases maximum profit. Our results suggest that this can be achieved by seeding homogeneously at low densities. 


\section{Nederlandse samenvatting}

Het thema van dit proefschrift is het verbinden van de populatiedynamiek van mosselen (voornamelijk de groei en de overleving) op percelen met de kweekactiviteiten van de mosselkwekers, vanuit het oogpunt van het rendement van de mosselkweek. Mosselen worden aan touwen of op de bodem gekweekt. Dit proefschrift richt zich op de mosselbodemcultuur.

De mosselbodemcultuur begint met het mosselzaad (kleine mosseltjes). Dat zaad wordt gevist van natuurlijke bestanden of ingevangen met mosselzaad invanginstallaties (MZI's) en wordt door mosselkwekers op percelen uitgezaaid. Deze percelen liggen in een natuurlijke omgeving. De mosselen op deze percelen zijn afhankelijk van hun omgeving voor voedsel en ruimte. Ook zijn de mosselen blootgesteld aan soorten die mosselen eten (predatoren) en aan omgevingsfactoren zoals de hydrodynamiek (stroming, golven), zoutgehaltes, slib en substraat. Mosselkwekers kunnen de productie optimaliseren door de groei en overleving van de mosselen te stimuleren. De productie-efficiëntie (het nettoresultaat van groei en overleving) is het rendement, wat in dit proefschrift is uitgedrukt met 'Relative Biomass Procution' (RBP). Het rendement wordt zo bepaald door de verhouding tussen de geoogste biomassa van een perceel en wat oorspronkelijk is gezaaid.

In het eerste hoofdstuk van dit proefschrift wordt een beschrijving gegeven van de factoren in de populatiedynamiek van mossel(bank)en. Er wordt op basis van de beschikbare literatuur ingegaan op factoren die van invloed zijn op de broedval, de groei en de overleving van mosselen. In dit hoofdstuk wordt ook het theoretisch kader geschetst en de onderzoeksdoelen van dit proefschrift geïntroduceerd. Deze doelen zijn gedefinieerd als: (1) een beter begrip van factoren die de populatiedynamiek van sublitorale (beneden de laagwaterlijn) mosselen bepalen en (2) het analyseren van de factoren die het rendement van 


\section{Samenvatting}

de mosselbodemcultuur bepalen en hoe dit rendement verbeterd zou kunnen worden.

In hoofdstuk twee wordt een beschrijving gegeven van kweekactiviteiten in de mosselbodemcultuur, waarbij de Nederlandse situatie als casestudie is gebruikt. Mosselkweek in Nederland is vrijwel uitsluitend mosselbodemcultuur en Nederland heeft wereldwijd het grootste oppervlak aan mosselkweekbodempercelen, met een gemiddelde jaarlijkse productie van ongeveer zestig miljoen kilo. Dit hoofdstuk focust op de relatie tussen de ontwikkelingen in kweektechniek (op hoofdlijnen) met ontwikkelingen in het kweekrendement. In Nederland vond een technologische transitie van de kweekpraktijk plaats van een arbeidsintensieve naar een gemechaniseerde kweek in de periode 1960-1990. Technologische innovaties en grotere schepen maakten het mogelijk om efficiënter te vissen en in een kort tijdsbestek op de percelen uit te zaaien. Tegelijkertijd ontstond maatschappelijke onrust over de duurzaamheid van de mosselkweek. Vanaf de jaren negentig van de twintigste eeuw nam de beschikbaarheid van mosselzaad voor de kweek af, vooral door een aantal gebiedssluitingen. Deze ontwikkeling resulteerde in een volgende technische innovatiegolf, de ontwikkeling van MZI's. De hogere kostprijs voor het MZI-zaad en de afname in beschikbaarheid van bodemzaad resulteert in de noodzaak het rendement te verbeteren.

Het uitzaaien van mosselen is een belangrijke kweekactiviteit. Dit gebeurt door de mosselen met water door gaten uit het ruim (zogenaamde zaaikokers) onder water te spoelen, terwijl het schip rondjes over het perceel vaart. Deze manier van zaaien zorgt voor de typische concentrische patronen waarmee de mosselen op de percelen komen te liggen. In hoofdstuk drie worden de resultaten van een experiment gepresenteerd waarbij het effect van deze manier van verspreiden van mosselen is getest. In dit experiment zijn dezelfde hoeveelheid mosselen zo egaal mogelijk verdeeld over vakken met verschillende oppervlakten. Dit is 


\section{Samenvatting}

gebaseerd op de praktische vraag, hoe een bepaalde hoeveelheid zaad het beste over de beschikbare ruimte verdeeld kan worden. Aggregatie van mosselen, de groei en het verlies zijn vervolgens over een periode van twaalf weken intensief gevolgd. De resultaten van deze studie laten zien dat de mosselen zich opnieuw organiseerden binnen het vak waar ze neergelegd zijn. Deze reorganisatie is afhankelijk van de dichtheid. Bij hogere dichtheden bleven de mosselen in een uniforme mat liggen, bij lagere dichtheden reorganiseerden de mosselen zich in een groot aantal kleine 'patches'. De overleving en het rendement waren hoger bij een lagere dichtheid. De suggestie die deze resultaten opwerpen is dat als mosselen de ruimte hebben zich te reorganiseren, dit de overleving bevordert. De grotere hoeveelheid patches hebben ook een hogere omtrek, waardoor meer mosselen aan de rand van de patch gepositioneerd zijn. Aan randen van patches is minder competitie om ruimte of voedsel. Terwijl bij een hogere dichtheid er minder ruimte is en er competitie optreedt. In de relatief korte periode dat het experiment liep kon geen verschil in groei en conditie van de mosselen aangetoond worden. Het opvallendste gegeven uit dit experiment waren de grote verliezen bij de mosselen (tot $75 \%$ bij de hoogste dichtheid) die binnen een tijdsbestek van slechts vier weken na inzet optraden.

Het zaaien lijkt dus een effect te hebben op de overleving van de mosselen en daarom op het rendement van de mosselkweek. Deze relatie is verder onderzocht in hoofdstuk vier. Dit hoofdstuk rapporteert een monitoring van percelen in de Waddenzee. In deze monitoring die drie jaar achter elkaar heeft plaatsgevonden zijn de groei en veranderingen in dichtheid over de tijd van 66 cohorten op 42 verschillende percelen of delen van percelen in kaart gebracht. Deze gegevens zijn gecombineerd met gegevens van de mosselkwekers. Verliezen van mosselen tijdens de kweek, over de hele periode vanaf zaaien tot verplaatsing of oogst waren hoog en was gemiddeld $92 \%$ voor het kleinste MZIzaad. Grote verliezen van mosselen vlak na het zaaien, zoals in het experiment in hoofdstuk drie is gevonden vonden we ook op de diepere percelen in de 


\section{Samenvatting}

Waddenzee. Het zaaien van de mosselen op de percelen werd binnen een aantal weken gevolgd door een verlies van gemiddeld $42 \%$ aan mosselen. Dit verlies nam toe met de dichtheid en nam af met de grootte van de mosselen. Uit de monitoring blijkt dat dit 'zaaiverlies' de belangrijkste factor was die het rendement bepaalde. Gemiddelde verliezen tijdens de uitgroei van de mosselen op de percelen waren substantieel lager. Ook voor mosselzaad (dat kleiner is dan $30 \mathrm{~mm}$ ) nam het verlies nog toe met de mosseldichtheid, voor mosselen (vanaf $30 \mathrm{~mm}$ ) werd geen dichtheidsafhankelijke relatie meer gevonden. Er kon ook geen relatie gevonden worden tussen de groei en dichtheid van mosselen. Dit kan te maken hebben met de te grote schaal waarop gemeten is.

Naast dichtheid zijn ook predatoren een belangrijke factor in het verlies. De belangrijkste predatoren van mosselen voor de (subtidale) bodemcultuur (in West-Europa) zijn de strandkrab, de eidereend en de zeester. Naar het effect van de eidereend en de zeester op subtidale mosselen zijn recentelijk een aantal studies uitgevoerd. In hoofdstuk vijf wordt daarom ingegaan op het effect van strandkrabben op het verlies van mosselzaad. Deze studie is uitgevoerd op een droogvallend mosselperceel in de Oosterschelde met het daar gezaaide MZI-zaad. MZI-zaad werd in verschillende dichtheden neergelegd en een deel van het zaad werd afgeschermd voor krabben. Dichtheid en predatie hadden beide een effect op de overleving van het mosselzaad. Overleving was hoger bij lagere dichtheden. In een periode van vijf weken na het zaaien werd ongeveer een derde van het verlies veroorzaakt door krabbenvraat. Er kon geen effect gevonden worden van dichtheid op krabbenvraat.

Mosselkweek vindt vaak plaats in natuurgebieden zoals de Waddenzee in Nederland. In de Waddenzee is ook een natuurlijk mosselbestand. Op een deel van dit bestand wordt ook gevist en deze mosselen worden naar de percelen verplaatst. Kweekactiviteiten zijn gericht op het stimuleren van groei en overleving, maar mosselen worden ook geoogst. De mosselkweek 


\section{Samenvatting}

heeft door deze activiteiten een effect op de subtidale mosselpopulatie in het Waddenzeesysteem. In hoofdstuk zes wordt de populatiedynamiek van de subtidale mosselen in de Waddenzee beschreven, waarbij een onderscheid is gemaakt tussen de wilde populatie en de populatie op de percelen, die (deels) afkomstig is van de wilde populatie. In dit hoofdstuk worden twee monitoringsprogramma's met elkaar vergeleken, namelijk het programma dat in hoofdstuk vier is beschreven en een meerjarig monitoringsprogramma op de wilde bestanden. De overleving van wilde banken laat een duidelijke gradiënt zien, die overeenkomt met de gradiënt in zoutgehalte. Dit kan worden verklaard door de positieve relatie tussen zoutgehalte en de activiteit van zeesterren. Zeesterren lijken voor een belangrijk deel de overleving van wilde banken te bepalen. Het grootste deel van de percelen liggen op locaties met hogere zoutgehaltes, waar de groei beter is dan op wilde banken maar waar wilde banken niet overleven. Mosselen op percelen laten namelijk veel minder verlies zien dan mosselen op wilde banken. Dit wordt verklaard door kweekactiviteiten die erop gericht zijn overleving te stimuleren, bijvoorbeeld door zeesterren te bestrijden. De productie van biomassa is zo hoger op percelen dan op wilde banken, wat leidt tot een verhoging van de totale subtidale mosselbestand in de Waddenzee.

Het hoofddeel van dit proefschrift heeft inzichten opgeleverd over factoren in de populatiedynamica van (subtidale) mosselbestanden en het effect van mosselkweek hierin. Hoofdstuk zeven bevat de generale discussie. Hier worden de belangrijkste uitkomsten van dit onderzoek vergeleken met verwante studies en wordt de vertaling naar de praktijk bediscussieerd. Het doel is om tot een beter begrip te komen van factoren die de populatiedynamiek van subtidale mosselen bepalen, om de factoren te analyseren die het rendement van de mosselbodemcultuur bepalen en te komen tot verbeterpunten rond het rendement. 


\section{Samenvatting}

In hoofdstuk drie vonden we een substantiële afname van de mosseldichtheid in een korte periode (weken) na het zaaien. In de uitgebreide veldmetingen van hoofdstuk vier vonden we dit patroon ook op subtidale percelen in de Waddenzee. Het kan verwacht worden dat dit 'zaaiverlies' samenhangt met de hoge dichtheden op de percelen, deels veroorzaakt door de hoge heterogeniteit in mosseldichtheid als gevolg van de zaaitechniek. Hoge, lokale mosselconcentraties zorgen voor competitie om plaats en/of voedsel en limiteren de bewegingsvrijheid van mosselen om zich in patronen te organiseren die optimaal zijn voor de omgeving waarin het perceel zich bevindt. Het zaaien lijkt ook te zorgen voor een piek in het aantal predatoren (met name krabben) die waarschijnlijk aangetrokken worden door de geur van beschadigde mosselen of geassocieerde fauna. Net gezaaide mosselen zijn ook gemakkelijker te bemachtigen voor krabben omdat ze nog niet zo vast gesponnen zijn. (Mosselen spinnen zich vast aan het substraat met hun byssusdraden.) In hoofdstuk vijf konden we dertig procent van het zaaiverlies toeschrijven aan krabbenvraat. Maar ook zeesterren zijn belangrijke predatoren op subtidale mosselpercelen en kunnen mosselbanken in korte tijd compleet laten verdwijnen. De verspreiding van zeesterren in de Waddenzee wordt gelimiteerd door lokale lage of fluctuerende zoutgehaltes, die we vooral in de buurt van het IJsselmeer vinden. Op deze locaties vinden we ook de beste overleving van wilde mosselbanken. De lage zoutgehaltes, maar waarschijnlijk vooral de lage voedselkwaliteit op deze locaties limiteren de groei van de mosselen. In hoofdstuk zes toonden we daarom aan dat het verplaatsen van deze mosselen naar de kweekpercelen, waar de mosselen wel goed groeien en waar de predatie van zeesterren door kweekactiviteiten sterk geremd wordt, leidt tot betere groei en overleving. Hierdoor is de productie van biomassa op percelen hoger dan op wilde banken, wat resulteert in een groter mosselbestand in het hele systeem. Soorten zoals de eidereend kunnen hier voordeel mee behalen. Een beter gebruik van mosselzaad, door het te verspreiden op het bezaaibare 
Samenvatting

oppervlak, zal naar alle waarschijnlijkheid het zaaiverlies verminderen en het rendement verbeteren. 
Acknowledgements

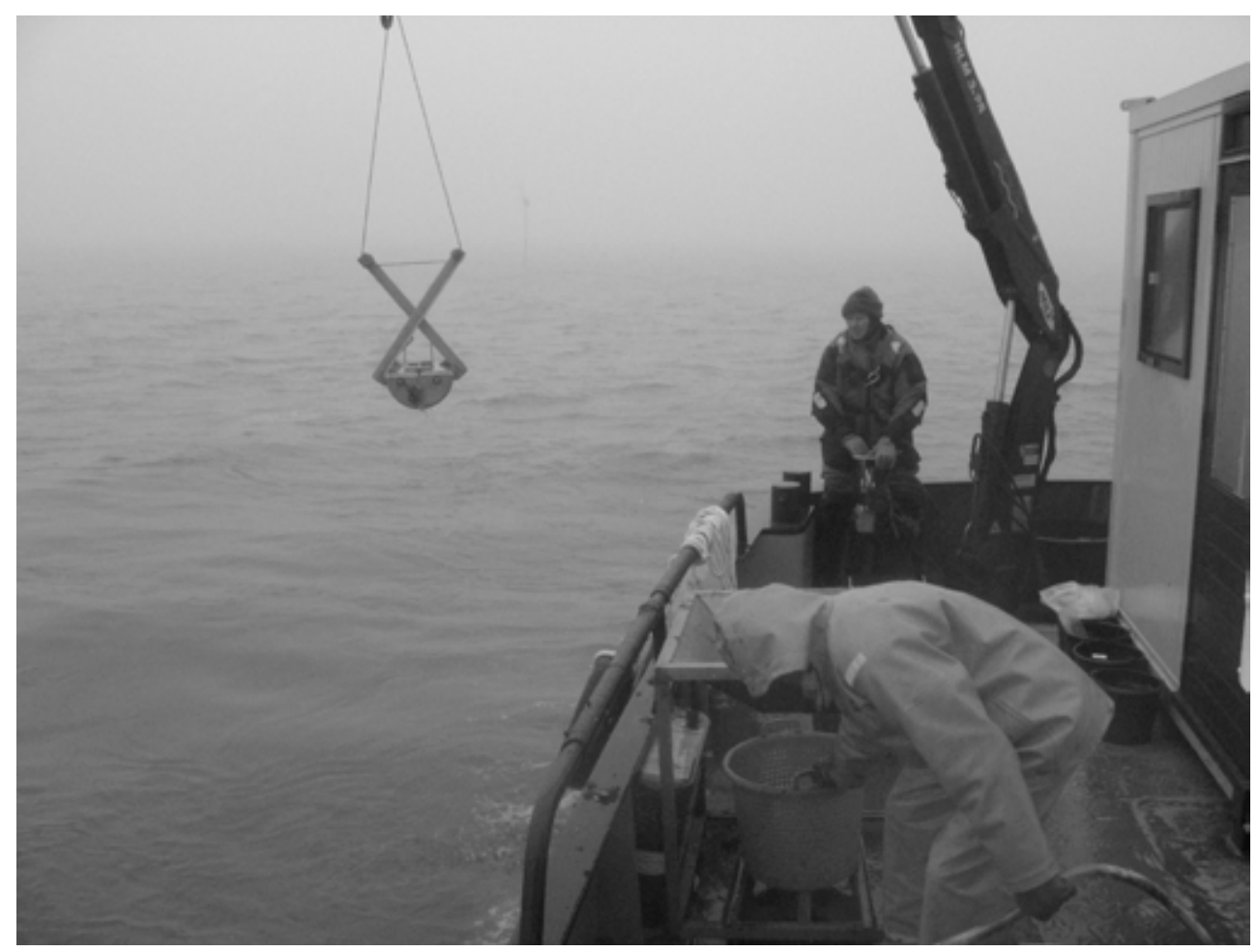


Een promotietraject doorloop je gelukkig niet alleen. Een aantal deskundigen hebben mij vanuit hun eigen expertise naar dit resultaat begeleid. Aad, je zag de zaken vaak net iets anders dan ik, dat maakte de discussies scherper en de artikelen beter. Maar wat ik vooral onthoud is je kwaliteit geen onderscheid te maken; je bent even aimabel met een student als met een collega professor en kan als geen ander mensen enthousiast maken voor schelpdieren. Zo ben ik er in ieder geval ooit ingetuind, waar ik je nu dankbaar voor ben. Jeroen, ik heb je geduld ongetwijfeld op de proef gesteld. Naast geduldig ben je ook grondig en daar heb ik als sloddervos veel profijt van gehad. Dank je voor dat alles. Na mijn promotietraject zijn we gewoon verder gegaan met het mosselonderzoek en nu zelfs vanuit dezelfde kamer. Marnix, jij kan de zaken met je karakteristieke vocabulaire net even anders belichten, of even een praktische toets uitvoeren. Ik heb daarvan geleerd en heb veel waardering voor je doorwrochte inbreng. Peter, dankjewel voor de immer kritische analyse en de creatieve toepassingen die je altijd uit de teksten wist te halen, altijd in vriendelijk geformuleerde woorden. Je hebt een significante rol gespeeld in het verbeteren van de kwaliteit en de leesbaarheid van de tekst.

Dit proefschrift was niet mogelijk geweest zonder de inzet en het harde werk van de bemanning van ms Stormvogel. Nico, Theo, Eelke Sybren, Arjan, ik hoop dat jullie ook een beetje trots kunnen zijn op dit resultaat. Dank voor de gezellige tijd aan boord, de goede gesprekken, de kennis van het Wad, het eindeloze happen, ooit eens tussen de ijsschotsen door.

Ook Johan Jol wil ik bedanken voor het helpen met de bemonstering. Ik denk terug aan een geweldig leuke tijd aan boord. Het werk, de borrel, de wôste, de gesprekken over bijen en geschiedenis.

Dit proefschrift was ook niet mogelijk geweest zonder de medewerking van een aantal mosselkwekers. Die wil ik hier speciaal danken voor hun medewerking aan dit onderzoek. Albert, voor je medewerking en de leerzame gesprekken over 
de mosselen. Marinus, als immer onderzoekende innovatieve mosselkweker, voor je hulp en alles wat ik van je geleerd heb. Adrian en Jos S., met een passie voor mosselen en mosselkweek. Johnny, jij bent er later ingerold, je wilde meedoen omdat je het onderwerp zo interessant vond. Cees, ook jij bent er ingerold toen je mosselen kwijt was in de Boontjes en we werken nog steeds samen. Jan, je was de eerste die me belde met de mededeling dat je wel mee wilde werken aan het onderzoek en nog steeds werken we samen. En toen ik specifiek percelen zocht met MZI-zaad hielp jij me, Jos vD.

Ik had praktisch mijn eigen onderzoekslab in de Zandkreek, waar ik heel veel heb kunnen meten bij de mosselen, dankzij de firma Praet. Leon, Sjaak, Robbie en Peter, dank voor deze mogelijkheid, voor de fijne samenwerking en vooral voor de gezelligheid.

Dank aan de PO Mossel, aan Paula, Hans en nu Addy, voor de steun waar nodig en voor het vertrouwen.

Dank ook aan de groep kwekers met wie ik samengewerkt heb of nog steeds samenwerk in het kadervan het PROFMOS of KOMPRO project. Deze projecten zijn eigenlijk de voortzetting van dit promotieonderzoek.

Diverse studenten hebben bijgedragen aan dit onderzoek. Dank aan Linde en Roos en aan Gerard, mooi dat het gelukt is ons experiment te publiceren!

Bedankt Mike Turenhout voor het beschikbaar stellen en toelichten van de economische input voor hoofdstuk 2.

Thanks to the fellow PhD'ers at IMARES: Stephan, Michel, Antonio, Wouter, Andre \& Brenda. Jeroen Kals, in fact also a fellow PhD'er, but at the same time once a supervisor of one of my MSc Theses and probably the reason I ended up at IMARES in the first place, its always a pleasure talking to you. Special thanks to Isabel \& Thorsten, Ainhoa \& Anton, Saskia \& Chris, for the good times we 
had at IMARES! Also special thanks to Saskia for wanting to be my paranimph.

I thank my (other) Wageningen Marine Research (IMARES) colleagues (Jack, Douwe, Marnix, Karin, Emiel, Ad, Margriet, Jouri, Pauline, Johan C, Martine, Henrice, Marnix, Eugene, Tom, Joke) for the good times I had at the institute and sometimes abroad. Special thanks to Kees for the nice conversations and the things he learned me, to Jeanet for the empathy and nice conversations. during my $\mathrm{PhD}$ time \& to Tim for his valuable input and enthousiasm.

Thanks to my HZ colleagues, for the good time I had there. Jasper, good luck with your last stretch, Michel again ;-), Michiel, for the beers, the talks and smoke curtains. Jouke for the nice proposition suggestions, which I did eventually not include, Eva, for being my paranimph and my memory for the last couple of years and to Tony, Pim, Wessel \& Christos.

Met genoegen denk ik terug aan de avonden zonder computer in Leiden, Utrecht of ergens nergens met Matthijs, Floris, Michiel, Christiaan, Martijn of met Rob, Jean, Michiel Sjors \& Ben (moeten we maar weer eens een keer plannen). Willem vanaf het begin al een voorrecht om met je bevriend te zijn. Maarten, dank voor de ontelbare gesprekken, het was soms nodig even te relativeren.

Een woord van dank aan de heer Haersma Buma van de stichting der Heerlijkheden Oosterland, Sirjansland en Oosterstein voor de mogelijkheid een deel van dit proefschrift te kunnen schrijven op een van de mooiste plekjes van Zeeland.

Dank aan mijn familie (pa, ma, broers \& zus), voor alle steun, geduld en interesse. Ik weet dat jullie ook hebben uitgekeken naar het einde van dit traject. Tenslotte, maar eigenlijk als eerste, Erika, dankjewel voor hoe je bent en een groet aan onze mooie kinderen (Aäron, Jonas \& Karel) en aan Fenna met haar mooie karakter. 


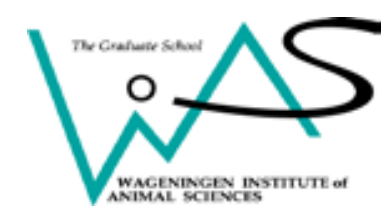

\section{Training and Supervision Plan}

\section{The Basic Package}

WIAS Introduction Course

Course on philosophy of science and/or ethics

\section{Scientific Exposure}

\section{International conferences}

Aquaculture Europe (EAS), Porto, Portugal, 5-8 oct

International symposium on the ecology of the Wadden Sea, Den Hoorn, Nederland, 10-14 oct

\section{Seminars and workshops}

Goods and services of shellfish, Yerseke, 24 feb

Workshop Mosselwad, Texel, 11-12 mar

\section{Presentations}

Factoren in the kweekrendement van mosselpercelen in de Waddenzee, Zierikzee, 4 feb, Oral 2011

Productivity factors of extensive mussel culture, Porto, 5 oct, Oral

Effects of spatial heterogeneity in mussel density on productivity of a commercial mussel bed, Seattle,

28 mar, oral

The effect of spatial heterogeneity in mussel density on the total productivity of a mussel bed, Den

Burg, 24 nov, oral

Effects of heterogeneity in mussel seed density on mussel bed organization and productivity, Den

Burg, 30 nov, Poster

Productivity factors of on-bottom mussel culture, Yerseke, 5 jun, oral

Density dependent mortality in the productivity of subtidal blue mussel beds in on-bottom mussel

culture, Den Burg, oral

1,5

1,5

$-$

$-$

\section{In-Depth Studies}

Orientation on mathematical modelling in biology

Wias Advanced Statics Course: Statistics for the life science (WIAS)

Wias Advanced Statics Course: Design of experiments (WIAS)

PhD students' discussion group IMARES 


\section{Research Skills Training}

Preparing own PhD research proposal (maximum 6 credits)

2009

6,0

Supervising theses

Het effect van stressoren op de overleving van mosselen, BSc thesis, Roos van der Velde, HAS, Den Bosch

Effects of predation of the shore crab (Carcinus maenas) on mussel (Mytilus edulis) seed, MSc Thesis, Gerard Scheiberlich, AFI, Wageningen

Analysis of mussel auction data from Oosterschelde and Wadden Sea in relation to abiotic parameters

BSc thesis Max Marcenco, HZ, Vlissingen

\section{Management Skills Training}

Organisation of seminars and courses

Organisation of IMARES PhD day

2011,2012

Education and Training Total 


\section{Colophon}

The research described in this thesis was part of the PRODUS project under contract of the Producers Organisation of the Dutch Mussel Culture and the Ministry of Economic Affairs.

Financial support from Wageningen University and Wageningen Marine Research for printing this thesis is gratefully acknowledged

Printed by Gildeprint - www.gildeprint.nl 